\title{
Aspen Process Flowsheet Simulation Model of a Battelle Biomass-Based Gasification, Fischer-Tropsch Liquefaction and Combined-Cycle Power Plant
}

\section{Topical Report \\ May 1998}

Work Performed Under Contract No.: DE-AC22-93PC91029

\author{
For \\ U.S. Department of Energy \\ Office of Fossil Energy \\ Federal Energy Technology Center \\ P.O. Box 880 \\ Morgantown, West Virginia 26507-0880
}

By

Bechtel

Pittsburgh, Pennsylvania 15236 


\section{Disclaimer}

This report was prepared as an account of work sponsored by an agency of the United States Government. Neither the United States Government nor any agency thereof, nor any of their employees, makes any warranty, express or implied, or assumes any legal liability or responsibility for the accuracy, completeness, or usefulness of any information, apparatus, product, or process disclosed, or represents that its use would not infringe privately owned rights. Reference herein to any specific commercial product, process, or service by trade

name, trademark, manufacturer, or otherwise does not necessarily constitute or imply its endorsement, recommendation, or favoring by the United States Government or any agency thereof. The views and opinions of authors expressed herein do not necessarily state or reflect those of the United States Government or any agency thereof. 


\section{TABLE OF CONTENTS}

\section{EXECUTIVE SUMMARY}

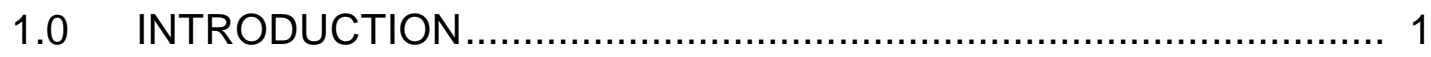

2.0 MODEL DESCRIPTION ........................................................ 3

$2.1 \quad$ Process Calculations .......................................................... 8

$2.2 \quad$ Utilities Calculations ......................................................... 9

2.3 Operating Labor ............................................................. 10

2.4 Capital Costs........................................................................11

2.5 Fortran User Block Model Input Paramteters........................13

2.6 Management Summary Report............................................18

3.0 INDIVIDUAL PLANT MODELS IN AREA 100..............................19

3.1 Plant 108 -- Sulfur Polishing Plant .....................................19

3.2 Plant 113 -- CO Shift Reactor (Hydrogen Production Plant)...20

3.3 Plant 115 -- Wood Drying Plant ..........................................21

3.4 Plant 116 -- Battelle Biomass Gasification Plant ....................24

3.5 Plant 117 -- Fischer-Tropsch Syngas Compression Plant.....26

3.6 Plant 118 -- Combined-Cycle Syngas Compression Plant.....26

3.7 Plant 119 -- Fuel Gas Compression Plant .............................27

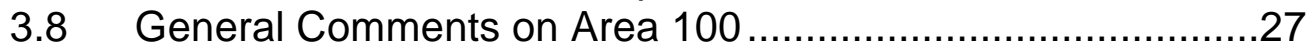

4.0 INDIVIDUAL PLANT MODELS IN AREA 200..............................28

4.1 Plant 201 -- Fischer-Tropsch Synthesis Plant .......................28

4.2 Plant 204N -- Hydropcarbon Recovery Plant..........................34

4.3 Plant 205 -- Hydrogen Recovery Plant .................................35

4.4 General Comments on Area 200 .......................................35

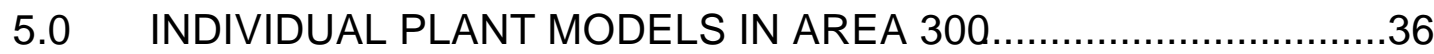

$5.1 \quad$ Plant 301 -- Wax Hydrocracking Plant .................................38

5.2 Plant 302 -- Distillate Hydrotreating Plant..............................39

5.3 Plant 303 -- Naphtha Hydrotreating Plant.............................41

5.4 Plant 304 -- Naphtha Catalytic Reforming Plant....................43

5.5 Plant 306 -- C5/C6 Isomerization Plant..................................44

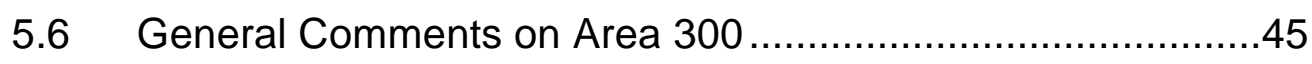

6.0 THE UTILITIES AND OSBL PLANTS MODELS ............................47

7.0 OVERALL PROCESS SIMULATION MODEL..................................50

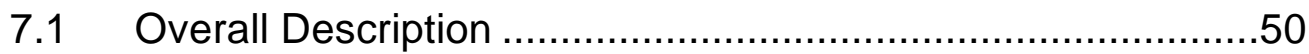

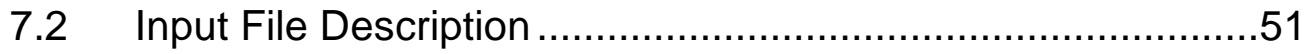


8.0 SIMULATION MODEL RESULTS FOR THE BATTELLE BIOMASS-BASED GASIFIER/F-T SYNTHESIS/COMBINED CYCLE PLANT MODEL ...............................................................53

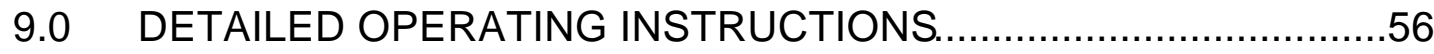

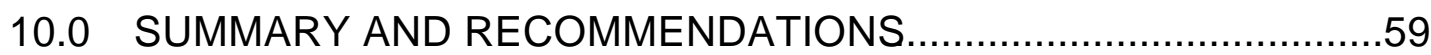

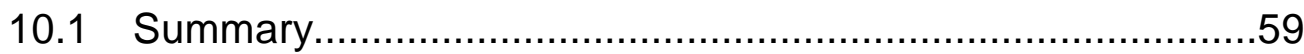

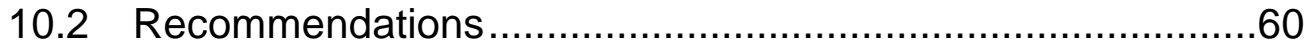

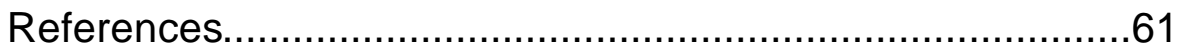

APPENDIX A - Input File Listing of the ASPEN Plus Process

Flowsheet Simulation Model of the Battelle

Biomass-Based Gasification, Fischer-Tropsch

Liquefaction and Combined-Cycle Plant ....

APPENDIX B - Listing of the Management Summary Report for the Maximum Fischer-Tropsch Liquids Production Case..........B-1 


\section{EXECUTIVE SUMMARY}

A conceptual design and ASPEN Plus process flowsheet simulation model was developed for a Battelle biomass-based gasification, Fischer-Tropsch (F-T) liquefaction and combined-cycle power plant. The plant design and model is an extension of that which was developed by Mitretek for the Battelle biomass gasification plant in 1996. ${ }^{1}$ This study was done to support the research and development program of the National Renewable Energy Laboratory (NREL) in the thermochemical conversion of biomass to liquid transportation fuels using current state-of-the-art technology. The Mitretek study investigated the use of two biomass gasifiers; the RENUGAS gasifier being developed by the Institute of Gas Technology, and the indirectly heated gasifier being developed by Battelle Columbus. The Battelle Memorial Institute of Columbus, Ohio indirectly heated biomass gasifier was selected for this model development because the syngas produced by it is better suited for Fischer-Tropsch synthesis with an iron-based catalyst for which a large amount of experimental data are available. ${ }^{2,3}$

The current ASPEN Plus process simulation model was developed in the same spirit as those models which previously were developed for indirect coal liquefaction under DOE contract no. DE-AC22-91PC90027. ${ }^{4}$ In this study, Bechtel with Amoco as a subcontractor developed a conceptual baseline design and several alternative designs for indirect coal liquefaction facilities. In addition, ASPEN Plus process flowsheet simulation models were developed for each of designs. These models were used to perform several parametric studies to investigate various alternatives for improving the economics of indirect coal liquefaction.

In a similar manner, the Battelle biomass gasifier/Fischer-Tropsch synthesis/ combined-cycle power plant model developed under this project was designed to be a research guidance tool, and not a detailed process design tool. However, the model does contain some process design features, such as sizing the F-T synthesis reactors. It was designed only to predict the effects of varying some process and operating conditions on the overall plant material and utility balances. It also

\footnotetext{
${ }^{1}$ Gray, D., Tomlinson G. and M. Berger, "Techno-Economic Assessment of Biomass Gasification Technologies for Fuels and Power," Report MP 96W0000065, Mitretek Systems, McLean, VA, January, 1996.

${ }^{2}$ J. C. Kuo et al (Mobil), "Slurry Fischer-Tropsch/Mobil Two-Stage Process of Converting Syngas to High Octane Gasoline," DOE Contract DE-AC22-80PC30022, Final Report, June, 1983.

3 J. C. Kuo et al (Mobil), "Two-Stage Process for Conversion of Synthesis Gas to High Quality Transportation Fuels," DOE Contract DE-AC22-83PC6019, Final Report, October, 1985.

${ }^{4}$ Topical Report, "Baseline Design/Economics for Advanced Fischer-Tropsch Technology," Volume IV, Process Flowsheet (PFS) Models, DOE contract no. DE-AC22-91PC90027, Bechtel Corporation, October, 1994.
} 
predicts the effect of operations on the capital cost and operating labor requirements.

Furthermore, this ASPEN Plus model was developed under the premise that it would use as much as possible of the previously developed ASPEN Plus indirect coal liquefaction model. As a result of this constraint, it contains three small hydroprocessing units; a wax hydrocracker, a distillate hydrotreater, and a naphtha hydrotreater. In reality, if this Battelle biomass gasifier plant were to be constructed, these three units probably would be combined into a single unit which would generate slightly different yields and have a reduced cost. However, the process engineering and design effort required for the development of the model of such a hydroprocessing unit was beyond the scope of this project.

In developing this ASPEN Plus model for the Battelle biomass gasifier/FischerTropsch synthesis/ combined-cycle power plant, several new individual plant models had to be developed. Such models included the Battelle gasification plant, a hydrogen production plant, and two syngas compression plants, one for the syngas going to the Fischer-Tropsch synthesis area and one for the syngas going to the combined-cycle plant.

The Battelle gasification plant model was developed based on the results reported by Gray. ${ }^{1}$ However, minor adjustments were made so that the resulting model is both in mass and elemental balance. This model was designed only to predict the correct flow rate of the syngas and slag production, and the composition of the syngas produced. The combustor section of the Battelle gasifier was not modeled rigorously.

The model for the hydrogen production plant was developed by using an equilibrium model to represent hydrogen production in a $\mathrm{CO}$ shift reactor.

Aspen Plus multistage compressor models were used to simulate the two new syngas compression plants.

In addition, three other plant models were developed by modifying previously developed models from the coal liquefaction study. A wood drying plant model was developed by extensively modifying the previously developed ASPEN model for the coal grinding and drying plant, and a simplified hydrocarbon recovery plant model was developed from the more comprehensive model used in the coal liquefaction study. A combined-cycle power plant model was developed by modifying the parameters in the previous utility plant model to reflect the power production and utilities consumption for the combined-cycle power plant as determined by a separate GateCycle simulation model study.

\footnotetext{
${ }^{5}$ GateCycle computer simulation program, Power Cycle Simulation Software, Enter Software Company, Menlo Park. CA.
} 
For the case where the plant processes 3550 tons/day of maple wood chips containing $37.9 \%$ water, the model predicts that $382 \mathrm{bbl} /$ day of gasoline and 775 $\mathrm{bbl} / \mathrm{day}$ of diesel blending stocks will be produced. ${ }^{6}$ In addition, about $85.8 \mathrm{MW}$ of surplus power will be exported. The plant will have a total installed cost of about 142 million dollars and employ about 212 workers. This cost estimate has an accuracy of $+1-30 \%$; the same as that of the previous cost estimates. Appendix B contains a complete material balance and cost breakdown for the facility.

This report contains descriptions of the individual plant models as well as detailed instructions for its use. Recommendations are given both for improving the plant design and extending and improving the ASPEN Plus simulation model.

${ }^{6}$ Equivalent to $183,750 \mathrm{lbs} / \mathrm{hr}$ or 2205 tons/day of moisture free wood. 


\subsection{INTRODUCTION}

A conceptual design and ASPEN Plus process flowsheet simulation model was developed for a Battelle biomass-based gasification, Fischer-Tropsch (F-T) liquefaction and combined-cycle power plant. The plant design and model is an extension of that which was developed by Mitretek for the Battelle biomass gasification plant in 1996. ${ }^{1}$ This study was done to support the research and development program of the National Renewable Energy Laboratory (NREL) in the thermochemical conversion of biomass to liquid transportation fuels using current state-of-the-art technology. The Mitretek study investigated the use of two biomass gasifiers; the RENUGAS gasifier being developed by the Institute of Gas Technology, and the indirectly heated gasifier being developed by Battelle Columbus. The Battelle Memorial Institute of Columbus, Ohio indirectly heated biomass gasifier was selected for this model development because the syngas produced by it is better suited for Fischer-Tropsch synthesis with an iron-based catalyst for which a large amount of experimental data are available.,

The current ASPEN Plus process simulation model was developed in the same spirit as those models which previously were developed for indirect coal liquefaction under DOE contract no. DE-AC22-91PC90027. In this study, Bechtel with Amoco as a subcontractor developed a conceptual baseline design and several alternative designs for indirect coal liquefaction facilities. In addition, ASPEN Plus process flowsheet simulation models were developed for each of designs. These models were used to perform several parametric studies to investigate various alternatives for improving the economics of indirect coal liquefaction.

In a similar manner, the Battelle biomass gasifier/Fischer-Tropsch synthesis/ combined-cycle power plant model developed under this project was designed to be a research guidance tool, and not a detailed process design tool. However, the model does contain some process design features, such as sizing the F-T synthesis reactors. It was designed only to predict the effects of varying some process and operating conditions on the overall plant material and utility balances. It also predicts the effect of operations on the capital cost and operating labor requirements.

This ASPEN Plus model for the Battelle biomass gasifier/Fischer-Tropsch synthesis/ combined-cycle power plant model was developed under the premise that it would

\footnotetext{
${ }^{1}$ Gray, D., Tomlinson G. and M. Berger, "Techno-Economic Assessment of Biomass Gasification Technologies for Fuels and Power," Report MP 96W0000065, Mitretek Systems, McLean, VA, January, 1996.

2 J. C. Kuo et al (Mobil), "Slurry Fischer-Tropsch/Mobil Two-Stage Process of Converting Syngas to High Octane Gasoline,” DOE Contract DE-AC22-80PC30022, Final Report, June, 1983.

${ }^{3}$ J. C. Kuo et al (Mobil), "Two-Stage Process for Conversion of Synthesis Gas to High Quality

Transportation Fuels," DOE Contract DE-AC22-83PC6019, Final Report, October, 1985.

${ }^{4}$ Topical Report, "Baseline Design/Economics for Advanced Fischer-Tropsch Technology," Volume IV, Process Flowsheet (PFS) Models, DOE contract no. DE-AC22-91PC90027, Bechtel Corporation, October, 1994.
} 
use as much as possible of the previously developed ASPEN Plus indirect coal liquefaction model. As a result of this constraint, the model contains three small hydroprocessing units; a wax hydrocracker, a distillate hydrotreater, and a naphtha hydrotreater. In reality, if this Battelle gasifier plant were to be constructed, these three units probably would be combined into a single unit which would generate slightly different yields and have a reduced cost. However, the process engineering and design effort required for the development of the model of such a hydroprocessing unit was beyond the scope of this project.

The use of this process flowsheet simulation model requires the ASPEN Plus process simulation program which is available from ASPEN Technology, Inc., Cambridge, MA.

The following sections provide more information on the individual plant models in the Battelle gasification, Fischer-Tropsch liquefaction and combined-cycle power plant model. Section 2 provides an overall description of the model, descriptions of the modeling techniques and parameters used for calculating the utilities consumptions, operating labor and capital cost for each plant, and the general input parameters for all the Fortran user block models. Sections 3, 4 and 5 provide detailed information on the ASPEN plant models in Areas 100, 200 and 300, the three key ISBL areas of syngas preparation, Fischer-Tropsch synthesis and product upgrading, respectively. Section 6 discusses the OSBL and utilities plants. Section 7 provides more details on the overall model, and Section 8 discusses the model results for the base design case. Section 9 provides operating instructions for executing the model. Section 10 contains a summary of this work and recommendations for enhancing and extending the ASPEN Plus process simulation model.

Appendix A contains the complete listing of the ASPEN Plus input file for this Battelle gasifier/Fischer-Tropsch synthesis/combined-cycle power plant model. Appendix B contains the full listing of the management summary report generated by the model for the base case (maximum liquids production case) where all the syngas from the Battelle gasifier goes the Fischer-Tropsch synthesis area for conversion to liquid products. 


\subsection{MODEL DESCRIPTION}

Figure 2.1 is a simplified diagram showing the overall configuration of the FischerTropsch/combined-cycle coproduction plant with the Battelle indirectly heated biomass gasifier. The wet maple wood chips containing about $38 \mathrm{wt} \%$ moisture are dried to about 23.8 wt\% moisture in Plant 115. The dried wood chips are sent to the Battelle gasifier (Plant 116) which produces a syngas with about a $0.5 \mathrm{H}_{2} / \mathrm{CO}$ molar ratio. The char leaving the gasifier with the sand is burned in the combustor to heat the recirculating sand and supply the heat for gasification. The hot syngas is washed and cooled in a spray tower. The syngas cooling and clean up operations are an integral part of Plant 116.

The washed and cooled syngas is compressed in Plant 117 to about 360 psia and sent to the sulfur polishing plant in which any residual sulfur $\left(\right.$ as $\left.\mathrm{H}_{2} \mathrm{~S}\right)$ is absorbed on zinc oxide and removed. In the maximum liquids production case, all of the syngas goes to the Fischer-Tropsch (F-T) synthesis area; most of which goes to the F-T synthesis reactor. However, a small portion (about 1\%) is split off for hydrogen production. The F-T synthesis is carried out in a slurry-bed reactor using an ironbased catalyst. This catalyst has water-gas shift activity for making hydrogen, and thus, a separate $\mathrm{CO}$ shift reactor is not needed to raise the $\mathrm{H}_{2} / \mathrm{CO}$ ratio of all the syngas to the stoichiometric value of slightly above 2.0 for the F-T synthesis. The unconverted syngas leaving the F-T reactor system is cooled to condense and remove liquids and then is sent to the high-pressure fuel gas system. The liquid product streams leaving the F-T synthesis area are sent to Plant 204 (not shown specifically, but included in the Product Recovery and Upgrading block) where the raw F-T liquids are separated into low-pressure fuel gas, naphtha, distillate and wax streams.

The small amount of syngas bypassing the F-T synthesis plant is sent to a CO shift reactor (Plant 113) to produce hydrogen for use in the product upgrading area. The hydrogen-rich gas from the $\mathrm{CO}$ shift reactor and a hydrogen-rich gas stream from the naphtha reformer are purified by pressure swing absorption in Plant 205 (not shown specifically, but included in the Product Recovery and Upgrading block) and sent to the product upgrading area.

Figure 2.2 is a schematic block flow diagram of the product upgrading area. This is a simplified version of that used in the baseline case of the coal liquefaction study. ${ }^{4}$ This area consists of five major plants. Plant 301 is the wax hydrocracking plant which cracks the raw F-T wax into naphtha, distillate and fuel gas. The distillate hydrotreater (Plant 302) and the naphtha hydrotreater (Plant 303) hydrotreat the raw F-T distillate and naphtha to stabilize them by saturating the olefins. The distillate product is sent to diesel blending. The $\mathrm{C} 7+$ naphtha product from Plant 303 , along with the naphtha produced by the wax hydrocracker, is sent to the naphtha reforming plant (Plant 304) where they are catalytically reformed into a high-octane gasoline blending component. Plant 304 also produces a hydrogenrich gas stream that is sent to Plant 205 for hydrogen recovery. The pentane/ 
Figure 2.1

BATTELLE GASIFICATION/ FISCHER-TROPSCH SYNTHESIS/COMBINED CYCLE PLANT - OVERALL CONFIGURATION

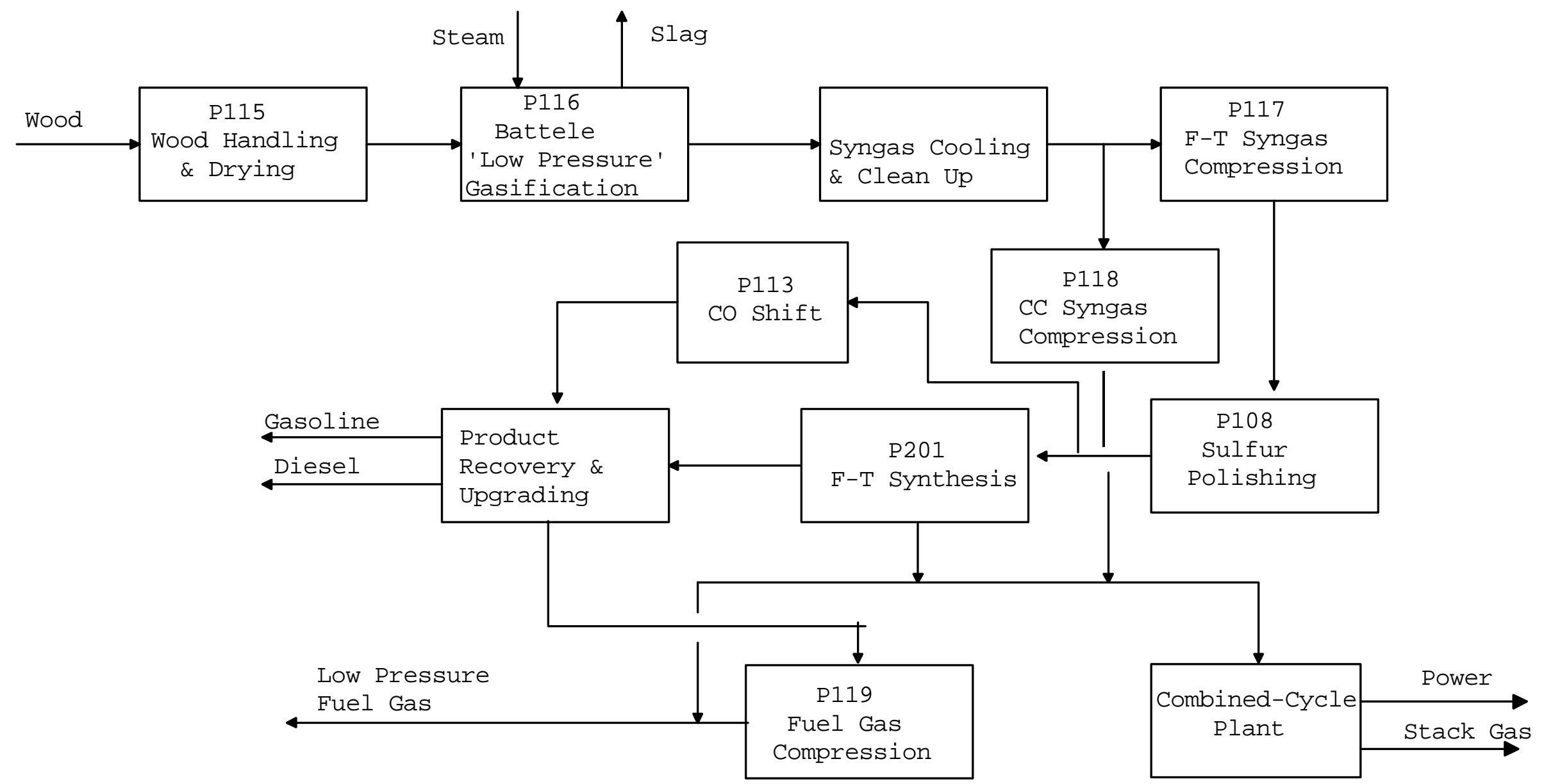


Figure 2.2

\section{F-T PRODUCT UPGRADING AREA \\ BLOCK FLOW DIAGRAM}

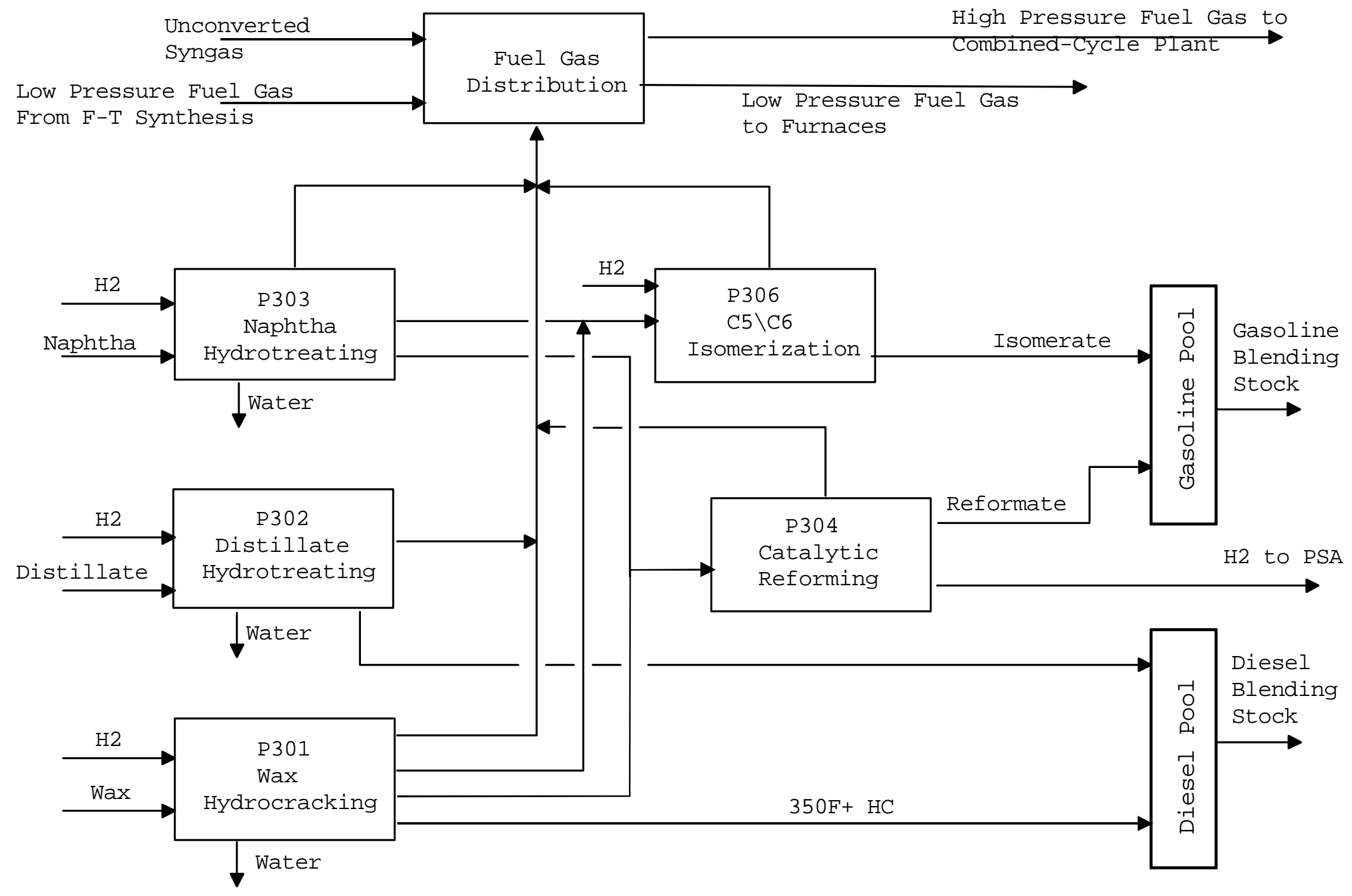


hexane stream from Plant 303 is sent to Plant 306, a C5/C6 isomerization plant to increase its octane number and produce a high quality gasoline blending component.

All the low-pressure fuel gas is compressed to 100 psia in Plant 119 and used for in-plant heating. In the maximum liquids production case, an insufficient amount of low-pressure fuel gas is available and some high-pressure fuel gas (unconverted syngas from Plant 201) has to be diverted from going to the combined-cycle power plant to supplement the low-pressure fuel gas for in-plant heating.

In addition, the model contains a feature where essentially all or a portion of the cooled and washed syngas leaving the Battelle biomass gasifier can be sent directly to the combined-cycle power plant after being compressed to 250 psia in Plant 118, the combined-cycle syngas compression plant. This feature allows using the model to compare liquids production versus power production.

Table 2.1 contains a list of the various ISBL process plant models within the ASPEN Plus process flowsheet simulation model for the Battelle gasification, FischerTropsch liquefaction, and combined-cycle power plant. The plant numbering system developed for the baseline coal liquefaction ASPEN Plus process simulation model has been retained wherever practical, and consequently, the plant numbering system is not sequential. Plants $113,115,116,117,118$, and 119 are newly developed plants for this Battelle biomass gasifier plant model. Plant $204 \mathrm{~N}$ is a modified version of the original Plant 204 Hydrocarbon Recovery Plant model (which was developed for the baseline coal liquefaction case), and to avoid confusion, it has been renamed Plant 204N.

Table 2.2 shows the OSBL plants. In addition to the above ISBL process plant models, a simplified model was developed for the one of the OSBL plants, the combined-cycle power plant (Plant 31). This model was developed based on a more detailed combined-cycle plant simulation using the GateCycle simulation model. ${ }^{5}$ All the other OSBL plants shown in Table 2.2 are accounted for in the ASPEN Plus model in a very simplified manner.

\footnotetext{
${ }^{5}$ GateCycle computer Simulation Program, Power Cycle Simulation Software, Enter Software Company, Menlo Park, CA.
} 
$\underline{\text { Table } 2.1}$

\section{ASPEN Plus ISBL Plant Models}

\begin{tabular}{c} 
Plant Number \\
\hline 108 \\
113 \\
115 \\
116 \\
117 \\
118 \\
119 \\
\\
201 \\
$204 \mathrm{~N}$ \\
205 \\
\\
301 \\
302 \\
303 \\
304 \\
306
\end{tabular}

Description

Sulfur Polishing

Hydrogen Production (CO Shift)

Wood Drying

Battelle Gasification

Fischer-Tropsch Syngas Compression

Combined-Cycle Syngas Compression

Combined-Cycle Fuel Gas Compression

Fischer-Tropsch Synthesis

NREL Hydrocarbon Recovery

Hydrogen Recovery (PSA)

Wax Hydrocracking

Distillate Hydrotreating

Naphtha Hydrotreating

Naphtha Reforming

C5/C6 Isomerization

Tthe previous report contains detailed descriptions of the general features of the ASPEN Plus process simulation models. Consequently, only a portion of this information is repeated here for the convenience of the reader. Although that information was prepared for the original ASPEN models using the ASPEN/SP process flowsheet simulation program, the information also applies to this model which uses the ASPEN Plus process flowsheet simulation program. However, two significant changes have been made to the component list. First the three nonconventional coal components have been replaced with three new non-conventional components, WOOD, SLAG and CHAR. Secondly, the hydrocarbon component list has been expanded by the addition of twelve new components to better characterize the raw $\mathrm{C} 20$ + Fischer-Tropsch wax. These new components are normal eicosane $\left(\mathrm{C}_{20} \mathrm{H}_{22}\right)$, 1-eicosene $\left(\mathrm{C}_{10} \mathrm{H}_{20}\right)$, eight pseudo-components representing mixtures of $70 \%$ olefins and $30 \%$ paraffins in the $\mathrm{C} 21$ through C29 carbon range (C21OP through C29OP), and a C30+ Fischer-Tropsch wax component (C30WAX). 
$\underline{\text { Table } 2.2}$

\title{
ASPEN Plus OSBL Plants
}

\begin{tabular}{c} 
Plant Number \\
\hline 19 \\
20 \\
21 \\
22 \\
23 \\
24 \\
25 \\
30 \\
31 \\
32 \\
33 \\
34 \\
35 \\
36 \\
37 \\
40 \\
41 \\
42 \\
43
\end{tabular}

\author{
Description \\ Relief and Blowdown System \\ Tankage \\ Interconnecting Piping \\ Product Shipping \\ Tank Car/Truck Loading \\ Ash Disposal \\ Catalyst and Chemical Loading \\ Electrical Distribution System \\ Steam and Power Generation \\ Raw, Cooling and Potable Water \\ Fire Protection System \\ Sewage and Effluent Water Treatment \\ Instrument and Plant Air Facilities \\ Purge and Flush Oil System \\ Solid Waste Management \\ General Site Preparation \\ Buildings \\ Telecommunications \\ Distributed Control System and Software
}

\subsection{Process Calculations}

For some plants, standard ASPEN Plus process simulation models do the process calculations, and for others, Fortran user block models are used. Standard ASPEN Plus models were used to do the process calculations when they were best suited for the task. However, in all cases a Fortran user block model still is used to do the utilities and capital cost calculations. All the Fortran user block models were programmed with a common user interface so that they appear similar to the user. However, the process calculation section in each Fortran user block differs depending on the specific plant. While any of the seventy REAL input parameters discussed in the following subsections may be changed by the user, generally only the first twenty are process-specific, i.e., values that the user may normally change in the input file specifications. These are reserved for process related items, such as conversions and separation ratios. Additional information on these parameters is provided in the following subsections that describe the individual plant models. The remaining REAL parameters control the utilities consumptions, plant costs, etc. and are not normally changed in the input file. 
Some of the output streams leaving the Fortran user block models are set to a default temperature of $70^{\circ} \mathrm{F}$ and a default pressure of $15 \mathrm{psia}$. These may be changed to more appropriate values for the specific simulation by the use of a FLASH-SPECS sentence in the block paragraph which calls the user Fortran block model. Any outlet stream conditions specified in the FLASH-SPECS sentence will override the default values set in the Fortran user block model. For example, the following FLASH-SPECS sentence will set the outlet temperature of the FLUE-GAS stream to $110^{\circ} \mathrm{F}$ and 50 psia and cause ASPEN to calculate the appropriate stream properties (enthalpy, entropy, etc.) at these conditions.

FLASH-SPECS STRM $=$ FLUE-GAS KODE $=2$ TEMP $=100$ PRES $=50$

\subsection{Utilities Calculations}

The Fortran user block models have been programmed to calculate the following eleven plant utility requirements.

1. Power consumption in kilowatts

2. $900 \mathrm{psig} / 1000 \mathrm{~F}$ steam consumption in Mlbs/hour*

3. $360 \mathrm{psig} / 440 \mathrm{~F}$ steam consumption in Mlbs/hour*

4. $600 \mathrm{psig} / 650 \mathrm{~F}$ steam consumption in Mlbs/hour

5. 600 psig saturated steam consumption in Mlbs/hour

6. 150 psig saturated steam consumption in Mlbs/hour

7. 50 psig steam saturated consumption in Mlbs/hour

8. Fuel consumption in MM BTU/hour

9. Cooling water consumption in Mgal/hour

10. Process water consumption in Mgal/hour

11. Nitrogen consumption in MM SCF/hour of nitrogen

* Plant 166, the Battelle gasification plant, actually produces $975 \mathrm{psig} / 750^{\circ} \mathrm{F}$ steam and $360 \mathrm{psig} / 530^{\circ} \mathrm{F}$ steam. For consistency with the other ASPEN Plus models, these steams have not been renamed. However, they are treated correctly where they are consumed in the combined-cycle power plant model.

If desired, additional utility consumptions (or productions) can be added. Such additional utilities might be condensate, boiler feed water or a steam at another pressure.

Each plant's utility requirement is modeled as a linear function of a key flow rate. This may be either the total flow rate of a specific feed or product stream, or the flow rate of the major component in a specific feed or product stream. For example, the key flow rate for the wood drying plant is the flow rate of the moisture free wood product stream in Mlbs/hr, and the key flow rate for the hydrogen recovery plant is the useable hydrogen production rate (flow rate of hydrogen in the hydrogen-rich 
product gas stream) in MM SCF/hr of hydrogen. Utilities requirements are calculated by Equation 2.2.1.

$$
U_{i}=A_{i}+B_{i}{ }^{*} F_{O}
$$

Where:

$\mathrm{i}$ = Subscript designating a specific utility in the above listed order

$U_{i}=$ Consumption of utility $i$

$F_{O}=$ Total key flow rate for all duplicate plants in appropriate units such as MM SCF/hour or Mlbs/hour

$A_{i}=$ Constant for the calculation of utility $i$

$B_{i}=$ Constant for the calculation of utility $i$

The sign convention used for all utilities is that positive values represent utilities that are imported to (consumed by) the plant, and negative values represent utilities that are exported from (produced by) the plant.

The numerical values for the $A_{i}$ and $B_{i}$ parameters for each utility are input parameters to each Fortran user block model. The user supplied parameters for the utilities calculations are REAL parameters 21 through 42. REAL(21) and REAL(22) are the $A$ and $B$ constants for the power consumption, respectively. REAL(23) and REAL(24) are the A and B constants for the 900 psig / $1000 \mathrm{~F}$ steam consumption, respectively. Similarly, REAL(25) and REAL(26) are for the 360 psig / $440 \mathrm{~F}$ steam consumption; REAL(27) and REAL(28) are for the 600 psig / $650 \mathrm{~F}$ steam consumption; REAL(29) and REAL(30) are for the 600 psig saturated steam consumption; REAL(31) and REAL(32) are for the 150 psig saturated steam consumption; REAL(33) and REAL(34) are for the 50 psig saturated steam consumption; REAL(35) and REAL(36) are for the plant fuel consumption; REAL(37) and REAL(38) are for the cooling water consumption; REAL(39) and REAL(40) are for the process water consumption; and $\operatorname{REAL}(41)$ and $\operatorname{REAL}(42)$ are for the nitrogen consumption.

All utility parameters must be on a consistent basis with respect to the values for any unit specific parameters that are supplied for the process calculation section.

\subsection{Operating Labor}

Dedicated operating labor for each process plant is modeled as a linear function of the number of operating trains or plants. An equation similar to Equation 2.2.1 is used to calculate the number of dedicated operators and boardmen for each 
process plant. No dedicated operators are allowed for a spare plant. After the number of dedicated operators for the entire complex have been determined, the total number of operators, extra operators, foremen, and maintenance workers are calculated by applying a multiplicative factor to account for them.

For example, if a single Fischer-Tropsch plant train of Plant 201 requires five dedicated operators per day, then the complete eight operating train plant would require eight times as many dedicated operators or forty operators per day.

The numerical values for the $A_{i}$ and $B_{i}$ parameters for the dedicated operating labor are input parameters to each Fortran user block model. Parameter REAL(49) is the constant factor for the number of dedicated plant operators per day, and REAL(50) is the number of dedicated plant operators per day per operating train. The number of extra, OSBL operators, foremen and maintenance workers per dedicated plant operator is set as variable XOF (eXtra Operator Function) in the inline Fortran block SUMNREL.

\subsection{Capital Costs}

The ISBL field cost for each plant is calculated as a function of plant capacity. After the total ISBL field cost for all plants in the complex has been calculated, the total installed cost of each plant is calculated by allocating an appropriate amount of OSBL, home office, engineering, and contingency costs to each plant based on the total ISBL field cost of all the individual plants in the complex.

The ISBL field cost for each plant except for Plant 201 (the Fischer-Tropsch synthesis plant) is calculated as a function of the key flow rate by Equations 2.4.1 through 2.4.3. The key flow rate may be either the total flow rate of a specific feed or product stream or the flow rate of the major component in a specific feed or product stream. For example, the key flow rate for the coal cleaning plant is the clean coal product stream rate in Mlbs/hr, and the key flow rate for the hydrogen recovery plant is the useable hydrogen production rate (flow rate of hydrogen in the hydrogen-rich product gas stream) in MM SCF/hr of hydrogen.

$$
\begin{aligned}
& \operatorname{COST}=F C O S T+(N-1){ }^{*} \operatorname{SCOST} \\
& F C O S T=A+B *\left(F_{O} /\left(N * R F_{O}\right)\right)^{E} \\
& S C O S T=F{ }^{*} \text { FCOST }
\end{aligned}
$$

Where:

COST $=$ Total ISBL field cost of all duplicate trains

$\mathrm{FCOST}=\mathrm{ISBL}$ field cost of the first train 
SCOST = ISBL field cost of each subsequent duplicate train after the first one

$\mathrm{N}=$ Total number of duplicate trains, including spares

$\mathrm{F}_{\mathrm{O}}=$ Total key flow rate of all duplicate trains in appropriate units, such as MM SCF/hour or Mlbs/hour

$\mathrm{RF}_{\mathrm{O}}=$ Reference key flow rate of a single train in appropriate units, such as MMSCF/hour or Mlbs/hour. This flow rate is used to scale the ISBL field cost of a single train as a function of train capacity

$\mathrm{A}, \mathrm{B}, \mathrm{E}$ and $\mathrm{F}=$ Constants for the calculation of the ISBL field cost of a single train as a function of train capacity

In the above capital cost equation, constant $A$ is the fixed ISBL field cost associated with a single train. The sum of constants $A$ and $B$ is the ISBL field cost of a single train of capacity $R F_{O}$. Thus, constant $B$ is the variable ISBL field cost of a single train of capacity $\mathrm{RF}_{\mathrm{O}}$. Constant $\mathrm{E}$ is the train cost scaling exponent. Constant $\mathrm{F}$ is the cost reduction factor for the construction of duplicate trains after the first one.

A special costing algorithm is used to calculate the cost of Plant 201, the FischerTropsch synthesis plant. This costing algorithm is based on detailed size and weight calculations of the Fischer-Tropsch reactor vessels, and from the vessel weight, the uninstalled vessel cost is calculated. From this, the cost of the installed vessel (including closely associated accessories) and the cost of the peripheral equipment associated with each reactor are calculated. All other equipment in the plant are then calculated using a modified form of the above described general cost scaling equation.

For those situations when the size and weight of the Fischer-Tropsch reactor vessels are not calculated, the general cost scaling equations may be used to calculate the cost of Plant 201.

The Fortran user block model will calculate the required number of duplicate trains or operating units in the plant from the total plant capacity and the specified maximum and minimum single train capacities. However, each Fortran user block model allows the user to specify the number of operating duplicate trains as an input parameter. When this number is supplied, that value will be used, and the calculation of the number of duplicate operating trains will be bypassed.

When the maximum capacity of a single operating train within a plant is not specified (i.e.; a zero or negative value is supplied), the total ISBL field cost will be calculated based on a single train. 
The numerical values for the plant costing parameters, number of duplicate operating trains, and number of spare trains are input parameters to each Fortran user block model. Parameter INT(3) is the specified number of duplicate operating trains, excluding spares, and parameter $\operatorname{REAL}(58)$ is the number of spare trains. If INT(3) has a value of zero, the model will calculate the number of duplicate operating trains based on the specified maximum capacity of a single train. If INT(3) has a positive value, that value will be the number of duplicate operating trains that will be used to calculate the total ISBL field cost.

Parameter REAL(51) is the reference capacity of a single operating train for the calculation of the ISBL field cost, expressed as the key flow rate in MM SCF/hour or Mlbs/hour. Parameters REAL(52) and REAL(53) are the maximum and minimum capacities, respectively, of a single operating train for which these costing parameters are applicable, expressed in the same manner as parameter REAL(51). Parameters REAL(54) through REAL(57) set the A, B, E and F parameters in Equations 2.4.2 and 2.4.3 for the calculation of the total ISBL field cost of the plant as a function of capacity. The units of all REAL plant cost parameters, Mlbs/hr, etc., must be consistent with the REAL parameters specified for the process calculations.

\subsection{Fortran User Block Model Input Parameters}

The ASPEN program allows values to be passed to and from Fortran user block models via parameters specified in the input files. There are two types of parameters, integer and real (floating point). The NINT= phrase of the PARAM sentence in the input file specifies the number of integer parameters, and the NREAL= phrase specifies the number real parameters. The values of the integer parameters are specified in the INT sentence, and the values of the real parameters are specified in the REAL sentence.

The Fortran user block model will calculate the required number of duplicate trains or operating units from the total plant capacity and the specified maximum and minimum single unit capacities. However, each Fortran user block model allows the user to specify the number of operating duplicate plants as an input parameter. When the number of operating duplicate plants is supplied as an input parameter, that value will be used, and the calculation of the number of operating duplicate plants will be bypassed.

When the maximum capacity of a single train or operating unit within a plant is not specified (i.e., a zero or negative value is supplied), the total plant cost will be calculated based on a single unit. Operating labor requirements are calculated as a function of the number of units in each plant.

Table 2.3 describes the input parameters that are common to all of the Fortran user block models. The models have at least four integer input parameters and up to 70 
real input parameters. Additional information on these parameters is provided in the following subsections that describe the individual plant models.

All of the Fortran user block models have four common integer input parameters, INT(1) through INT(4). The first integer parameter, INT(1), is the user block summary report control switch which controls the printing of the three sections of the user block summary report. When INT(1) has a value of zero, all three sections of the summary report are printed. When it has a value of one, only the stream report and utilities report sections are printed. When it has a value of two, only the stream report section is printed. When it has a value of three or more, the entire user block model summary report is not printed.

The second integer parameter, INT(2), is the user Fortran block summary report destination control switch. When INT(2) has a value of zero, the summary report will be written to the normal ASPEN report file. When it has a value of one, the user block summary report will be written to a separate summary report file for each plant. This file name will begin with the letters ICL followed by some numbers and possibly some letters to identify the specific plant or option, and have a filespec of REP. Thus, the separate summary report file for Plant 108 is ICL108.REP and the separate report file for Plant 115 is ICL115.REP.

The third integer parameter, INT(3), is the number of operating duplicate trains, excluding spares. When INT(3) has a positive value, it is the number of operating duplicate trains that will is used in the calculation of the ISBL field cost of the plant. When INT(3) is zero, the number of operating duplicate trains will be calculated based on the specified maximum train capacity given in parameter REAL(52).

The fourth integer parameter, INT(4), controls how much additional information is written to the history file for debugging purposes. When INT(4) has a value of zero, no information except any warning or error messages are written to the history file. When INT(4) has a value of one or greater, some additional information will be written to the history file. In general, the amount of information written to the history file increases as the value of INT(4) increases. Normally, INT(4) should be set either to zero so that no additional information is written to the history file, or to one so that only the master subroutine entry and exit messages are written to the history file. 


\section{Table 2.3}

\section{General Fortran User Block Model Input Parameters}

\section{Parameter Description}

\section{Integer Parameters}

INT(1) User block summary report control switch.

$0=>$ Write the complete user block summary report.

$1=>$ Skip the capital cost portion of the summary report.

$2=>$ Skip the capital cost and utilities portions of the summary report.

$3=>$ Skip writing the entire user block summary report.

INT(2) User block summary report destination control switch.

$0=>$ Write the user block summary report to the normal ASPEN output report file.

1 => Write the user block summary report to a separate user block output report file.

INT(3) Number of operating duplicate trains, excluding spares. If INT(3) $=0$, the minimum number of operating duplicate trains, excluding spares, will be determined so that the capacity of each train does not exceed the maximum train capacity specified by parameter $\operatorname{REAL}(52)$. If $\operatorname{INT}(3)>0$, the number of operating duplicate trains, excluding spares.

INT(4) History file additional output control switch.

$0=>$ Write no additional output to the history file.

$1=>$ Write only the subroutine entry and exit messages to the history file.

$2=>$ Write some additional output to the history file.

3-5 => Write some more additional output to the history file. Larger values will generate more additional output.

\section{Real Parameters}

REAL(1)- Model specific parameters. These parameter locations are reserved

REAL(20) for items which are specific to each Fortran user block model, such as conversion, component distribution factors, etc.

REAL(21) Constant factor for the power consumption, kw.

REAL(22) Power consumption per CAP unit, kw/(CAP units).

REAL(23) Constant factor for the $900 \mathrm{psig} / 1000^{\circ} \mathrm{F}$ steam consumption, Mlbs $/ \mathrm{hr}$.

REAL(24) $900 \mathrm{psig} / 1000^{\circ} \mathrm{F}$ steam consumption per CAP unit, (Mlbs/hr)/(CAP units).

REAL(25) Constant factor for the $360 \mathrm{psig} / 440^{\circ} \mathrm{F}$ steam consumption, Mlbs $/ \mathrm{hr}$.

REAL(26) $360 \mathrm{psig} / 440^{\circ} \mathrm{F}$ steam consumption per CAP unit, (Mlbs/hr)/(CAP units).

- Continued on Next Page - 


\section{Table 2.3 (Continued)}

\section{General Fortran User Block Model Input Parameters}

\section{Parameter Description}

REAL(27) Constant factor for the $600 \mathrm{psig} / 650^{\circ} \mathrm{F}$ steam consumption, Mlbs $/ \mathrm{hr}$.

REAL(28) $600 \mathrm{psig} / 650^{\circ} \mathrm{F}$ steam consumption per CAP unit, (Mlbs/hr)/(CAP units).

REAL(29) Constant factor for the 600 psig saturated steam consumption, Mlbs $/ \mathrm{hr}$.

REAL(30) 600 psig saturated steam consumption CAP unit, (Mlbs/hr)/(CAP units).

REAL(31) Constant factor for the 150 psig saturated steam consumption, Mlbs/hr.

REAL(32) 150 psig saturated steam consumption per CAP unit, (Mlbs/hr)/(CAP units).

REAL(33) Constant factor for the 50 psig saturated steam consumption, Mlbs/hr.

REAL(34) 50 psig saturated steam consumption per CAP unit, (Mlbs/hr)/(CAP units).

REAL(35) Constant factor for the plant fuel consumption, MM BTU/hr.

REAL(36) Plant fuel consumption per CAP unit, (MM BTU/hr)/(CAP units).

REAL(37) Constant factor for the cooling water consumption, Mgal/hr.

REAL(38) Cooling water consumption per CAP unit, (Mgal/hr)/(CAP units).

REAL(39) Constant factor for the process water consumption, Mgal/hr.

REAL(40) Process water consumption per CAP unit, (Mgal/hr)/(CAP units).

REAL(41) Constant factor for the nitrogen consumption, MM SCF/hr.

REAL(40) Nitrogen consumption per CAP unit, (MM SCF/hr)/(CAP units).

REAL(42) -

REAL(48) Future use.

REAL(49) Constant factor for the number of dedicated operators per day.

REAL(50) Number of dedicated operators per day per operating train.

REAL(51) Reference capacity of a single train as defined by the key flow rate in CAP units for the calculation of the ISBL field cost of a single train as a function of train capacity.

REAL(52) Maximum size of a single train as defined by the key flow rate in CAP units.

REAL(53) Minimum size of a single train as defined by the key flow rate in CAP units.

REAL(54) Constant $A$ in the plant ISBL field cost equation, the fixed capital cost of a single plant in MM \$.

REAL(55) Constant B in the plant ISBL field cost equation, the variable capital cost of a single plant having the key flow rate specified in variable REAL(51) in MM \$.

\section{- Continued on Next Page -}




\section{Table 2.3 (Continued)}

\section{General Fortran User Block Model Input Parameters}

\section{$\underline{\text { Parameter }} \underline{\text { Description }}$}

REAL(56) Constant $E$ in the plant ISBL field cost equation, the plant cost scaling exponent.

REAL(57) Constant $F$ in the plant ISBL field cost equation, the cost reduction factor for the construction of duplicate trains after the first one.

REAL(58) Number of spare trains.

REAL(59) -

REAL(70) Future use.

NOTE: The plant capacity as used in the various calculations is defined as a key flow rate. This key flow rate may be either the total flow rate of a specific stream or the flow rate of the main component in a specific stream. This flow rate is expressed in an appropriate set of units such as MM SCF/hr, $\mathrm{Mlbs} / \mathrm{hr}$, or MM SCF/hr of hydrogen. In this generalize table, this set of units is called CAP units since the key flow rate item and appropriate units are not known. 
The first twenty REAL (floating point) parameters, REAL(1) through REAL(20), are used to specify the conversions, component distributions, etc. necessary for the calculation of the output stream flow rates and compositions in each model.

The next twenty-eight REAL parameters, REAL(21) through REAL(48), are used to calculate the utilities consumptions or productions for this plant as a linear function of the plant capacity expressed as the flow rate of a key stream.

The next two REAL parameters, REAL(49) and REAL(50), are used to calculate the number of dedicated plant operators per day as a function of the number of operating plants or trains.

The next 10 REAL parameters, REAL(51) through $\operatorname{REAL(60),~are~used~to~calculate~}$ the number of duplicate operating units, the capacity of each, and the total ISBL field cost of the entire plant.

The final 10 REAL parameters, REAL(61) through $R E A L(70)$, are reserved for future use or for specific use within a model.

\subsection{Management Summary Report}

As discussed previously, the user can select several levels of reporting by setting model specific integer parameters in the input files. In addition, the standard ASPEN Plus stream reports, history reports, etc. may be modified or expanded. A customized management summary report was designed for this project which summarizes the operations of the entire complex. The total model specific output report starts with the one-page management summary report, and is followed by a short summary for each plant of the key streams and components, costs, utilities and manpower requirements that may be of interest in evaluating various wood liquefaction scenarios.

An example of the complete management summary report containing all the individual plant summary reports is given in Appendix B. This sample report was generated by the ASPEN Plus process simulation model for the Battelle biomass gasification/ Fischer-Tropsch synthesis/combined-cycle power plant model for the maximum liquids production case (All of the syngas going to Area 200 for F-T synthesis.). 


\subsection{INDIVIDUAL PLANT MODELS IN AREA 100}

Area 100, the syngas preparation area, contains seven process plants. Figure 2.1 is a block flow diagram showing the various ASPEN models in Area 100. This processing area receives the wet wood chips, dries and gasifies them to produce syngas which is compressed before being sent on for further processing. In addition, this area contains a $\mathrm{CO}$ shift reactor for producing the hydrogen required for processing in Area 300, the product upgrading area.

The following subsections present a brief process description, followed by a discussion of the Fortran user block model for each of these seven plants. Calculation methods are discussed, and the plant-specific model input parameters to be set by the user in the ASPEN Plus input file are listed for each model.

Area 100 is the only processing area of this process simulation model where solids may be present. The entering WOOD stream must be of ASPEN Plus stream class MIXNC or MIXNCPSD and contain two substreams; one being a mixed substream of conventional components, and the other being a substream containing solid nonconventional components. All material streams entering and leaving the simulation blocks for Plants 115 and 116 must be of the ASPEN Plus stream class MIXNC or MIXNCPSD. All entering and intermediate material streams associated with these two plants also must be of stream class MIXNC or MIXNCPSD. The syngas stream leaving Plant 116 passes through ASPEN stream class changer block P116C to convert it to a stream containing a single mixed substream of conventional components (ASPEN Plus stream class CONVEN). This change to stream class CONVEN simplifies the subsequent ASPEN process block models and speeds up the simulation.

Each of the following ASPEN Plus models (which will be discussed in numerical order) was developed to simulate the specific plant only to provide sufficient detail to determine the major output streams, utilities consumptions, ISBL cost and number of operators as a function of the input streams.

\subsection{Plant 108 -- Sulfur Polishing Plant}

Plant 108, the sulfur polishing plant, removes the sulfur compounds from the washed syngas leaving the Battelle biomass gasification plant (Plant 116) after compression in Plant 117 before it goes either to the Fischer-Tropsch synthesis plant or to the CO shift plant as shown in Figure 2.1. This sulfur removal is necessary because sulfur compounds can poison the Fischer-Tropsch synthesis catalyst. The sulfur is removed in fixed bed reactors filled with zinc oxide ( $\mathrm{ZnO})$ pellets that react with the sulfur to form solid zinc sulfide (ZnS). The zinc oxide is permanently consumed and periodically replaced with fresh material. 
Since the sulfur content of the syngas entering the sulfur polishing plant is significantly higher than that of the baseline coal design, the cost of this plant was recalculated to reflect this situation. A proportionately larger reactor volume was used to provide a one year cycle life between changes of the zinc oxide adsorbent. The remainder of the plant cost, namely furnaces and heat exchangers, was apportioned according to the syngas flow rate. The annual zinc oxide cost also was adjusted to reflect the high sulfur content of the syngas produced by the Battelle biomass gasification plant.

Plant 108 is modeled by two ASPEN process blocks. Block P108F is a Fortran user block model that has a single input stream and generates an identical single output stream. Block P108S is a standard ASPEN SEP block that quantitatively removes all sulfur from the entering syngas stream and places it in a waste stream (stream 108S3). This waste stream is equivalent to the capture of the sulfur by the zinc oxide that is eventually discarded. The clean syngas in stream $108 \mathrm{~S} 2$ is sent to the Fischer-Tropsch reactors in Area 200 for conversion to liquid products. All streams associated with Plant 108 are of the MIXED stream class.

A separation process is used to simulate the removal of the sulfur compounds from the syngas by reaction with solid zinc oxide to produce solid zinc sulfide. Since only small amounts of sulfur in the parts per million range enter the sulfur polishing plant, the byproduct production also is small and insignificant compared to that in the entering syngas. Consequently, any byproduct production is ignored. Thus, this simple physical separation model adequately represents the sulfur polishing plant.

The Fortran user block model for Plant 108 only calculates the utilities consumptions and ISBL cost of the plant as a function of the entering syngas flow rate. This model requires no special user input parameters other than the general Fortran user block model input parameters discussed in Section 2.5.

\subsection{Plant 113 -- CO Shift Reactor (Hydrogen Production Plant)}

Plant 113, the CO shift reactor or hydrogen production plant, is a new plant for this Battelle gasification plant model. The purpose of this plant is to produce hydrogen for use by the hydroprocessing processes in the product upgrading area, Area 300. The hydrogen that is produced here is recovered and purified in Plant 205, the hydrogen recovery plant. This plant utilizes the water-gas shift reaction to react the carbon monoxide in the entering syngas with water to produce hydrogen and carbon dioxide.

In this plant, a small portion of the compressed sulfur-free syngas is mixed with steam and heated to $675^{\circ} \mathrm{F}$ before entering a high temperature shift converter to react the carbon monoxide with water to produce hydrogen and carbon dioxide. The exiting gas is cooled by steam generation, air cooling and water cooling before going to the hydrogen recovery plant. 
Plant 113 is modeled by seven ASPEN process blocks. Block P113S1 splits off some of the compressed sulfur-free syngas from Plant 108 into stream $113 S 1$ for hydrogen production in Plant 113. The remainder of the syngas in stream $113 \mathrm{~S} 2$ goes to the F-T synthesis plant. The syngas in stream $113 \mathrm{~S} 1$ is mixed with 360 psig $/ 440^{\circ} \mathrm{F}$ steam and heated to $675^{\circ} \mathrm{F}$ in block $\mathrm{P} 113 \mathrm{H} 1$. The heated mixture enters block P113R, an ASPEN REQUIL equilibrium reactor model, where the water-gas shift reaction occurs. A $50^{\circ} \mathrm{F}$ approach to equilibrium is used in this reactor model. The reactor effluent is cooled in three steps in process blocks $\mathrm{P} 113 \mathrm{H} 2, \mathrm{P} 113 \mathrm{H} 3$ and $\mathrm{P} 113 \mathrm{~S} 2$. $\mathrm{P} 113 \mathrm{H} 2$ cools the effluent to $480^{\circ} \mathrm{F}$ represents the generation of $360 \mathrm{psig} / 440^{\circ} \mathrm{F}$ steam. $\mathrm{P} 113 \mathrm{H} 3$ cools the effluent to $150^{\circ} \mathrm{F}$ and represents a combination of BFW preheat and air coolers. P113S2 simultaneously cools the gas to $100^{\circ} \mathrm{F}$ with cooling water and separates the condensed water. Block P113F is a Fortran user block model which predicts the utilities consumptions and ISBL field cost of the plant as a function of flow rate of the dried and shifted syngas product in stream 113SS8. Stream $113 \mathrm{~S} 10$ leaving block P113F goes to Plant 205 for hydrogen recovery.

The Fortran user block model for Plant 113 only predicts the utilities consumptions and ISBL cost of the plant as a function of the dry shifted syngas product rate. This model requires no special user input parameters other than the general Fortran user block model input parameters discussed in Section 2.5.

\subsection{Plant 115 -- Wood Drying Plant}

Plant 115, the wood drying plant, is a new plant for this Battelle gasification plant model. Figure 3.1 is a schematic block flow diagram of the ASPEN Plus model for the wood drying and Battelle biomass gasification plants, Plants 115 and 116.

This plant model is based on the design which Gray used in his study. Maple wood chips containing $37.9 \mathrm{wt} \%$ moisture are dried to $23.8 \mathrm{wt} \%$ moisture in rotary drum dryers before going to the Battelle biomass gasifier. A furnace using bleed gas, unconverted carbon or tar is used to heat the wood for drying. Gray reports the exit temperature of the dried maple wood chips to be about $400^{\circ} \mathrm{F}$. In another study, Breault and Morgan report a temperature of $155^{\circ} \mathrm{F}$ for dried poplar wood chips. ${ }^{6}$ Therefore, the exit temperature of the dried wood chips was arbitrarily reduced to $220^{\circ} \mathrm{F}$ for this study.

In addition, the energy input used by Gray is excessively low compared to that of Breault and Morgan. Consequently, an energy balance calculation was made around the wood drying plant, and the energy consumption parameter in the

\footnotetext{
${ }^{6}$ Breault, R and D. Morgan, "Design and Economics of Electricity Production from an Indirectly Heated Biomass Gasifier," Tecogen, Inc., Waltham, MA, October 22, 1992.
} 
Figure 3-1

SCHEMATIC BLOCK DIAGRAM OF THE ASPEN MODEL OF THE WOOD DRYING AND BATTELLE GASIFICATION PLANT

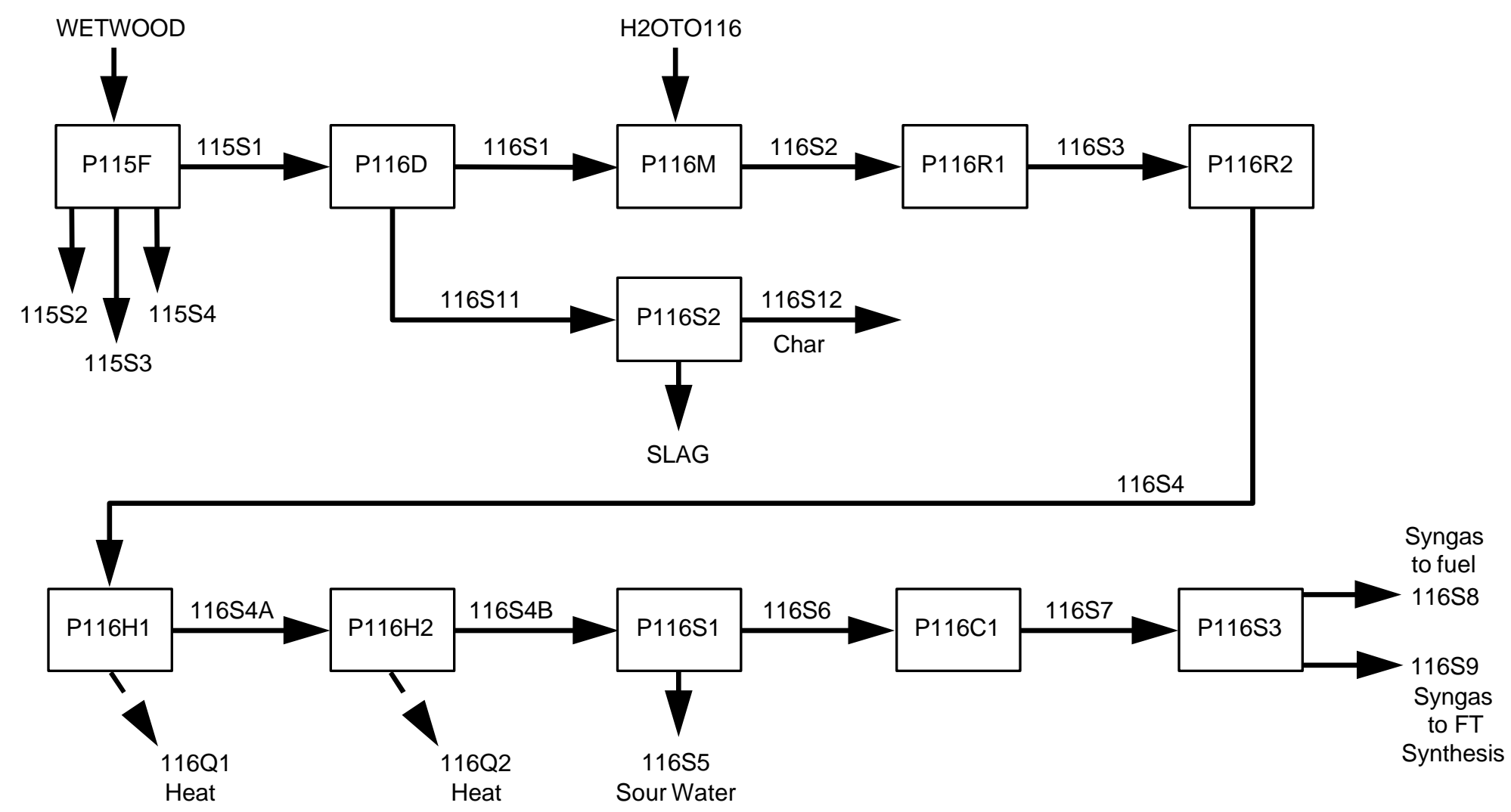


ASPEN model is based on this energy balance. The electric power consumption is that reported by Gray. The ISBL plant cost for the wood drying plant is that given by Gray also.

A single ASPEN Fortran user block model is used to represent the wood drying plant. This model is a derivative of the one which was developed for coal grinding and drying for the baseline indirect coal liquefaction design and the direct coal liquefaction study. ${ }^{4,7}$ As such, it is more sophisticated than necessary and also can model a wood cleaning operation which may produce up to three grades of wood product. This model is used here only for mass balance purposes, and consequently, does not model a wood cleaning operation. Complete instructions on the use of this model for wood cleaning are similar to those that were previously given for coal cleaning. ${ }^{4}$ Consequently, only the necessary parameters for wood drying will be discussed.

Fortran user block model P115F requires one input stream and four output streams. These streams must be of ASPEN Plus stream class MIXNC or MIXNCPSD. The first output stream, stream 115S1 is the dried wood stream, and stream 115S4 is the water removed during drying. Streams $115 \mathrm{~S} 2$ and $115 \mathrm{~S} 3$ are not used, but must be present to satisfy the requirements of the Fortran user block model.

This model will work with any number of conventional components and nonconventional components. The wood to be cleaned must be the first nonconventional component listed in the input file.

In addition, the model requires the following seventeen plant-specific REAL parameters besides those discussed in Section 2.5. For simplicity, the following description will relate to the use of the model for wood drying only, and not for wood cleaning.

$$
\begin{aligned}
& \operatorname{REAL}(1)=\text { Set to } 1.0 \\
& \operatorname{REAL}(2)=\text { Set to } 0.0 \\
& \operatorname{REAL}(3)=\text { Set to } 1.0 \\
& \operatorname{REAL}(4)=\text { Set to } 0.0 \\
& \operatorname{REAL}(5)=\text { Set to } 1.0 \\
& \operatorname{REAL}(6)=\text { Set to } 0.0 \\
& \operatorname{REAL}(7)=\text { Set to } 1.0 \\
& \operatorname{REAL}(8)=\text { Set to } 0.0 \\
& \operatorname{REAL}(9)=\text { Set to } 1.0 \\
& \operatorname{REAL}(10)=\text { Set to } 0.0 \\
& \operatorname{REAL}(11)=\text { Set to } 1.0 \\
& \operatorname{REAL}(12)=\text { Set to } 0.0 \\
& \operatorname{REAL}(13)=\text { Set to } 1.0
\end{aligned}
$$

\footnotetext{
7 Topical Report, "Direct Coal Liquefaction Baseline Design and System Analysis," Task V Topical Report, Process Simulation Model for Baseline and Options, DOE contract number DE-AC2290PC89857, Bechtel Corporation, December, 1992.
} 


$$
\begin{aligned}
& \operatorname{REAL}(14)= \text { Set to } 0.0 \\
& \operatorname{REAL}(15)= \text { Moisture content of the dried wood product expressed on a dry } \\
& \text { wood basis, wt\%. } \\
& \operatorname{REAL}(16)= \text { Set to } 3.0-\text { Moisture content of the middlings wood product } \\
& \text { expressed on a dry wood basis, wt\%. } \\
& \operatorname{REAL}(17)= \text { Set to } 10.0-- \text { Moisture content of the refuse stream expressed } \\
& \text { on a dry wood basis, wt\%. }
\end{aligned}
$$

\subsection{Plant 116 -- Battelle Biomass Gasification Plant}

Plant 116, the Battelle biomass gasification plant, is a new plant for this ASPEN model. This plant model is based on the design and material balance that Gray used in his study. ${ }^{1}$ Maple wood chips which were dried to $23.8 \mathrm{wt} \%$ moisture are gasified in the Battelle indirectly heated biomass gasifier. The mass balance reported by Gray was adjusted slightly to make it both in mass and elemental balance.

For modeling purposes, the tar/C2+ component reported by Gray is represented by a mixture of ethylene $\left(\mathrm{C}_{2} \mathrm{H}_{4}\right)$, benzene $\left(\mathrm{C}_{6} \mathrm{H}_{6}\right)$, and $\mathrm{C}_{10} \mathrm{H}_{20}$ (1-nonene). This requires slightly more moles than those used by Gray (406.3 vs. 404), but this representation does give an exact elemental balance, and the difference in the number of moles is insignificant. A higher molecular weight olefin could have been used to represent the heaviest portion of the tar and get an exact mole match, but 1nonene was selected because it is the highest olefin presently available in the ASPEN Plus data bank.

This model of the Battelle gasification plant concentrated was developed primarily to predict the correct flow rates and composition of the syngas stream leaving the gasifier. It does not model the combustion section of the unit or the sand flow between the gasification and combustion sections. In order to reproduce the slag flow rate used by Gray ${ }^{1}$, an appropriate amount of char is called slag. Consequently, the elemental composition of this 'so called' slag stream is not correct.

TEN ASPEN process blocks are used to model the Battelle indirect gasifier. Figure 3.1 is a schematic block flow diagram of the ASPEN Plus model for the wood drying and Battelle gasification plants, Plants 115 and 116 . This model concentrates on producing the correct amount and composition of the syngas and does not attempt to represent the combustor section or the circulating sand. As such, it only predicts the correct amount of the solid slag waste product stream, and does not try to adequately represent its elemental composition.

The entering dried wood stream and all intermediate streams in the ASPEN model of the Battelle biomass gasifier before block P116C1 are of ASPEN Plus stream class MIXNC or MIXNCPSD. The final three washed syngas streams (streams 
116S7, 116 S8 and 116S9) are of ASPEN Plus stream class CONVEN and contain only a single substream of conventional components. These streams were converted to ASPEN Plus stream class CONVEN containing only a single substream of conventional components in order to simplify the modeling of the downstream processing steps.

The entering dried wood stream is decomposed in Fortran user block model P116D into a pseudo gaseous wood chip stream (stream 116S1) and a solids stream of char (stream 116S11) that is burned in the combustor (block P116S2). The P116D decomposition block also converts all the sulfur in the wood feed to $\mathrm{H}_{2} \mathrm{~S}$. Block $\mathrm{P} 116 \mathrm{~S} 2$ simulates the slag production in the gasifier by producing a slag product stream (stream SLAG) and a stream that is burned in the combustor (stream $116 \mathrm{S12}$ ) which will eventually leave as flue gas. As mentioned previously, this SLAG product stream has the correct flow rate, but not the correct elemental composition.

Steam is added to the pseudo gaseous wood chip stream in mixing block P116M1 and fed to two sequential RSTOICH reactor blocks (blocks P116R1 and P116R2). Two RSTOICH reactor blocks are necessary to handle the sequential reactions in the gasifier reaction model. The first reactor block, block P116R1, is a carbon burner which converts the carbon in the feed to the desired products. The second reactor block, block $\mathrm{P} 116 \mathrm{R} 2$, converts any remaining oxygen to water. Blocks $\mathrm{P} 116 \mathrm{H} 1$ and $\mathrm{P} 116 \mathrm{H} 1$ represents the syngas cooler blocks which cool the syngas and generate the $975 \mathrm{psig} / 750^{\circ} \mathrm{F}$ and $360 \mathrm{psig} / 530^{\circ} \mathrm{F}$ steams. Streams 116Q1 and 116Q2 are heat streams which represent the heat transferred to the $975 \mathrm{psig} /$ $750^{\circ} \mathrm{F}$ and $360 \mathrm{psig} / 530^{\circ} \mathrm{F}$ steams, respectively. Block P116S1 simulates the water quench tower (which washes and cools the syngas stream) by a simple ASPEN component separator SEP block. The inlet water stream going to the quench tower is not modeled, and consequently, the flow rate of the cooled and condensed waste water stream, stream 116S5, is under predicted. Stream 116S6 is the cooled and washed syngas stream which goes to ASPEN Plus class changer block P116C1 which changes its stream class from ASPEN Plus stream class MIXNC to stream class CONVEN.

Block P116S3 is an ASPEN FSPLIT flow splitter block that allows the switching of the washed and cooled syngas stream between Fischer-Tropsch synthesis and power generation in the combined-cycle plant. Stream 116S8 goes to the combined-cycle syngas compression plant, and stream 116S9 goes to the FischerTropsch syngas compression plant. For the maximum liquids production case, the split fraction in block P116S3 is set to 0.0 to send all the syngas to Fischer-Tropsch synthesis. A value of 0.5 will split the syngas evenly between Fischer-Tropsch synthesis and combined-cycle power generation. Because of a quirk in the ASPEN Plus program itself, the model will not function with a value of 1.0 for the split fraction. However, it will function with a value of 0.999 which will send essentially all the syngas to the combined-cycle power plant and approximate the all power production case. If a pure all power production case is desired, one easily can be 
constructed by removing all the processing steps related to the Fischer-Tropsch synthesis and product upgrading operations.

Fortran user block P116D also calculates the utilities consumptions and ISBL cost of the Battelle indirectly heated biomass gasification plant. The ISBL plant cost is based on that of Gray with the addition of the syngas water wash tower.

The Fortran user block model for Plant 116 only predicts the utilities consumptions and ISBL cost of the plant as a function of the entering dry wood flow rate. This model requires no special user input parameters other than the general Fortran user block model input parameters discussed in Section 2.5.

\subsection{Plant 117 -- Fischer-Tropsch Syngas Compression Plant}

Plant 117, the Fischer-Tropsch syngas compression plant, is a new plant for this Battelle gasification plant model. This plant simulates the multistage compression of the cooled and washed syngas from the atmospheric pressure Battelle gasification plant to 360 psia for F-T synthesis after sulfur removal in Plant 108.

The F-T syngas compression plant is modeled by two ASPEN process blocks, block $\mathrm{P} 117 \mathrm{~F}$ and block $\mathrm{P} 117 \mathrm{C} 1$. Fortran user block P117F calculates the utilities consumptions and ISBL field cost of Plant 117 as a function of the entering dry syngas flow rate. Block $\mathrm{P} 117 \mathrm{C} 1$ simulates a five-stage polytropic compressor with interstage cooling and water removal from the interstage coolers. Stream 117S2 is the compressed syngas stream going to the sulfur removal plant. Streams KO1, $\mathrm{KO} 2, \mathrm{KO} 3$ and $\mathrm{KO} 4$ are four condensed water streams leaving the four interstage coolers.

The Fortran user block model for Plant 117 only predicts the utilities consumptions and ISBL cost of the plant as a function of the entering syngas flow rate. This model requires no special user input parameters other than the general Fortran user block model input parameters discussed in Section 2.5.

\subsection{Plant 118 -- Combined-Cycle Syngas Compression Plant}

Plant 118, the combined-cycle syngas compression plant, is a new plant for this Battelle gasification plant model. This plant simulates the multistage compression of the cooled and washed syngas from the atmospheric pressure Battelle gasification plant to 250 psia for electricity production in the combined-cycle power plant.

The combined-cycle syngas compression plant is modeled by two ASPEN process blocks, block P118F and block P118C1. Fortran user block P118F calculates the utilities consumptions and ISBL field cost of Plant 118 as a function of the entering 
dry syngas flow rate. Block $\mathrm{P} 118 \mathrm{C} 1$ simulates a four-stage polytropic compressor with interstage cooling and water removal from the interstage coolers. Stream $118 \mathrm{~S} 2$ is the compressed syngas stream going to the combined-cycle power plant. Streams KO5, KO6 and KO7 are the condensed water streams leaving the three interstage coolers.

The Fortran user block model for Plant 118 only predicts the utilities consumptions and ISBL cost of the plant as a function of the entering syngas flow rate. This model requires no special user input parameters other than the general Fortran user block model input parameters discussed in Section 2.5.

\subsection{Plant 119 -- Fuel Gas Compression Plant}

Plant 119, the fuel gas compression plant, is a new plant for this Battelle gasification plant model. This plant simulates the multistage compression of the low-pressure fuel gas from the Fischer-Tropsch synthesis area and the product upgrading areas, (process Areas 200 and 300) to 100 psia for in-plant heating.

The fuel gas compression plant is modeled by two ASPEN process blocks, block $\mathrm{P} 119 \mathrm{~F}$ and block P119C1. Fortran user block P119F calculates the utilities consumptions and ISBL field cost of Plant 119 as a function of the entering dry fuel gas flow rate. Block $\mathrm{P} 119 \mathrm{C} 1$ simulates a two-stage polytropic compressor with interstage cooling and water removal from the interstage cooler. Stream 119S2 is the compressed syngas stream going to the combined-cycle power plant. Stream $\mathrm{KO} 8$ is the condensed water stream from the single interstage cooler.

The Fortran user block model for Plant 119 only predicts the utilities consumptions and ISBL cost of the plant as a function of the entering syngas flow rate. This model requires no special user input parameters other than the general Fortran user block model input parameters discussed in Section 2.5.

\subsection{General Comments on Area 100}

There is one additional ASPEN mixing block in Area 100 that has not been described. Block $\mathrm{A} 100 \mathrm{M} 1$ is the waste water mixing block which mixes streams $113 \mathrm{~S} 9,116 \mathrm{~S} 5, \mathrm{KO} 1, \mathrm{KO} 2, \mathrm{KO} 3, \mathrm{KO} 4, \mathrm{KO} 5, \mathrm{KO} 6, \mathrm{KO} 7$, and $\mathrm{KO} 8$ to produce stream 100WATER which contains the total waste water produced in Area 100. 


\subsection{INDIVIDUAL PLANT MODELS IN AREA 200}

Area 200, the Fischer-Tropsch synthesis area, contains three process plants. This processing area takes the clean syngas from Plant 108 and processes it to produce hydrogen, fuel gas, light gaseous products, liquids and wax in the Fischer-Tropsch synthesis plant. Plant $204 \mathrm{~N}$, the hydrocarbon recovery plant recovers the liquid hydrocarbon products and separates them into separate streams for further processing in Area 300, the product upgrading area, to gasoline and diesel fuel blending components. Plant 205, the hydrogen recovery plant, recovers the hydrogen produced by Plant 113, the CO shift reactor, and Plant 304, the naphtha reformer, for use by the hydroprocessing plants in Area 300.

Figure 4.1 is a block flow diagram showing the various ASPEN models and their interconnecting streams used to simulate Area 200. Eighteen ASPEN Plus blocks are used to simulate these three process plants.

The following subsections present a brief process description, followed by a discussion of the Fortran user block model for each of these three plants. Calculation methods are discussed, and the plant-specific parameters to be set by the user in the ASPEN Plus input file are listed for each model.

All streams in the Area 200 section of the model are of ASPEN Plus stream class CONVEN and have only one substream containing only conventional components. No solid non-conventional components may be present in this processing area. Each of the following models was developed to simulate the specific plant only to provide sufficient detail to determine the major output streams, utilities consumptions, ISBL cost and number of operators as a function of the input streams. Utility balances are developed based on the detailed design, and their consumptions calculated as linear functions of plant capacity.

\subsection{Plant 201 -- Fischer-Tropsch Synthesis Plant}

Plant 201, the Fischer-Tropsch synthesis plant, converts the syngas from Area 100 in a single slurry-bed F-T reactor into hydrocarbon products. As shown in Figure 4.1, twelve ASPEN process blocks are used to simulate Plant 201. Block P201M1 mixes the cleaned unshifted syngas from Plant 113 (stream 113S2) with steam (stream 201S2). Not shown in the figure is an inline Fortran block, called SETUP201 which sets the flow rate of the inlet steam stream, stream H2OTO201, to maintain a specified $\mathrm{H}_{2} \mathrm{O}$ to $\mathrm{CO}$ ratio in the F-T reactor inlet stream. Fortran user block $\mathrm{P} 201 \mathrm{~F}$ models the slurry phase F-T reactions, predicts the utilities consumptions and productions for the entire F-T plant, sizes the slurry bed F-T reactors, and optionally, prints an equipment list for Plant 201. Block P201S1 is an ASPEN flash block which does an equilibrium flash calculation on the total reactor 
Figure 4-1

ASPEN BLOCK FLOW DIAGRAM FOR AREA 200 - FISCHER-TROPSCH SYNTHESIS

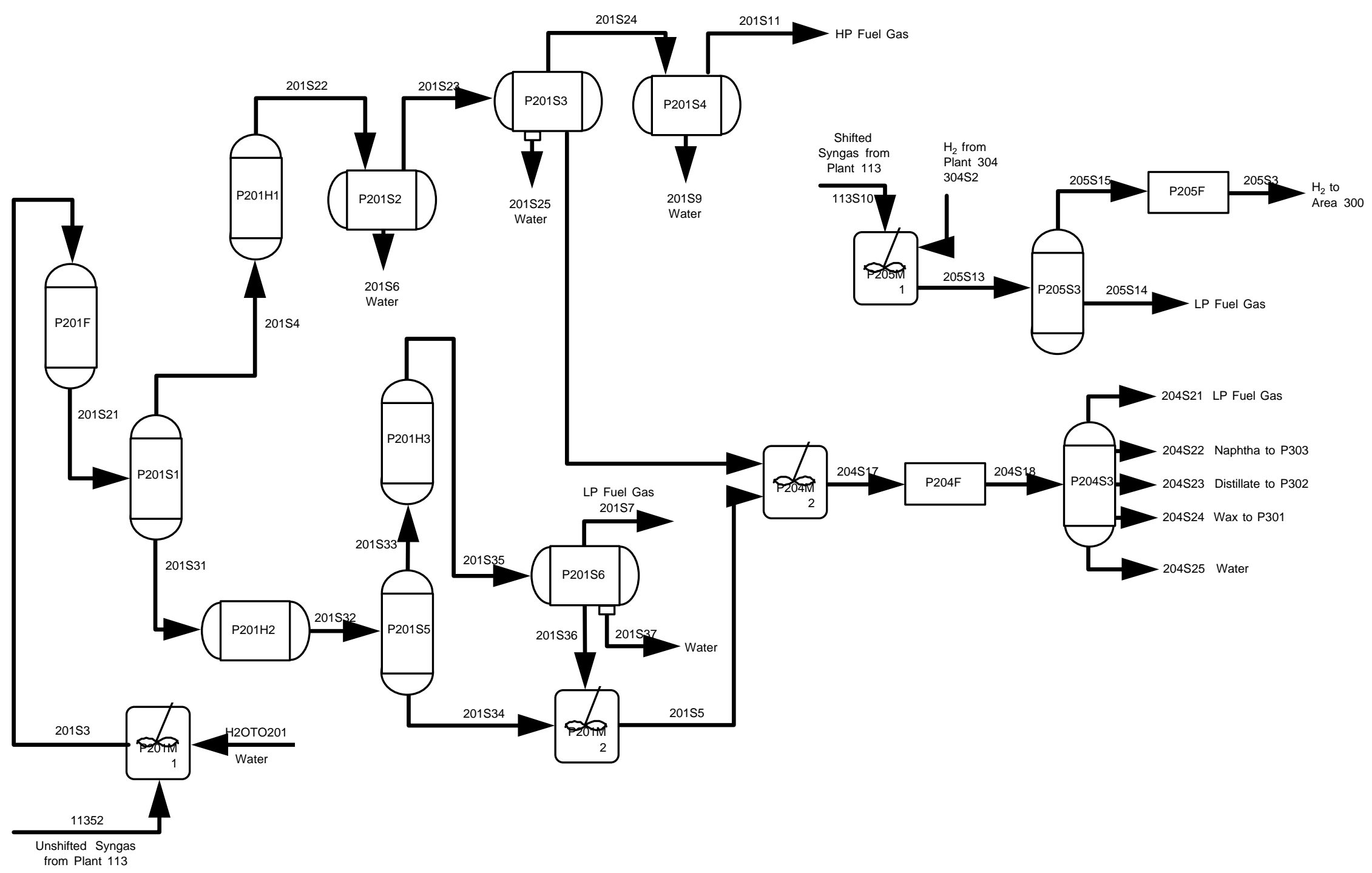


effluent to generate vapor and liquid streams. Thus, blocks P201F and P201S1 together simulate the slurry-bed Fischer-Tropsch reactor and generate the two reactor effluent streams. Not shown in Figure 5.1 is inline Fortran block SETUP21A which sets the temperature in Flash block P201S1 to be the same as that in the P201F reactor block.

The liquid reactor effluent stream, stream 201S31, is cooled in heat exchanger block P201H2 and then flashed in block P201S5, the primary wax vapor separator. The overhead vapor stream, stream 201S33, is further cooled in heater block P201 H3, the F-T wax vapor cooler and flashed in block P201S6. The overhead stream, stream 201S7, goes to low-pressure fuel gas, the bottoms wax stream, stream 201S5, goes to Plant 204 for further purification, and stream 201S37 is waste water.

The hot vapor overhead stream leaving the F-T slurry-bed reactor, stream 201S4, is cooled in block P201H1 and sent to separator blocks P201S2, P201S3, and P201S4. These separator blocks generate two oxygenates streams, streams $201 \mathrm{~S} 6$ and 201S9, a waste water stream, stream 201S6, a liquid hydrocarbons stream, stream 201S10, and a vapor stream, stream 201S11. The liquid hydrocarbons stream goes to Plant $204 \mathrm{~N}$ for further product separation, and the unconverted syngas vapor stream goes to high-pressure fuel gas.

The Fortran user block model for Plant 201 is the most sophisticated of all the Fortran user block models. This block model consists of thirteen Fortran subroutines. It models the F-T reactions and predicts the yields, predicts the utilities consumptions and productions for the entire F-T plant, sizes the slurry bed F-T reactors, and optionally, prints an equipment list for the entire Plant 201.

This empirical yields model contains the F-T yield correlations that were developed from the Mobil data and documented in the Second Quarterly Progress Report for January-March, $1992 .^{8}$ This reactor yields model is elementally balanced. It requires four model specific input parameters; the desired F-T wax yield, the percent hydrogen conversion, the mole fraction olefins in the C7-C20 olefin/paraffin hydrocarbons, and the temperature approach to equilibrium of the water-gas shift reaction.

The user specified F-T wax yield must be between 9.6 and 76.0 wt\% wax. According to the Mobil data, the F-T reactor temperature controls the wax yield, the specification of the wax yield indirectly specifies the reaction temperature. Thus, the F-T reactor temperature is calculated from the wax yield by the following equation:

$$
\mathrm{T}=275-0.4375 * \mathrm{WAX}
$$

\footnotetext{
${ }^{8}$ Quarterly Report, "Baseline Design/Economics for Advanced Fischer-Tropsch Technology," Quarterly Report for Jan. - March 1992, DOE contract no. DE-AC22-91PC90027, Bechtel Corporation, 1992.
} 
where $\mathrm{T}$ is the $\mathrm{F}-\mathrm{T}$ reactor temperature in Celsius, and WAX is the $\mathrm{C} 20+$ wax yield in $w t \%$.

The properties of the wax will change as the wax yield changes. The density, boiling point and average molecular weight of the wax will increase as the wax yield increases. Unfortunately, since the C30 + WAX is being handled in the ASPEN Plus model as a single conventional pseudocomponent called C30WAX, its basic properties (gravity, molecular weight and boiling point) have to be supplied before the simulation model can be executed. Therefore, a manual iteration around the model is required to set the properties of the C30WAX pseudocomponent in the components section of the ASPEN input file to those C30+ wax properties calculated by the F-T reactor model. These $\mathrm{C} 30+$ wax properties are reported on the first page of the Plant 201 summary report. Failure to do this will cause the model to incorrectly predict the vapor-liquid split of the wax in block P201S1. An incorrect split here will influence the subsequent calculations.

The specification of the percent hydrogen conversion is equivalent to specifying the carbon monoxide conversion since the two are related by the stoichiometry of the F-T reactions. The specified hydrogen conversion should be between 20 and $70 \%$. In addition to the specified hydrogen conversion, the model reports both the carbon monoxide conversion and the overall syngas conversion.

The third user input parameter, the mole fraction olefins in the C7-C19 olefin/ paraffin hydrocarbons, specifies the amount of olefinicity in the C7-C19 material. This parameter specifies the mole fraction of olefins in the C7-C19 material. The same olefin fraction is used for each carbon number. At present, the FischerTropsch yield model uses this same value for the mole fraction of olefins in the wax (C20 plus material).

The fourth and final yields model input parameter, the temperature approach to equilibrium of the water-gas shift reaction, specifies the effectiveness of the FischerTropsch catalyst for the water-gas shift reaction.

This Fortran user block model also has the capability of sizing the slurry bed F-T reactors using the Bechtel model that is documented in the final report for the "Slurry Reactor Design Studies" project with slightly different values of some parameters. ${ }^{9}$ After the model calculates the reactor size, it also can calculate the reactor weight and approximate its ISBL field cost. Thus, this reactor sizing and costing model requires the following twelve additional input parameters.

1. Number of spare slurry bed Fischer-Tropsch reactors in the entire plant that are not associated with a specific train. (This parameter must have an integer value.)

\footnotetext{
${ }^{9}$ Final Report, "Slurry Reactor Design Studies," Slurry vs. Fixed Bed Reactors for Fischer-Tropsch and Methanol, DOE contract no. DE-AC22-89PC89867.
} 
2. Number of parallel slurry bed Fischer-Tropsch reactors per plant train. (This parameter must have an integer value.)

3. Fischer-Tropsch slurry bed inlet gas velocity in $\mathrm{cm} / \mathrm{sec}$ (between 5 and $20 \mathrm{~cm} / \mathrm{sec}$ )

4. Fischer-Tropsch catalyst concentration in the slurry in wt \% (between 10 and $45 \mathrm{wt} \%$ )

5. Fischer-Tropsch catalyst makeup rate in percent of catalyst inventory per day. Note that a change in this item also requires a corresponding change in the annual catalyst cost supplied in inline Fortran block SUMNREL.

6. Temperature of the steam generated in the tubes of the Fischer-Tropsch slurry bed reactor in degrees Fahrenheit

7. Pressure of the steam generated in the tubes of the Fischer-Tropsch slurry bed reactor in psig

8. Weight of the reference Fischer-Tropsch slurry bed reactor in thousands of pounds for the reactor vessel cost calculation

9. Cost of the reference Fischer-Tropsch slurry bed reactor vessel in millions of dollars

10. ISBL cost of the reference Fischer-Tropsch slurry bed reactor system including its closely associated items in millions of dollars

11. ISBL cost of the peripheral equipment associated with each reference Fischer-Tropsch slurry bed reactor system

12. ISBL cost of the other equipment in millions of dollars in a single Fischer-Tropsch plant train that is not covered in the above costs

Although this Fortran user block model only simulates the slurry-bed FischerTropsch reactor, it has the optional capability of printing an equipment list with approximate sizes for all the pieces of major equipment within Plant 201. The model does not do detailed equipment sizing calculations for any pieces of equipment other than the F-T reactors. Instead, it estimates the sizes of the other pieces based on flow rates relative to those of the baseline coal liquefaction design case.

This Fortran user block model requires one plant-specific INTEGER parameter in the input file in addition to those discussed in Section 2.5. This INTEGER parameter, INT(5), controls the sizing and costing of the F-T reactors and the printing of the detailed equipment list for the plant. When the detailed sizing calculations for the F-T reactors are not done, the cost of Plant 201 will be calculated by the general cost scaling equation that is used for all the other plants. The INT(5) switch controls all these options.

INT(5) = Switch to control the equipment sizing and costing for this plant. When the F-T reactors are sized, the plant costs are calculated based on the reactor sizing results; otherwise, they are based on the overall cost model that is used for all the other plants. $0=>$ Do NOT size the F-T reactors and use the special costing 
method based on the reactor sizes. Cost the plant based on the total plant cost equation constants in the REAL(51) REAL(58) parameters.

$1=>$ Write the reactor sizing results to the plant summary report file.

$2=>$ Also write the sizes of the other pieces of major equipment in this plant based on the baseline design to the plant summary report file.

$3=>$ Also write the sizes of the other pieces of major equipment in this plant using wax filters for the catalyst/wax separation to the plant summary report file.

In addition, the model requires the following plant-specific REAL parameters besides those discussed in Section 2.5.

REAL(1) = Desired wax yield in wt\%. (Valid values are between 9.6 and $76 \mathrm{wt} \%$ wax)

REAL(2) = Hydrogen conversion in \%. (Valid values are between 20 and $90 \%$ )

$\operatorname{REAL}(3)=$ Mole fraction olefins in the $\mathrm{C} 7-\mathrm{C} 19$ olefin/paraffin hydrocarbons.

REAL(4) = Future use.

REAL(5) = Future use.

REAL(6) = Future use.

$\operatorname{REAL}(7)=$ Temperature approach of the water-gas shift reaction in Celsius.

$\operatorname{REAL}(8) \quad=$ Future use.

REAL(9) = Fischer-Tropsch reactor pressure drop in psi.

$\operatorname{REAL}(10)=$ Number of spare slurry-bed Fischer-Tropsch reactors in the entire plant not associated with a specific plant train. (This parameter must have an integer value.)

REAL $(11)=$ Number of parallel slurry-bed Fischer-Tropsch reactors per plant train. (This parameter must have an integer value.)

REAL(12) = Fischer-Tropsch slurry bed inlet gas velocity in $\mathrm{cm} / \mathrm{sec}$. (between 5 and $20 \mathrm{~cm} / \mathrm{sec}$ ) Note that a change in this parameter also requires a corresponding change to the annual catalyst cost in the inline Fortran block which summarizes the model results for the entire complex.

$\operatorname{REAL}(13)=$ Fischer-Tropsch catalyst concentration in the slurry in wt \%. (between 10 and $45 \mathrm{wt} \%$ )

$\operatorname{REAL}(14)=$ Fischer-Tropsch catalyst makeup rate in percent of catalyst inventory per day.

$\operatorname{REAL}(15)=$ Temperature of the steam generated in the tubes of the slurrybed Fischer-Tropsch reactor in degrees Fahrenheit.

$\operatorname{REAL}(16)=$ Pressure of the steam generated in the tubes of the slurry-bed Fischer-Tropsch reactor in psig.

$\operatorname{REAL}(59)=$ Weight of the reference slurry-bed Fischer-Tropsch reactor vessel in thousands of pounds for the ISBL reactor cost 
calculation.

$\operatorname{REAL}(60)=$ Cost of the reference slurry-bed Fischer-Tropsch reactor vessel in millions of dollars having the weight given in REAL(59).

$\operatorname{REAL}(61)=I S B L$ cost of a single slurry-bed Fischer-Tropsch reactor system and its closely associated accessories in millions of dollars for a reactor vessel having the weight given above in REAL(59).

(Such items include the foundation, instrumentation, piping, etc.)

$\operatorname{REAL}(62)=\mathrm{ISBL}$ cost of the peripheral equipment in millions of dollars associated with each slurry-bed Fischer-Tropsch reactor vessel having the weight given above in REAL(59). (Such items maybe cyclones, hydroclones, steam drums, etc.)

\subsection{Plant 204N -- Hydrocarbon Recovery Plant}

Plant 204N, the hydrocarbon recovery plant, recovers the C5+ naphtha, distillate and wax fractions for further processing. All C4 and lighter material is sent to lowpressure fuel gas because it is not economic to recover the C3 and C4 material for further processing at the low rates of this design. This version of Plant 204 is significantly different than that of the baseline coal design which uses cryogenic recovery to recover the C3 and C4 material. Hence, this plant has been renamed Plant 204N to distinguish it from the more comprehensive Plant 204 of the baseline coal case.

As shown in Figure 4.1, three ASPEN blocks are used to model the hydrocarbon recovery plant. Block P204M2 combines all the feed to Plant $204 \mathrm{~N}$ into a single stream, stream 204S17, which goes to user Fortran block 204NF. User Fortran user block P204NF predicts the utilities consumptions and ISBL cost of Plant 204N as a function of the entering flow rate. This combined hydrocarbon stream is now separated in block P204S3, which represents a series of fractionation towers, into a low-pressure fuel gas stream, three streams for further processing in Area 300 and a wastewater stream. Stream $204 S 21$ is the low-pressure fuel gas stream. Stream 201S22 is a C5+ naphtha stream that goes to the naphtha hydrotreater. Stream $204 S 23$ is a distillate stream that goes to the distillate hydrotreater. Stream 204 S24 is the wax hydrocracker feed stream, and stream 204 S25 is a wastewater stream.

The Fortran user block model for Plant $204 \mathrm{~N}$ has a single input stream and produces a single identical output stream. This Fortran model predicts the utilities consumptions and estimates the ISBL cost of the plant as a function of the entering flow rate. This model requires no special user input parameters other than the general Fortran user block model input parameters discussed in Section 2.5. 


\subsection{Plant 205 -- Hydrogen Recovery Plant}

Plant 205, the hydrogen recovery plant, provides high purity hydrogen for use in Area 300 , the product upgrading area. Hydrogen is recovered from the $\mathrm{CO}$ shift reactor effluent in Plant 113 and the hydrogen-rich gas produced in the naphtha reforming plant (Plant 304) in a PSA (pressure swing absorption) unit.

As shown in Figure 4.1, three ASPEN blocks are used to model the hydrogen recovery plant. Mixer block P205M1 combines the cooled shift reactor outlet gas stream from Plant 113 and the hydrogen-rich gas from the naphtha reforming plant into a single stream, stream 205S13. ASPEN separator block P205S3 simulates the PSA portion of Plant 205. Fortran user block P205F calculates the utilities consumptions and ISBL cost of Plant 205 as a function of the hydrogen production rate in stream 205S3. The reject material from the PSA unit (block P205S3) goes to low-pressure fuel gas. An ASPEN design specification controls the split fraction in block P113S13 so that the hydrogen production from block P205S3 matches the hydrogen consumption in the product upgrading area.

The Fortran user block model for Plant 205 has a single input stream and produces a single identical output stream. This Fortran model predicts the utilities consumptions and estimates the ISBL cost of the plant as a function of the hydrogen production rate. This model requires no special user input parameters other than the general Fortran user block model input parameters discussed in Section 2.5.

\subsection{General Comments on Area 200}

There are two additional ASPEN mixing blocks in Area 200 that have not been described. Block A200M1 is the fuel gas mixing block which mixes streams 201S7, 204S21 and 205S14 to create a stream called 200FUEL which contains the total amount of low-pressure fuel gas produced in Area 200. Block A200M2 is the waste water mixing block which mixes streams 201S6, 201S9, 201S25, 201S37, and $204 S 25$ to produce stream 200WATER which contains the total wastewater produced in Area 200.

The hydrogen production from Plant 205 is adjusted by ASPEN design specification H2MAKE so that it exactly satisfies the hydrogen demand in Area 300.

Convergence block H2MAKE converges design specification H2MAKE using the SECANT method which is a modified linear approximation method. Convergence block H2MAKE, which contains some processing blocks from Areas 100, 200 and 300 , balances the hydrogen production against the hydrogen demand by adjusting the amount of syngas withdrawn by block P113S1 before the F-T synthesis reactor and sent to the CO shift reactor of Plant 113, the hydrogen production plant. 


\subsection{INDIVIDUAL PLANT MODELS IN AREA 300}

Area 300, the Fischer-Tropsch product upgrading area, contains five process plants. These are standard petroleum refining units which use conventional technologies to upgrade the hydrocarbons produced in Area 200 to high quality transportation fuel blending stocks.

Figure 5.1 is an ASPEN block flow diagram showing the various ASPEN models and their interconnecting streams used to simulate Area 300, the product upgrading and refining area. Ten ASPEN Plus blocks are used to simulate these five process plants. This model is not process rigorous in that it only employs Fortran user block models containing empirical, elementally balanced yield models to simulate all of the conversion processes and predict the utilities consumptions and ISBL costs of the plants. Not shown in this figure are four inline Fortran blocks which set the flow rates of the makeup hydrogen streams to the three hydroprocessing plants (Plants 301, 302 and 303) and the C5/C6 isomerization plant (Plant 306).

The following subsections present a brief process description, followed by a discussion of the Fortran user block models for the five product upgrading plants in this model. Calculation methods are discussed, and the user specified plantspecific parameters in the input file are listed for each model.

All streams in the Area 300 section of the model are of the ASPEN stream class CONVEN and have only one substream containing only conventional components. No solid non-conventional components may be present in Area 300. Each of the following models was developed to simulate the specific plant only to provide sufficient detail to determine the major output streams and their qualities, utilities consumptions, ISBL cost and number of operators as a function of the input streams. Utility balances are developed based on the detailed design, and utility consumptions are calculated as linear functions of plant capacity.

Area 300 contains three small individual hydroprocessing units for hydrocracking the wax and for hydrotreating the raw Fischer-Tropsch distillate and naphtha. These three units are a carry over from the baseline coal design that produced high-quality gasoline and distillate blending stocks in essentially a small petroleum refinery. For this case, a single hydroprocessing unit that only produces a stabilized syncrude, which would be upgraded elsewhere in a conventional petroleum refinery, may be more appropriate. However, the development of a process design for such an unit was beyond the scope of this project. 
Figure 5-1

ASPEN BLOCK FLOW DIAGRAM FOR AREA 300 - NREL PRODUCT UPGRADING

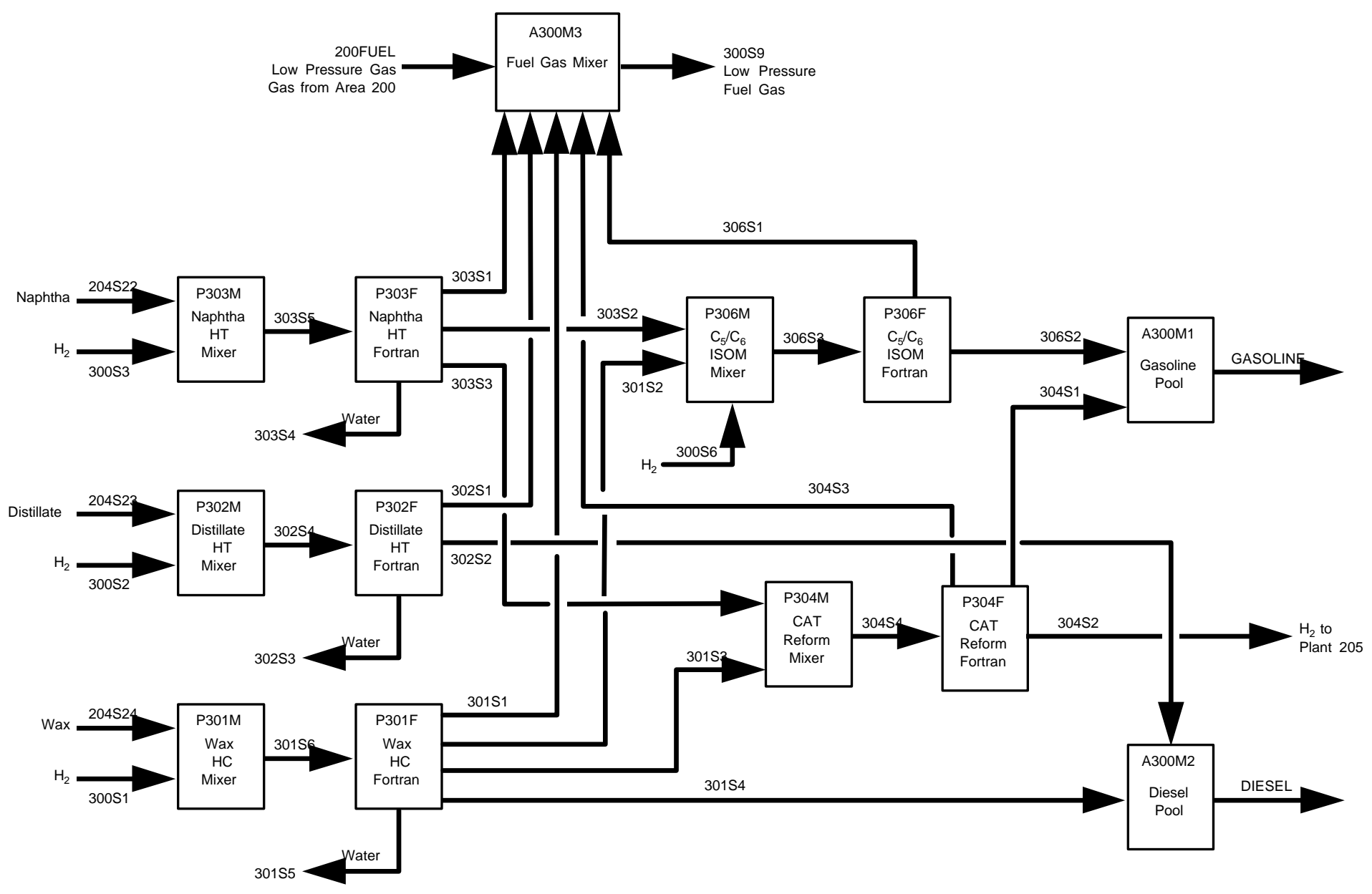




\subsection{Plant 301 -- Wax Hydrocracking Plant}

Plant 301, the wax hydrocracking plant, catalytically cracks the Fischer-Tropsch wax produced in Plant 201 in a high-pressure hydrogen environment to yield more desirable naphtha and distillate products.

As shown in Figure 5.1, the ASPEN block flow diagram, two ASPEN Plus process blocks are used to simulate Plant 301. ASPEN mixer block P301M mixes the wax product stream from Plant 204N, stream 204S24, with a makeup hydrogen stream, stream $300 \mathrm{~S} 1$, and produces the total plant feed stream. Block P301F is the Fortran user block model that simulates the behavior of the entire wax hydrocracking plant and generates five product streams. Stream 301S1, which contains the C4 and lighter material, goes low-pressure fuel. Stream 301S2 is a C5/C6 stream that goes to the C5/C6 isomerization plant. Stream $301 \mathrm{~S} 3$ is the C7+ naphtha stream that goes to Plant 304 , the naphtha reformer, for further upgrading. Stream 301S4 is the distillate product stream that goes to diesel blending. Stream $301 \mathrm{~S} 5$ is a water stream that goes to the waste water treatment plant. Not shown in Figure 5.1 is an inline Fortran block, called SETUP301, which sets the flow rate of the inlet hydrogen stream as a function of the flow rate of the wax feed stream.

The Fortran user block model in ASPEN block P301F was developed to represent the generic single-stage, fixed-bed wax hydrocracker. It generates elementally balanced yields and properties of the following four pseudocomponents which represent the hydrocracked product.

1. $\mathrm{C} 7-300 \mathrm{HC}$, the $\mathrm{C} 7$ through $300^{\circ} \mathrm{F}$ boiling range hydrocracked naphtha

2. $3-350 \mathrm{HC}$, the $300-350^{\circ} \mathrm{F}$ boiling range hydrocracked heavy naphtha

3. $350-5 \mathrm{HC}$, the $350-500^{\circ} \mathrm{F}$ boiling range hydrocracked product

4. $500+\mathrm{HC}$, the hydrocracked product boiling above $500^{\circ} \mathrm{F}$

This empirical, elementally balanced yields model

1. Calculates the pounds of wax and other liquids to be converted.

2. Calculates the hydrogen consumption based on an internally stored value, and adjusts it, if necessary, if insufficient hydrogen has been supplied.

3. Stoichiometrically converts all the entering oxygen to water.

4. Calculates the light ends yields using internal yield distribution factors.

5. Calculates the total hydrocrackate yield by difference.

6. Distributes the total hydrocrackate yield among the four hydrocrackate pseudocomponents called $\mathrm{C} 7-300 \mathrm{HC}, 3-350 \mathrm{HC}, 350-5 \mathrm{HC}$ and $500+\mathrm{HC}$ using internal yield distribution factors.

7. Calculates the elemental composition of the total hydrocrackate so that an elemental balance is maintained. Because insufficient information is available on how the elemental composition of the hydrocracked product 
varies with boiling point, the elemental composition of each boiling range fraction is set to the average elemental composition.

8. Estimates the densities, Research octanes, motor œtanes, blending octanes, RVP, pour point, and cetane index of the various boiling range products, as appropriate. Because no reliable blending octane correlations could be found, the Research and motor blending octanes are set to their pure component values. Sets the benzene, aromatics and olefins contents of the gasoline blending components to zero.

This Fortran user block model also contains component distribution factors to simulate the product fractionation section and generate the five product streams; a C4 and lighter gas stream, a C5/C6 stream, a naphtha product stream, a diesel product stream, and a waste water stream. These component distribution factors specify the fraction of each component leaving in a given product stream. This section of the Fortran user block model is equivalent to an ASPEN SEP block model.

In addition, this Fortran user block model predicts the utilities consumptions, number of dedicated plant operators and ISBL plant cost as a function of capacity.

In the future, this Fortran user block model can be improved and extended by

1. Adding correlations to predict the elemental composition of the hydrocracked products as a function of boiling range.

2. Adding correlations to predict the pseudocomponent blending properties.

3. Improving the prediction of the properties and compositions of the products as new information becomes available.

This model requires no special user input parameters other than the general Fortran user block model input parameters discussed in Section 2.5.

\subsection{Plant 302 -- Distillate Hydrotreating Plant}

Plant 302, the distillate hydrotreating plant, catalytically hydrotreats the FischerTropsch distillate boiling range material produced in Plant 201 under a hydrogen environment to yield a high quality diesel blending component.

As shown in Figure 5.1, two ASPEN Plus process blocks are used to simulate Plant 302. ASPEN mixer block P302M mixes the distillate product stream from Plant 204, stream 204S23, with a makeup hydrogen stream, stream 300S2, and produces the total plant feed stream. Block P302F is the Fortran user block model that simulates the behavior of the entire distillate hydrotreating plant and generates three product streams. Stream 302S1, which contains the C4 and lighter material, goes to lowpressure fuel. Stream $302 S 2$ is the distillate product stream that goes to diesel blending. Stream $302 S 3$ is a water stream that goes to the waste water treatment 
plant. Not shown in Figure 5.1 is an inline Fortran block, called SETUP302, which sets the flow rate of the inlet hydrogen stream as a function of the flow rate of the distillate feed stream.

The Fortran user block model in ASPEN block P302F was developed to represent a generic fixed-bed diesel hydrotreater. It generates elementally balanced yields and properties of the following two pseudocomponents which represent the hydrotreated product.

1. $350-5 \mathrm{HT}$, the $350-500^{\circ} \mathrm{F}$ boiling range hydrotreated product

2. $500+\mathrm{HT}$, the hydrotreated product boiling above $500^{\circ} \mathrm{F}$

This empirical, elementally balanced yields model

1. Calculates the pounds of distillate feed to be hydrotreated.

2. Calculates the hydrogen consumption based on an internally stored value, and adjusts it, if necessary, if insufficient hydrogen has been supplied.

3. Calculates the light ends yields using internal yield distribution factors and hydrogenates all C4 and lighter olefins to the corresponding saturated paraffin compound.

4. Calculates the water production by converting an internally specified amount of oxygen in the feed to water.

5. Calculates the total hydrotreated product yield by difference.

6. Distributes the total hydrotreated product yield among the two hydrotreated product pseudocomponents called 350-5HT and $500+\mathrm{HT}$ using internal yield distribution factors.

7. Calculates the elemental composition of the total hydrotreated product so that an elemental balance is maintained. Because insufficient information is available on how the elemental composition of the hydrotreated product varies with boiling point, the elemental composition of each boiling range fraction is set to the average elemental composition.

8. Estimates the densities, pour point and cetane index of the two hydrotreated pseudocomponent products.

This Fortran user block model also contains component distribution factors to simulate the product fractionation section and generate the three product streams; a C4 and lighter gas stream, a diesel product stream and a waste water stream. These component distribution factors specify the fraction of each component leaving in a given product stream. This section of the Fortran user block model is equivalent to an ASPEN SEP block model.

In addition, this Fortran user block model predicts the utilities consumptions, number of dedicated plant operators and ISBL plant cost as a function of capacity. 
In the future, this Fortran user block model can be improved and extended by

1. Adding correlations to predict the elemental composition of the hydrotreated products as a function of boiling range.

2. Adding correlations to predict the pseudocomponent diesel blending properties.

3. Improving the prediction of the properties and compositions of the products as new information becomes available.

This model requires no special user input parameters other than the general Fortran user block model input parameters discussed in Section 2.5.

\subsection{Plant 303 -- Naphtha Hydrotreating Plant}

Plant 303, the naphtha hydrotreating plant, catalytically hydrotreats the FischerTropsch naphtha produced from Plant $204 \mathrm{~N}$ under a hydrogen environment to yield a saturated naphtha that is further processed in the naphtha reformer to make a high octane gasoline blending component.

As shown in Figure 5.1, two ASPEN Plus process blocks are used to simulate Plant 303. ASPEN mixer block P303M mixes the naphtha product stream from Plant 201, stream 204S24, with a makeup hydrogen stream, stream 300S1, and produces the total plant feed stream. Block P303F is the Fortran user block model that simulates the behavior of the entire naphtha hydrotreating plant and generates four product streams. Stream 30351, which contains the C4 and lighter material, goes to lowpressure fuel. Stream $303 S 2$ is a $\mathrm{C} 5 / \mathrm{C} 6$ stream that goes to the $\mathrm{C} 5 / \mathrm{C} 6$ isomerization plant. Stream $303 \mathrm{~S} 3$ is the $\mathrm{C} 7+$ gasoline stream that goes to Plant 304, the naphtha reformer, for further upgrading. Stream 30354 is a water stream which goes to the waste water treatment plant. Not shown in Figure 5.1 is an inline Fortran block, called SETUP303, which sets the flow rate of the inlet hydrogen stream as a function of the flow rate of the naphtha feed stream.

The Fortran user block model in ASPEN block P303F was developed to represent a generic single-stage, fixed-bed naphtha hydrotreater. It generates elementally balanced yields and properties of the following two pseudocomponents which represent the hydrotreated product.

1. $\mathrm{C} 7-300 \mathrm{HT}$, the $\mathrm{C} 7$ through $300^{\circ} \mathrm{F}$ boiling range hydrotreated naphtha

2. $3-350 \mathrm{HT}$, the $300-350^{\circ} \mathrm{F}$ boiling range hydrotreated heavy naphtha

This empirical, elementally balanced yields model

1. Calculates the pounds of naphtha to be hydrotreated. 
2. Calculates the hydrogen consumption based on an internally stored value, and adjusts it, if necessary, if insufficient hydrogen has been supplied.

3. Calculates the light ends yields using internal yield distribution factors and hydrogenates all C4 and lighter olefins to the corresponding saturated paraffin compound.

4. Calculates the $\mathrm{C} 5$ and $\mathrm{C} 6$ yields by hydrogenating all the $\mathrm{C} 5$ and $\mathrm{C} 6$ olefins to the corresponding saturated paraffin, calculates the $\mathrm{C} 5$ and $\mathrm{C} 6$ paraffin production by cracking, and distributes them among the appropriate iso and normal paraffins.

5. Calculates the water production by converting an internally specified amount of oxygen in the feed to water.

6. Calculates the total hydrotreated product yield by difference.

7. Distributes the total hydrotreated product yield among the two hydrotreated product pseudocomponents called $\mathrm{C} 7-300 \mathrm{HT}$ and $3-350 \mathrm{HT}$ using internal yield distribution factors.

8. Calculates the elemental composition of the total hydrotreated product so that an elemental balance is maintained. Because insufficient information is available on how the elemental composition of the hydrotreated product varies with boiling point, the elemental composition of each boiling range fraction is set to the average elemental composition.

8. Estimates the densities and pour points of the two boiling range products, as appropriate.

In addition, this Fortran user block model predicts the utilities consumptions, number of dedicated plant operators and ISBL plant cost as a function of capacity.

This Fortran user block model also contains component distribution factors to simulate the product fractionation section and generate the four product streams; a C4 and lighter gas stream, a C5/C6 stream, a naphtha product stream, and a waste water stream. These component distribution factors specify the fraction of each component leaving in a given product stream. This section of the Fortran user block model is equivalent to an ASPEN SEP block model.

In the future, this Fortran user block model can be improved and extended by

1. Adding correlations to predict the elemental composition of the hydrotreated products as a function of boiling range.

2. Adding correlations to predict the pseudocomponent blending properties.

3. Adding correlation extending the prediction of the properties and compositions of the products as new information becomes available.

This model requires no special user input parameters other than the general Fortran user block model input parameters discussed in Section 2.5. 


\subsection{Plant 304, Naphtha Catalytic Reforming Plant}

Plant 304, the naphtha catalytic reforming plant, catalytically reforms the hydrocracked naphtha produced in Plant 301 and the hydrotreated naphtha produced in Plant 303 to yield a high octane gasoline blending component. The $\mathrm{C} 5+$ product produced by this plant is represented by a single pseudocomponent called REFORMAT.

As shown in Figure 5.1, two ASPEN Plus process blocks are used to simulate Plant 304. ASPEN mixer block P304M mixes the hydrocracked naphtha product stream from plant 301, stream 301S3, and the hydrotreated naphtha product stream from Plant 303, stream 303S3 to produce the total plant feed stream. Block P304F is the Fortran user block model that simulates the behavior of the entire naphtha reforming plant and generates three product streams. Stream 304S1, is the C5+ reformate product stream which goes to gasoline blending. Stream 304S2 is a C2 and lighter gas stream that goes to Plant 205 for hydrogen recovery. Stream $304 S 3$ is a $\mathrm{C} 3 / \mathrm{C} 4$ stream that goes to low-pressure plant fuel.

The Fortran user block model in ASPEN block P304F was developed to represent a complete UOP low-pressure CCR catalytic reforming plant. It generates the yields and properties of the REFORMAT pseudocomponent that represents the entire C5+ reformate product that goes to gasoline blending.

This empirical, elementally balanced yields model

1. Calculates the pounds of $\mathrm{C} 7+$ naphtha to be reformed.

2. Calculates appropriate yield distribution factors as a function of the specified $\mathrm{C} 5+$ reformate octane number to be produced.

3. Calculates the light ends yields using the above calculated yield distribution factors.

4. Calculates the reformate (REFORMAT pseudocomponent) yield by difference.

5. Calculates the elemental composition of the REFORMAT pseudocomponent so that an elemental balance is maintained.

6. Estimates the densities, Research octanes, motor octanes, blending octanes, RVP, benzene concentration, aromatics concentration and olefins concentration of the REFORMAT pseudo- component. Because no reliable blending octane correlations could be found, the Research and motor blending octanes are set to their pure component values.

This Fortran user block model also contains component distribution factors to simulate the product fractionation section and generate the three product streams; a $\mathrm{C} 2$ and lighter gas stream, a C3/C4 stream, and the reformate product stream. These component distribution factors specify the fraction of each component 
leaving in a given product stream. This section of the Fortran user block model is equivalent to an ASPEN SEP block model.

In addition, this Fortran user block model predicts the utilities consumptions, number of dedicated plant operators and ISBL plant cost as a function of capacity.

In the future, this Fortran user block model can be improved and extended by

1. Adding correlations to predict the REFORMAT pseudocomponent blending properties.

2. Improving the correlations that predict the properties and compositions of the REFORMAT pseudocomponent as new information becomes available.

The Fortran user block model for Plant 304 requires the following plant-specific REAL parameter besides the general Fortran user block input parameters discussed in Section 2.5.

$$
\begin{aligned}
\mathrm{REAL}(1)= & \text { Clear Research octane number of the C5+ reformate } \\
& \text { product. Only RONC values between } 88 \text { and } 101 \text { are } \\
& \text { allowed. }
\end{aligned}
$$

\subsection{Plant 306 -- C5/C6 Isomerization Plant}

Plant 306, the $\mathrm{C5} / \mathrm{C} 6$ isomerization plant, isomerizes low octane straight chain C5 and $\mathrm{C} 6$ paraffins to higher octane branched isoparaffins. The mixed $\mathrm{C} 5 / \mathrm{C} 6$ product produced by this plant is represented by a single pseudocomponent called ISOMERAT.

As shown in Figure 5.1, two ASPEN Plus process blocks are used to simulate Plant 306. ASPEN mixer block P306M mixes the $\mathrm{C} 5 / \mathrm{C} 6$ paraffin naphtha product stream from plant 301, stream 301S2, the C5/C6 paraffin product stream from Plant 303, stream 303S2, and a makeup hydrogen stream, stream 300S6, to produce the total plant feed stream, stream 306S3. Block P306F is the Fortran user block model which simulates the behavior of the entire $\mathrm{C} 5 / \mathrm{C} 6$ isomerization plant and generates two product streams. Stream 306S1, is a C4 and lighter gas stream which goes to low-pressure fuel. Stream 306S2 is the higher octane C5/C6 isomerate product stream that goes to gasoline blending. Not shown in Figure 5.1 is an inline Fortran block, called SETUP306, which sets the flow rate of the inlet hydrogen stream as a function of the total $\mathrm{C} 5$ and $\mathrm{C} 6$ paraffin feed rate.

The Fortran user block model in ASPEN block P306F was developed to represent the complete once-through UOP Penex $\mathrm{C} 5 / \mathrm{C} 6$ catalytic isomerization plant. It generates the component yields leaving the unit. 
This empirical, elementally balanced yields model

1. Calculates the amount of entering $\mathrm{C} 5$ and $\mathrm{C} 6$ paraffins to be converted.

2. Calculates the light ends yields using the internal yield distribution factors based on the amount of entering normal butane.

3. Calculates the net C5/C6 isomerate yield (represented by the single pseudocomponent ISOMERAT) by difference.

4. Calculates the properties of the ISOMERAT component.

5. Calculates the elemental composition of the ISOMERAT pseudocomponent

6. Passes any components in the feed other than those which react to the total product.

7. Writes a warning message to the history file if insufficient hydrogen has been supplied.

This Fortran user block model also contains component distribution factors to simulate the product fractionation section and generate the two product streams; a C4 and lighter gas stream and the C5/C6 isomerate product stream. This section of the Fortran user block model is equivalent to an ASPEN SEP block model.

In addition, this Fortran user block model predicts the utilities consumptions, number of dedicated plant operators, and ISBL plant cost as a function of capacity.

This model requires no special user input parameters other than the general Fortran user block model input parameters discussed in Section 2.5.

\subsection{General Comments on Area 300}

There are three additional mixing blocks in Area 300 that are not related to any specific plant. Block A300M1 combines the distillate product streams from Plants 301 and 302 into a diesel blending component. Block A300M2 combines the reformed naphtha product from Plant 304 and the C5/C6 isomerate from Plant 306 into a $\mathrm{C} 5+$ gasoline blending component. The waster water mixing block $\mathrm{A} 300 \mathrm{M} 3$, which is not shown in Figure 5.1, mixes streams 301S5, 302S3 and 303S4 to produce stream 300WATER which contains the total waste water produced in Area 300 .

There is one recycle stream between Areas 200 and 300 . The hydrogen-rich C2 and lighter gas stream from the naphtha reforming plant (stream 304S2) is sent to Plant 205 for hydrogen recovery. ASPEN convergence block REFMH2 converges this recycle loop using stream $304 \mathrm{~S} 2$ as the tear stream by the Wegstein method.

As discussed in Section 4.4, the hydrogen production from Plant 205 is adjusted by ASPEN design specification H2MAKE so that it exactly satisfies the hydrogen demand in Area 300. Convergence block H2MAKE converges design specification 
H2MAKE using the SECANT method which is a modified linear approximation method. Convergence block H2MAKE, which contains some processing blocks from Areas 100, 200 and 300 and the REFMH2 convergence block, balances the hydrogen production against the hydrogen demand by adjusting the amount of syngas split off in block 113S1 that goes to Plant 113, the CO shift reactor to produce hydrogen which is recovered in Plant 205, the hydrogen recovery plant. 


\subsection{THE UTILITIES AND OSBL PLANTS MODELS}

The only one of all the OSBL plants that is modeled in other than a simple linear model is Plant 31 , the power plant. The power plant model is designed to consume all the fuel gas produced within the complex and use this energy to balance the steam consumptions and productions from all the other plants by either making or consuming steam, as required, and using the remaining fuel gas and steam to produce electricity in a combined-cycle power plant, which is shown schematically in Figure 6.1.

The power plant model first balances the steam demands against the steam availability and consumes as much plant fuel as required by the other plants. Any excess plant fuel as well as any excess steam goes to the combined-cycle power plant. As shown in Figure 6.1, the combined-cycle power plant consists of a gas turbine, a three-stage steam turbine, and a HRSG (heat recovery, steam generation) system. The hot flue gases leaving the gas turbine are sent to the high pressure steam generation section of the HRSG which generates $965 \mathrm{psig} / 850^{\circ} \mathrm{F}$ steam from BFW (boiler feed water) and the $975 \mathrm{psig} / 750^{\circ} \mathrm{F}$ steam generated by the Battelle gasification plant. This $965 \mathrm{psig} / 850^{\circ} \mathrm{F}$ steam is sent to the high pressure steam turbine from which a small amount of $650 \mathrm{psig} / 735^{\circ} \mathrm{F}$ steam is extracted. This extreacted steam is sent to a de-superheater where it is mixed with $\mathrm{BFW}$ to produce $650 \mathrm{psig} / 650^{\circ} \mathrm{F}$ steam for use in some process plants.

The intermediate pressure section of the HRSG consumes the excess $360 \mathrm{psig} /$ $530^{\circ} \mathrm{F}$ and $360 \mathrm{psig} / 440^{\circ} \mathrm{F}$ steams produced in the process areas and generates $360 \mathrm{psig} / 625^{\circ} \mathrm{F}$ steam for the intermediate pressure steam turbine. The low pressure section of the HRSG consumes the excess 50 psig staurated steam produced in the process areas and generates $50 \mathrm{psig} / 305^{\circ} \mathrm{F}$ steam for the low pressure steam turbine.

The ASPEN Plus model of the combined-cycle power plant is a very simplified one which was developed to match a more detailed simulation which was performed using the GateCycle simulation model. ${ }^{5}$ In addition, the ASPEN model contains provisions for bringing in a specified amount of natural gas to supplement the plant fuel if desired. The cost of the power plant is calculated based on the electric power production using a simplified exponential cost scaling equation.

The utilities consumptions for all the OSBL plants are calculated based on a linear function of plant capacity as measured by the wood feed rate. The total OSBL plant costs are calculated by ratio to the total ISBL plant cost. This is equivalent to using a constant fraction of the ISBL cost for the OSBL cost. 


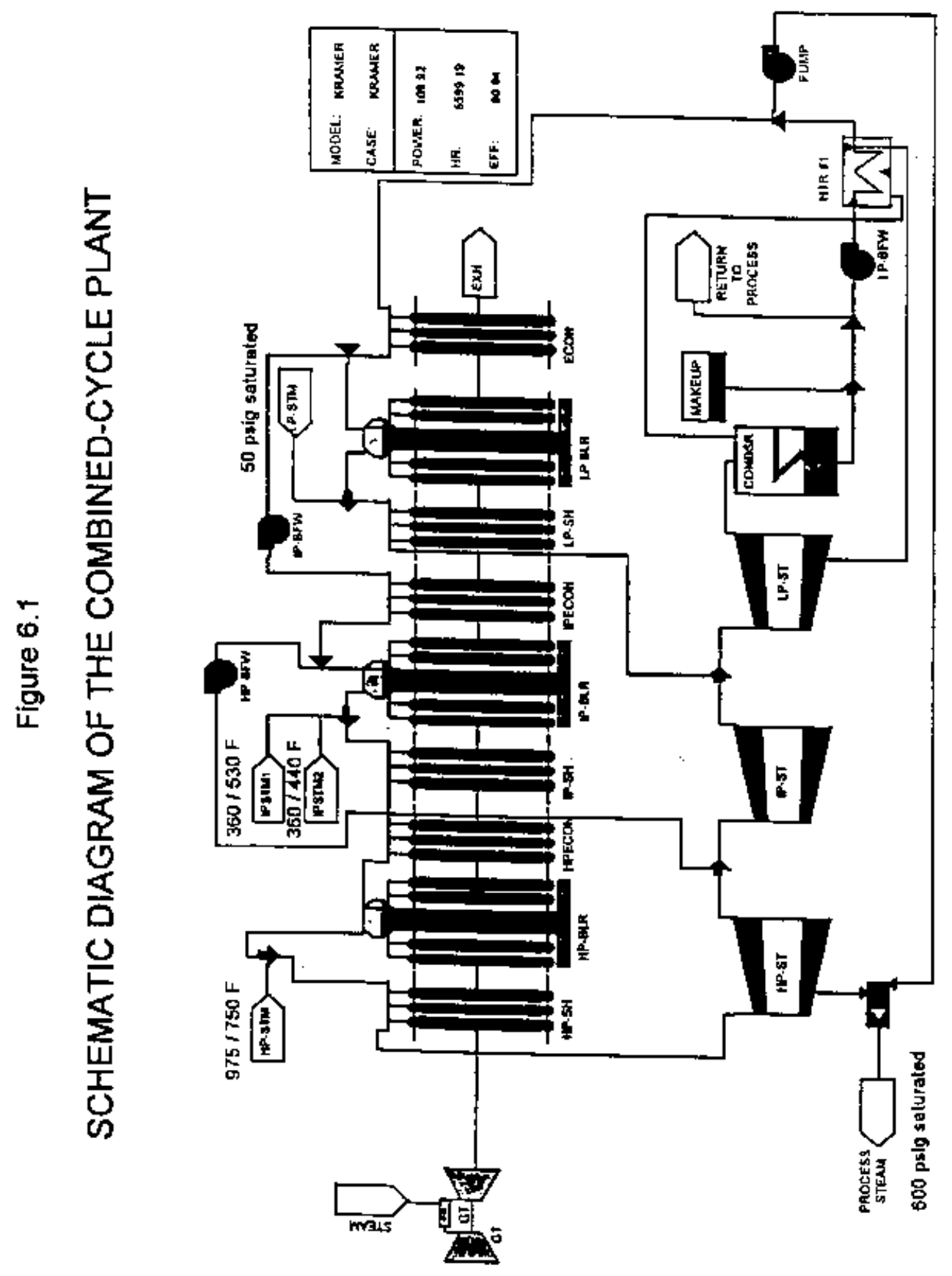


The raw water makeup rate is calculated as a linear function of the total cooling water circulation rate within the complex since the majority of the water loss is through evaporation at the cooling towers.

The annual catalyst and chemicals cost is calculated as a linear function of the gasoline and diesel production. However, when the catalyst makeup rate to the Fischer-Tropsch synthesis plant is changed from the design value of $0.5 \% /$ day, manual adjustments must be made to account for the new catalyst makeup rate.

All the above described calculations related to the utilities plant and the OSBL plants are performed in an inline Fortran block called SUMNREL. Besides doing all of the above calculation, this inline Fortran block writes the plant summary report and an ASCIl file containing the key model results for transfer to a LOTUS spreadsheet economics model. 


\subsection{OVERALL PROCESS SIMULATION MODEL}

\subsection{Overall Description}

The overall process simulation model for the Battelle biomass-based gasification/ Fischer-Tropsch synthesis/combined-cycle power plant basically is the combination of the previously discussed flowsheets, shown schematically in Figures 2.1, 2.2, 4.1 and 5.1 for process Areas 100, 200 and 300 .

In this model, two streams flow between Area 100 and Area 200. Stream 113 S2 is the major portion of the compressed, sulfur-free syngas that goes to the FischerTropsch synthesis plant, Plant 201. The second is stream 113S10, the hydrogenrich stream from leaving the CO shift reactor that goes to Plant 205, the hydrogen recovery plant. There are no recycle streams which flow from Area 200 to Area 100.

Several streams flow between Area 200 and Area 300. Three hydrocarbon product streams and four hydrogen streams flow from Area 200 to Area 300. However, there is one recycle stream which flows back to Area 200 from Area 300, and that is stream 304S2, the hydrogen-rich product gas from the naphtha reforming plant, Plant 304, that goes to the hydrogen recovery plant. ASPEN convergence block REFMH2 converges this recycle loop by the Wegstein method using stream $304 \mathrm{~S} 2$ as the tear stream.

The hydrogen produced by Plant 205 is used in Plants 301, 302, 303 and 306 . The amount of hydrogen produced in Plant 113 and recovered by Plant 205 is controlled by the syngas feed rate to Plant 113, which is set by the split fraction in the ASPEN stream splitter block P113S1. Since Plant 205 produces essentially pure hydrogen, it is not necessary to connect the hydrogen streams within the ASPEN model. After the total hydrogen consumption in Plants 301, 302, 303 and 306 is known, it is only necessary to make Plant 205 produce the correct amount of hydrogen by adjusting the split fraction in block P113S1. An ASPEN design specification around portions of Areas 100, 200 and 300 balances the hydrogen production against the hydrogen consumption. Design specification H2MAKE varies the split fraction in block P113S1 so that the hydrogen produced by Plant 205 in stream 205S3 matches the hydrogen consumption by the other plants. Convergence block H2MAKE converges this design specification using the SECANT method which is a modified linear approximation method.

There are two additional ASPEN mixing blocks in the model that are not shown on any of the previous flow diagrams. Block A400M1 is the total low-pressure fuel gas mixing block which mixes the total low-pressure fuel gas produced by Area 200 in stream 200FUEL with the low-pressure fuel gas produced by Area 300 . Block A400M2 generates the total amount of low-pressure and high-pressure fuel gas produced by the entire plant and generates stream FUEL-GAS. 


\subsection{Input File Description}

Appendix A contains a listing of the ASPEN input file for the Battelle gasification/ Fischer-Tropsch synthesis/combined-cycle plant model. This input file contains all the specifications and commands for simulating the base design case. This section will not provide a detailed description of the entire input file, but will only discuss a few interesting sections of the code since the input file is well commented.

Several pure component physical properties are loaded in the components section to override and/or supplement those in the data bank to provide a consistent set of properties. The properties of the conventional wax and oxygenate pseudocomponents (C3OWAX, OXVAP, OXHC and OXH2O) may be modified by the Fortran user block model for Plant 201, the F-T synthesis plant. When the specified wax yield in Plant 201 is changed, the compositions and molecular weights of these components may change, and for absolute rigor, the molecular weights calculated by the F-T reactor model should be entered here and the simulation should be rerun. Pure components with modified properties are used to represent lumped components such as the $\mathrm{C} 9 \mathrm{~A}$ (the $\mathrm{C} 9$ aromatics), and the boiling range fractions such as the 350-5HC (the hydrocracked product boiling between 350 and $500 \mathrm{~F}$ ).

Since the solid non-conventional pseudocomponents only can be present in Area 100 , the syngas preparation area, the DEF-STREAMS paragraph defines all streams as conventional streams except for those in Area 100 which may contain solids and the single heat stream (Stream 113Q1) leaving the CO shift reactor.

Nine inline Fortran blocks are used to set the flowrates of the minor input streams to various plants, maintain temperature uniformity, calculate the overall utilities balance, calculate the blended product properties, and write the executive summary portion of the report. Fortran block SETUP21A forces the temperature of flash block P201S1 to be the same as that of the Fischer-Tropsch synthesis reactor effluent stream since this block represents the vapor-liquid split within the slurry-bed Fischer-Tropsch reactor.

Fortran block SUMNREL controls the final summarizing calculations and calls six subroutines to do these calculations. This block calculates the properties of the blended gasoline and diesel products, utilities consumptions of the OSBL plants, simulates Plant 31 (the utilities plant), reports the overall utilities balance, total plant cost, and catalyst and chemicals cost. It also writes the summary portion of the plant summary reports and the ICL.PRN output file for transfer of the principal model results to a spreadsheet economics model.

The major portion of the input file contains the input for the ASPEN unit operation and Fortran user block models. These input items are grouped according to process area. Within each area, the models for each plant are ordered numerically. 
Within each plant, the individual models are ordered alphabetically by block name whenever more than one block model is required for a given plant.

There is one ASPEN design specification (DES-SPEC) in the simulation. Design specification H2MAKE balances the hydrogen production in Plant 113 and recovery in Plant 205 with the hydrogen consumption in Area 300. Design specification H2MAKE adjusts the hydrogen recovery from Plant 205 to match the consumption in the other plants by varying the syngas feed rate to the hydrogen production plant, Plant 113. This design specification should function correctly over the expected range of model operations and require no adjustments by the user.

Although ASPEN will select tear streams and determine a calculation sequence, the input file contains a specified tear stream and a calculation sequence. These items are shown near the end of the input file listing in Appendix A.

This calculation sequence is a modification of one that ASPEN originally determined. The modifications were made to make it easier to follow and understand. The complete calculation sequence consists of one main sequence called ENTIRE and six subsequences, AREA100A, AREA100B, AREA200A, AREA200B, AREA300 and FINAL. Sequence ENTIRE controls the ordering of the other six subsequences and the H2MAKE and REFMH2 convergence blocks. Convergence block H2MAKE, which varies the amount of syngas going to produce hydrogen, contains almost all of the process blocks following the syngas generation. Convergence block REFMH2 controls the balancing of the recycle hydrogen stream from the naphtha reformer going to the hydrogen recovery plant in Area 200.

Subsequence AREA100A contains the calculation sequence for the syngas generation by Plants 115, 116, 117, and 108. This sequence contains the first ASPEN blocks to be executed. Subsequence AREA100B, which contains the calculations around Plant 113, the hydrogen production plant, and subsequence AREA200A are the first two subsequences in convergence block H2MAKE. The REFMH2 convergence loop is executed next. It contains subsequences AREA200B and AREA300. Both convergence block H2MAKE and convegence block REFMH2 end following the execution of subsequence AREA300. When the two convergence blocks are satisified, subsequence FINAL is executed. This subsequence contains those blocks which may be executed after the entire model has converged, such as the blocks which calculate the total output stream flow rates and properties, and generate the final report. 


\subsection{SIMULATION MODEL RESULTS FOR THE BATTELLE BIOMASS GASIFIER / F-T SYNTHESIS / COMBINED-CYCLE PLANT MODEL}

The output generated by the ASPEN Plus process simulation model that is of interest to the user is contained in several output files; the standard ASPEN report file (the ABCD.REP file), the ASPEN history file (the ABCD.HIS), the plant summary report file (the ALL.REP file), and the ASCIl transfer file (the ICL.PRN file). Since ASPEN uses the characters of the input file name before the period to name its output files, the letters ABCD in the previous sentence are used to designate these first characters.

The standard ASPEN Plus report file basically reports how the simulation progressed and contains the block and stream reports. The stream report contains the flow rates, compositions and properties of all the streams as specified in the STREAM-REPORT paragraph. The ASPEN Plus history file is a history of the progress of the ASPEN input translation and execution steps. This file contains a listing of the input file, details on the component properties and thermodynamic models which are being used, and the calculation sequence which will be employed. It also can contain some supplemental output information generated by the Fortran user block models.

Supplemental output generated by individual plant Fortran user block models as specified by the INT(4) input parameter are printed to the history file. Near the end of this file, the calculated properties of the gasoline and diesel products are printed by inline Fortran block SUMNREL. The Fortran user block model for the FischerTropsch synthesis plants also prints additional details of the slurry-bed reactor sizing and costing calculations.

Appendix B contains a listing of the entire Plant Summary Report file. This file is produced in addition to the above described standard ASPEN output files. The Plant Summary Report file was developed to summarize the individual plant operations in a standard format on a single page whenever possible. The first page of this report is the title page of the report.

The second page contains the management summary report which summarizes the entire model results on a single page. A summary of the major plant input and output streams is given at the top of the page. The middle section of the page provides a summary of the individual plants. This includes the number of operating and spare plants, the number of dedicated operators, the ISBL cost, and the total installed plant cost. The total installed cost includes an apportioned amount for the OSBL cost, home office cost, fees, and contingency. The total number of operators, foremen and maintenance workers are given at the bottom of the page.

As shown on this page for the case where the plant processes 3550 tons/day of maple wood chips containing $37.9 \%$ water, the model predicts that $382 \mathrm{bbl} / \mathrm{day}$ of 
gasoline and $775 \mathrm{bbl} /$ day of diesel blending stocks will be produced." In addition, about $85.8 \mathrm{MW}$ of surplus power will be exported. The plant will have a total installed cost of about 142 million dollars and employ about 212 workers. This cost estimate has an accuracy of $+/-30 \%$; the same as that of the previous cost estimates that were developed for the coal based designs. The Management Summary Report shown on page B-3 of Appendix B contains a complete material balance and plant by plant cost breakdown for the facility.

The remainder of the report contains short summaries (a single page whenever possible) of the individual plant operations and an overall utilities summary table. Generally, these plant reports summarize the inlet and outlet stream flows, utilities consumptions or productions, and the ISBL field cost.

The plant summary report for Plant 201, the Fischer-Tropsch synthesis plant is four pages when all the output options are requested. The first page contains the component flow rates in the inlet and outlet streams. The conversion expressed in three different ways (as hydrogen conversion, carbon monoxide conversion, and overall syngas conversion) is shown at the top of the second page. Below this are the results of the reactor sizing and costing calculations. More details of the reactor sizing and costing calculations are given near the end of the standard ASPEN history output file (ABCD.HIS) in case they are needed. The utilities consumptions or productions and the ISBL field cost are given at the bottom of the page.

The third and fourth pages contain a listing of the major pieces of equipment in the entire Plant 201 and their approximate sizes, whenever possible. These equipment sizes are based on a proration of the baseline coal liquefaction plant design, and are not the results of detailed sizing calculations for the Battelle gasification plant situation. For either very small or very large capacity plants, the user may wish to adjust the number of spare items or the amount of parallel capacity in some plant sections.

In certain cases, the following warning message may be printed after the plant costing information.

$\begin{aligned} \text { WARNING - } & \text { THE ABOVE PLANT COSTS MAY BE IN ERROR SINCE THE CALCULATED } \\ & \text { TRAIN SIZE IS BELOW THE SPECIFIED MINIMUM TRAIN SIZE. }\end{aligned}$

This message is designed to warn the user that the cost calculations for this plant are based on an extrapolation of a plant cost that is quite removed from the current case, and the predicted cost could be erroneous. No accuracy claims can be made for the plant cost when this warning message is displayed. For example, the cost basis of Plant 301, the wax hydrocracking plant, was developed for a plant processing about $285,000 \mathrm{lbs} / \mathrm{hr}$ of wax feed, and for this Battelle gasification plant design, only processing about $9,000 \mathrm{lbs} / \mathrm{hr}$ of wax feed are being processed.

\footnotetext{
* Equivalent to $183,750 \mathrm{lbs} / \mathrm{hr}$ or 2205 tons/day of moisture free wood.
} 
Consequently, the plant cost predicted by the model should be used with extreme caution.

A utilities summary table is given an the end of the Plant Summary Report. This table shows the steam, power, fuel, cooling water, process water and nitrogen consumptions or productions of the individual process and OSBL plants. The others line item contains the total utilities consumptions or productions for all the OSBL plants except Plant 31, the steam and power generation plant, which is shown separately. 


\subsection{DETAILED OPERATING INSTRUCTIONS}

These instructions are for executing the Battelle biomass gasifier/Fischer-Tropsch synthesis/combined-cycle power plant model described in this report using PC Version 9.2 of ASPEN Plus. Minor changes may be required to the previously described ASPEN Plus input and Fortran files if other versions of ASPEN Plus or other implementations of ASPEN (such as ASPEN/SP) are to be used.

In order to run the ASPEN Plus computer program (Version 9.2) and simulate the Battelle gasification plant design, the following are required.

\section{$\underline{\text { Hardware Requirements }}$}

An IBM compatible personal computer with the following:

1. Intel Pentium main processor, or equivalent

2. A minimum of 16 Mbytes of RAM

3. A minimum of 80 Mbytes of available hard disk space

4. VGA graphics capability

5. Windows 95 operating system

6. A mouse

\section{Software Requirements}

For simulating this Battelle biomass gasification plant model, the following software files are required.

1. NREL3.INP - The ASPEN Plus input file for simulating the Battelle gasification/Fischer-Tropsch synthesis/combined-cycle power plant.

2. NRELF1.FOR, NRELF2.FOR and NRELF3.FOR - Fortran source code files for the ASPEN user block models required for simulating the Battelle gasifier/Fischer-Tropsch synthesis/combined-cycle power plant.

The NRELF1.FOR file contains the Fortran subroutines for Area 100; file NRELF2.FOR contains the Fortran subroutines for Area 200; and file NRELF3.FOR contains the Fortran subroutines for Area 300.

3. OTHERI.FOR - Additional Fortran source code required by the user block models in the above ICLFOR.FOR file. This file is identical to the OTHERI.FOR file used in the indirect coal liquefaction plant models.

4. ICLRPT.BAT - A batch file for combining the individual plant summary report files together into a single management summary report file. 
5. ICLSTART.REP - The œver page for the management summary report file that is produced by the ICLRPT.BAT file.

Appendix A contains a listing of the NREL3.INP file, the input file for the Battelle biomass gasification/Fischer-Tropsch synthesis/combined-cycle power plant model.

The proprietary ASPEN Plus general purpose, process simulation software program should be installed as recommended by the program vendor, ASPEN Technology, Inc., Cambridge, MA.

The ASPEN Plus model of the Battelle biomass gasification/Fischer-Tropsch synthesis/combined-cycle power plant is executed as follows.

1. Enter MSDOS.

2. Load all of the required files, listed above, into the same subdirectory from which ASPEN Plus will be run.

3. Compile all the filename.FOR Fortran files to create filename.OBJ files by typing

ASPCOMP filename<Enter> for each of the filename.FOR files. Once compiled, the Fortran file does not need to be recompiled unless the Fortran source code file, filename.FOR, has been changed. It is not necessary to use the .FOR filespec with the ASPCOMP command.

4. Execute the ASPEN Plus process simulation model by typing ASPEN NREL3 <Enter>

NOTE: NREL3.INP in the input file which simulates the Battelle gasifier/Fischer-Tropsch synthesis/combined-cycle plant model. The PC filespec (.INP) does not need to be entered. When other cases that are contained in different input files are to be simulated, enter the appropriate input file name.

The ASPEN Plus process simulation program will now execute generating numerous output files. These will include several ASPEN Plus system generated files having the same first portion of the file name as the input file. Of primary interest are the NREL3.REP file (the standard ASPEN Plus report file) and the NREL3.HIS file (the standard ASPEN Plus history file) which contains supplemental information.

The model will also generate several ICL???.REP files containing the block model summary reports. For example, the block model summary report for Plant 201 will be called ICL201.REP. In addition, the model will generate two other files called ICLSUM.REP and ICL.PRN. The ICL.PRN file is the file 
used to transfer the process simulation model results to a spreadsheet economics model.

5. Execute the ICLRPT.BAT file to combine all the individual plant summary report files into the combined summary report file called ALL.REP file by typing ICLRPT <Enter>

This ALL.REP file then may be viewed or printed, as desired. When the ICLRPT command is executed, each of the ICL???.REP files for the individual plants are erased as they are copied into the ALL.REP file.

Making another ASPEN run using either the same input file or another one having the same filename will cause ASPEN Plus to overwrite all the standard ASPEN output files. Therefore, to retain these files for future scrutiny, they should either be renamed or copied to another subdirectory. The same is true with the ALL.REP file. Rerunning the ICLRPT.BAT will overwrite any existing ALL.REP file. Thus, to retain this file for future scrutiny, it also should either be renamed or copied to another subdirectory.

During execution of a simulation, ASPEN Plus generates numerous output files having the same filename as the input file with different filespecs which are retained. After running several different simulation models, these files can start to fill the available hard disk space. The ASPEN Plus file called GETRIDOF will remove all the files generated by ASPEN Plus for a given job except the input ('.INP) file. This clean-up file is executed by the command GETRIDOF ABCD where $A B C D$.INP is the input file that generated all the output files. It is not necessary to add the .INP filespec to the filename when using the GETRIDOF command. 


\subsection{SUMMARY AND RECOMMENDATIONS}

\subsection{Summary}

A conceptual design and ASPEN Plus process flowsheet simulation model was developed for a Battelle biomass-based gasification, Fischer-Tropsch (F-T) liquefaction and combined-cycle power plant. This model was developed in a similar manner to those coal liquefaction models that were developed under DOE contract DE-AC22-91PC90027. As such, this process flowsheet simulation model was designed to be a research guidance tool and not a detailed process design tool. However, it does contain some process design features, such as sizing the F-T synthesis reactors. This model was designed only to predict the effects of various process and operating changes on the overall plant heat and material balances, utilities, capital and operating costs.

The ASPEN Plus model for this Battelle biomass-based gasification/FischerTropsch synthesis/combined-cycle power plant was developed using as much as possible of the existing ASPEN indirect coal liquefaction models. No new designs and models were to be developed for the product upgrading and refining units. Those from the baseline coal liquefaction case were be used. As a result of this constraint, the model contains three small hydroprocessing units; a wax hydrocracker, a distillate hydrotreater, and a naphtha hydrotreater. In reality, if this plant were to be constructed, these three units probably would be combined into a single unit that would generate slightly different yields and have a substantially reduced cost. However, the process engineering and design effort required for the development of such a hydroprocessing unit model was beyond the scope of this project.

The current ASPEN Plus model was developed based on a plant design that originally was developed by Mitretek for the Battelle biomass gasification plant in 1996. ${ }^{1}$ This study was done to support the research and development program of the National Renewable Energy Laboratory (NREL) in the thermochemical conversion of biomass to liquid transportation fuels using current state-of-the-art technology. The Mitretek study investigated the use of two gasifiers, and the Battelle indirectly heated biomass gasifier was selected for this model development study because the syngas produced by it is better suited for Fischer-Tropsch synthesis with an iron-based catalyst.

This model can be used to study the effects of plant size, syngas conversion, and Fischer-Tropsch synthesis product distribution on the yields and cost of the plant. It also can be used to study the trade off between power production and liquids production.

This model does not do detailed simulations of the wood drying plant and the Battelle gasification plant. Both of these plants are modeled by empirical models 
which concentrate on matching the reported composition and flow rate of the main product streams from each plant; namely, the dry wood and syngas streams. More detailed simulation models of these plants were not developed because such model development requires significant effort that was beyond the scope of this project, and insufficient data were available to support such development.

Starting with an empirical model is standard procedure for any significant development project. As the project progresses and more data become available, the model then is enhanced and extended to add other features as desired. The following section provides some specific recommendations for extending and enhancing the model.

\subsection{Recommendations}

This section expands on the general recommendations discussed in the previous sections and provides the following specific recommendations for possible future study.

1. Extend the model of the Battelle biomass gasification plant to more rigorously represent the gasification and combustion sections including the transfer of the heat transfer media (sand) between the two sections.

2. Extend the model of the syngas spray tower cooling section to account for the wash water and predict the wash water consumption.

3. Develop a more detailed model of the combined-cycle power plant and HRSG (heat recovery and steam generation) section to provide better integration of the steam balance with the other sections of the plant and better reflect the effects of changes in processing conditions.

4. Develop yields, a conceptual engineering design, and simplified ASPEN model for a single hydroprocessing unit which will process the Fischer-Tropsch synthesis products into a stable, transportable syncrude for further processing into finished products elsewhere.

5. Develop a model of a Battelle gasification/combined-cycle power plant only by removing those sections of the current model which deal with the Fischer-

Tropsch synthesis. This model should provide a starting point for evaluating the Battelle biomass gasifier for power applications under various conditions.

6. Investigate other means of sulfur removal from the raw syngas produced by the Battelle gasifier to see if they are more economic. 


\title{
Appendix A
}

\author{
Input File Listing \\ of the
}

ASPEN Plus Process Flowsheet Simulation

Model of the Battelle Biomass-Based Gasification, Fischer-Tropsch Liquefaction and Combined-Cycle Plant 
; FILE: NREL3.INP - Renuable Energy Gasifier Coproduction Plant.

;

TITLE 'NREL3. INP - Renuable Energy Gasifier Coproduction Plant'

;

DESCRIPTION \&

"THIS ASPEN PLUS INPUT FILE, SIMULATES BATTELLE'S RENUABLE ENERGY GASIFIER PROCESSING MAPLE WOOD CHIPS COUPLED WITH A ONCE THROUGH FISCHER-TROPSCH SYNTHESIS PLANT, A FULL PRODUCT UPGRADING AREA, AND A POWER COPRODUCTION PLANT. THIS MODEL WAS DEVELOPED FOR THE DOE UNDER DOE CONTRACT NUMBER DE-AC22-93PC91029, REFINING AND END USE STUDY OF COAL LIQUIDS. PORTIONS WERE ORIGINALLY DEVELOPED UNDER DE-AC22-91PC90027, BASELINE DESIGN/ECONOMICS FOR ADVANCED FISCHER-TROPSCH TECHNOLOGY. THESE ARE BECHTEL JOBS 22439 AND 21655, RESPECTIVELY ."

Final Version - November 6, 1997 - For issue to DOE.

Last Revised - Oct 31, 1997 - To set the parameters for the combined-cycle power plant based on the GateCycle simulation.

This model simulates a Battelle gasifier processing maple wood chips with the associated wood drying plant and gasifier outlet quench system followed by an iron-based Fischer-Tropsch plant and a product upgrading area.

o Block P116S3 controls the split of the cooled syngas between the Fischer-Tropsch synthesis section and the combined-cycle power section. Normal fraction of stream $116 \mathrm{~S} 8$ value is 0.0 (all syngas to $\mathrm{F}-\mathrm{T}$ ), but maximum value is 0.9995 at base flow rate because higher values causes ASPEN to have calculation problems.

IN-UNITS ENG

DIAGNOSTICS

HISTORY PROP-LEVEL $=2$

RUN-CONTROL MAX-TIME $=5000$ MAX-ERRORS $=500$

; In ASPEN PLUS Trace=yes prints FORTRAN tracebacks in History file SYS-OPTIONS TRACE=YES

;

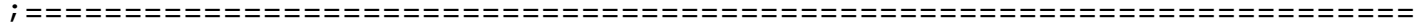

; $\quad$ Physical Property Data

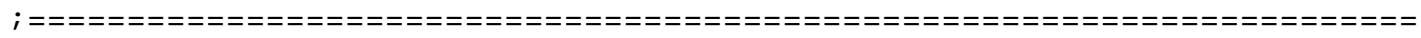

; Use the Peng-Robinson Equation-of-state with the Rackett equation for ; liquid density.

PROPERTIES PENG-ROB GLOBAL

;

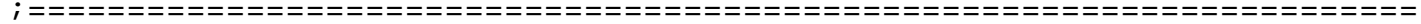

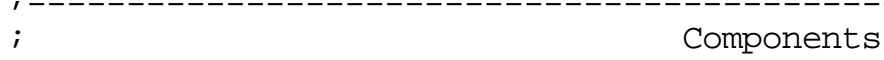

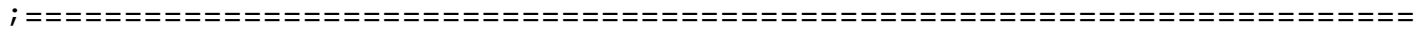

; C30WAX is the $\mathrm{C} 30$ and heavier F-T wax.

;

PC-USER

PC-DEF API-METH C30WAX NBP=1128.3 API=36.42 MW=742.6992

Adjust the C30WAX (C30+ wax) boiling point to get a better approximation of the flash characteristics of the C30WAX by subtracting 154 degrees from the boiling point calculated in subroutine USRW21 of the Plant 201 model. C2010P thru C290P

and the wax are 70 mole o olefins.

PC-DEF API-METH C3OWAX $\quad \mathrm{NBP}=974.3 \quad \mathrm{API}=36.42 \quad \mathrm{MW}=742.6992$

PC-DEF API-METH $\quad \mathrm{C} 21 \mathrm{OP} \quad \mathrm{NBP}=672.2 \quad \mathrm{API}=45.24 \quad \mathrm{MW}=295.1675$

PC-DEF API-METH $\quad$ C22OP $\quad \mathrm{NBP}=694.2 \quad \mathrm{API}=44.68 \quad \mathrm{MW}=309.1943$ 


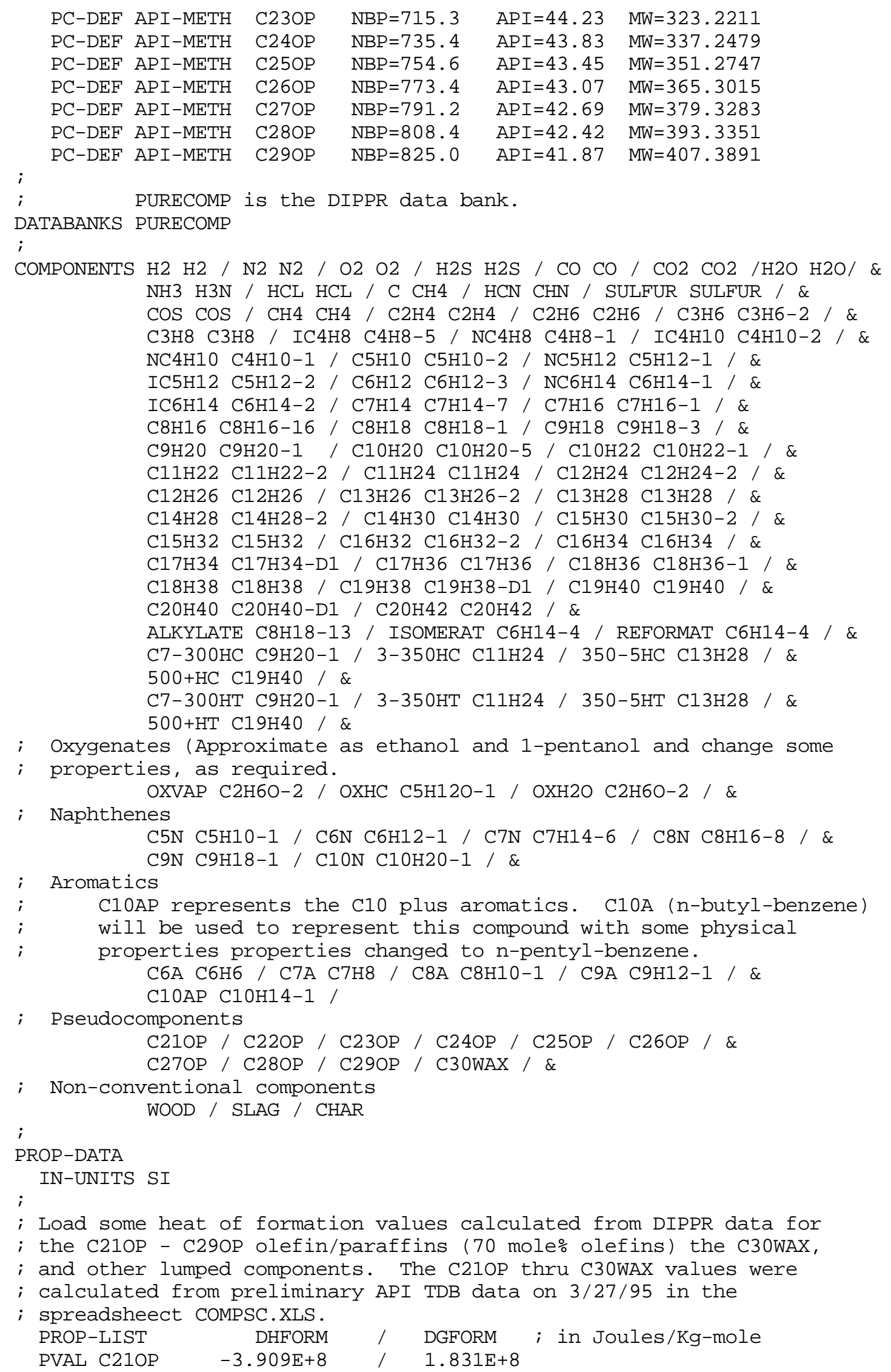




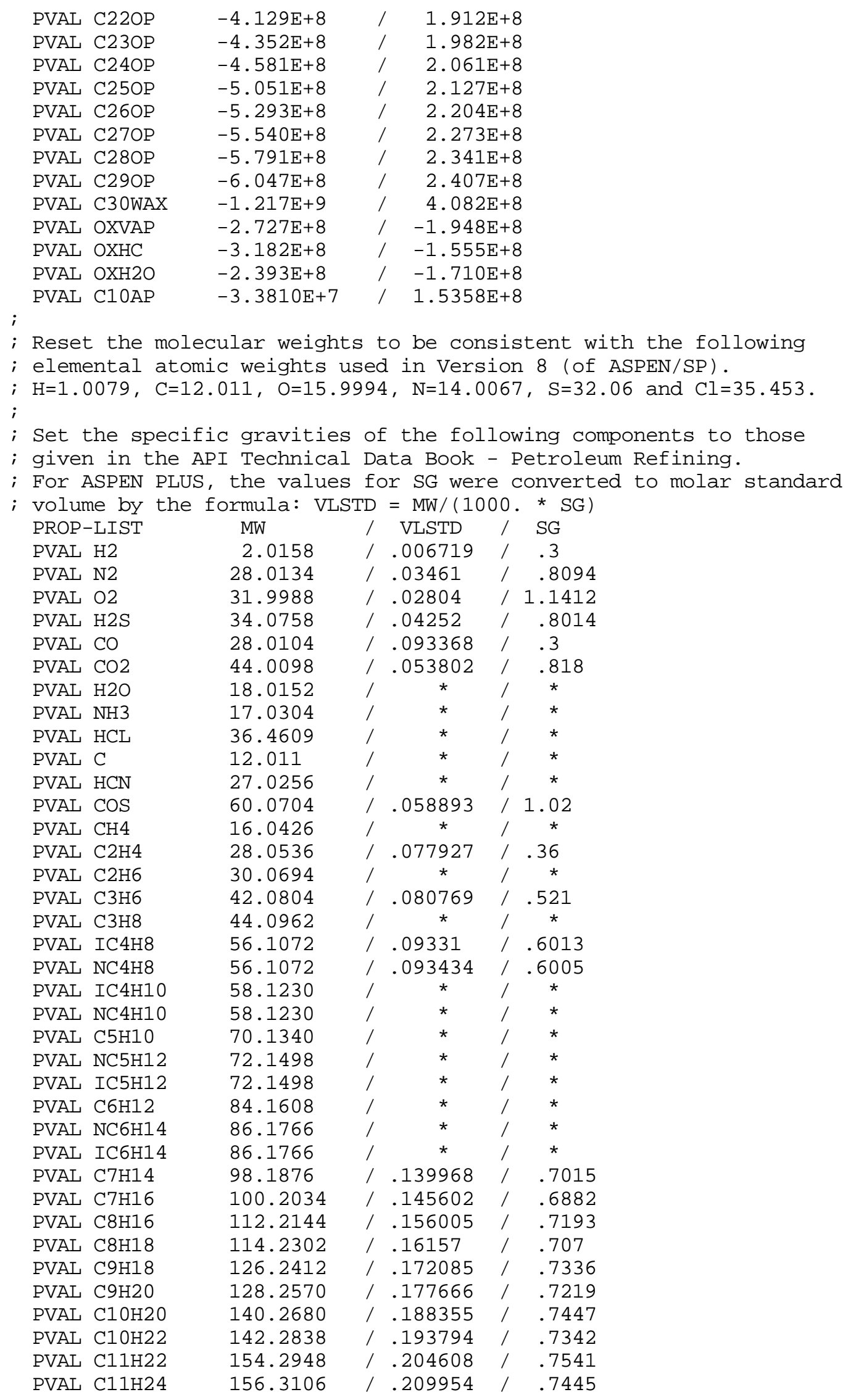




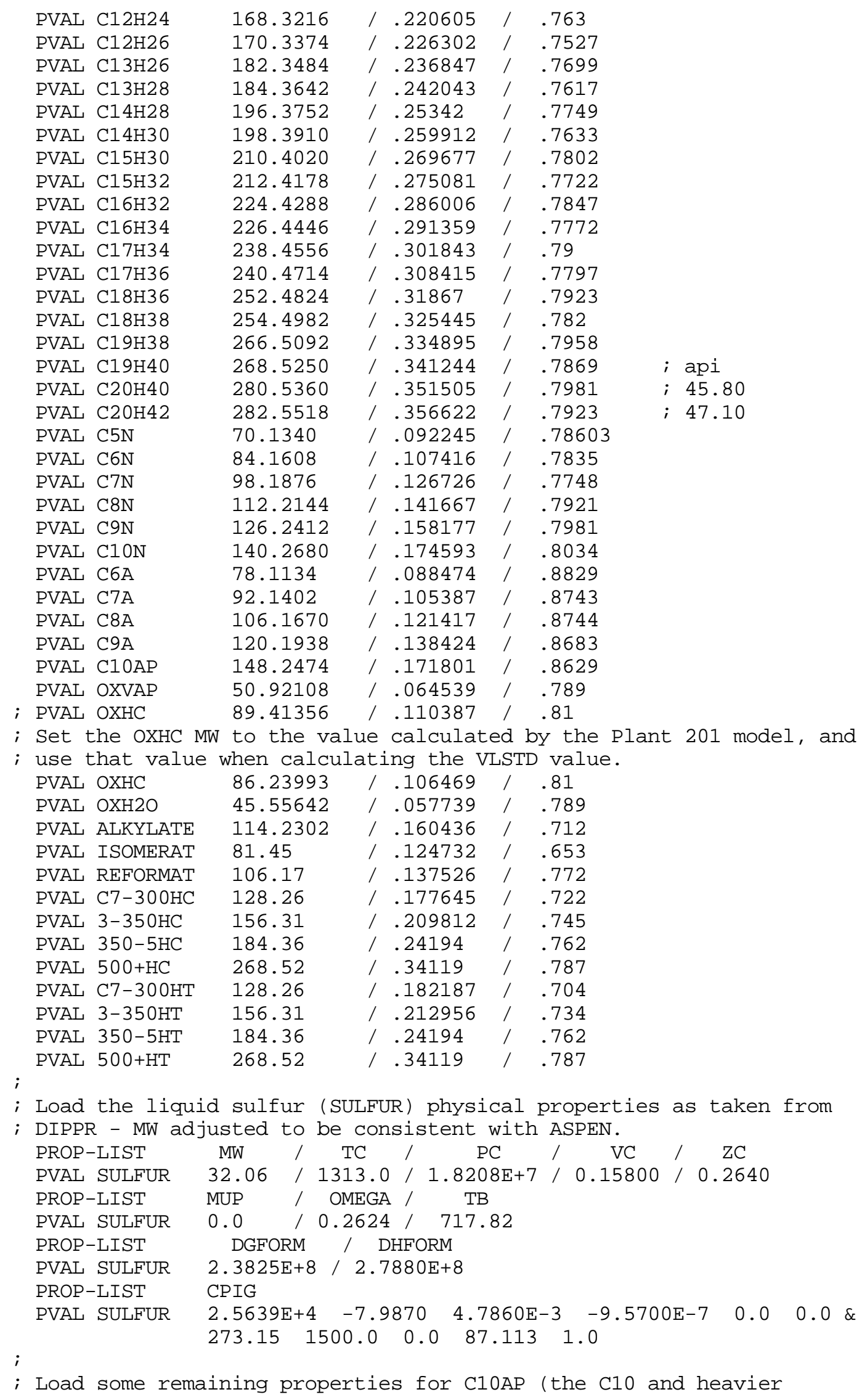




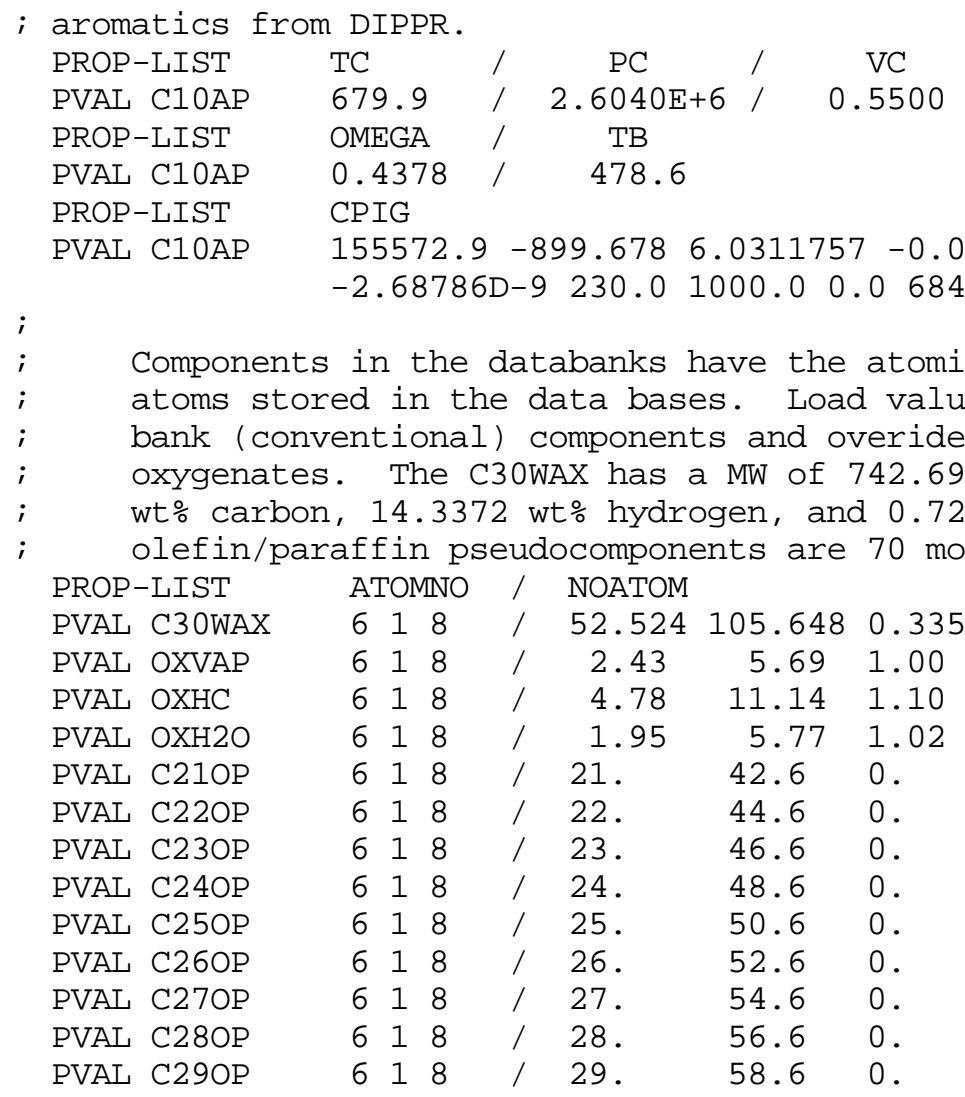

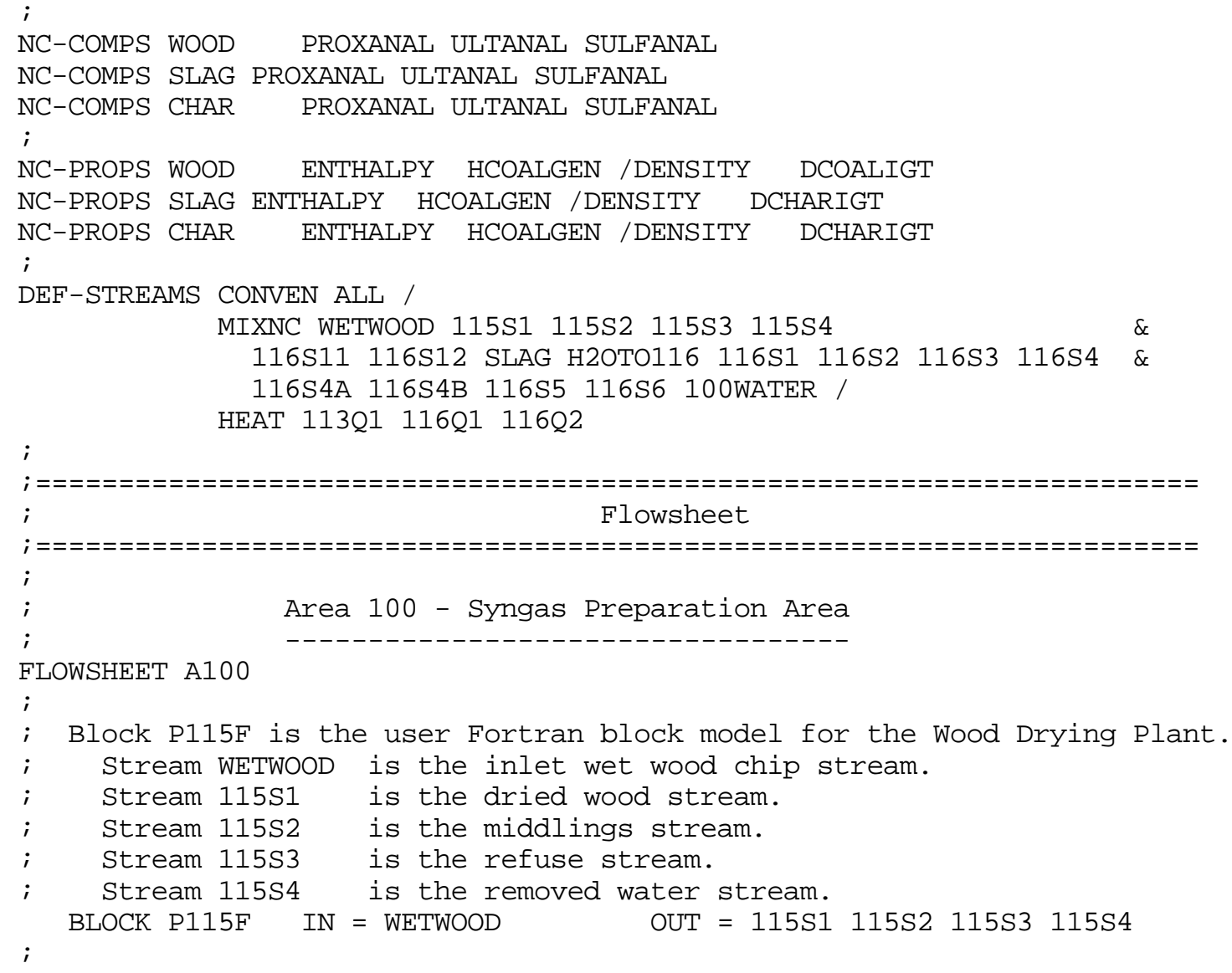


Block P116D is the user Fortran block model for the start of the equilibrium model for Plant 116, the Batelle Gasification Plant. This block decomposes the wood to conventional components and produces the char product stream.

Stream 115S1 is the dried maple wood chip feed stream.

Stream 116S1 is the intermediate decomposed (pseudo gaseous) wood chip stream.

Stream 116S11 is the solids (char) product stream leaving the gasifier, part of which is consummed in the gasifier combustor section, and part of which is the solids waste stream.

$\begin{array}{lll}\mathrm{BLOCK} P 116 \mathrm{D} & \mathrm{IN}=115 \mathrm{~S} 1 & \text { OUT }\end{array}=116 \mathrm{~S} 1116 \mathrm{~S} 11$

Block P116S2 produces the solids waste stream (slag) and a char stream which is burned in the combustor. This block sets the correct waste solids stream flow rate, but does not set the correct compositional analysis of this SLAG stream.

Stream 116S11 is the char stream that is burned in the combustor section of the gasifier.

Stream SLAG is the solids waste product slag stream.

BLOCK P116S2 IN $=116 \mathrm{~S} 11 \quad$ OUT $=116 \mathrm{~S} 12$ SLAG

Block P116M is a mixer to mix the gasified decomposed wood chip stream with the other gasifier feed streams.

Stream H2OTO116 is the steam feed stream to the gasifier.

Stream 116S2 is the mixed total gasifier overhead stream.

BLOCK P116M IN $=116 \mathrm{~S} 1 \mathrm{H} 20 \mathrm{TO} 116 \quad$ OUT $=116 \mathrm{~S} 2$

Blocks P116R1 and P116R2 are two RSTOICH reactors which model the yields produced by the Battelle gasifier as given in the Mitretek Report MP 96W0000065, January 1996. The tar is represented by a mixture of benzene and $\mathrm{C} 10 \mathrm{H} 20$. An RGIBBS equilibrium reactor model could not be adjusted to match the gasifier yields.

Block P116R1 is the first-stage carbon burner reactor which converts some of the pseudo $\mathrm{C}$ (carbon) to $\mathrm{CO}$, $\mathrm{CO} 2$, methane, ethylene and tar $\mathrm{C} 10 \mathrm{H} 20$ ) to match the adjusted Mitretek yields.

Stream $116 \mathrm{~S} 3$ is the first-stage reactor outlet stream.

BLOCK P116R1 IN $=116 \mathrm{~S} 2 \quad$ OUT $=116 \mathrm{~S} 3$

Block P116R2 is the second-stage reactor which converts the remaining oxygen to water.

Stream 116S4 is the hot second-stage reactor outlet stream.

$\begin{array}{lll}\text { BLOCK P116R2 IN }=116 \mathrm{~S} 3 & \text { OUT }=116 \mathrm{~S} 4\end{array}$

Block $\mathrm{P} 116 \mathrm{H} 1$ is the first-stage Battelle gasifier effluent cooler which cools the gas to $800 \mathrm{~F}$ producing 990 psia, $750 \mathrm{~F}$ steam. Stream 116S4A is the effluent gas cooled to $800 \mathrm{~F}$.

BLOCK P116H1 IN $=116 \mathrm{~S} 4 \quad$ OUT $=116 \mathrm{~S} 4 \mathrm{~A} 116 \mathrm{Q} 1$

Block $\mathrm{P} 116 \mathrm{H} 2$ is the second-stage Battelle gasifier effluent cooler which cools the gas to $580 \mathrm{~F}$ producing $530 \mathrm{~F}$ steam.

Stream 116S4B is the effluent gas cooled to $590 \mathrm{~F}$.

BLOCK P116H2 IN $=116 \mathrm{~S} 4 \mathrm{~A} \quad$ OUT $=116 \mathrm{~S} 4 \mathrm{~B} 116 \mathrm{Q} 2$

Block P116S1 is the water quench section which washes and cools hot syngas stream. This splitter block ignores the quench water. Stream 116S4B is the cooled second-stage reactor outlet stream. Stream 116S5 is the cooled and condensed waste water stream. Stream $116 \mathrm{~S} 6$ is the cooled and washed syngas stream.

BLOCK P116S1 IN $=116 \mathrm{~S} 4 \mathrm{~B} \quad$ OUT $=116 \mathrm{~S} 5116 \mathrm{~S} 6$ 


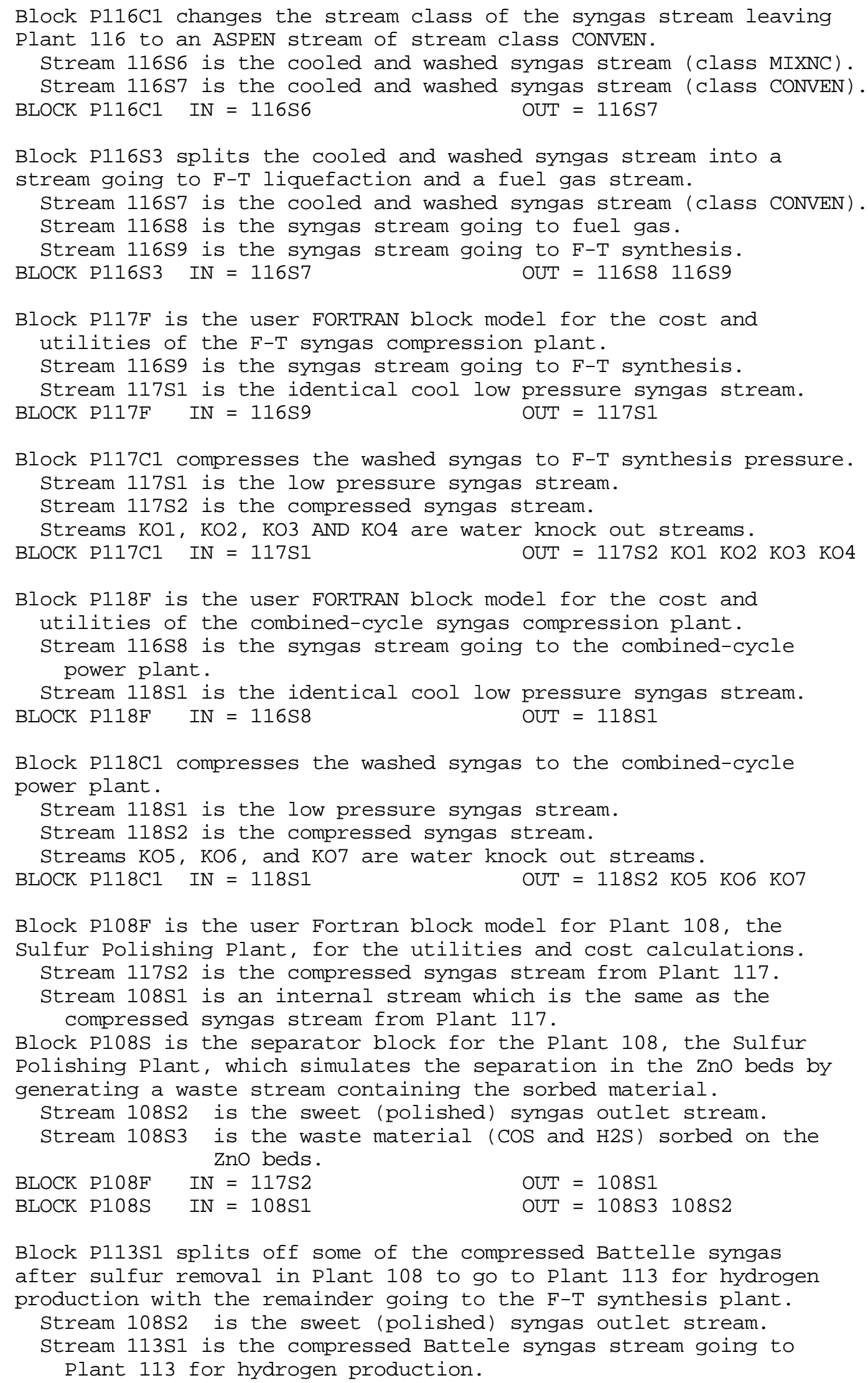


; Stream 113S2 is the remaining compressed Battele syngas stream ; going to the F-T synthesis plant, Plant 201.

BLOCK P113S1 IN $=108 \mathrm{~S} 2 \quad$ OUT $=113 \mathrm{~S} 1113 \mathrm{~S} 2$

i

Block P113H1 heats the compressed Battelle gasifier syngas stream

to the shift reactor inlet temperature.

Stream 113S1 is the compressed Battele syngas stream going to Plant 113 for hydrogen production.

Stream H2OTO113 is the water (steam) feed stream.

Stream 113S3 is the heated syngas gas feed stream going to the CO shift reactor of Plant 113.

BLOCK $\mathrm{P} 113 \mathrm{H} 1 \quad \mathrm{IN}=113 \mathrm{~S} 1 \mathrm{H} 2 \mathrm{OTO113} \quad$ OUT $=113 \mathrm{~S} 3$

Block P113R is the REQUIL equilibrium reactor model for the CO shift reactor of $\mathrm{Plant} 113$.

Stream $113 \mathrm{~S} 3$ is the heated syngas gas feed stream going to the CO shift reactor of Plant 113 .

Stream 113S4 is the CO shift reactor vapor effluent stream.

Stream $113 \mathrm{~S} 5$ is the CO shift reactor liquid effluent stream. BLOCK P113R IN = 113S3 OUT = 113S4 113S5 $113 \mathrm{Q} 1$

Cool the shift reactor effluent to $100 \mathrm{~F}$ in 3 steps. Step 1 to make 360 psig steam at $440 \mathrm{~F}$ - Cool to $480 \mathrm{~F}$ Step 2 - Air cool to $150 \mathrm{~F}$ - (preheat BFW here also?) Step 3 - Water cool to $100 \mathrm{~F}$ and flash

Block $\mathrm{P} 113 \mathrm{H} 2$ cools the $\mathrm{CO}$ shift reactor effluent to $480 \mathrm{~F}$. BLOCK $\mathrm{P} 113 \mathrm{H} 2 \quad \mathrm{IN}=113 \mathrm{~S} 4 \quad$ OUT $=113 \mathrm{~S} 6$

;

; Block P113H3 cools the reactor effluent to $150 \mathrm{~F}$. $\begin{array}{llll}\mathrm{BLOCK} & \mathrm{P} 113 \mathrm{H} 3 & \mathrm{IN}=113 \mathrm{~S} 6 & \mathrm{OUT}=113 \mathrm{~S} 7\end{array}$

;

Block P113S2 simultaneously cools the shift reactor effluent effluent stream to $100 \mathrm{~F}$ with cooling water and separates it into a vapor and condensate (mostly water) stream.

Stream $113 \mathrm{~S} 7$ is the partially cooled shift reactor effluent stream. Stream $113 \mathrm{~S} 8$ is the cooled CO shift reactor effluent vapor stream.

Stream 11359 is the cooled CO shift reactor effluent liquid stream.

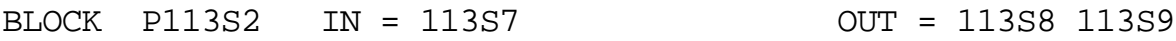

Block P113F is the Fortran user block for Plant 113 which

calculates the utilities consumptions and plant cost.

Stream $113 \mathrm{~S} 8$ is the reheated CO reactor effluent vapor stream.

Stream 113S9 is the reheated CO reactor effluent vapor stream leaving $\mathrm{P} 113 \mathrm{~F}$. It is identical to stream $113 \mathrm{~S} 8$.

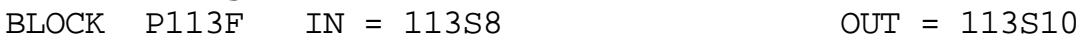

;

; General Area 100 output mixer for the waste water.

BLOCK A100M1 IN=113S9 116S5 KO1 KO2 KO3 KO4 KO5 KO6 KO7 KO8 \& OUT=10OWATER

;

;

Area 200 - Fischer-Tropsch Synthesis Area

FLOWSHEET A200

Plants 201 - The F-T reactor and product separation facilities.

BLOCK P201M1 IN=113S2 H2OTO201 OUT=201S3

BLOCK P201F IN=201S3 OUT $=201 \mathrm{~S} 21$

BLOCK P201S1 IN=201S21

BLOCK P201H1 IN=201S4

OUT $=201 \mathrm{~S} 4201 \mathrm{~S} 31$

OUT $=201 \mathrm{~S} 22$ 
BLOCK P201S2

BLOCK P201S3

BLOCK P201S4

BLOCK P201H2

BLOCK P201S5

BLOCK P201H3

BLOCK P201S6

BLOCK P201M2
$\mathrm{IN}=201 \mathrm{~S} 22$

$\mathrm{IN}=201 \mathrm{~S} 23$

$\mathrm{IN}=201 \mathrm{~S} 24$

$\mathrm{IN}=201 \mathrm{~S} 31$

$\mathrm{IN}=201 \mathrm{~S} 32$

$\mathrm{IN}=201 \mathrm{~S} 33$

$\mathrm{IN}=201 \mathrm{~S} 35$

IN=201534
OUT $=201 \mathrm{~S} 6 \quad 201 \mathrm{~S} 23$

OUT $=201 \mathrm{~S} 24 \quad 201 \mathrm{~S} 10 \quad 201 \mathrm{~S} 25$

OUT $=201 \mathrm{~S} 11 \quad 201 \mathrm{~S} 9$

OUT $=201 \mathrm{~S} 32$

OUT $=201 \mathrm{~S} 33 \quad 201 \mathrm{~S} 34$

OUT $=201 \mathrm{~S} 35$

OUT $=201 S 7 \quad 201 S 36 \quad 201 S 37$

OUT $=201 \mathrm{~S} 5$

; Plant 204 - The 'simpified' hydrocarbons recovery plant.

; Blocks P204M2 and P204S3 simulate the F-T product fractionation. BLOCK P204M2 IN=201S5 201S10 OUT=204S17

; Block P204NF is the Fortran user block for the NREL hydrocarbon

; recovery plant. This is NOT the same as the DOE P204F Fortran block. BLOCK P204NF IN=204S17 OUT=204S18

BLOCK P204S3 IN=204S18 OUT=204S21 204S22 204 S23 204S24 204 S25

; Plant 205 - The hydrogen recovery plant.

BLOCK P205M1 IN=113S10 304S2 OUT=205S13

BLOCK P205S3 IN=205S13 OUT=205S14 205S15

BLOCK P205F IN=205S15 OUT=205S3

; General Area 200 output mixers for low pressure fuel gas and

; sour water.

BLOCK A200M1 IN=201S7 204S21 205S14 OUT=200FUEL

BLOCK A200M2 IN=201S6 201S9 201S25 204S25 201S37 OUT=200WATER

;

;

F

FLOWSHEET A300

Area 300 - Product Upgrading Area

Block P301M is the feed mixer for Plant 301, the wax hydrocracking

plant.

Stream 300s1 is the makeup hydrogen stream.

Stream 204S24 is the wax feed stream.

Stream 30156 is the total feed stream to the wax hydrocracking plant.

Block P301F is the Plant 301 wax hydrocracking plant. Stream $301 \mathrm{~S} 6$ is the total plant feed stream.

Stream 301S1 is the first plant effluent stream, the C4 and lighter gases.

Stream 301S2 is the second plant effluent stream, the C5 and C6s. Stream $301 \mathrm{S3}$ is the third plant effluent stream, the C7+ gasoline. Stream $301 \mathrm{~S} 4$ is the fourth plant effluent stream, distillate. Stream 301S5 is the fifth plant effluent stream, the sour water.

Plant $\mathrm{P} 302 \mathrm{M}$ is the feed mixer for the distillate hydrotreater.

Stream 204S23 is the liquid feed stream from the F-T reactor loop. Stream $300 \mathrm{~S} 2$ is the make-up hydrogen feed stream.

Stream 302S4 is the total distillate hydrotreater feed stream.

Plant $\mathrm{P} 302 \mathrm{~F}$ is the distillate hydrotreater.

Stream 302S1 is the C4 and lighter gas product stream.

Stream $302 \mathrm{~S} 2$ is the hydrotreated distillate (diesel) stream

Stream $302 \mathrm{~S} 3$ is the sour water stream

Plant P303M is the feed mixer for the naphtha hydrotreater.

Stream 204S22 is the liquid feed stream from the F-T reactor loop.

Stream 300S3 is the make-up hydrogen feed stream.

Stream 303S5 is the total naphtha hydrotreater feed stream.

Plant $\mathrm{P} 303 \mathrm{~F}$ is the naphtha hydrotreater.

Stream 303S1 is the C4 and lighter gas product stream.

Stream 303S2 is the C5 and C6s stream

Stream 303S3 is the hydrotreated naphtha (gasoline) stream

Stream 303S4 is the sour water stream

Block P304M is the feed mixer for Plant 304, the naphtha reforming 
plant.

Stream $301 \mathrm{~S} 3$ is the naphtha stream from Plant 301, the wax hydrocracker.

Stream 303 S3 is the naphtha stream from Plant 303, the naphtha hydrotreater.

Block P304F is the Plant 304 naphtha reforming plant.

Stream 304S4 is the total plant feed stream.

Stream 304S2 is the first plant effluent stream, the C2 and lighter gases.

Stream 304S3 is the second plant effluent stream, the C3 and C4s.

Stream 304S1 is the third plant effluent stream, the reformate.

Block P306M is the feed mixer for Plant 306, the C5/C6

isomerization plant.

Stream 301S2 is the C5/C6 stream from Plant 301, the wax hydrocracker.

Stream 303S2 is the C5/C6 stream from Plant 303, the naphtha hydrotreater.

Stream 300S6 is the make-up hydrogen stream.

Block P306F is the Plant 306 C5/C5 isomerization plant.

Stream $306 \mathrm{~S} 3$ is the total plant feed stream.

Stream 306S1 is the first plant effluent stream, the C4 and

lighter gases.

Stream 306S2 is the second plant effluent stream, the isomerate.

Block A300M1 is the gasoline pool product mixer for streams from

Plants 304 and 306 .

Stream 304S1 is the reformate stream from the cat reformer.

Stream 306S2 is the isomerate stream from the C5/C6 isom.

Stream GASOLINE is the combined gasoline product stream.

Block A300M2 is the diesel pool product mixer for distillate from

Plants 301 and 302 .

Stream 301S4 is the distillate stream from the wax hydrocracker.

Stream 302S2 is the distillate stream from the dist hydrotreater.

Stream DIESEL is the combined diesel product stream.

BLOCK P301M IN $=204$ S24 300S1 OUT $=301$ S6

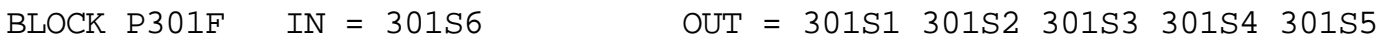

BLOCK P302M IN $=204523300 S 2$

BLOCK P302F IN $=302 \mathrm{~S} 4$

BLOCK P303M IN $=204$ S22 300S3

BLOCK P303F IN $=303$ S5

BLOCK P304M IN $=301 \mathrm{~S} 3303 \mathrm{~S} 3$

OUT $=302 \mathrm{~S} 4$

OUT $=302 \mathrm{~S} 1302 \mathrm{~S} 2302 \mathrm{~S} 3$

$\mathrm{OUT}=303 \mathrm{~S} 5$

BLOCK P304F IN $=304 S 4$

BLOCK P306M IN $=301 \mathrm{~S} 2303 \mathrm{~S} 2300 \mathrm{~S}$

BLOCK P306F IN $=306 \mathrm{~S} 3$

$\mathrm{OUT}=303 \mathrm{~S} 1303 \mathrm{~S} 2303 \mathrm{~S} 3 \quad 303 \mathrm{~S} 4$

OUT $=304 \mathrm{~S} 4$

OUT $=304 \mathrm{~S} 2304 \mathrm{~S} 3 \quad 304 \mathrm{~S} 1$

OUT $=306 \mathrm{~S} 3$

OUT $=306 \mathrm{~S} 1306 \mathrm{~S} 2$

General Area 300 output mixers for the GASOLINE blending component,

DIESEL blending component, the total low pressure fuel gas from

- Areas 200 and 300, and the sour water produced in Area 300.

BLOCK A300M1 IN = 304S1 306S2 OUT = GASOLINE

BLOCK A300M2 IN $=301 \mathrm{~S} 4302 \mathrm{~S} 2 \quad$ OUT $=$ DIESEL

BLOCK A300M3 IN = 200FUEL 301S1 302S1 303S1 304S3 306S1 \&

$\begin{array}{lll}\text { BLOCK A300M4 } & \text { IN }=301 \mathrm{~S} 5302 \mathrm{~S} 3 \quad 303 \mathrm{~S} 4 \quad \text { OUT=300WATER }\end{array}$

Block P119F is the user FORTRAN block model for the cost and

utilities of the fuel gas compression plant which compresses the

low pressure fuel gas from the $\mathrm{F}-\mathrm{T}$ synthesis and product upgrading areas for in-plant use.

Stream 116S8 is the fuel gas stream going to in-plant use.

Stream 119S1 is the identical cool low pressure fuel gas stream.

BLOCK P119F IN $=300 \mathrm{~S} 9 \quad$ OUT $=119 \mathrm{~S} 1$ 


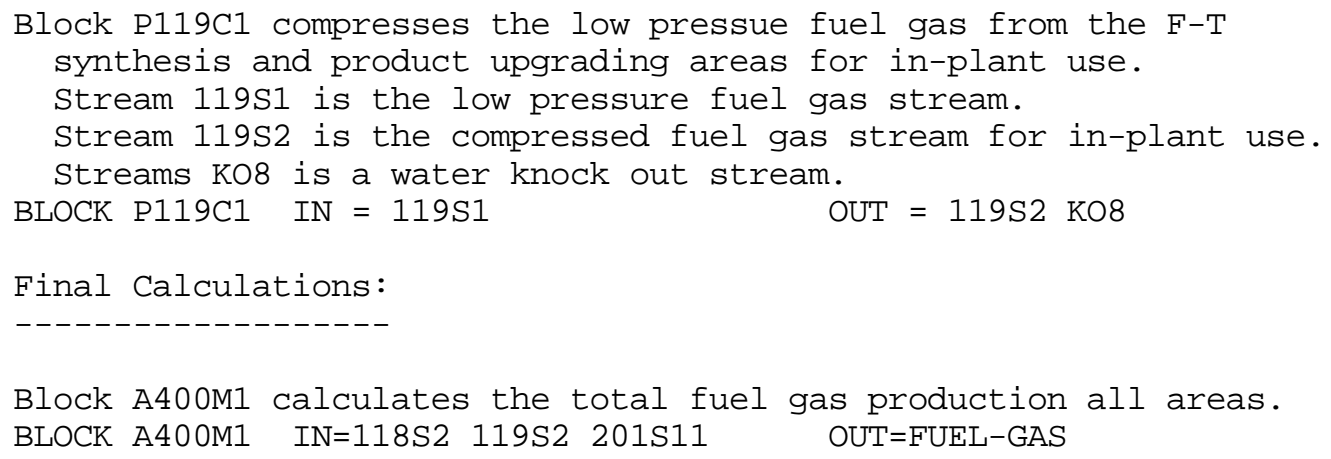

; Fake the SLAG properties.

COMP-ATTR SLAG PROXANAL ( $\left.\begin{array}{lllll}0.0 & 96.75 & 0.0 & 3.25\end{array}\right)$ /

$\left.\begin{array}{lllllllll}\text { ULTANAL } & (3.25 & 89.20 & 7.48 & 0.0 & 0.0 & 0.07 & 0.0\end{array}\right)$ SULFANAL $\left(\begin{array}{llll}0.0 & 0.0 & 0.07\end{array}\right)$

; Set the average properties of the CHAR based on that in major CHAR

; stream and that entrained in the vapor.

COMP-ATTR CHAR PROXANAL (0.0 $96.75 \quad 0.0 \quad 3.25)$ / ULTANAL $\quad\left(\begin{array}{llllllll}3.25 & 89.20 & 7.48 & 0.0 & 0.0 & 0.07 & 0.0\end{array}\right)$ SULFANAL $\left(\begin{array}{llll}0.0 & 0.0 & 0.07\end{array}\right)$

;

; INITIAL GUESS for the total water (steam) flow to the CO shift ; reactor of Plant 113 .

STREAM H2OTO113

SUBSTREAM MIXED TEMP $=440.0 \quad \mathrm{PRES}=375.0$

MOLE-FLOW H2O 400.0

;

; INITIAL GUESS for the flow rate of the steam stream to Plant 116,

; the wood gasification plant. Fortran block SETUP116 sets the 


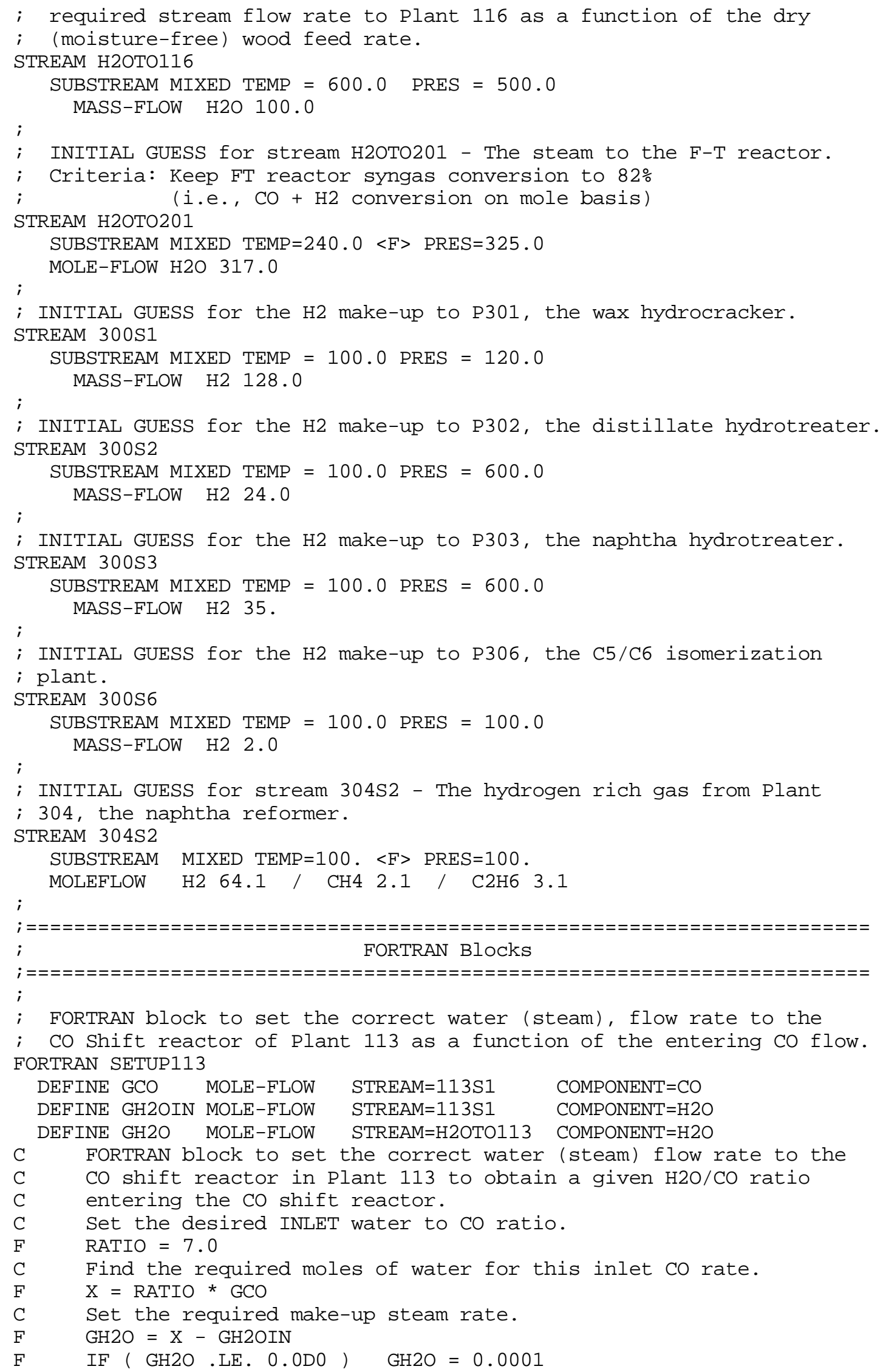


; FORTRAN block to set the steam flow rate to the Battelle gasifier ; as a function of the dry (moisture-free) wood flow rate.

FORTRAN SETUP116

DEFINE WOODFD MASS-FLOW STREAM=115S1 SUBSTREAM=NC COMPONENT=WOOD

DEFINE STM116 STREAM-VAR STREAM=H2OTO116 VAR=MASSFLOW

C FORTRAN block to set the steam flow rate to the Battelle gasifier

$C$ as a function of the moisture-free wood flow rate.

F $\quad$ STM116 = WOODFD * 10769.0D0 / 183750.0D0

;

; FORTRAN block to set the make-up steam rate to the $\mathrm{F}-\mathrm{T}$ reactors in

; Plant 201 as a function of the total molar inlet CO flow rate.

; NOTE: A change in this ratio will require a compensating change in

;

FORTRAN SETUP201

DEFINE COA MOLE-FLOW STREAM $=108 \mathrm{~S} 2 \quad$ COMPONENT $=\mathrm{CO}$

DEFINE H2OA MOLE-FLOW STREAM=108S2 COMPONENT $=\mathrm{H} 20$

DEFINE STTO21 STREAM-VAR STREAM=H2OTO201 VAR=MOLEFLOW

C FORTRAN block to set the make-up steam rate to the $\mathrm{F}-\mathrm{T}$ reactors

$\mathrm{C}$ in Plant 201 based on the total molar inlet CO flow rate.

C NOTE: A change in this ratio will require a compensating change

C in the 360 psi steam consumption for Plant 201.

C $\quad$ STTO21 $=(\mathrm{COA}) * 5405.0 /(92245.25+8860.65)$

$\mathrm{F} \quad \mathrm{STTO} 21=(\mathrm{COA}) *(11087.4875 \mathrm{D} 0 / 101099.363 \mathrm{D} 0)-\mathrm{H} 2 \mathrm{OA}$

F IF $\quad$ STTO21 .LE. 0.001D0) STTO21 = $0.001 \mathrm{D} 0$

;

; FORTRAN block to set the temperature of flash block P201S1 to be the

; same as that of P201F, the F-T reactor, since block P201S1 simulates

; the internal F-T slurry reactor vapor/liquid equilibrium calculations.

FORTRAN SETUP21A

DEFINE TS21 STREAM-VAR STREAM=201S21 VARIABLE=TEMP

DEFINE TP201 BLOCK-VAR BLOCK=P201S1 SENTENCE=PARAM VARIABLE=TEMP

C FORTRAN block to force the temperature of flash block P201S1 to

$\mathrm{C}$ the same as that of $\mathrm{P} 201 \mathrm{~F}$, the $\mathrm{F}-\mathrm{T}$ reactor, since block $\mathrm{P} 201 \mathrm{~S} 1$

C simulates the internal $\mathrm{F}-\mathrm{T}$ slurry reactor vapor/liquid

C equilibrium calculations.

$\mathrm{F} \quad \mathrm{TP} 201=\mathrm{TS} 21$

; Fortran block SETUP301 sets the make-up hydrogen flow rate to

; Plant 301 based on the feed rate of the crackable components (OXHC

; and the C10 and heavier components) in the feed.

FORTRAN SETUP301

F COMMON /USRFT2/ $\operatorname{PROP}(5,7)$

C This Fortran block sets the inlet hydrogen flow rate to

C Plant 301 (the wax hydrocracker) based on the feed rate of

C the crackable components (OXHC and the C10 and heavier

C components) in the feed.

DEFINE WAXFD MASS-FLOW STREAM=204S24 COMPONENT=C3OWAX

DEFINE HC29 MASS-FLOW STREAM=204S24 COMPONENT $=$ C29OP

DEFINE HC28 MASS-FLOW STREAM=204S24 COMPONENT=C28OP

DEFINE HC27 MASS-FLOW STREAM=204S24 COMPONENT=C27OP

DEFINE HC26 MASS-FLOW STREAM=204S24 COMPONENT=C26OP

DEFINE HC25 MASS-FLOW STREAM $=204 \mathrm{~S} 24 \quad$ COMPONENT $=$ C25OP

DEFINE HC24 MASS-FLOW STREAM=204S24 COMPONENT=C24OP

DEFINE HC23 MASS-FLOW STREAM=204S24 COMPONENT $=$ C23OP

DEFINE HC22 MASS-FLOW STREAM=204S24 COMPONENT $=$ C22OP

DEFINE HC21 MASS-FLOW STREAM=204S24 COMPONENT $=$ C21OP

DEFINE HC20P MASS-FLOW STREAM=204S24 COMPONENT $=\mathrm{C} 20 \mathrm{H} 42$

DEFINE HC20O MASS-FLOW STREAM=204S24 COMPONENT $=\mathrm{C} 20 \mathrm{H} 40$

DEFINE HC19P MASS-FLOW STREAM=204S24 COMPONENT $=$ C19H40 


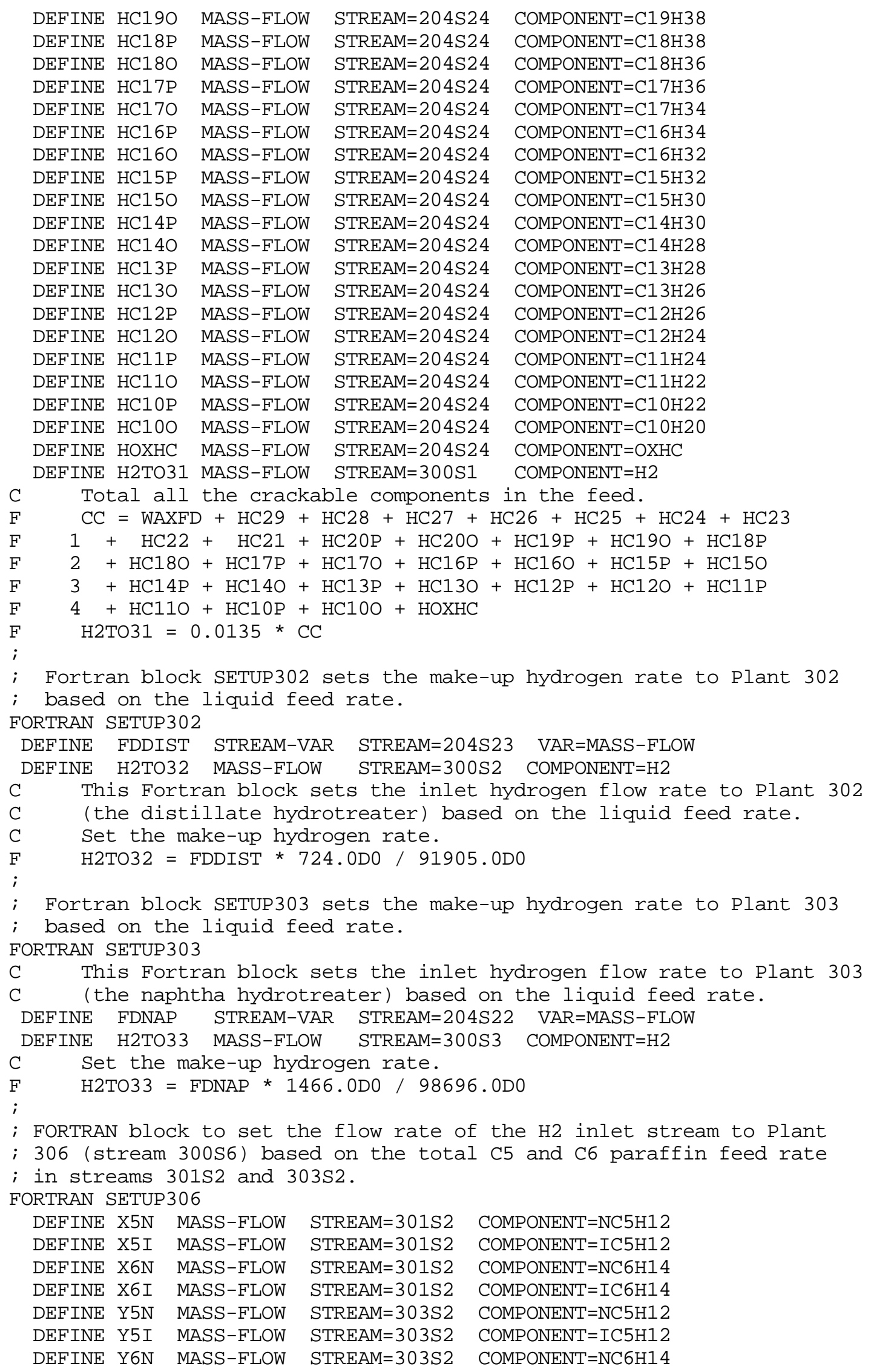

MASS-FLOW

MASS-FLOW

MASS-FLOW

MASS-FLOW

MASS-FLOW

MASS-FLOW

MASS-FLOW

MASS-FLOW

MASS-FLOW

MASS-FLOW

MASS-FLOW

MASS-FLOW

MASS-FLOW

MASS-FLOW

MASS-FLOW

MASS-FLOW

MASS-FLOW

MASS-FLOW

MASS-FLOW

MASS-FLOW

DEFINE H2TO31 MASS-FLOW

STREAM $=204 \mathrm{~S} 24$

STREAM=204S24

STREAM=204S24

STREAM=204S24

STREAM $=204 \mathrm{~S} 24$

STREAM=204S24

STREAM=204S24

STREAM=204S24

STREAM $=204 \mathrm{~S} 24$

STREAM=204S24

STREAM $=204 \mathrm{~S} 24$

STREAM $=204 \mathrm{~S} 24$

STREAM $=204 \mathrm{~S} 24$

STREAM=204S24

STREAM=204S24

STREAM $=204 \mathrm{~S} 24$

STREAM=204S24

STREAM $=204 \mathrm{~S} 24$

STREAM $=204 \mathrm{~S} 24$

STREAM $=204 S 24$

STREAM $=300 \mathrm{~S} 1$

COMPONENT $=\mathrm{C} 19 \mathrm{H} 38$

COMPONENT $=\mathrm{C} 18 \mathrm{H} 38$

COMPONENT $=\mathrm{C} 18 \mathrm{H} 36$

COMPONENT $=\mathrm{C} 17 \mathrm{H} 36$

COMPONENT $=\mathrm{C} 17 \mathrm{H} 34$

COMPONENT $=\mathrm{C} 16 \mathrm{H} 34$

COMPONENT $=\mathrm{C} 16 \mathrm{H} 32$

COMPONENT $=\mathrm{C} 15 \mathrm{H} 32$

COMPONENT $=\mathrm{C} 15 \mathrm{H} 30$

COMPONENT $=\mathrm{C} 14 \mathrm{H} 30$

COMPONENT $=\mathrm{C} 14 \mathrm{H} 28$

COMPONENT $=\mathrm{C} 13 \mathrm{H} 28$

COMPONENT $=\mathrm{C} 13 \mathrm{H} 26$

COMPONENT $=\mathrm{C} 12 \mathrm{H} 26$

COMPONENT $=\mathrm{C} 12 \mathrm{H} 24$

COMPONENT $=\mathrm{C} 11 \mathrm{H} 24$

COMPONENT $=\mathrm{C} 11 \mathrm{H} 22$

$\mathrm{COMPONENT}=\mathrm{C} 10 \mathrm{H} 22$

COMPONENT $=\mathrm{C} 10 \mathrm{H} 20$

COMPONENT $=O X H C$

COMPONENT $=\mathrm{H} 2$

C Total all the crackable components in the feed.

$\mathrm{F} \quad \mathrm{CC}=$ WAXFD $+\mathrm{HC} 29+\mathrm{HC} 28+\mathrm{HC} 27+\mathrm{HC} 26+\mathrm{HC} 25+\mathrm{HC} 24+\mathrm{HC} 23$

$\mathrm{F} 1+\mathrm{HC} 22+\mathrm{HC} 21+\mathrm{HC} 20 \mathrm{P}+\mathrm{HC} 20 \mathrm{O}+\mathrm{HC} 19 \mathrm{P}+\mathrm{HC} 19 \mathrm{O}+\mathrm{HC} 18 \mathrm{P}$

$\mathrm{F} 2+\mathrm{HC} 180+\mathrm{HC} 17 \mathrm{P}+\mathrm{HC} 170+\mathrm{HC} 16 \mathrm{P}+\mathrm{HC} 160+\mathrm{HC} 15 \mathrm{P}+\mathrm{HC} 150$

$\mathrm{F} 3+\mathrm{HC} 14 \mathrm{P}+\mathrm{HC} 14 \mathrm{O}+\mathrm{HC} 13 \mathrm{P}+\mathrm{HC} 13 \mathrm{O}+\mathrm{HC} 12 \mathrm{P}+\mathrm{HC} 12 \mathrm{O}+\mathrm{HC} 11 \mathrm{P}$

$\mathrm{F} \quad 4+\mathrm{HC} 110+\mathrm{HC} 10 \mathrm{P}+\mathrm{HC} 10 \mathrm{O}+\mathrm{HOXHC}$

$\mathrm{F} \quad \mathrm{H} 2 \mathrm{TO} 31=0.0135 * \mathrm{CC}$

; Fortran block SETUP302 sets the make-up hydrogen rate to Plant 302

; based on the liquid feed rate.

FORTRAN SETUP302

\section{DEFINE FDDIST STREAM-VAR STREAM=204S23 VAR=MASS-FLOW}

DEFINE H2TO32 MASS-FLOW STREAM=300S2 COMPONENT=H2

C This Fortran block sets the inlet hydrogen flow rate to Plant 302

C (the distillate hydrotreater) based on the liquid feed rate.

C Set the make-up hydrogen rate.

$\mathrm{F} \quad \mathrm{H} 2 \mathrm{TO} 32=$ FDDIST $\star 724.0 \mathrm{DO} /$ 91905.0D0

; Fortran block SETUP303 sets the make-up hydrogen rate to Plant 303

; based on the liquid feed rate.

FORTRAN SETUP303

$\mathrm{C}$ This Fortran block sets the inlet hydrogen flow rate to Plant 303

C (the naphtha hydrotreater) based on the liquid feed rate.

DEFINE FDNAP STREAM-VAR STREAM=204S22 VAR=MASS-FLOW

DEFINE H2TO33 MASS-FLOW STREAM=300S3 COMPONENT=H2

C Set the make-up hydrogen rate.

$\mathrm{F} \quad \mathrm{H} 2 \mathrm{TO} 33=\mathrm{FDNAP} * 1466.0 \mathrm{DO} /$ 98696.0D0

; FORTRAN block to set the flow rate of the $\mathrm{H} 2$ inlet stream to $\mathrm{Plant}$

; 306 (stream 300S6) based on the total C5 and C6 paraffin feed rate

; in streams 301S2 and 303s2.

FORTRAN SETUP 306

DEFINE X5N MASS-FLOW STREAM $=301 \mathrm{~S} 2$

DEFINE X5I MASS-FLOW STREAM=301S2

DEFINE X6N MASS-FLOW STREAM=301S2

DEFINE X6I MASS-FLOW STREAM=301S2

DEFINE Y5N MASS-FLOW STREAM=303S2

DEFINE Y5I MASS-FLOW STREAM=303S2

DEFINE Y6N MASS-FLOW STREAM=303S2

COMPONENT $=\mathrm{NC} 5 \mathrm{H} 12$

COMPONENT $=$ IC $5 \mathrm{H} 12$

COMPONENT $=\mathrm{NC} 6 \mathrm{H} 14$

COMPONENT $=\mathrm{IC} 6 \mathrm{H} 14$

COMPONENT $=\mathrm{NC} 5 \mathrm{H} 12$

COMPONENT $=$ IC $5 \mathrm{H} 12$

COMPONENT $=\mathrm{NC} 6 \mathrm{H} 14$

;

;

; 


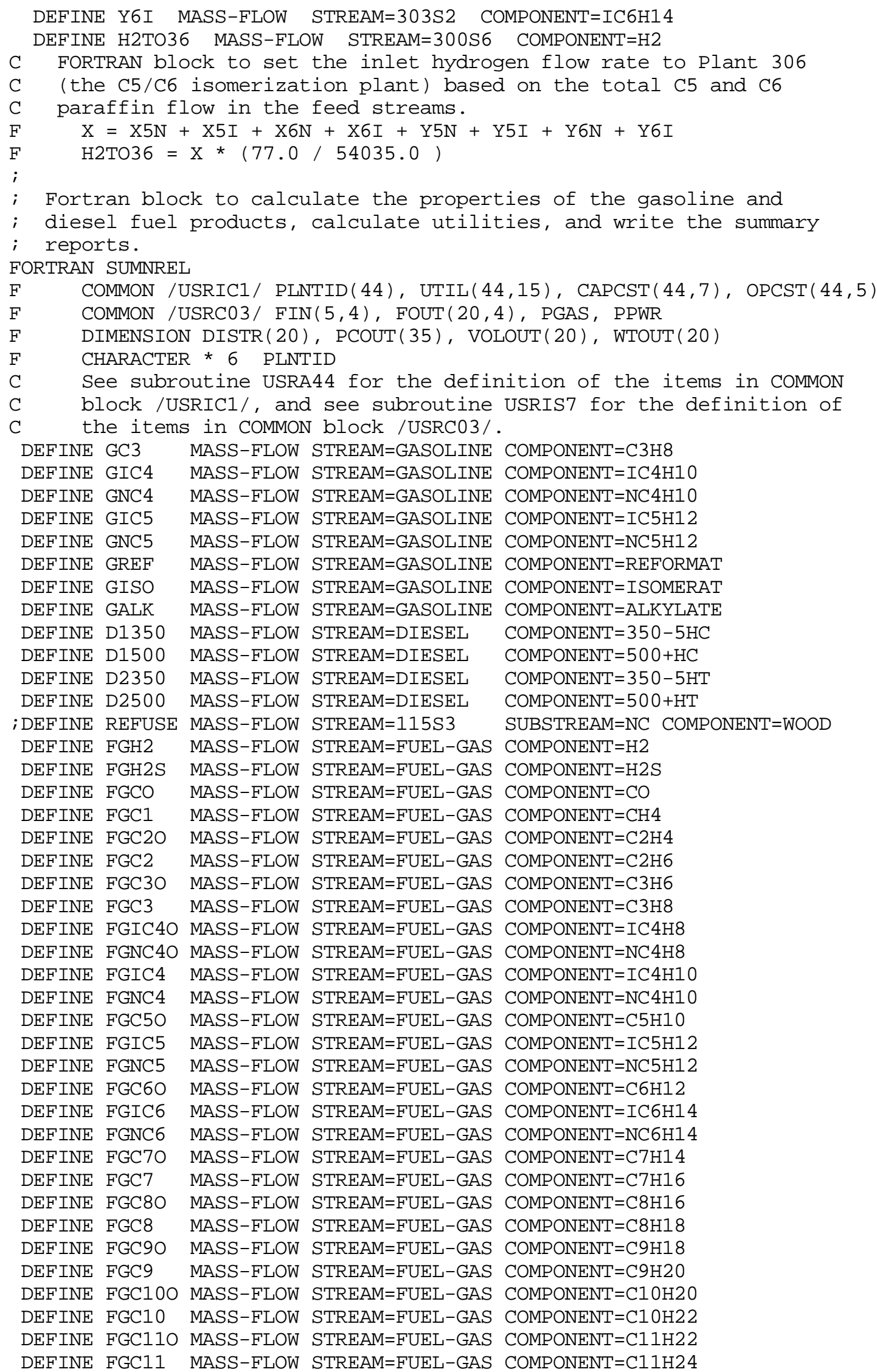


DEFINE FGC12O MASS-FLOW STREAM=FUEL-GAS COMPONENT $=\mathrm{C} 12 \mathrm{H} 24$

DEFINE FGC12 MASS-FLOW STREAM=FUEL-GAS COMPONENT=C12H 6

DEFINE FGC130 MASS-FLOW STREAM=FUEL-GAS COMPONENT=C13H26

DEFINE FGC13 MASS-FLOW STREAM=FUEL-GAS COMPONENT $=$ C13H 28

DEFINE FGC140 MASS-FLOW STREAM=FUEL-GAS COMPONENT $=\mathrm{C} 14 \mathrm{H} 28$

DEFINE FGC14 MASS-FLOW STREAM=FUEL-GAS COMPONENT=C14H30

DEFINE FGC150 MASS-FLOW STREAM=FUEL-GAS COMPONENT=C15H30

DEFINE FGC15 MASS-FLOW STREAM=FUEL-GAS COMPONENT=C15H32

DEFINE FGC160 MASS-FLOW STREAM=FUEL-GAS COMPONENT $=\mathrm{C} 16 \mathrm{H} 32$

DEFINE FGC16 MASS-FLOW STREAM=FUEL-GAS COMPONENT=C16H34

DEFINE FGC170 MASS-FLOW STREAM=FUEL-GAS COMPONENT=C17H34

DEFINE FGC17 MASS-FLOW STREAM=FUEL-GAS COMPONENT=C17H36

DEFINE FGC180 MASS-FLOW STREAM=FUEL-GAS COMPONENT=C18H36

DEFINE FGC18 MASS-FLOW STREAM=FUEL-GAS COMPONENT $=\mathrm{C} 18 \mathrm{H} 38$

DEFINE FGC190 MASS-FLOW STREAM=FUEL-GAS COMPONENT $=\mathrm{C} 19 \mathrm{H} 38$

DEFINE FGC19 MASS-FLOW STREAM=FUEL-GAS COMPONENT $=\mathrm{C} 19 \mathrm{H} 40$

DEFINE FGC200 MASS-FLOW STREAM=FUEL-GAS COMPONENT=C2OH40

DEFINE FGC20 MASS-FLOW STREAM=FUEL-GAS COMPONENT $=\mathrm{C} 20 \mathrm{H} 42$

DEFINE FGC21 MASS-FLOW STREAM=FUEL-GAS COMPONENT=C21OP

DEFINE FGC22 MASS-FLOW STREAM=FUEL-GAS COMPONENT $=$ C22OP

DEFINE FGC23 MASS-FLOW STREAM=FUEL-GAS COMPONENT=C23OP

DEFINE FGC24 MASS-FLOW STREAM=FUEL-GAS COMPONENT=C24OP

DEFINE FGC25 MASS-FLOW STREAM=FUEL-GAS COMPONENT=C25OP

DEFINE FGC26 MASS-FLOW STREAM=FUEL-GAS COMPONENT=C26OP

DEFINE FGC27 MASS-FLOW STREAM=FUEL-GAS COMPONENT=C27OP

DEFINE FGC28 MASS-FLOW STREAM=FUEL-GAS COMPONENT=C28OP

DEFINE FGC29 MASS-FLOW STREAM=FUEL-GAS COMPONENT=C29OP

DEFINE FGOXV MASS-FLOW STREAM=FUEL-GAS COMPONENT=OXVAP

DEFINE FGOXHC MASS-FLOW STREAM=FUEL-GAS COMPONENT=OXHC

DEFINE FGWAX MASS-FLOW STREAM=FUEL-GAS COMPONENT=C3OWAX

DEFINE WOODIN MASS-FLOW STREAM=WETWOOD SUBSTREAM=NC COMPONENT=WOOD

DEFINE SLAG MASS-FLOW STREAM=SLAG SUBSTREAM=NC COMPONENT=CHAR

DEFINE X21S3 STREAM-VAR STREAM=201S3 VAR=MOLE-FLOW

DEFINE X21S21 STREAM-VAR STREAM=201S21 VAR=MOLE-FLOW

DEFINE X201CO MOLE-FLOW STREAM=201S3 COMPONENT=CO

DEFINE X201W MOLE-FLOW STREAM=201S3 COMPONENT $=\mathrm{H} 20$

DEFINE H25S13 MOLE-FLOW STREAM=205S13 COMPONENT=H2

DEFINE F25S13 STREAM-VAR STREAM=205S13 VAR=MOLE-FLOW

DEFINE HBY205 MASS-FLOW STREAM=205S3 COMPONENT=H2

DEFINE H301 MASS-FLOW STREAM=300S1 COMPONENT=H2

DEFINE H302 MASS-FLOW STREAM=300S2 COMPONENT $=\mathrm{H} 2$

DEFINE H303 MASS-FLOW STREAM $=300 \mathrm{~S} 3 \quad$ COMPONENT $=\mathrm{H} 2$

DEFINE H306 MASS-FLOW STREAM=300S6 COMPONENT $=\mathrm{H} 2$

DEFINE H2S108 MASS-FLOW STREAM=108S1 COMPONENT=H2S

$\mathrm{C}$

C Fortran block SUMNREL to calculate the properties of the gasoline

C and diesel fuel products, calculate utilities, perform the final

C calculations, and write the overall summary reports.

C

C

$\mathrm{F}$

Set the SULFUR, LPG and purchased C4s stream flows to zero. SULFUR $=0$.

$\mathrm{XLPG}=0$.

$\mathrm{PC} 4 \mathrm{~S}=0$.

If the wood drying plant is modified to produce a refuse stream, remove the ';' on the above 'DEFINE REFUSE...' statement and remove the following line which sets the REFUSE rate to zero. REFUSE $=0.0$

Set NPURE equal to the number of pure components that can be 


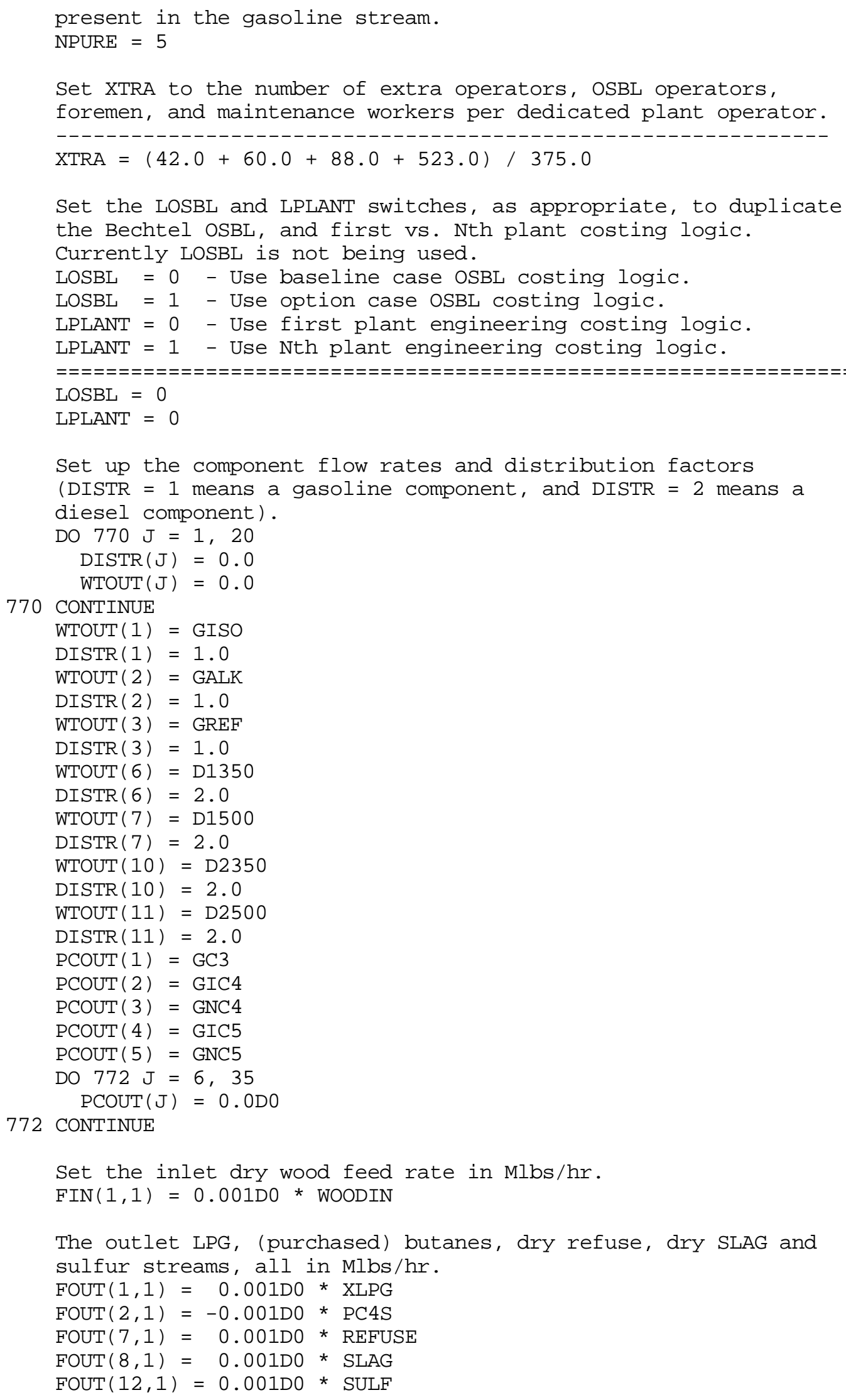




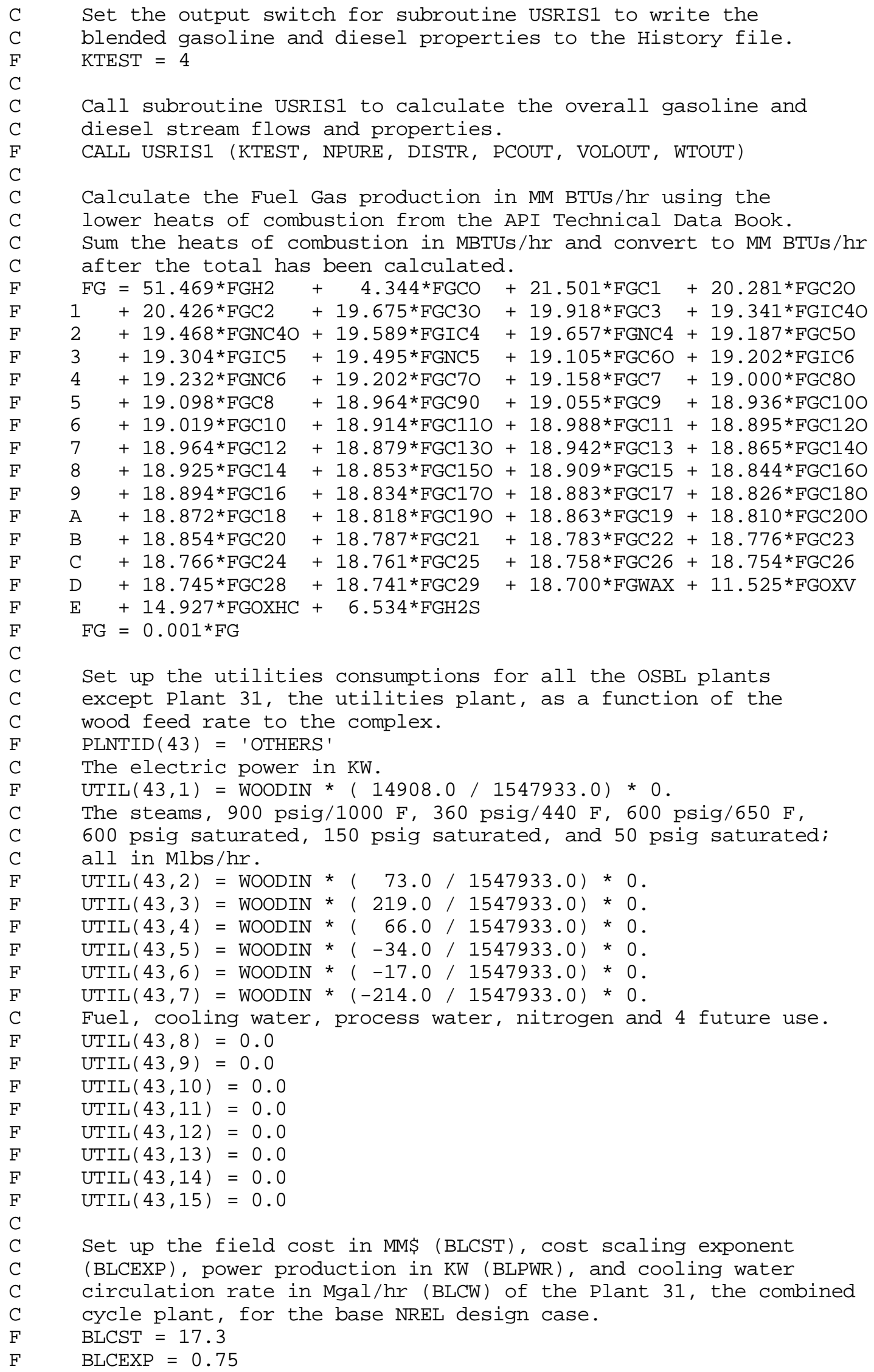




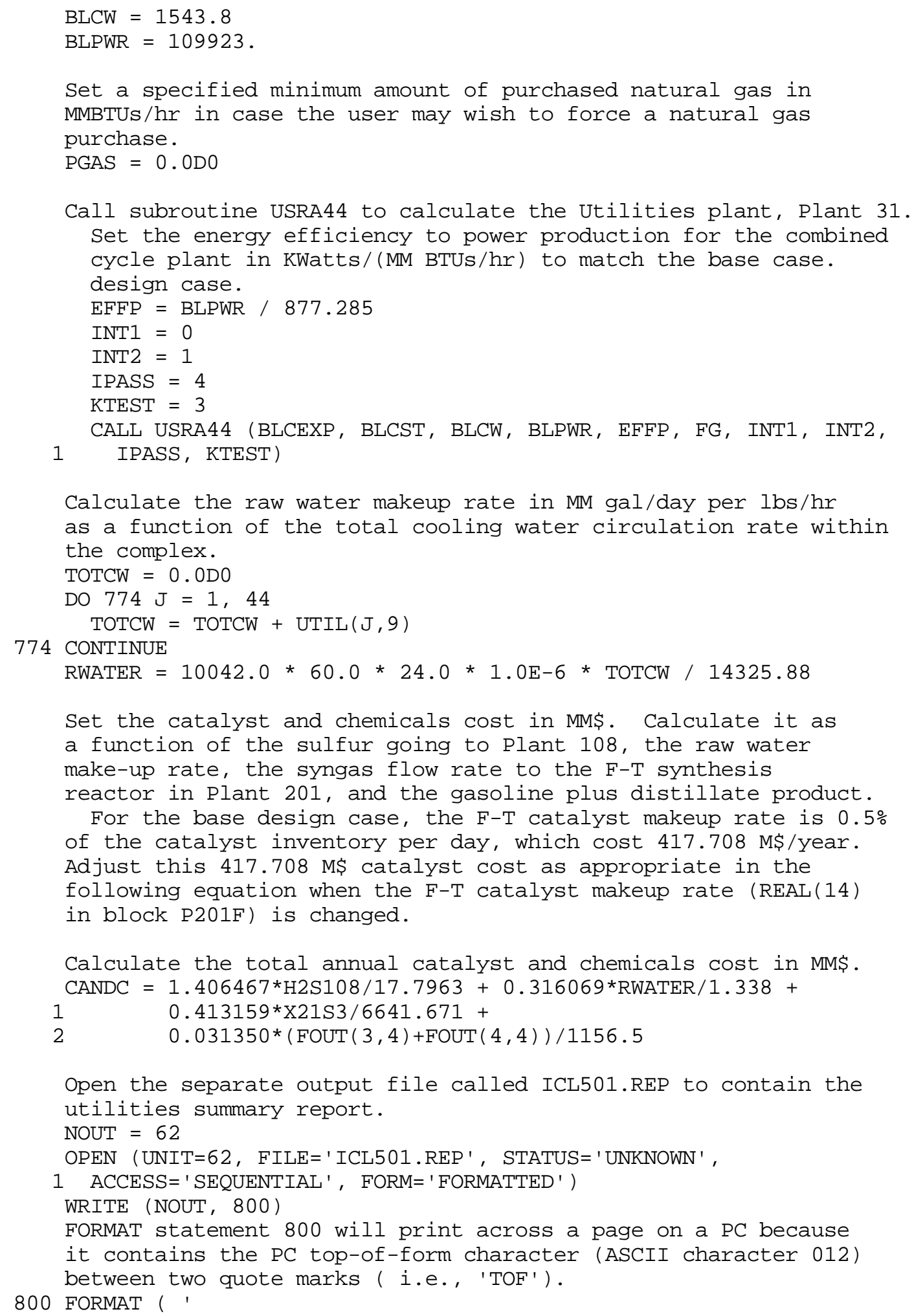


C

Call subroutine USRT44 to summarize the utilities for all plants.

$\mathrm{KTEST}=3$

CALL USRT44 (FG, INT1, INT2, IPASS, KTEST, NOUT)

Close the output file on logical unit 62 containing the utilities summary report.

CLOSE (UNIT=NOUT, STATUS='KEEP')

Open the separate output file called ICLSUM. REP to contain the overall plant summary report.

NOUT $=62$

OPEN (UNIT=62, FILE=' ICLSUM.REP' , STATUS='UNKNOWN' ,

1 ACCESS=' SEQUENTIAL', FORM='FORMATTED' )

Call subroutines USRIS7 to write the top of the first page of the overall plant summary report. CALL USRIS7 (NOUT, RWATER)

Call subroutines USRIS3 to calculate the total plant cost and write the bottom of first page of the overall plant summary report.

Set the total installed ISBL field costs in MMS for the base case for all the ISBL plants, the individual OSBL plants except Plant 31, and calculate the total installed cost of all these OSBL plants. The installed field cost for Plant 31 was calculated previously as a function of power production in subroutine USRA44.

CISBL $=61.313$

$\mathrm{CP} 19=0.279$

$\mathrm{CP} 20=1.955$

$\mathrm{CP} 21=1.706$

$\mathrm{CP} 22=0.353$

$\mathrm{CP} 23=0.586$

$\mathrm{CP} 24=1.373$

$\mathrm{CP} 25=0.047$

$\mathrm{CP} 30=7.346$

$\mathrm{CP} 32=10.091$

$\mathrm{CP} 33=0.576$

$\mathrm{CP} 34=6.949$

$\mathrm{CP} 35=0.690$

$\mathrm{CP} 36=0.365$

$\mathrm{CP} 37=0.183$

$\mathrm{CP} 40=1.565$

$\mathrm{CP} 41=1.064$

$\mathrm{CP} 42=0.146$

$\mathrm{CP} 43=1.064$

$\mathrm{COSBL}=\mathrm{CP} 19+\mathrm{CP} 20+\mathrm{CP} 21+\mathrm{CP} 22+\mathrm{CP} 23+\mathrm{CP} 24+\mathrm{CP} 25+\mathrm{CP} 30$

$1+\mathrm{CP} 32+\mathrm{CP} 33+\mathrm{CP} 34+\mathrm{CP} 35+\mathrm{CP} 36+\mathrm{CP} 37+\mathrm{CP} 40$

$2+\mathrm{CP} 41+\mathrm{CP} 42+\mathrm{CP} 43$

CALL USRIS3 (CANDC, CISBL, COSBL, LOSBL, LPLANT, NOUT, XTRA)

Close the output file on logical unit 62 containing the overall plant summary report.

CLOSE (UNIT=NOUT, STATUS='KEEP')

Open the separate output file called ICL.PRN to contain the model predictions for transfer to the spreadsheet economics model. 


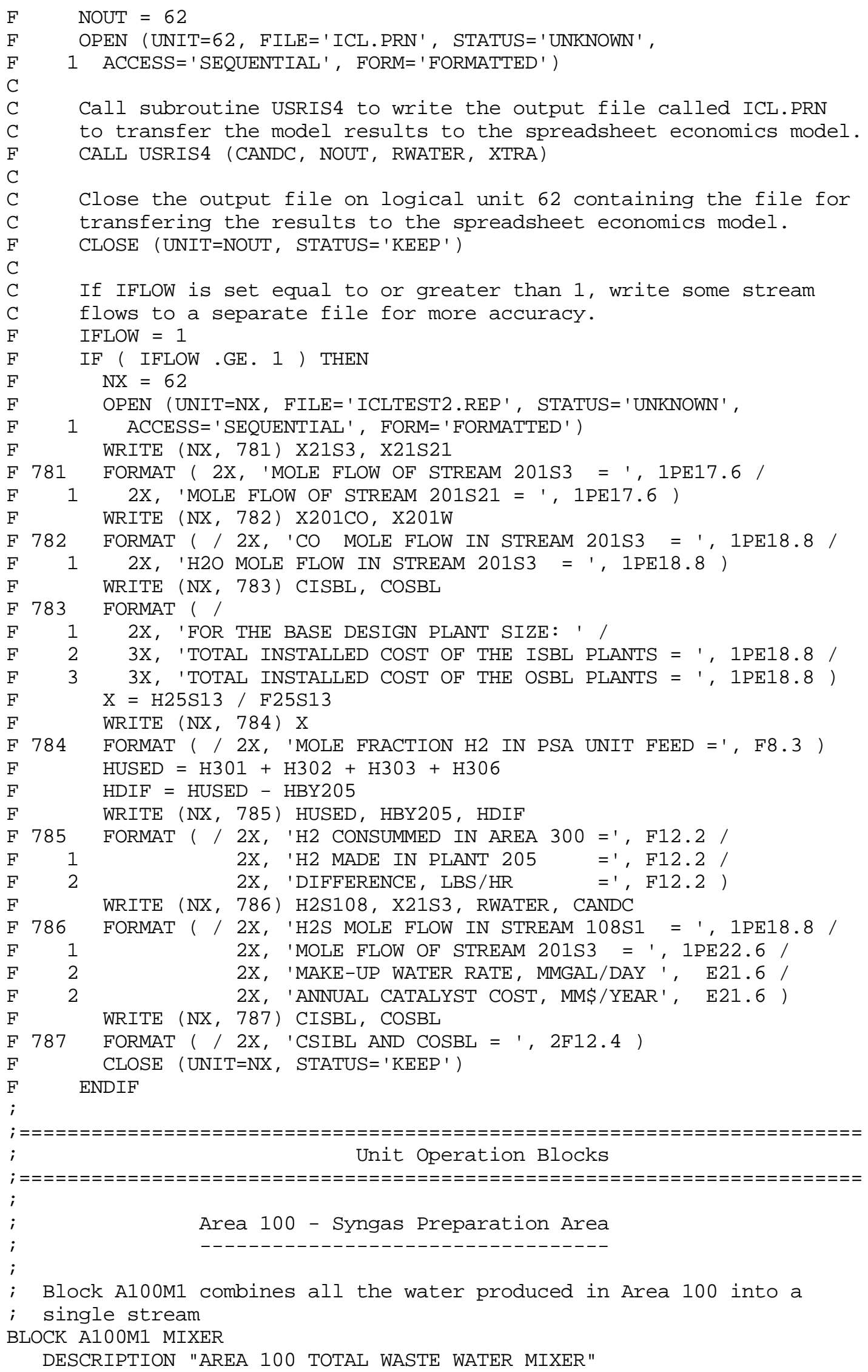




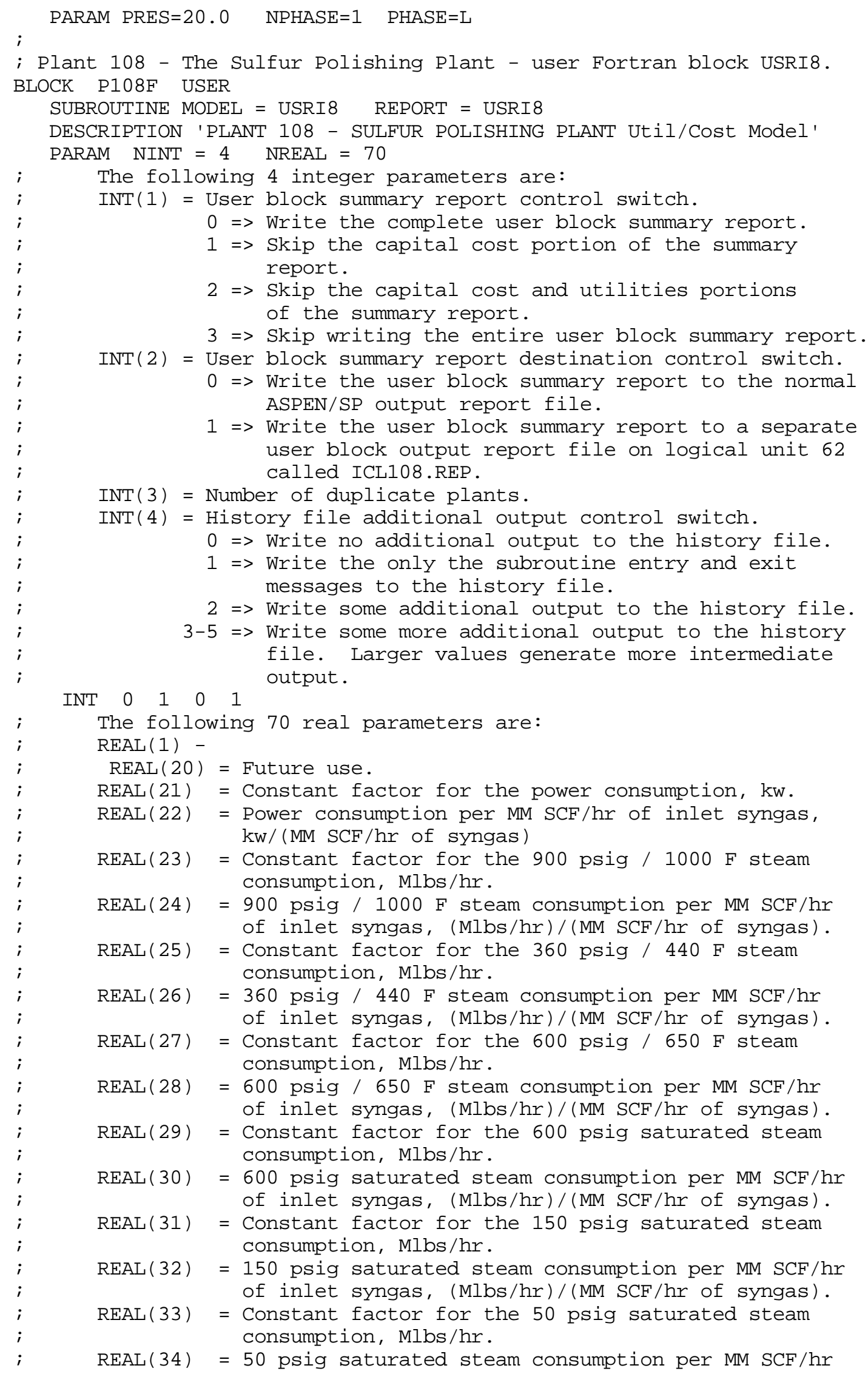




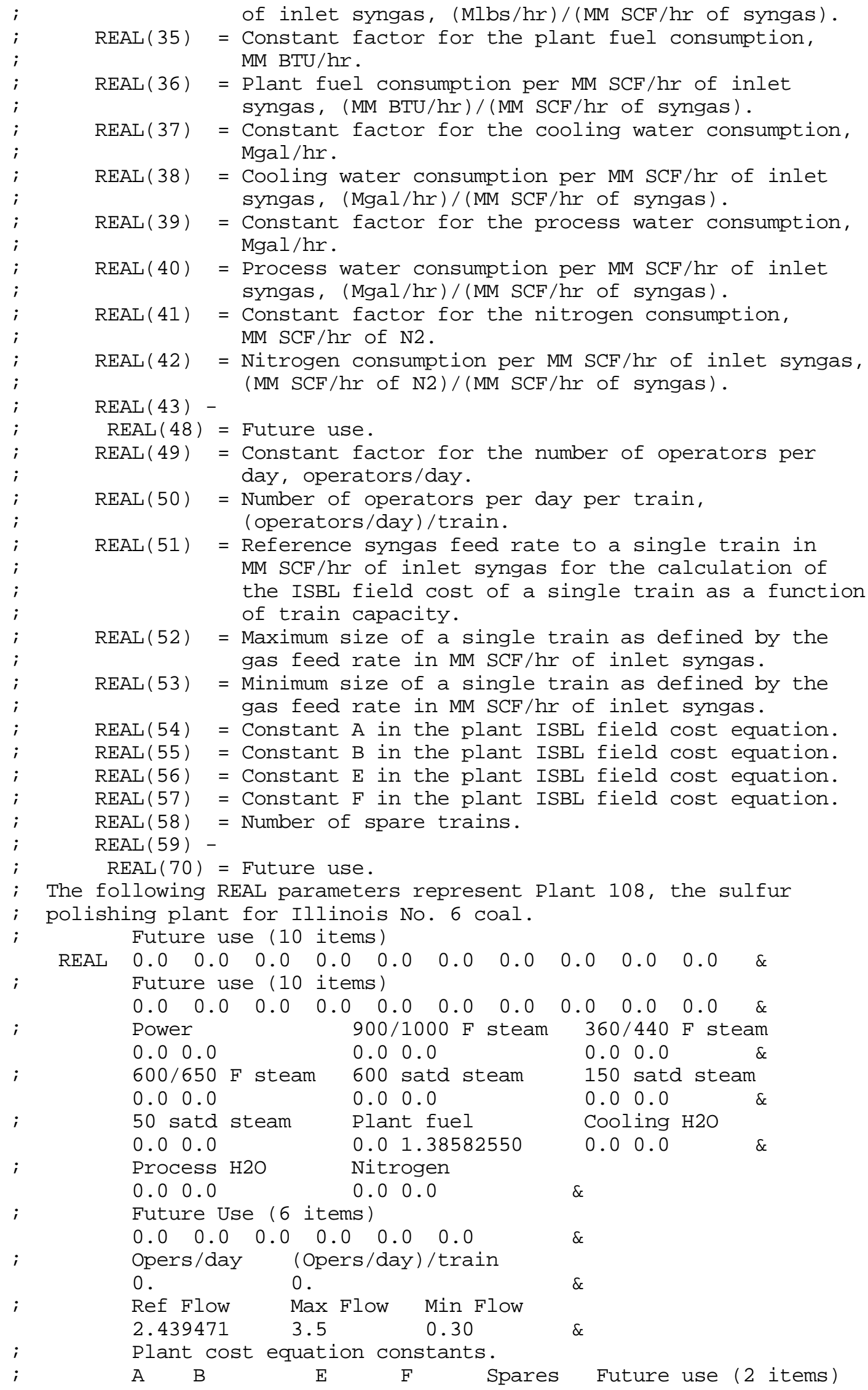




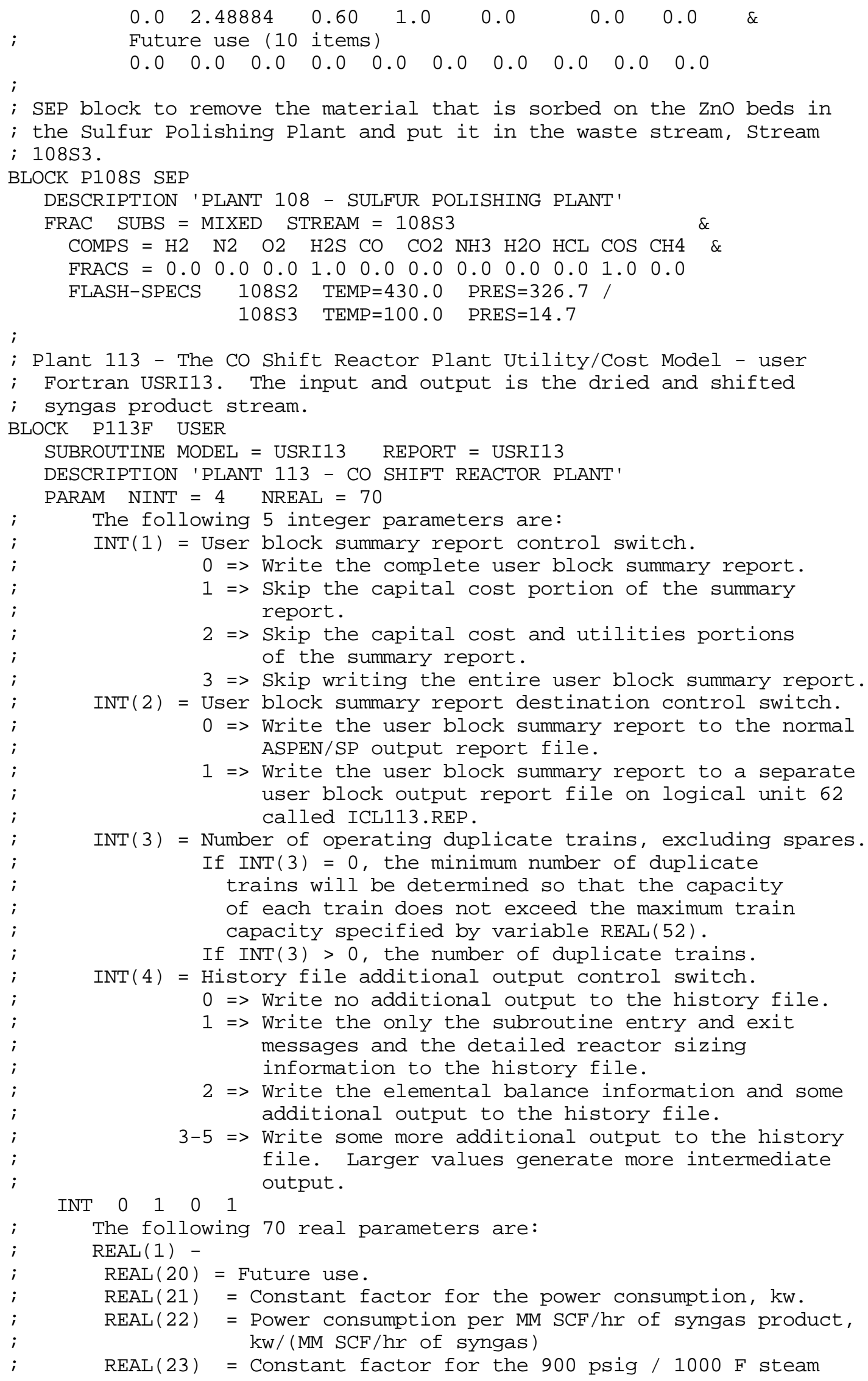




\begin{tabular}{|c|c|c|}
\hline & & consumption, Mlbs/hr. \\
\hline ; & REAL (24) & $=900$ psig / $1000 \mathrm{~F}$ steam consumption per MM SCF/hr \\
\hline i & & of syngas product, (Mlbs/hr)/(MM SCF/hr of syngas). \\
\hline ; & REAL (25) & $=$ Constant factor for the 360 psig / $440 \mathrm{~F}$ steam \\
\hline ; & & consumption, Mlbs/hr. \\
\hline ; & REAL (26) & $=360$ psig / $440 \mathrm{~F}$ steam consumption per MM SCF/hr \\
\hline ; & & of syngas product, (Mlbs/hr)/(MM SCF/hr of syngas). \\
\hline ; & REAL (27) & $=$ Constant factor for the 600 psig / $650 \mathrm{~F}$ steam \\
\hline ; & & consumption, Mlbs/hr. \\
\hline ; & REAL (28) & $=600$ psig / $650 \mathrm{~F}$ steam consumption per MM SCF/hr \\
\hline ; & & of syngas product, (Mlbs/hr)/(MM SCF/hr of syngas). \\
\hline ; & REAL (29) & $=$ Constant factor for the 600 psig saturated steam \\
\hline ; & & consumption, Mlbs/hr. \\
\hline ; & REAL (30) & $=600$ psig saturated steam consumption per $\mathrm{MM}$ SCF/hr \\
\hline ; & & of syngas product, (Mlbs/hr)/(MM SCF/hr of syngas). \\
\hline ; & REAL (31) & $=$ Constant factor for the 150 psig saturated steam \\
\hline ; & & consumption, Mlbs/hr. \\
\hline ; & REAL (32) & $=150$ psig saturated steam consumption per MM SCF/hr \\
\hline ; & & of syngas product, (Mlbs/hr)/(MM SCF/hr of syngas). \\
\hline ; & REAL (33) & $=$ Constant factor for the 50 psig saturated steam \\
\hline ; & & consumption, Mlbs/hr. \\
\hline ; & REAL (34) & $=50$ psig saturated steam consumption per MM SCF/hr \\
\hline ; & & of syngas product, (Mlbs/hr)/(MM SCF/hr of syngas). \\
\hline ; & REAL (35) & $=$ Constant factor for the plant fuel consumption, \\
\hline ; & & MM BTU/hr. \\
\hline ; & REAL (36) & $=$ Plant fuel consumption per $\mathrm{MM} \mathrm{SCF} / \mathrm{hr}$ of syngas \\
\hline ; & & product, (MM BTU/hr)/(MM SCF/hr of syngas) \\
\hline ; & REAL (37) & $=$ Constant factor for the cooling water consumption, \\
\hline ; & & Mgal/hr. \\
\hline ; & REAL (38) & $=$ Cooling water consumption per $\mathrm{MM}$ SCF/hr of syngas \\
\hline ; & & product, (Mgal/hr)/(MM SCF/hr of syngas). \\
\hline ; & REAL (39) & $=$ Constant factor for the process water consumption, \\
\hline ; & & Mgal/hr. \\
\hline ; & REAL ( 40) & $=$ Process water consumption per MM SCF/hr of syngas \\
\hline ; & & product, (Mgal/hr)/(MM SCF/hr of syngas). \\
\hline ; & REAL ( 41 ) & $=$ Constant factor for the nitrogen consumption, \\
\hline ; & & $\mathrm{MM} \mathrm{SCF} / \mathrm{hr}$ of $\mathrm{N} 2$ \\
\hline ; & REAL (42) & $=$ Nitrogen consumption per $\mathrm{MM} S \mathrm{SCF} / \mathrm{hr}$ of syngas \\
\hline ; & & product, (MM SCF/hr of N2)/(MM SCF/hr of syngas). \\
\hline ; & REAL (43) & - \\
\hline ; & REAL ( 48) & $=$ Future use. \\
\hline ; & REAL ( 49) & $=$ Constant factor for the number of operators per \\
\hline ; & & day, operators/day. \\
\hline ; & REAL ( 50$)$ & $=$ Number of operators per day per train, \\
\hline ; & & (operators/day)/train. \\
\hline ; & REAL (51) & $=$ Reference syngas production rate of a single train \\
\hline ; & & in $\mathrm{MM} \mathrm{SCF} / \mathrm{hr}$ of dried syngas product for the \\
\hline ; & & calculation of the ISBL field cost of a single \\
\hline ; & & train as a function of train capacity. \\
\hline ; & REAL (52) & $=$ Maximum size of a single train as defined by the \\
\hline ; & & syngas production rate in $\mathrm{MM} \mathrm{SCF} / \mathrm{hr}$ of dried syngas \\
\hline ; & & product. \\
\hline ; & REAL (53) & $=$ Minimum size of a single train as defined by the \\
\hline ; & & syngas production rate in $\mathrm{MM} \mathrm{SCF} / \mathrm{hr}$ of dried syngas \\
\hline ; & & product. \\
\hline ; & REAL ( 54 ) & $=$ Constant $\mathrm{A}$ in the plant ISBL field cost equation. \\
\hline ; & REAL (55) & $=$ Constant $\mathrm{B}$ in the plant ISBL field cost equation. \\
\hline ; & REAL (56) & $=$ Constant $\mathrm{E}$ in the plant ISBL field cost equation. \\
\hline ; & REAL (57) & $=$ Constant $\mathrm{F}$ in the plant ISBL field cost equation. \\
\hline ; & REAL (58) & $=$ Number of spare trains. \\
\hline
\end{tabular}




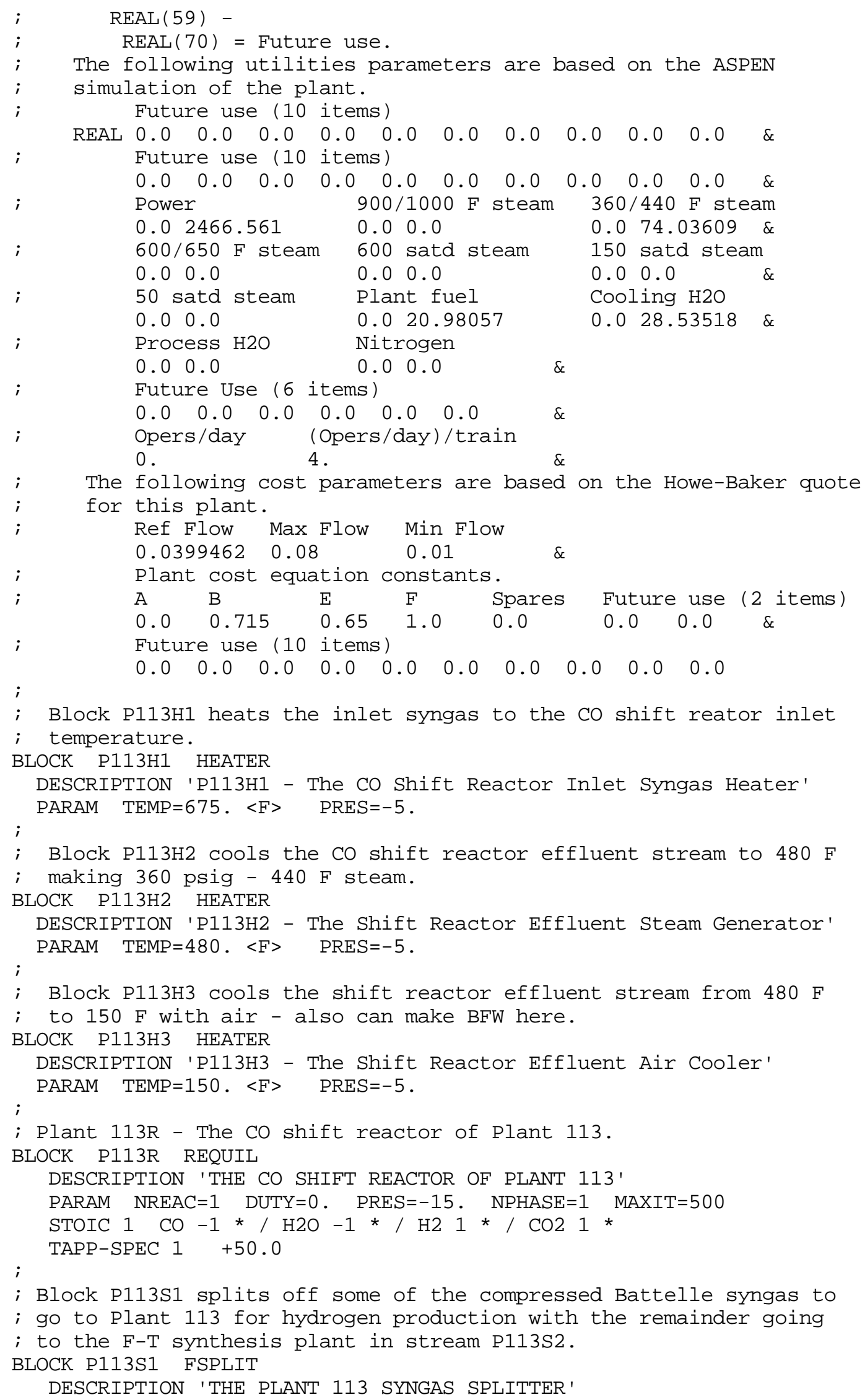


FRAC STREAM=113S1 VAL $=0.02$

; Block P113S2 simultaneously cools and separates the CO shift reactor

; effluent stream into a vapor and condensate (mostly water) stream.

BLOCK P113S2 FLASH2

DESCRIPTION 'THE P113 CO SHIFT REACTOR EFFLUENT COOLER \& SEPARATOR'

PARAM TEMP $=100<\mathrm{F}>\mathrm{PRES}=-5$

;

; Plant 115 - Wood Drying Plant; User Fortran Model USRI15

BLOCK P115F USER

SUBROUTINE MODEL = USRI15 REPORT $=$ USRI15

DESCRIPTION 'PLANT 115 - WOOD DRYING PLANT'

NOTES: 1. This model treats the plant fuel as a utility, and does not do the combustion and vent gas calculations since no significant extra knowledge would be gained.

2. This model was adapted from a coal cleaning and drying model and was modified to include wood cleaning.

PARAM NINT $=4 \quad$ NREAL $=70$

The following 5 integer parameters are:

INT(1) = User block summary report control switch.

$0=>$ Write the complete user block summary report.

$1=>$ skip the capital cost portion of the summary report.

2 => Skip the capital cost and utilities portions of the summary report.

3 => Skip writing the entire user block summary report. INT(2) = User block summary report destination control switch.

0 => Write the user block summary report to the mormal ASPEN/SP output report file.

1 => Write the user block summary report to a separate user block output report file on logical unit 62 .

INT(3) = Number of operating duplicate trains, excluding spares. If INT(3) $=0$, the minimum number of duplicate trains will be determined so that the capacity of each train does not exceed the maximum train capacity specified by variable REAL(52).

If INT(3) >0, the number of duplicate trains. INT(4) = History file additional output control switch.

$0=>$ Write no additional output to the history file.

$1=>$ Write the only the subroutine entry and exit messages to the history file.

2 => Write some additional output to the history file.

3-4 => Write some more additional output to the history file. Larger values generate more intermediate

INT $\quad 0 \quad 1 \quad 001$ output.

The following 70 real parameters are:

REAL(1) = Fraction of carbon in the inlet wood leaving in the dried wood product stream.

REAL (2) = Fraction of carbon in the inlet wood leaving in the middlings stream.

REAL (3) = Fraction of hydrogen in the inlet wood leaving in the dried wood product stream.

REAL (4) = Fraction of hydrogen in the inlet wood leaving in the middlings stream.

REAL (5) = Fraction of nitrogen in the inlet wood leaving in the dried wood product stream.

REAL (6) = Fraction of nitrogen in the inlet wood leaving in the middlings stream.

REAL (7) = Fraction of chlorine in the inlet wood leaving 


\begin{tabular}{|c|c|c|}
\hline & & in the dried wood product stream. \\
\hline & REAL ( 8) & $=$ Fraction of chlorine in the inlet wood leaving \\
\hline & & in the middlings stream. \\
\hline & REAL ( 9 ) & $=$ Fraction of sulfur in the inlet wood leaving \\
\hline & & in the dried wood product stream. OPTIONAL - See \\
\hline & & Note 2 \\
\hline & REAL (10) & $=$ Fraction of sulfur in the inlet wood leaving \\
\hline & & in the middlings stream. OPTIONAL - See Note 2. \\
\hline & REAL (11) & $=$ Fraction of oxygen in the inlet wood leaving \\
\hline & & in the dried wood product stream. \\
\hline & REAL (12) & $=$ Fraction of oxygen in the inlet wood leaving \\
\hline & & in the middlings stream. \\
\hline & REAL (13) & $=$ Fraction of ash in the inlet wood leaving \\
\hline & & in the dried wood product stream. \\
\hline & REAL (14) & $=$ Fraction of ash in the inlet wood leaving \\
\hline & & in the middlings stream. \\
\hline & REAL (15) & $=$ Moisture content of the dried wood product on a dry \\
\hline & & basis, wt\% \\
\hline & REAL ( 16 ) & $=$ Moisture content of the middlings on a dry \\
\hline & & basis, wt\% \\
\hline & REAL (17) & $=$ Moisture content of the refuse on a dry basis, wt\%. \\
\hline & REAL (18) & - \\
\hline & REAL (20) & uture use. \\
\hline & REAL (21) & $=$ Constant factor for the power consumption, $\mathrm{kw}$. \\
\hline & REAL (22) & $=$ Power consumption per Mlbs/hr of dry wood, \\
\hline & & $\mathrm{kw} /(\mathrm{Mlbs} / \mathrm{hr})$ \\
\hline & REAL (23) & $=$ Constant factor for the 900 psig / 1000 F steam \\
\hline & & consumption, Mlbs/hr. \\
\hline & REAL (24) & $=900 \mathrm{psig} / 1000 \mathrm{~F}$ steam consumption per Mlbs/hr of \\
\hline & & dry wood, (Mlbs/hr)/(Mlbs/hr) \\
\hline & REAL (25) & $=$ Constant factor for the 360 psig / $440 \mathrm{~F}$ steam \\
\hline & & consumption, Mlbs/hr. \\
\hline & REAL (26) & $=360$ psig / $440 \mathrm{~F}$ steam consumption per Mlbs/hr of \\
\hline 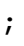 & & dry wood, (Mlbs/hr)/(Mlbs/hr) \\
\hline & REAL (27) & $=$ Constant factor for the 600 psig / 650 F steam \\
\hline ; & & consumption, Mlbs/hr. \\
\hline ; & REAL (28) & $=600$ psig / $650 \mathrm{~F}$ steam consumption per Mlbs/hr of \\
\hline ; & & dry wood, (Mlbs/hr) /(Mlbs/hr) \\
\hline ; & REAL (29) & $=$ Constant factor for the 600 psig saturated steam \\
\hline ; & & consumption, Mlbs/hr. \\
\hline ; & REAL (30) & $=600$ psig saturated steam consumption per Mlbs/hr of \\
\hline ; & & dry wood, (Mlbs/hr) / (Mlbs/hr) \\
\hline ; & REAL (31) & $=$ Constant factor for the 150 psig saturated steam \\
\hline ; & & consumption, Mlbs/hr. \\
\hline ; & REAL (32) & $=150$ psig saturated steam consumption per Mlbs/hr of \\
\hline ; & & dry wood, (Mlbs/hr) / (Mlbs/hr) \\
\hline ; & REAL (33) & $=$ Constant factor for the 50 psig saturated steam \\
\hline ; & & consumption, Mlbs/hr. \\
\hline 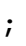 & REAL (34) & $=50$ psig saturated steam consumption per Mlbs/hr of \\
\hline ; & & dry wood, (Mlbs/hr) / (Mlbs/hr) \\
\hline ; & REAL (35) & $=$ Constant factor for the plant fuel consumption, \\
\hline ; & & $\mathrm{MM} \mathrm{BTU/hr}$ \\
\hline ; & REAL (36) & $=$ Plant fuel consumption per Mlbs/hr of dry wood, \\
\hline ; & & $(\mathrm{MM} \mathrm{BTU} / \mathrm{hr}) /(\mathrm{Mlbs} / \mathrm{hr})$ \\
\hline ; & REAL (37) & $=$ Constant factor for the cooling water consumption, \\
\hline ; & & Mgal/hr. \\
\hline ; & REAL (38) & $=$ Cooling water consumption per Mlbs/hr of dry \\
\hline ; & & wood (Mgal/hr)/(Mlbs/hr) \\
\hline ; & REAL (39) & $=$ Constant factor for the process water consumption, \\
\hline & & Mgal/hr. \\
\hline
\end{tabular}




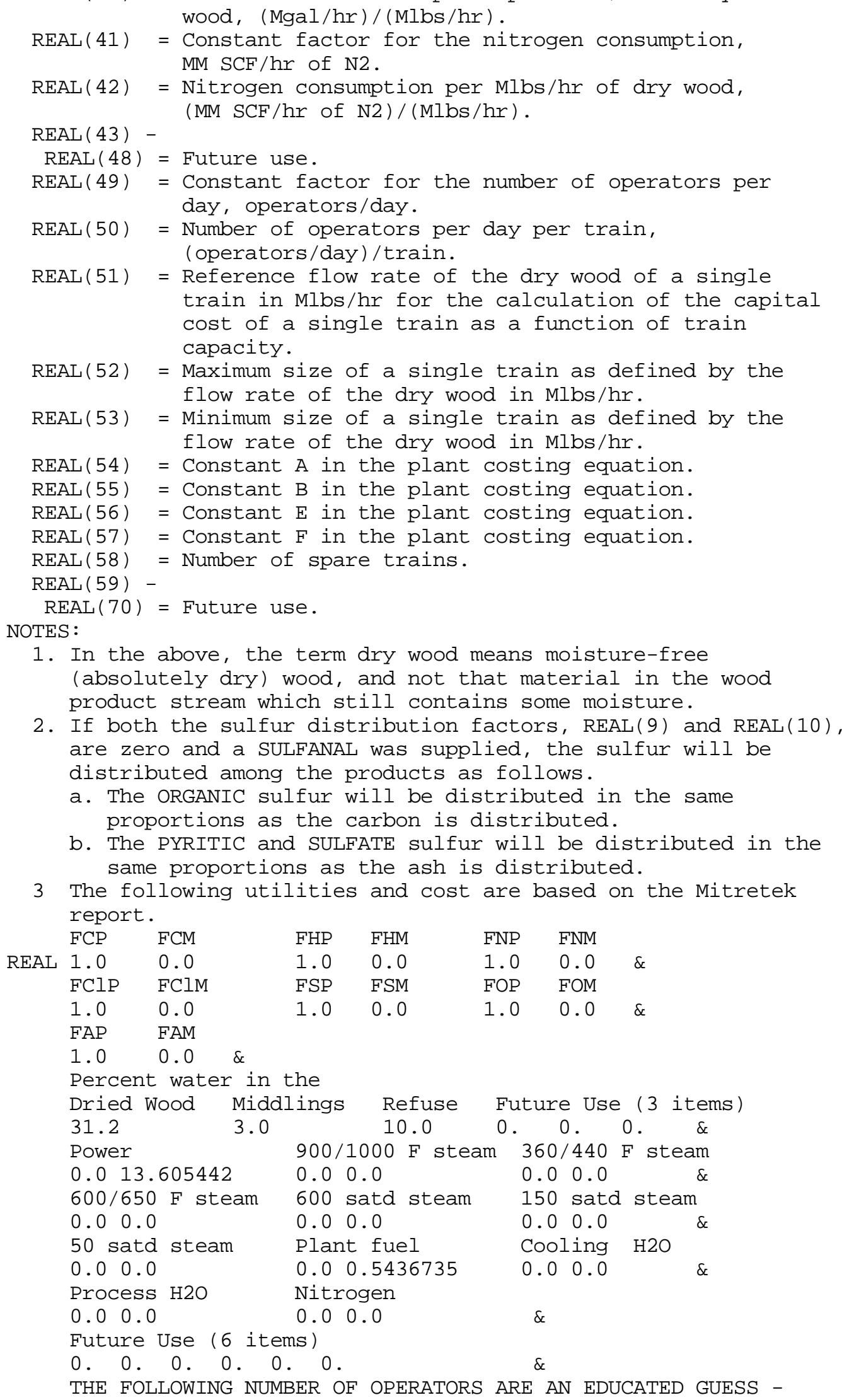

2. If both the sulfur distribution factors, REAL(9) and REAL(10), are zero and a SULFANAL was supplied, the sulfur will be distributed among the products as follows.

a. The ORGANIC sulfur will be distributed in the same proportions as the carbon is distributed.

b. The PYRITIC and SULFATE sulfur will be distributed in the same proportions as the ash is distributed.

3 The following utilities and cost are based on the Mitretek report. $\begin{array}{lllll}\text { FCP } & \text { FCM } & \text { FHP } & \text { FHM } & \text { FNP }\end{array}$

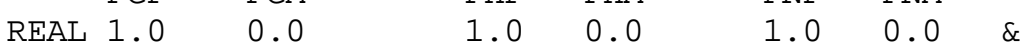

FClP FClM $\quad$ FSP $\quad$ FSM $\quad$ FOP $\quad$ FOM

$\begin{array}{lllllll}1.0 & 0.0 & 1.0 & 0.0 & 1.0 & 0.0\end{array}$

$1.0 \quad 0.0$ \&

Percent water in the

Dried Wood Middlings Refuse Future Use (3 items)

$\begin{array}{llllll}31.2 & 3.0 & 10.0 & 0 . & 0 . & 0 .\end{array}$


;

TO BE REFINED AS THE TECHNOLOGY AND DESIGN ARE DEVELOPED. Opers/day (Opers/day)/train

$\begin{array}{lll}0 . & 8 . & \\ \text { Ref Flow } & \text { Max Flow Min Flow } \\ 183.750 & 185 . & 50.0\end{array}$
Plant cost equation constants.

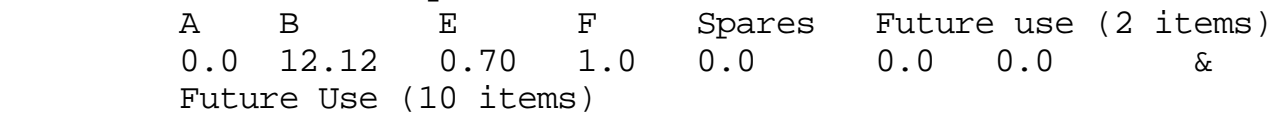
0. 0. 0. 0. 0. 0. 0. 0. 0. 0. 0 . Set the temperature and pressure of the outlet streams. These values will override the default values in subroutine USRI15. FLASH-SPECS STREAM $=115 \mathrm{~S} 1 \quad \mathrm{TP} \quad$ TEMP $=220 . \quad$ PRES $=14.7 / \%$ STREAM $=115 \mathrm{~S} 2 \quad \mathrm{TP} \quad \mathrm{TEMP}=190 . \quad \mathrm{PRES}=14.7 / \&$ STREAM $=115 \mathrm{~S} 3 \quad \mathrm{TP} \quad \mathrm{TEMP}=200 . \quad \mathrm{PRES}=14.7 / \&$ STREAM $=115 \mathrm{~S} 4 \quad \mathrm{TP} \quad \mathrm{TEMP}=210 . \quad \mathrm{PRES}=14.7$

Block P116C1 changes the stream class of the syngas stream leaving Plant 116 from an ASPEN stream of class MIXNC to an ASPEN stream of stream class CONVEN. BLOCK P116C1 CLCHNG DESCRIPTION 'CHANGES STREAM CLASS OF CLEAN COOLED SYNGAS STREAM'

;

; Block P116D - User Fortran block USRI16 to decompose the wood for ; use in the equilibrium wood gasification reactor model. In ; addition, for modeling simplicity, this block produces the char ; product stream. 


\begin{tabular}{|c|c|c|}
\hline & REAL (5) & $=$ Weight percent sulfur in the char. \\
\hline & REAL ( 6) & $=$ Percent char leaving in the gasified stream. \\
\hline & REAL ( 7) - & \\
\hline & REAL (20) & = Future use. \\
\hline & REAL (21) & $=$ Constant factor for the power consumption, \\
\hline & REAL (22) & $=$ Power consumption per Mlbs/hr of dry wood, \\
\hline & & $\mathrm{kw} /($ Mlbs/hr of dry wood) \\
\hline & REAL (23) & = Constant factor for the 975 psig / 750 F steam \\
\hline & & consumption, Mlbs/hr. \\
\hline & REAL (24) & $=975$ psig / 750 F steam consumption per Mlbs/hr of \\
\hline & & dry wood, (Mlbs/hr)/(Mlbs/hr of dry wood). \\
\hline & & This steam goes directly to the combined cycle \\
\hline & & plant for power production. \\
\hline & REAL (25) & $=$ Constant factor for the 360 psig / 530 F steam \\
\hline & & consumption, Mlbs/hr. \\
\hline & REAL (26) & $=360$ psig / 530 F steam consumption per Mlbs/hr \\
\hline & & of dry wood, (Mlbs/hr)/(Mlbs/hr of dry wood). \\
\hline & & This steam goes directly to the combined cycle \\
\hline & & plant for power production. \\
\hline & REAL (27) & $=$ Constant factor for the 600 psig / $650 \mathrm{~F}$ steam \\
\hline & & consumption, Mlbs/hr. \\
\hline & REAL (28) & $=600$ psig / $650 \mathrm{~F}$ steam consumption per Mlbs/hr of \\
\hline & & dry wood, (Mlbs/hr)/(Mlbs/hr of dry wood) \\
\hline & REAL (29) & $=$ Constant factor for the 600 psig saturated steam \\
\hline & & consumption, Mlbs/hr. \\
\hline & REAL (30) & $=600$ psig saturated steam consumption per Mlbs/hr \\
\hline & & of dry wood, (Mlbs/hr)/(Mlbs/hr of dry wood). \\
\hline & REAL (31) & $=$ Constant factor for the 150 psig saturated steam \\
\hline & & consumption, Mlbs/hr. \\
\hline & REAL (32) & $=150$ psig saturated steam consumption per Mlbs/hr \\
\hline & & of dry wood, (Mlbs/hr)/(Mlbs/hr of dry wood). \\
\hline & REAL (33) & $=$ Constant factor for the 50 psig saturated steam \\
\hline & & consumption, Mlbs/hr. \\
\hline & REAL (34) & $=50$ psig saturated steam consumption per Mlbs/hr \\
\hline & & of dry wood, (Mlbs/hr)/(Mlbs/hr of dry wood). \\
\hline & REAL (35) & $=$ Constant factor for the plant fuel consumption, \\
\hline & & MM BTU/hr. \\
\hline & REAL (36) & $=$ Plant fuel consumption per Mlbs/hr of dry wood, \\
\hline & & $(\mathrm{MM} \mathrm{BTU} / \mathrm{hr}) /(\mathrm{Mlbs} / \mathrm{hr}$ of dry wood) \\
\hline & REAL (37) & $=$ Constant factor for the cooling water consumption, \\
\hline & & Mgal/hr. \\
\hline & REAL (38) & $=$ Cooling water consumption per Mlbs/hr of unit \\
\hline & & feed, (Mgal/hr)/(Mlbs/hr of dry wood) \\
\hline & REAL (39) & $=$ Constant factor for the process water consumption, \\
\hline & & Mgal/hr. \\
\hline & REAL ( 40 ) & $=$ Process water consumption per Mlbs/hr of unit \\
\hline & & feed, (Mgal/hr)/(Mlbs/hr of dry wood). \\
\hline & REAL ( 41 ) & $=$ Constant factor for the nitrogen consumption, \\
\hline & & MM SCF/hr of N2. \\
\hline & REAL ( 42 ) & $=$ Nitrogen consumption per Mlbs/hr of dry wood, \\
\hline & & (MM SCF/hr of N2)/(Mlbs/hr of dry wood). \\
\hline & REAL ( 43) & \\
\hline & REAL (48) & $=$ Future use. \\
\hline & REAL ( 49) & $=$ Constant factor for the number of operators per \\
\hline & & day, operators/day. \\
\hline & REAL (50) & $=$ Number of operators per day per train, \\
\hline & & (operators/day)/train. \\
\hline & REAL ( 51 ) & $=$ Reference feed rate to a single train in Mlbs/hr \\
\hline & & of dry wood for the calculation of the ISBL field \\
\hline & & cost of a single train as a function of train \\
\hline
\end{tabular}




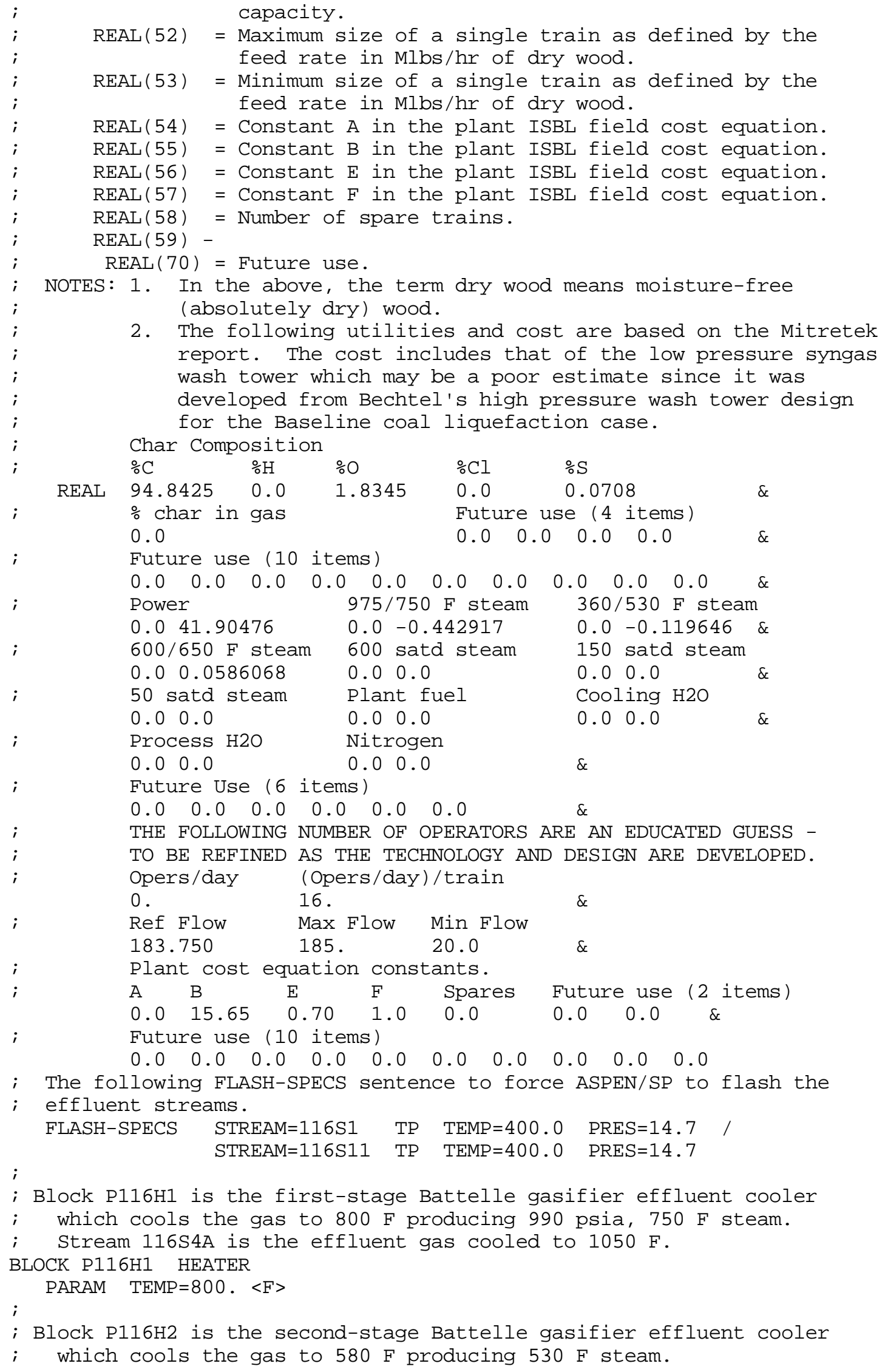


; Stream 116S4B is the effluent gas cooled to $590 \mathrm{~F}$.

BLOCK P116H2 HEATER

PARAM TEMP $=580 . \quad\langle\mathrm{F}>$

;

; Block P116M is a mixer to mix the gasified decomposed wood stream

; with the other gasifier feed streams.

BLOCK P116M MIXER

DESCRIPTION 'PLANT 116 - WOOD GASIFIER INLET STREAM MIXER'

;

; Blocks P116R1 and P116R2 are two RSTOICH reactors which model the

; yields produced by the Battelle gasifier as given in the Mitretek

; Report MP 96W0000065, January 1996. The tar is represented by a

; mixture of benzene and $\mathrm{C} 10 \mathrm{H} 20$. An RGIBBS equilibrium reactor model

; could not be adjusted to match the reported gasifier yields.

; Block P116R1 is the first-stage carbon burner reactor which converts

; some of the pseudo $\mathrm{C}$ (carbon) to $\mathrm{CO}, \mathrm{CO} 2$, methane, ethylene and

; tar $\mathrm{C} 10 \mathrm{H} 20$ ) to match the adjusted Mitretek yields.

; Stream 116S3 is the first-stage reactor outlet stream.

BLOCK P116R1 RSTOIC

DESCRIPTION 'PLANT 116 - FIRST PRELIMINARY GASIFIER (C BURNER) REACTOR'

PARAM TEMP $=1595$ PRES $=14.7 \mathrm{KODE}=2$

STOICH 1 MIXED C $-1 /$ H2 -2 / $\mathrm{CH} 4 \quad 1$

STOICH 2 MIXED C -2 / $\mathrm{H} 2-2$ / $22 \mathrm{H} 41$

STOICH 3 MIXED C $-10 / \mathrm{H} 2-10$ / C10H20 1

STOICH 4 MIXED C -6 / $\mathrm{H} 2-3$ / C6A 1

STOICH 5 MIXED C $-1 / \mathrm{O}_{2}-1 / \mathrm{CO} 2 \quad 1$

STOICH 6 MIXED C -2 / O2 -1 / CO 2

$\begin{array}{lllll}\text { CONV } & 1 & \text { MIXED } & \mathrm{C} & 0.179501289\end{array}$

$\begin{array}{lllll}\text { CONV } & 2 & \text { MIXED } & \mathrm{C} & 0.145844798\end{array}$

$\begin{array}{llll}\text { CONV } 3 & \text { MIXED } & \mathrm{C} & 0.028064877\end{array}$

CONV 4 MIXED C 0.001507811

CONV 5 MIXED C 0.074418243

$\begin{array}{lllll}\text { CONV } & 6 & \text { MIXED } & \mathrm{C} & 0.570662982\end{array}$

; Block P116R2 is the second-stage reactor which converts the

; remaining oxygen to water.

BLOCK P116R2 RSTOIC

DESCRIPTION 'PLANT 116 - 2ND GASIFIER REACTOR'

PARAM TEMP $=1595$ PRES $=14.7 \mathrm{KODE}=2$

STOICH 1 MIXED $\mathrm{H} 2-2 / \mathrm{O} 2-1 / \mathrm{H} 2 \mathrm{O} 2$

CONV $\quad 1$ MIXED O2 1.0

;

; Block P116S1 is the water quench section which washes and cools the

; hot syngas stream. This splitter block ignores the quench water. BLOCK P116S1 SEP

DESCRIPTION 'SEP BLOCK SIMULATION OF WATER QUENCH SECTION'

FRAC SUBSTREAM $=$ MIXED STREAM $=116 \mathrm{~S} 5 \quad \mathrm{COMP}=\mathrm{H} 20 \mathrm{C} 10 \mathrm{H} 20 \mathrm{C} 6 \mathrm{~A} \&$

FRACS $=0.54632260 .991 .0$

SUBSTREAM $=\mathrm{NC} \quad$ STREAM=116S5 $\quad \mathrm{COMP}=\mathrm{CHAR} \quad$ FRACS $=1.0$

; NOTE; Syngas vapor stream outlet temperature increased by 5 degrees

; from Mitretek value to maintain an all vapor stream.

FLASH-SPECS 116S5 TEMP $=165.0 \quad \mathrm{PRES}=14.7 \quad$ /

$116 \mathrm{~S} 6 \quad \mathrm{TEMP}=156.0 \quad \mathrm{PRES}=14.7$

;

; Block P116S2 produces the solids waste stream (slag) and a char

; stream which is burned in the combustor. This block sets the

; correct waste solids stream flow rate, but does not set the

; correct compositional analysis of the SLAG stream.

BLOCK P116S2 FSPLIT 


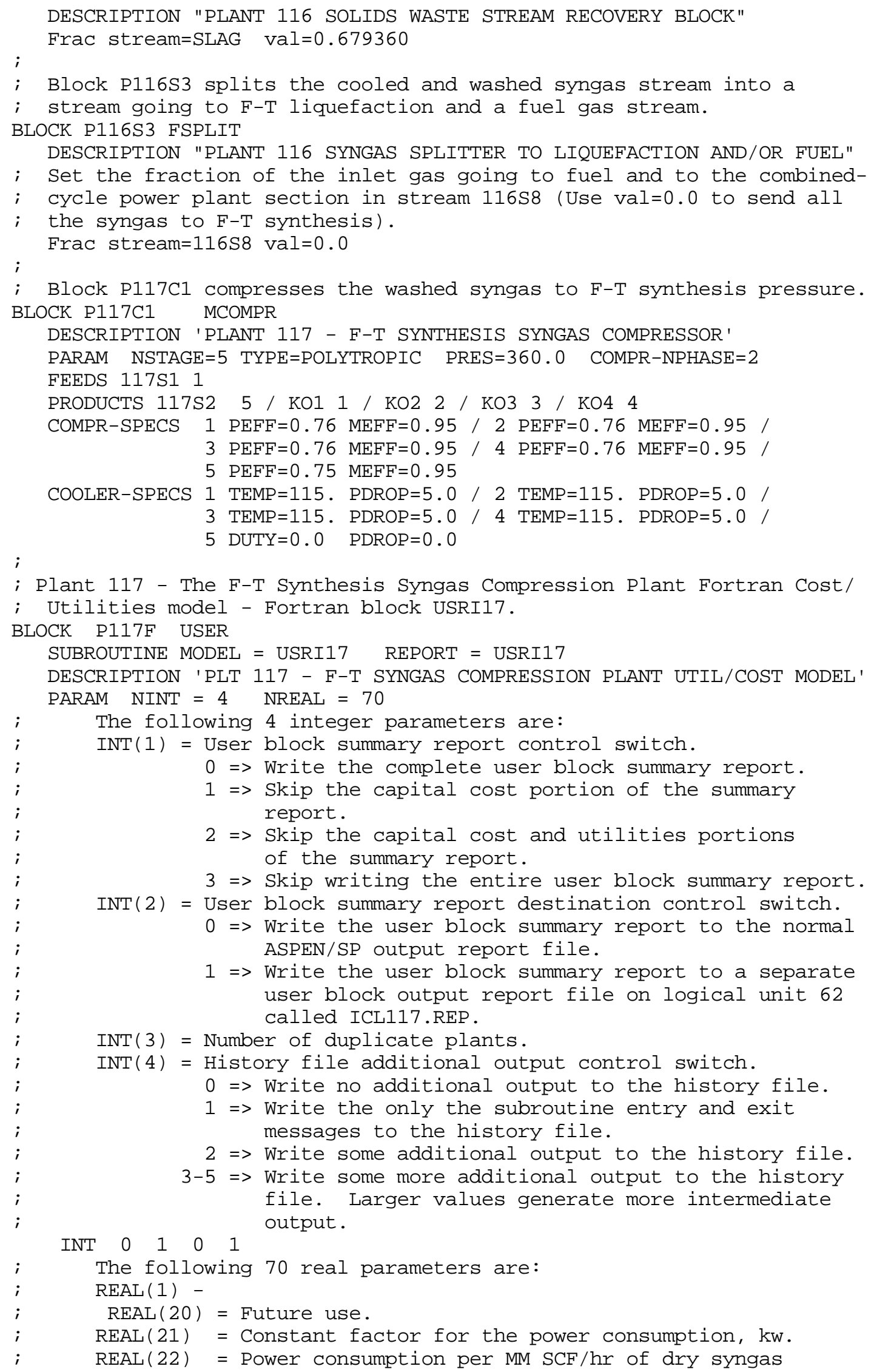


compressor feed, kw/(MM SCF/hr of dry feed)

REAL (23) = Constant factor for the 900 psig/ 1000 F steam consumption, Mlbs/hr.

REAL (24) = 900 psig / $1000 \mathrm{~F}$ steam consumption per MM SCF/hr of dry syngas compressor feed, (Mlbs/hr)/(MM SCF/hr of dry feed).

REAL (25) = Constant factor for the 360 psig / $440 \mathrm{~F}$ steam consumption, Mlbs/hr.

$\operatorname{REAL}(26)=360 \mathrm{psig} / 440 \mathrm{~F}$ steam consumption per $\mathrm{MM} \mathrm{SCF} / \mathrm{hr}$ of dry syngas compressor feed, (Mlbs/hr)/(MM SCF/hr of dry feed).

REAL(27) = Constant factor for the 600 psig / $650 \mathrm{~F}$ steam consumption, Mlbs/hr.

$\operatorname{REAL}(28)=600 \mathrm{psig} / 650 \mathrm{~F}$ steam consumption per $\mathrm{MM} \mathrm{SCF} / \mathrm{hr}$ of dry syngas compressor feed, (Mlbs/hr)/(MM SCF/hr of dry feed).

REAL(29) = Constant factor for the 600 psig saturated steam consumption, Mlbs/hr.

REAL (30) = 600 psig saturated steam consumption per MM SCF/hr of dry syngas compressor feed, (Mlbs/hr)/(MM SCF/hr of dry feed).

REAL (31) = Constant factor for the 150 psig saturated steam consumption, Mlbs/hr.

REAL (32) = 150 psig saturated steam consumption per MM SCF/hr of dry syngas compressor feed, (Mlbs/hr)/(MM SCF/hr of dry feed).

REAL(33) = Constant factor for the 50 psig saturated steam consumption, Mlbs/hr.

REAL (34) = 50 psig saturated steam consumption per MM SCF/hr of dry syngas compressor feed, (Mlbs/hr)/(MM SCF/hr of dry feed).

REAL(35) = Constant factor for the plant fuel consumption, $\mathrm{MM} \mathrm{BTU/hr.}$

REAL(36) = Plant fuel consumption per MM SCF/hr of dry syngas compressor feed, (MM BTU/hr)/(MM SCF/hr of dry feed).

REAL (37) = Constant factor for the cooling water consumption, Mgal/hr.

REAL(38) = Cooling water consumption per MM SCF/hr of dry syngas compressor feed, (Mgal/hr)/(MM SCF/hr of dry feed).

REAL(39) = Constant factor for the process water consumption, Mgal/hr.

REAL (40) = Process water consumption per MM SCF/hr of dry syngas compressor feed, (Mgal/hr)/(MM SCF/hr of dry feed).

REAL(41) = Constant factor for the nitrogen consumption, MM SCF/hr of N2.

REAL (42) = Nitrogen consumption per MM SCF/hr of dry syngas compressor feed, (MM SCF/hr of N2)/(MM SCF/hr of dry feed).

REAL (43) -

REAL (48) = Future use.

REAL (49) = Constant factor for the number of operators per day, operators/day.

REAL (50) = Number of operators per day per train, (operators/day)/train.

REAL(51) = Reference feed rate to a single train in MM SCF/hr of dry syngas compressor feed for the calculation of the ISBL field cost of a single train as a function of train capacity.

REAL(52) = Maximum size of a single train as defined by the feed rate in MM SCF/hr of dry sungas compressor feed. 


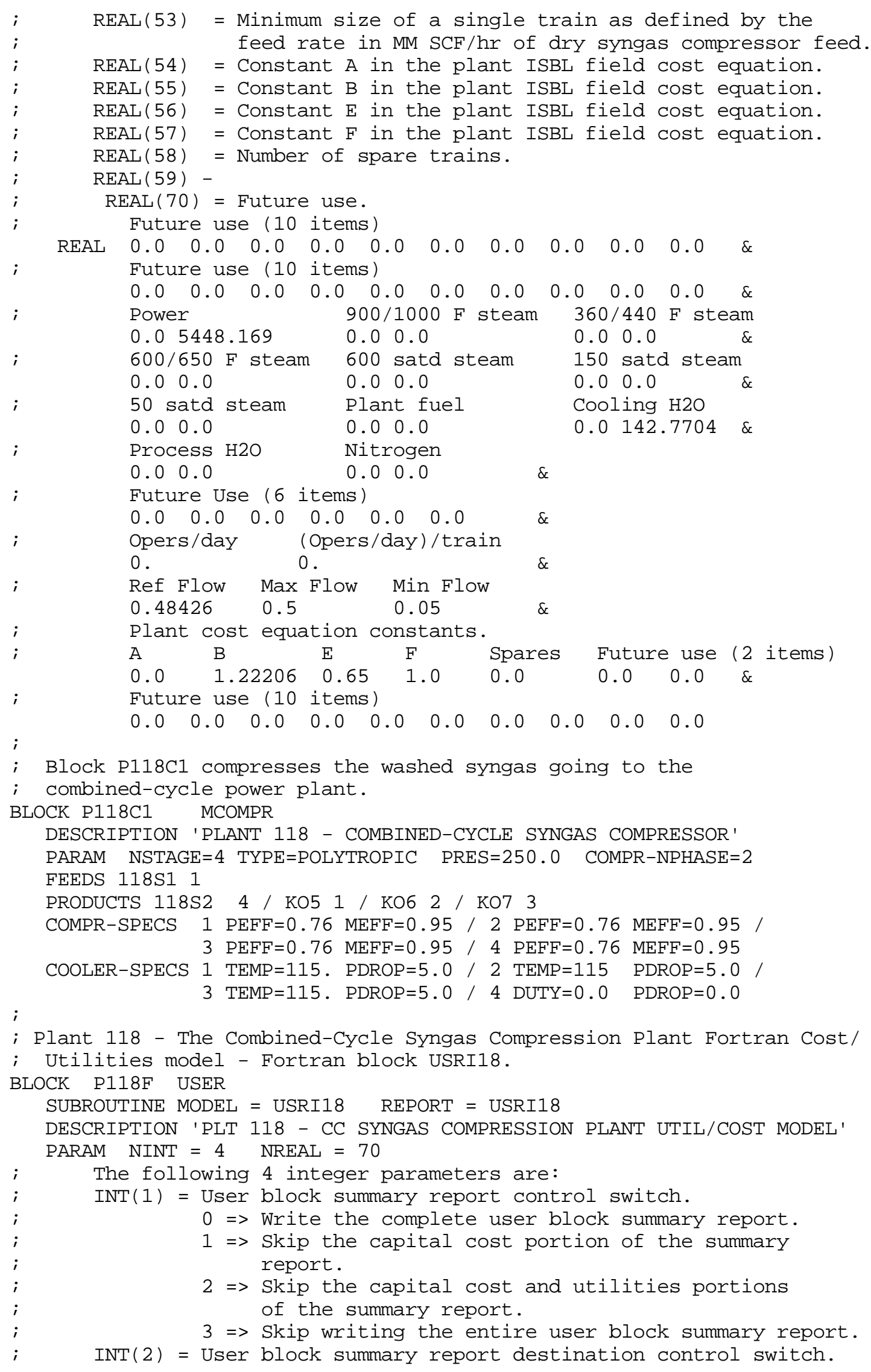


$0=>$ Write the user block summary report to the normal ASPEN/SP output report file.

1 => Write the user block summary report to a separate user block output report file on logical unit 62 called ICL118.REP.

REAL(39) = Constant factor for the process water consumption, 


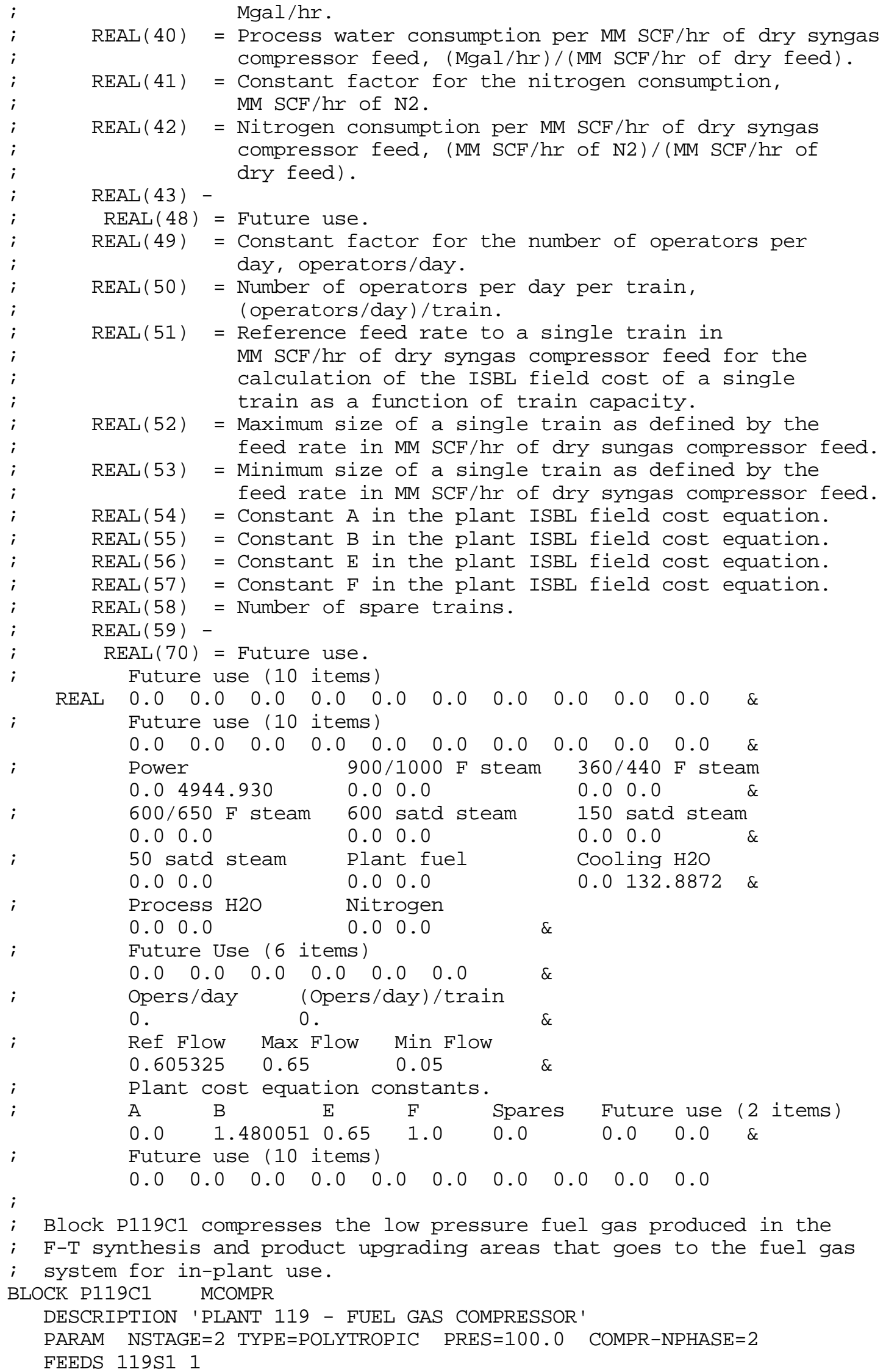


PRODUCTS 119S2 2 / KO8 1

COMPR-SPECS $1 \mathrm{PEFF}=0.76 \mathrm{MEFF}=0.95 / 2 \mathrm{PEFF}=0.76 \mathrm{MEFF}=0.95$

COOLER-SPECS $1 \mathrm{TEMP}=115 . \mathrm{PDROP}=5.0 / 2 \mathrm{DUTY}=0.0 \mathrm{PDROP}=0.0$

i

; Plant 119 - The Fuel Gas Compression Plant Fortran Cost/

; Utilities model - Fortran block USRI19.

BLOCK P119F USER

SUBROUTINE MODEL = USRI19 REPORT = USRI19

DESCRIPTION 'PLT 119 - FUEL GAS COMPRESSION PLANT UTIL/COST MODEL'

PARAM NINT $=4$ NREAL $=70$

i

The following 4 integer parameters are:

INT(1) = User block summary report control switch.

$0=>$ Write the complete user block summary report.

$1=>$ Skip the capital cost portion of the summary report.

$2=>$ Skip the capital cost and utilities portions of the summary report.

3 => Skip writing the entire user block summary report.

INT(2) = User block summary report destination control switch.

$0=>$ Write the user block summary report to the normal ASPEN/SP output report file.

1 => Write the user block summary report to a separate user block output report file on logical unit 62 called ICL119.REP.

INT (3) = Number of duplicate plants.

INT(4) = History file additional output control switch.

$0=>$ Write no additional output to the history file.

1 => Write the only the subroutine entry and exit messages to the history file.

2 => Write some additional output to the history file.

3-5 => Write some more additional output to the history file. Larger values generate more intermediate output.

INT $\quad 0 \quad 1 \quad 001$

The following 70 real parameters are:

REAL (1) -

REAL (20) = Future use.

REAL (21) = Constant factor for the power consumption, kw.

REAL (22) = Power consumption per MM SCE/hr of dry syngas compressor feed, kw/(MM SCF/hr of dry feed)

REAL (23) = Constant factor for the 900 psig / 1000 F steam consumption, Mlbs/hr.

REAL (24) = 900 psig / $1000 \mathrm{~F}$ steam consumption per MM SCF/hr of dry syngas compressor feed, (Mlbs/hr)/(MM SCF/hr of dry feed).

REAL (25) = Constant factor for the 360 psig / $440 \mathrm{~F}$ steam consumption, Mlbs/hr.

REAL (26) = 360 psig / $440 \mathrm{~F}$ steam consumption per $\mathrm{MM} \mathrm{SCF} / \mathrm{hr}$ of dry syngas compressor feed, (Mlbs/hr)/(MM SCF/hr of dry feed).

REAL (27) = Constant factor for the 600 psig / 650 F steam consumption, Mlbs/hr.

REAL (28) = 600 psig / $650 \mathrm{~F}$ steam consumption per $\mathrm{MM} \mathrm{SCF/hr}$ of dry syngas compressor feed, (Mlbs/hr)/(MM SCF/hr of dry feed).

REAL (29) = Constant factor for the 600 psig saturated steam consumption, Mlbs/hr.

REAL (30) = 600 psig saturated steam consumption per $\mathrm{MM} \mathrm{SCF} / \mathrm{hr}$ of dry syngas compressor feed, (Mlbs/hr)/(MM SCF/hr of dry feed). 


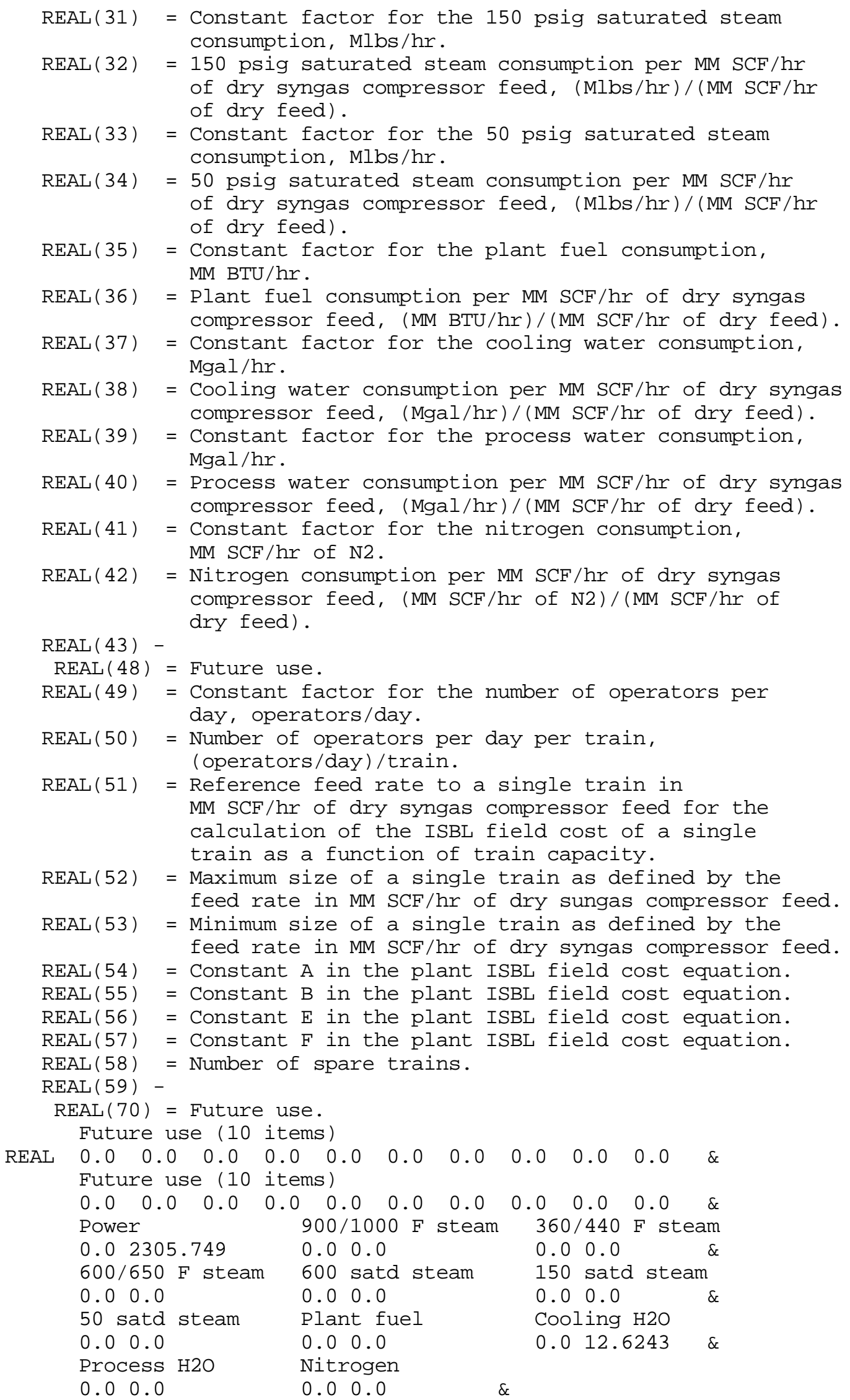




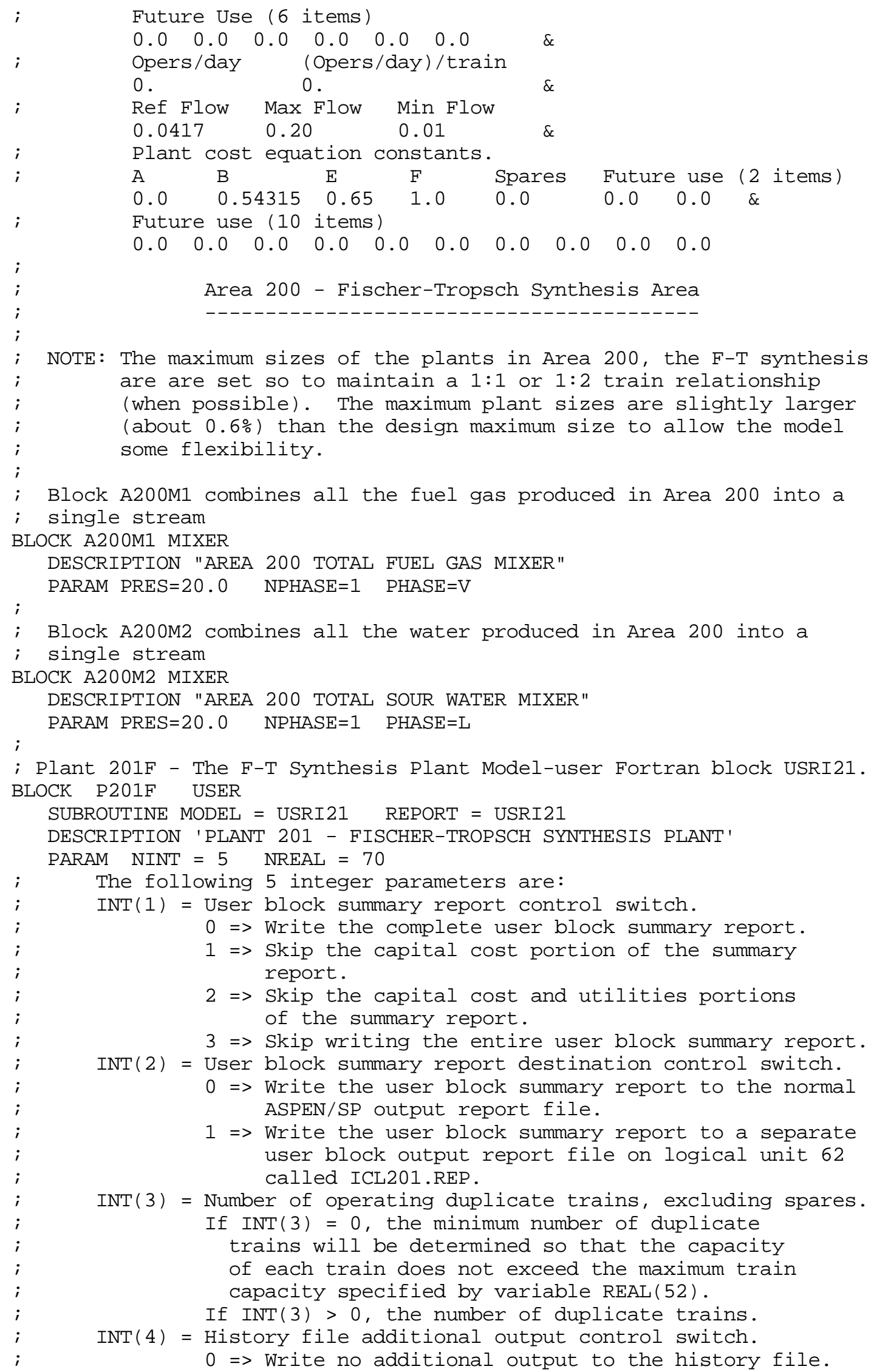


$1=>$ Write the only the subroutine entry and exit messages and the detailed reactor sizing information to the history file.

2 => Write the elemental balance information and some additional output to the history file.

3-5 => Write some more additional output to the history file. Larger values generate more intermediate output.

INT(5) = Switch to control the equipment sizing and costing for this plant. When the $\mathrm{F}-\mathrm{T}$ reactors are sized, the plant costs are calculated based on the reactor sizing results; otherwise, they are based on the overall cost model that is used for all the other plants.

$0 \Rightarrow$ Do NOT size the $\mathrm{F}-\mathrm{T}$ reactors and use the special costing method based on the reactor sizes. Cost the plant based on the total plant cost equation constants in the REAL (51) - REAL (58) parameters.

$1=>$ Write the reactor sizing results to the plant summary report file.

2 => Also write the sizes of the other pieces of major equipment in this plant based on the baseline design to the summary report file.

3 => Also write the sizes of the other pieces of major equipment in this plant using wax $\begin{array}{llllll}\text { INT } & 0 & 1 & 0 & 2 & 2\end{array}$ filters for the catalyst/wax separation.

The following 70 real parameters are:

REAL (1) = Wax yield in weight percent. (Valid values are between 9.6 and 76 wt\% wax)

REAL (2) = H2 conversion, wt\%

REAL(3) = Mole fraction olefins in the C7-C19 olefin/paraffin hydrocarbons.

$\operatorname{REAL}(4) \quad=$ Future use.

REAL (6) = Future use.

$\operatorname{REAL}(6) \quad=$ Future use.

REAL (7) = Temperature approach in water gas shift reaction in Celsius degrees.

REAL (8) = Future use.

REAL (9) = Reactor pressure drop, psi.

REAL (10) = Number of spare F-T slurry bed reactors in the entire plant not associated with a specific plant train (MUST have an integer value).

REAL(11) = Number of $\mathrm{F}-\mathrm{T}$ parallel slurry bed reactors per plant train (MUST have an integer value).

REAL(12) = F-T reactor slurry bed inlet gas velocity, $\mathrm{cm} / \mathrm{sec}$.

REAL (13) $=\mathrm{F}-\mathrm{T}$ reactor catalyst concentration in the slurry, wto.

REAL (14) = F-T catalyst makeup rate, of catalyst inventory per day. SEE NOTE 1.

REAL (15) = Temperature of steam generated in tubes of the $\mathrm{F}-\mathrm{T}$ slurry bed reactor, F.

REAL (16) = Pressure of steam generated in tubes of the $\mathrm{F}-\mathrm{T}$ slurry bed reactor, psig.

REAL (17) = Relative catalyst activity, i i.e., catalyst activity relative to that of the baseline design case.

$\operatorname{REAL}(18) \quad-$

REAL (20) = Future use.

REAL (21) = Constant factor for the power consumption, $\mathrm{kw}$. 


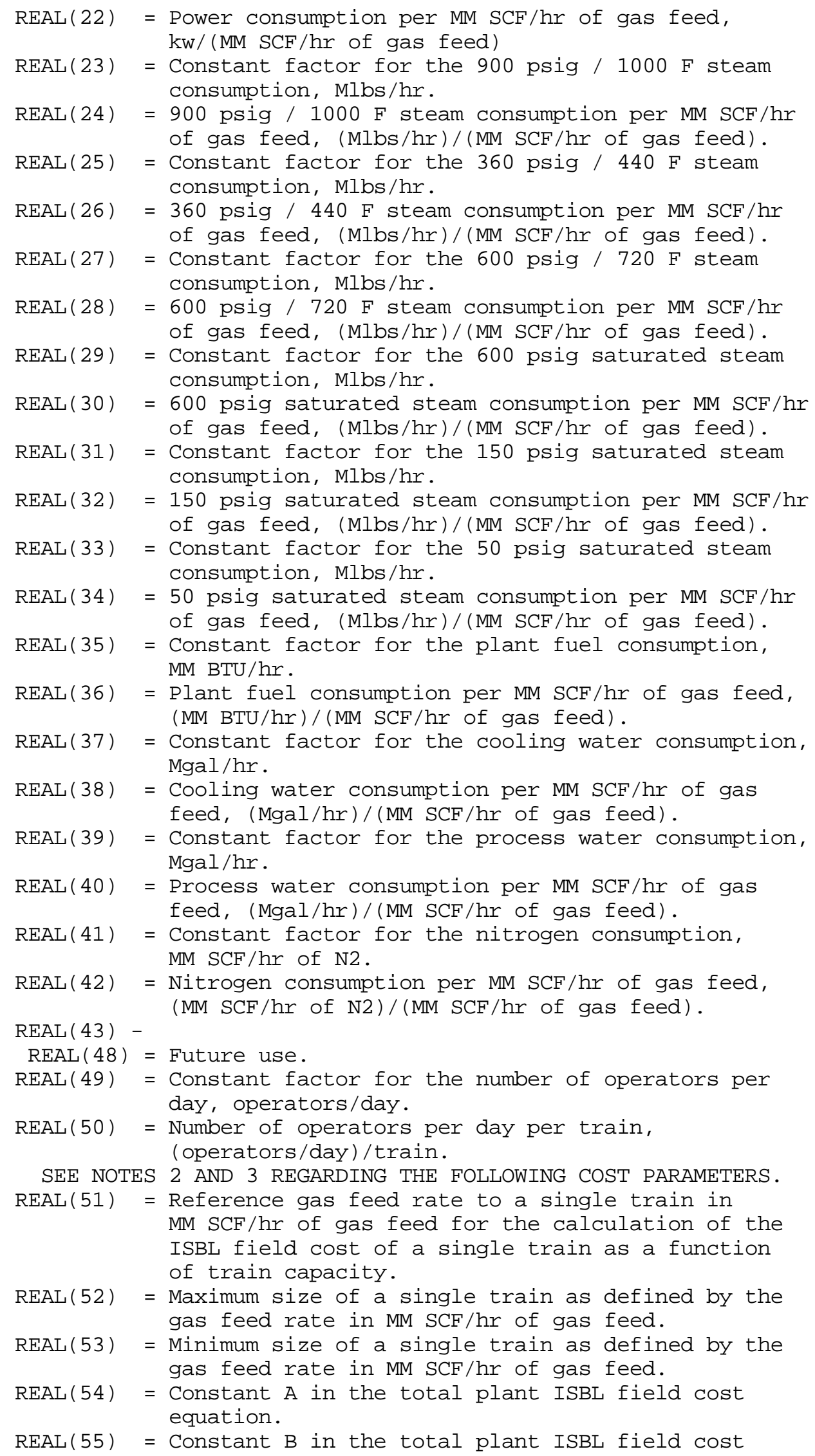


equation - SEE NOTE 3..

REAL (56) = Constant $\mathrm{E}$ in the total plant ISBL field cost equation.

REAL (57) = Constant $\mathrm{F}$ in the total plant ISBL field cost equation.

REAL (58) = Number of duplicate spare complete plant trains.

REAL (59) = Reference weight of a single $\mathrm{F}-\mathrm{T}$ slurry reactor vessel in Mlbs for the estimation of the cost of a single reactor vessel as a function of weight.

REAL (60) = Cost of a single $\mathrm{F}-\mathrm{T}$ slurry reactor vessel in MMS having the weight given above in REAL(59) .

REAL (61) = ISBL cost of a single F-T slurry bed reactor system and its closely associated accesories in MM\$ for a reactor vessel having the weight given above in REAL(59). (Such items include the foundation, instrumentation, piping, etc.)

REAL (62) = ISBL cost of the peripheral equipment in MM\$ associated with each slurry bed $\mathrm{F}-\mathrm{T}$ reactor vessel having the weight given above in REAL(59). (Such items may be cyclones, hydroclones, steam drums, etc.)

REAL(63) = ISBL cost of all the other equipment in MM\$ in a single $\mathrm{F}-\mathrm{T}$ plant train not covered in the

$\operatorname{REAL}(64) \quad-$ REAL $(70)=$ Future use.

NOTES: The following parameters are for the BASE Battelle gasifier design processing maple wood chips and were adapted from those for the baseline Illinois No. coal case.

1. The baseline plant design has a makeup catalyst rate of $0.5 \%$ of the catalyst inventory per day, which costs $10.51 \mathrm{MM} /$ year. If the catalyst makeup rate is changed, then the catalyst and chemicals cost in inline Fortran block SUMALT should be changed appropriately. Also, to be absolutely rigorous, the ISBL cost for Plant 201 should be adjusted appropriately for the revised capacities of the catalyst preparation and disposal sections. For the baseline plant design, the ISBL cost of these sections is $3.94 \mathrm{MM}$ for all 8 trains, or $0.4925 \mathrm{MM} /$ train. Thus, if the catalyst makeup rate is doubled and assuming a linear cost/ capacity relationship, then the following B cost parameter should be increased by $0.4925 \mathrm{MM}$. The same adjustment also should be made to the other equipment parameter (REAL(63)).

2. There are two methods for calculating the cost of Plant 201 . If the $\mathrm{F}-\mathrm{T}$ reactor size is NOT calculated, the total ISBL plant cost is calculated using the REAL(54) - REAL (58) parameters in the same manner as the other plants by the general cost scaling equation. If the $F-T$ reactor size is calculated, then a more detailed method is used which sizes and costs the reactors, then adds the cost of the peripheral equipment associated with each reactor, and then finds the cost of all the other items in each train with the general cost scaling equation.

3. The baseline plant design has 8 parallel Fischer-Tropsch reactor trains, each train containing 3 reactors. In addition there is one spare $\mathrm{F}-\mathrm{T}$ reactor for all trains giving a total of $25 \mathrm{~F}-\mathrm{T}$ reactors. The installed ISBL cost of this spare reactor and its associated peripherals and related equipment is $6.07168 \mathrm{MM}$. In the total plant cost scaling equation using the REAL(54)-Real (58) parameters, 


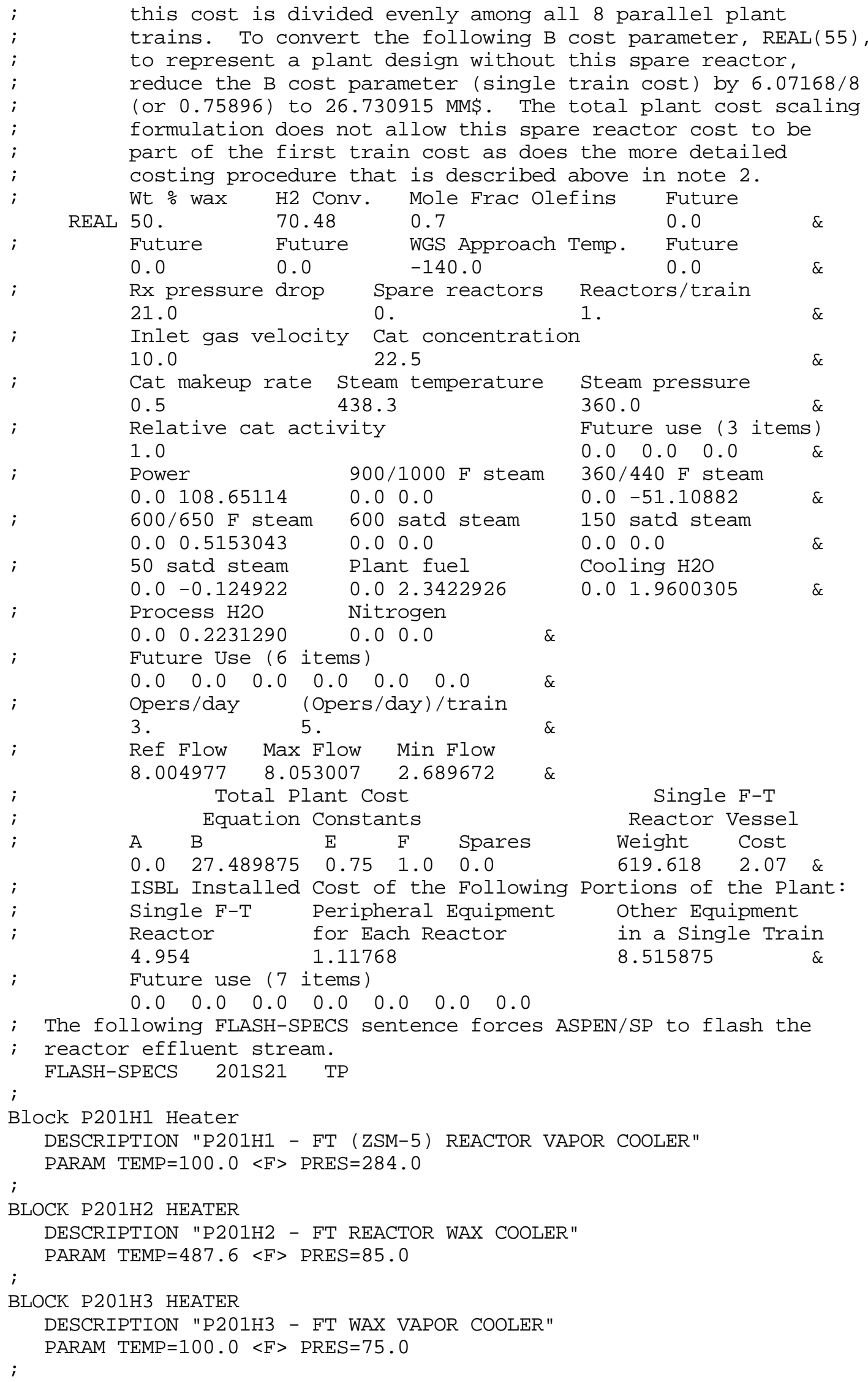




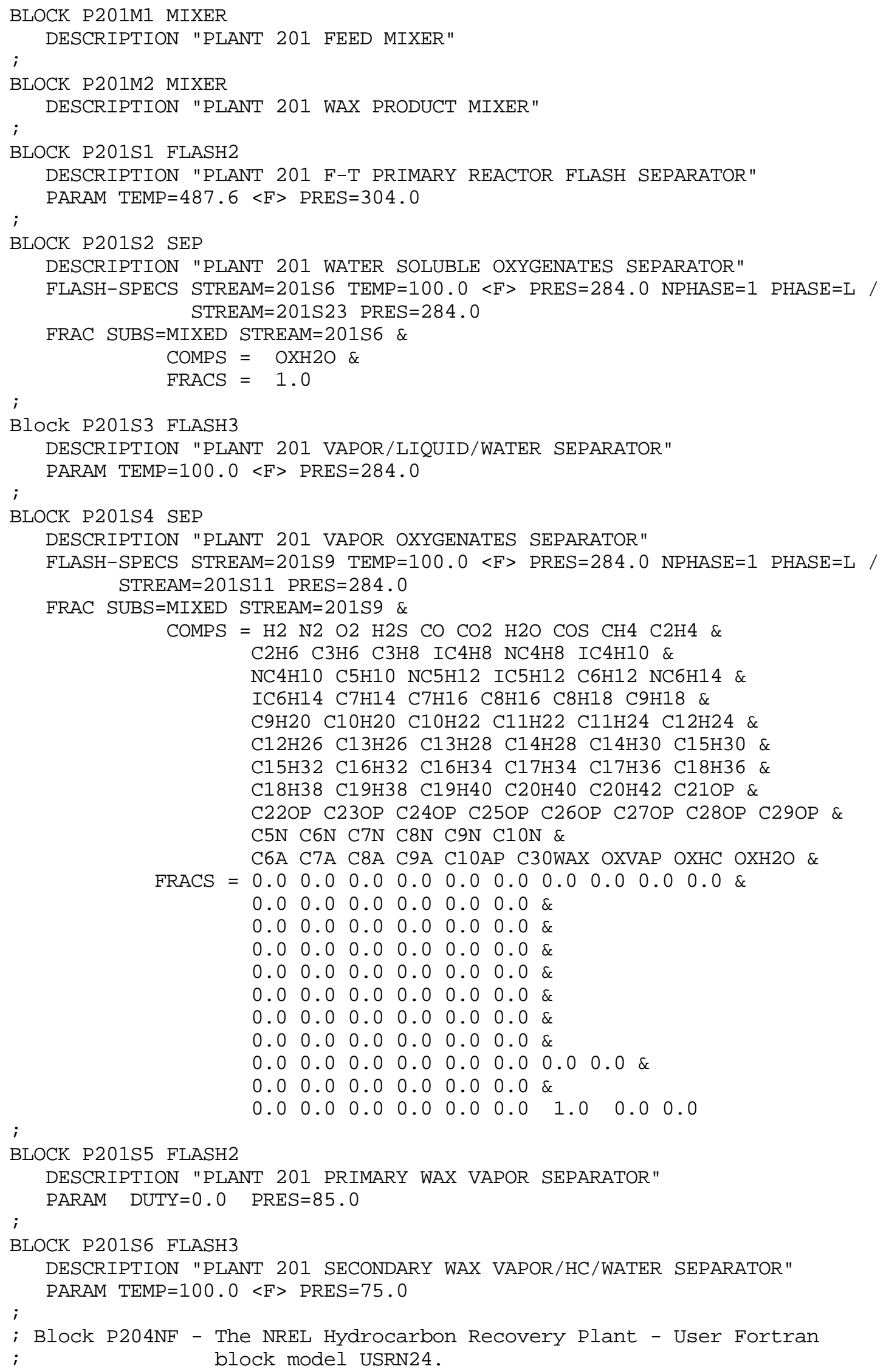




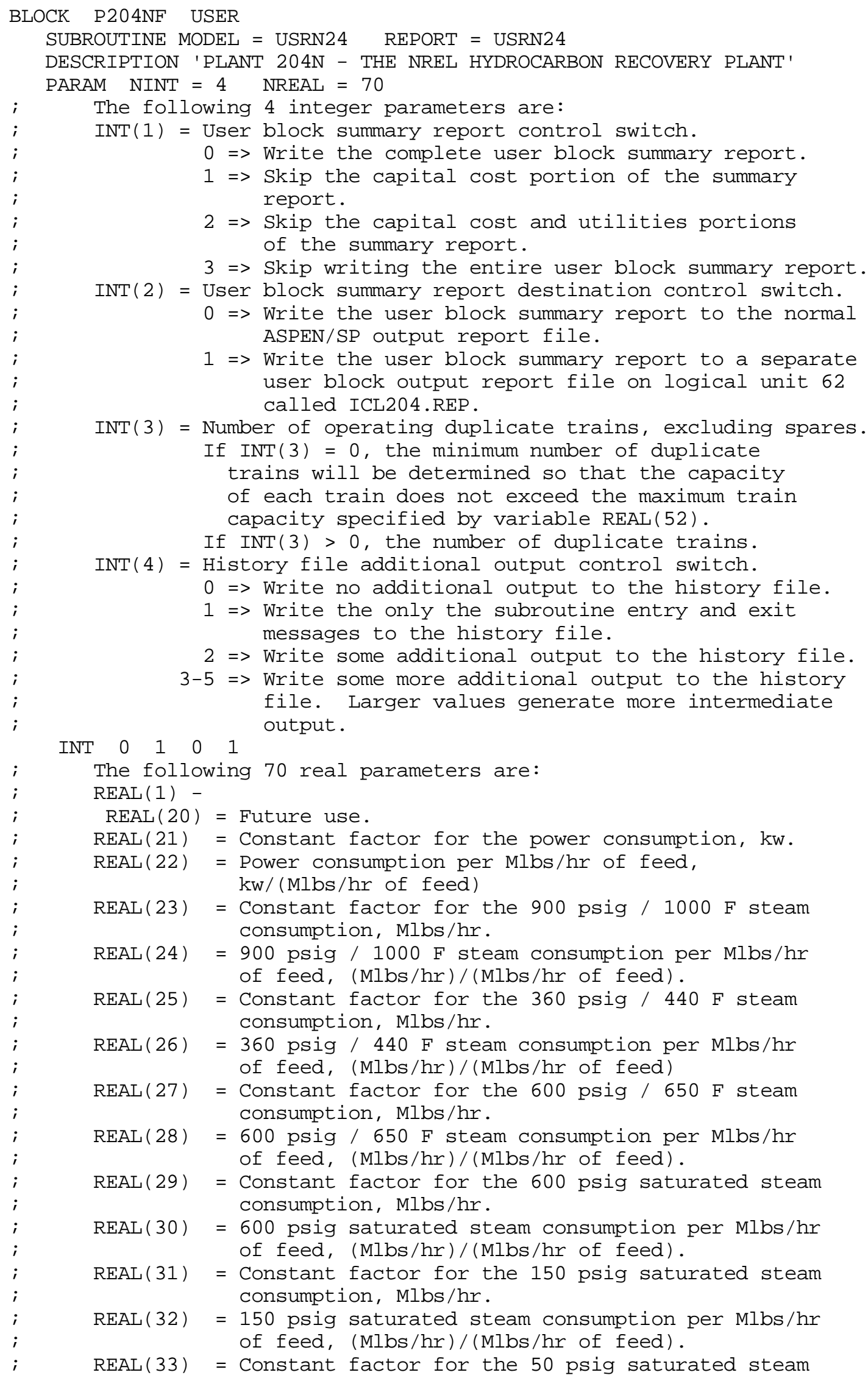




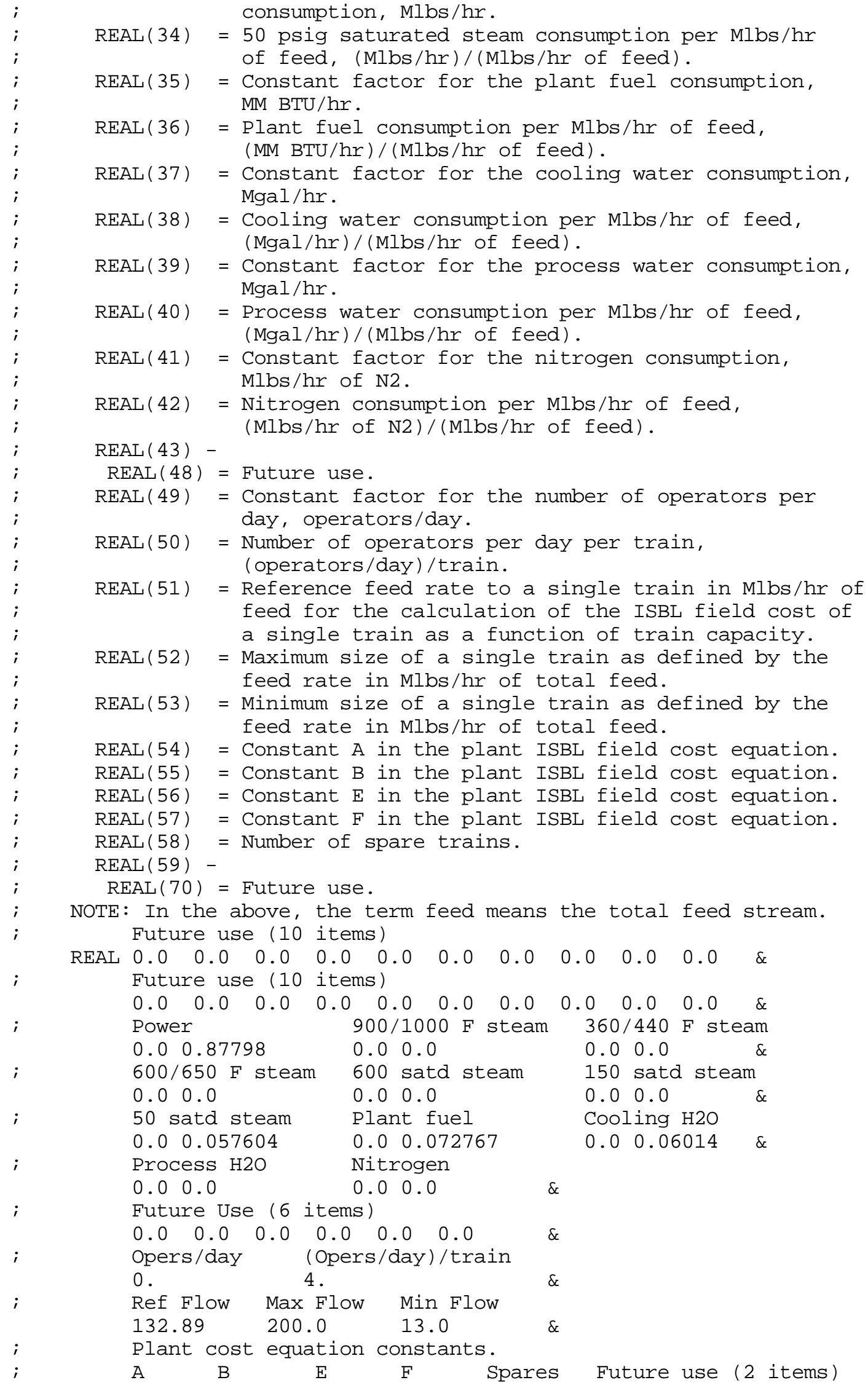




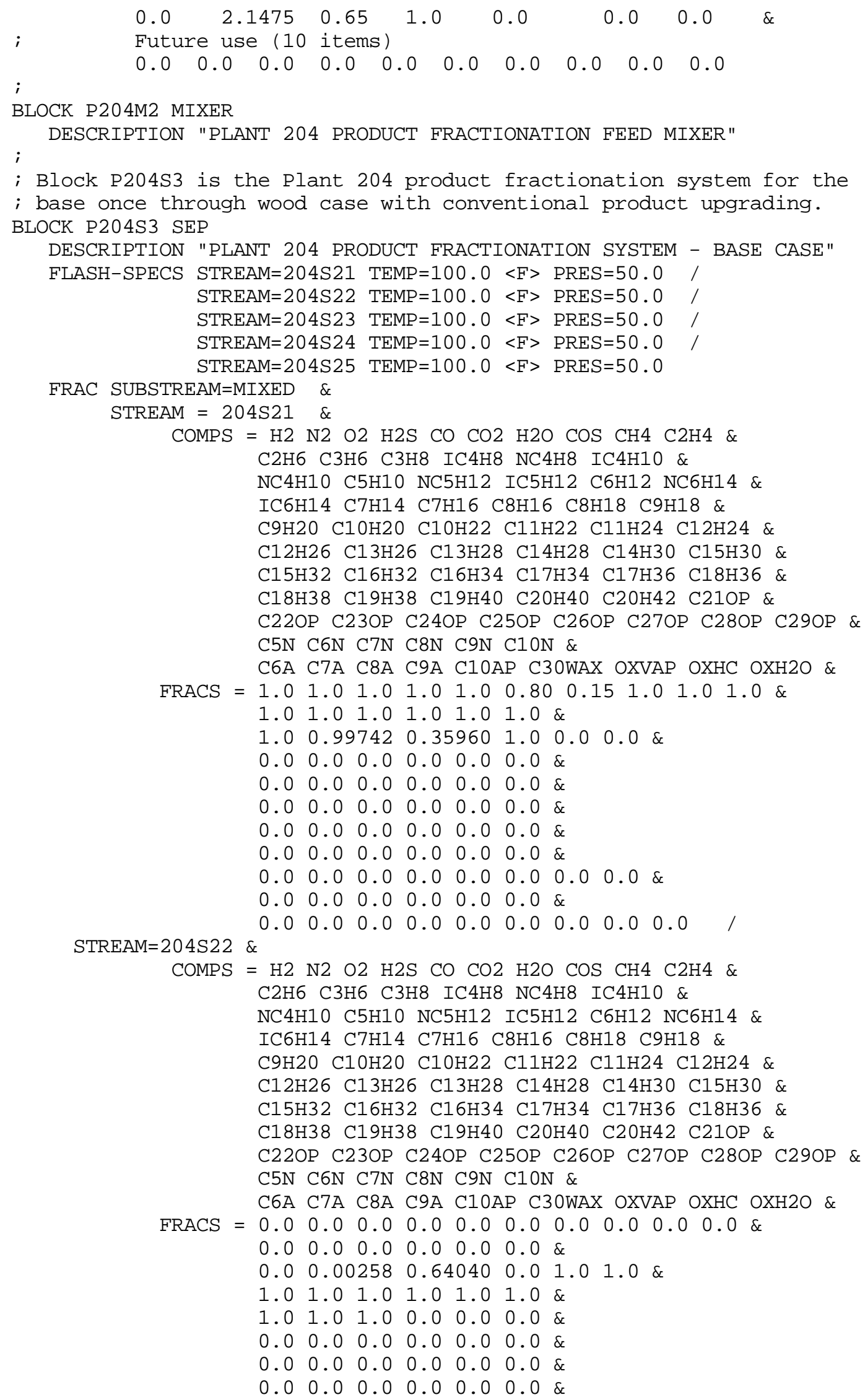




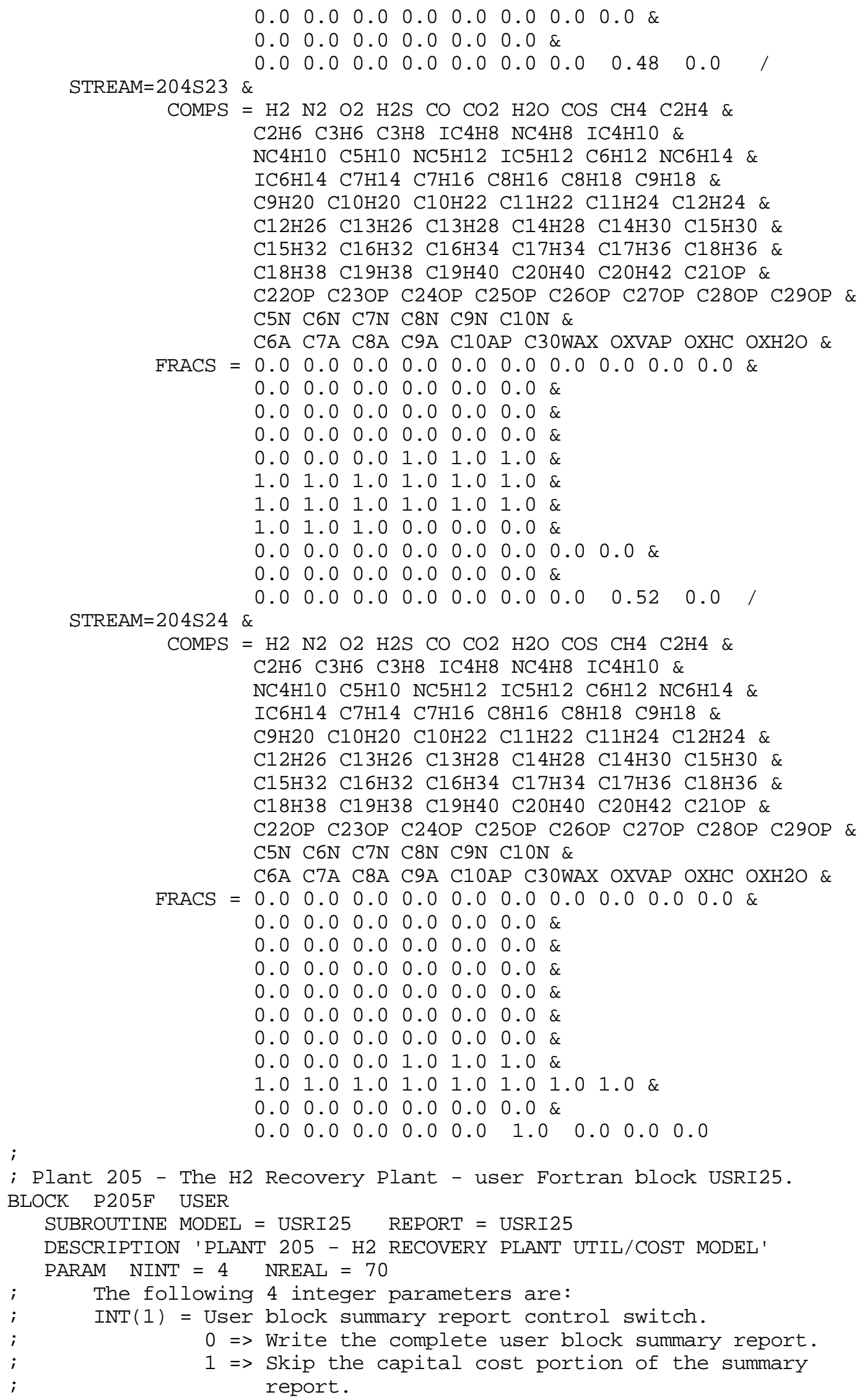


2 => Skip the capital cost and utilities portions of the summary report.

3 => Skip writing the entire user block summary report. INT(2) = User block summary report destination control switch.

$0=>$ Write the user block summary report to the normal ASPEN/SP output report file.

1 => Write the user block summary report to a separate user block output report file on logical unit 62 called ICL205.REP.

INT (3) = Number of duplicate plants.

INT $(4)=$ History file additional output control switch.

$0 \Rightarrow$ Write no additional output to the history file.

$1 \Rightarrow$ Write the only the subroutine entry and exit messages to the history file.

2 => Write some additional output to the history file. 3-5 => Write some more additional output to the history file. Larger values generate more intermediate

INT $0 \begin{array}{llll}1 & 0 & 1\end{array}$ output.

The following 70 real parameters are:

REAL (1) -

REAL (20) = Future use.

REAL (21) = Constant factor for the power consumption, kw.

REAL (22) = Power consumption per MM SCF/hr of H2 product, $\mathrm{kw} /(\mathrm{MM} \mathrm{SCF} / \mathrm{hr}$ of $\mathrm{H} 2$ )

REAL(23) = Constant factor for the 900 psig / 1000 F steam consumption, Mlbs/hr.

REAL $(24)=900$ psig / $1000 \mathrm{~F}$ steam consumption per MM SCF/hr of $\mathrm{H} 2$ product, (Mlbs/hr)/(MM SCF/hr of H2).

REAL (25) = Constant factor for the $360 \mathrm{psig} / 440 \mathrm{~F}$ steam consumption, Mlbs/hr.

REAL (26) = 360 psig / $440 \mathrm{~F}$ steam consumption per MM SCF/hr of $\mathrm{H} 2$ product, (Mlbs/hr)/(MM SCF/hr of H2).

REAL (27) = Constant factor for the $600 \mathrm{psig} / 650 \mathrm{~F}$ steam consumption, Mlbs/hr.

REAL (28) $=600$ psig / $650 \mathrm{~F}$ steam consumption per MM SCF/hr of $\mathrm{H} 2$ product, (Mlbs/hr)/(MM SCF/hr of H2).

REAL(29) = Constant factor for the 600 psig saturated steam consumption, Mlbs/hr.

REAL (30) = 600 psig saturated steam consumption per MM SCF/hr of $\mathrm{H} 2$ product, (Mlbs/hr)/(MM SCF/hr of H2).

REAL(31) = Constant factor for the 150 psig saturated steam consumption, Mlbs/hr.

REAL(32) = 150 psig saturated steam consumption per MM SCF/hr of H2 product, (Mlbs/hr)/(MM SCF/hr of H2).

REAL(33) = Constant factor for the 50 psig saturated steam consumption, Mlbs/hr.

REAL (34) = 50 psig saturated steam consumption per MM SCF/hr of H2 product, (Mlbs/hr) / (MM SCF/hr of H2).

REAL (35) = Constant factor for the plant fuel consumption, $\mathrm{MM} \mathrm{BTU/hr}$.

REAL(36) = Plant fuel consumption per MM SCF/hr of H2 product, (MM BTU/hr)/(MM SCF/hr of H2).

REAL(37) = Constant factor for the cooling water consumption, Mgal/hr.

REAL (38) = Cooling water consumption per MM SCF/hr of $\mathrm{H} 2$ product, (Mgal/hr)/(MM SCF/hr of H2).

REAL(39) = Constant factor for the process water consumption, $\mathrm{Mgal} / \mathrm{hr}$.

REAL $(40)=$ Process water consumption per MM SCF/hr of $\mathrm{H} 2$ 


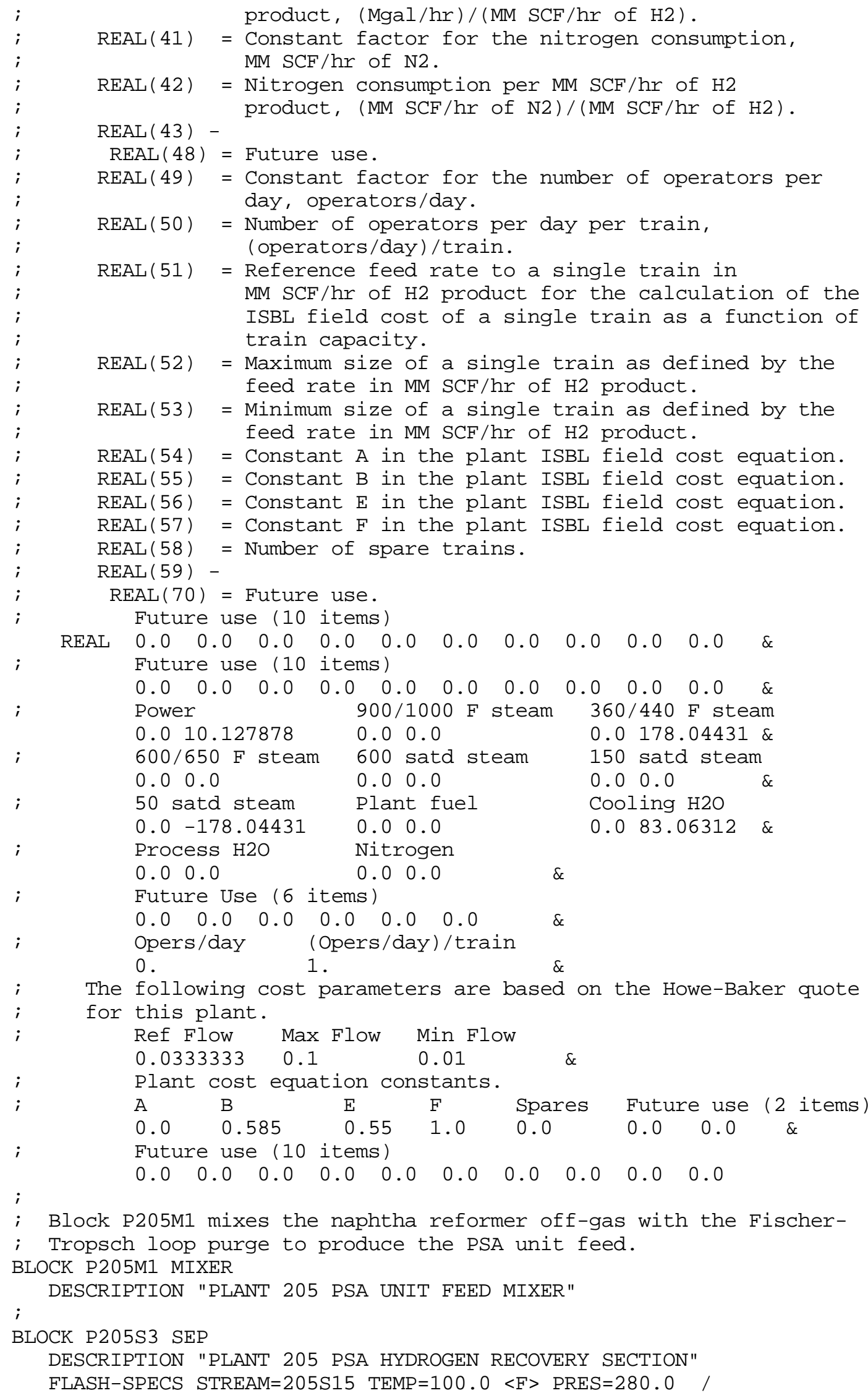




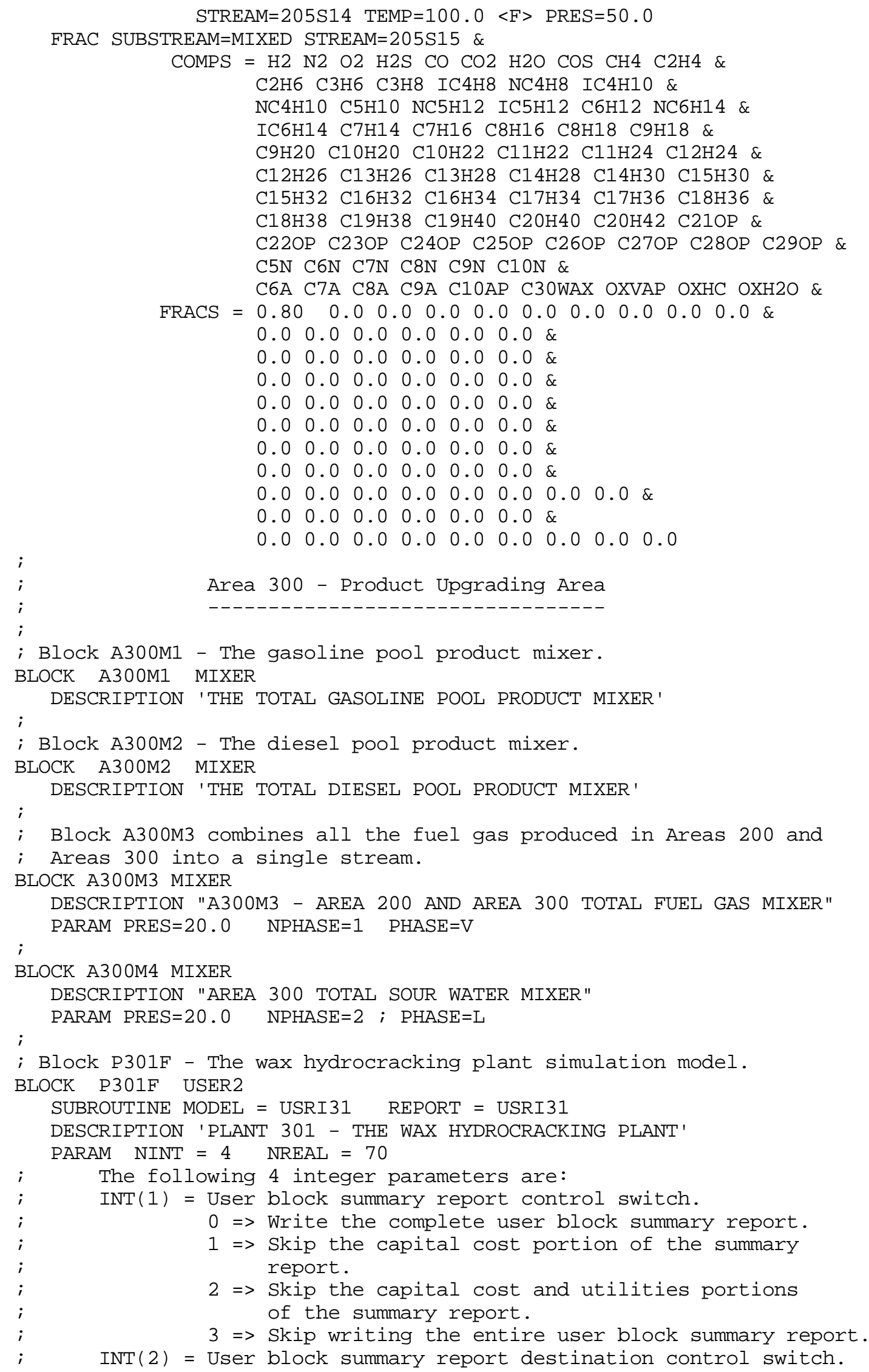


$0=>$ Write the user block summary report to the normal ASPEN/SP output report file.

1 => Write the user block summary report to a separate user block output report file on logical unit 62 called ICL301.REP.

REAL(37) = Constant factor for the cooling water consumption, Mgal/hr.

REAL (38) = Cooling water consumption per Mlbs/hr of wax feed, (Mgal/hr)/(Mlbs/hr of wax feed).

REAL(39) = Constant factor for the process water consumption, Mgal/hr. 


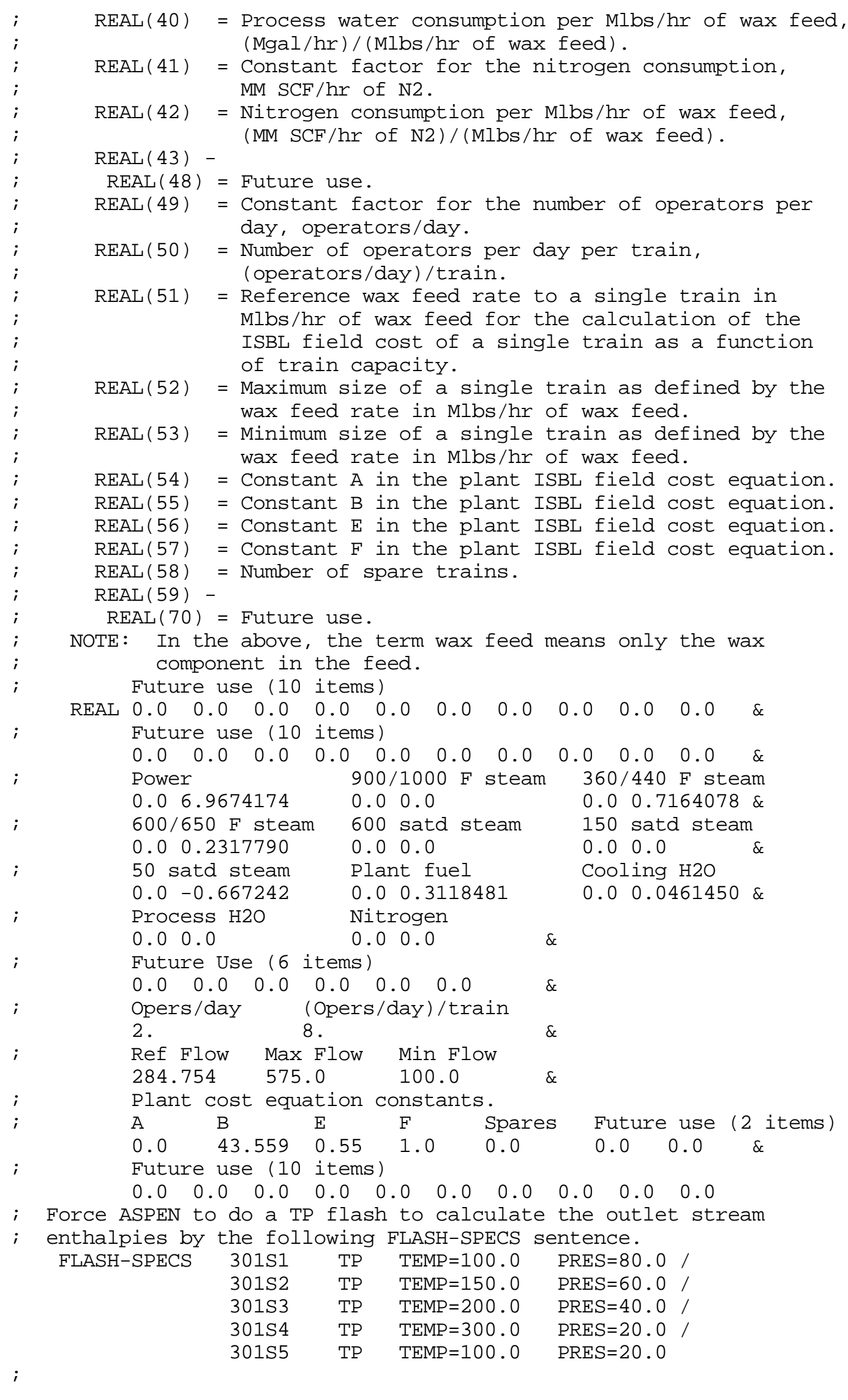




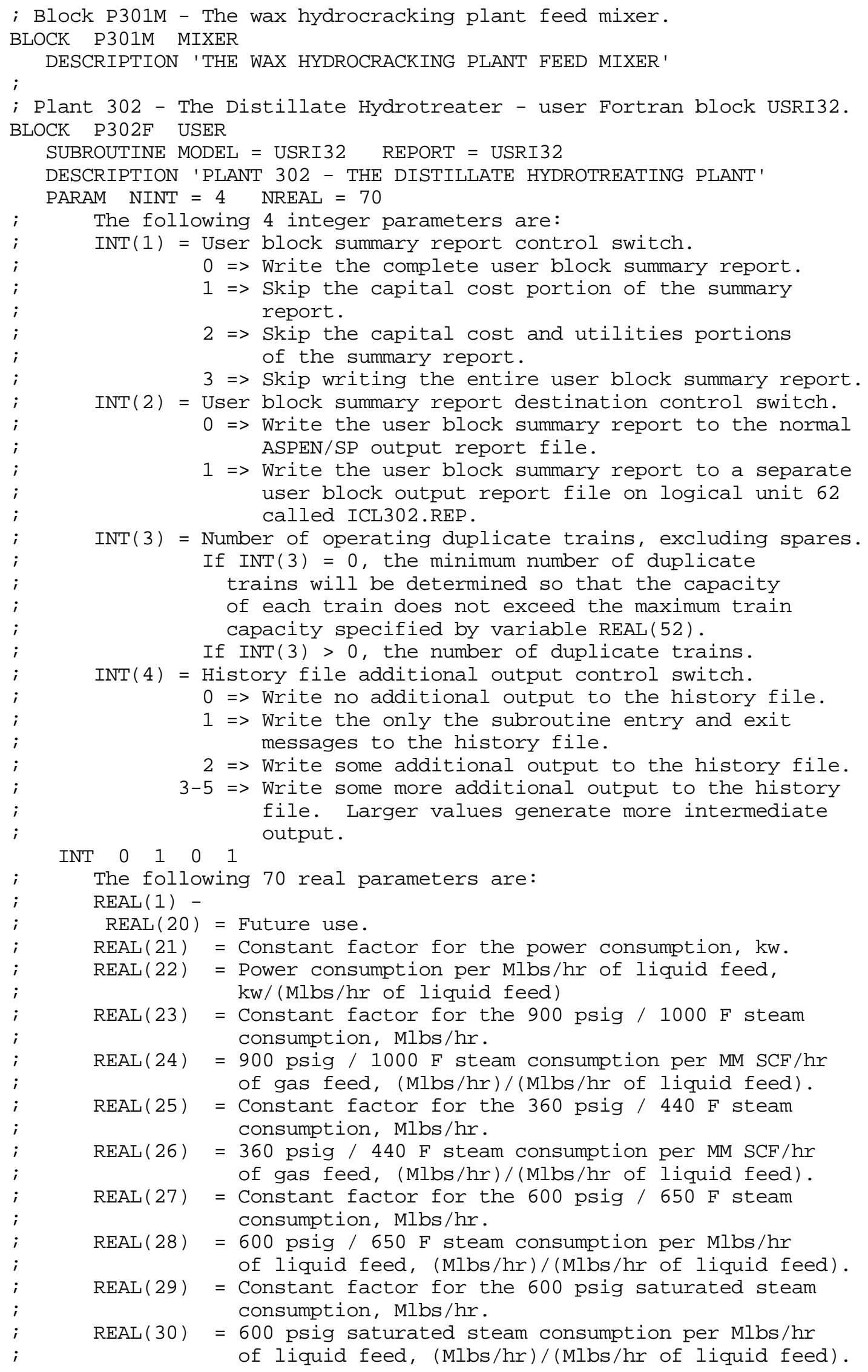




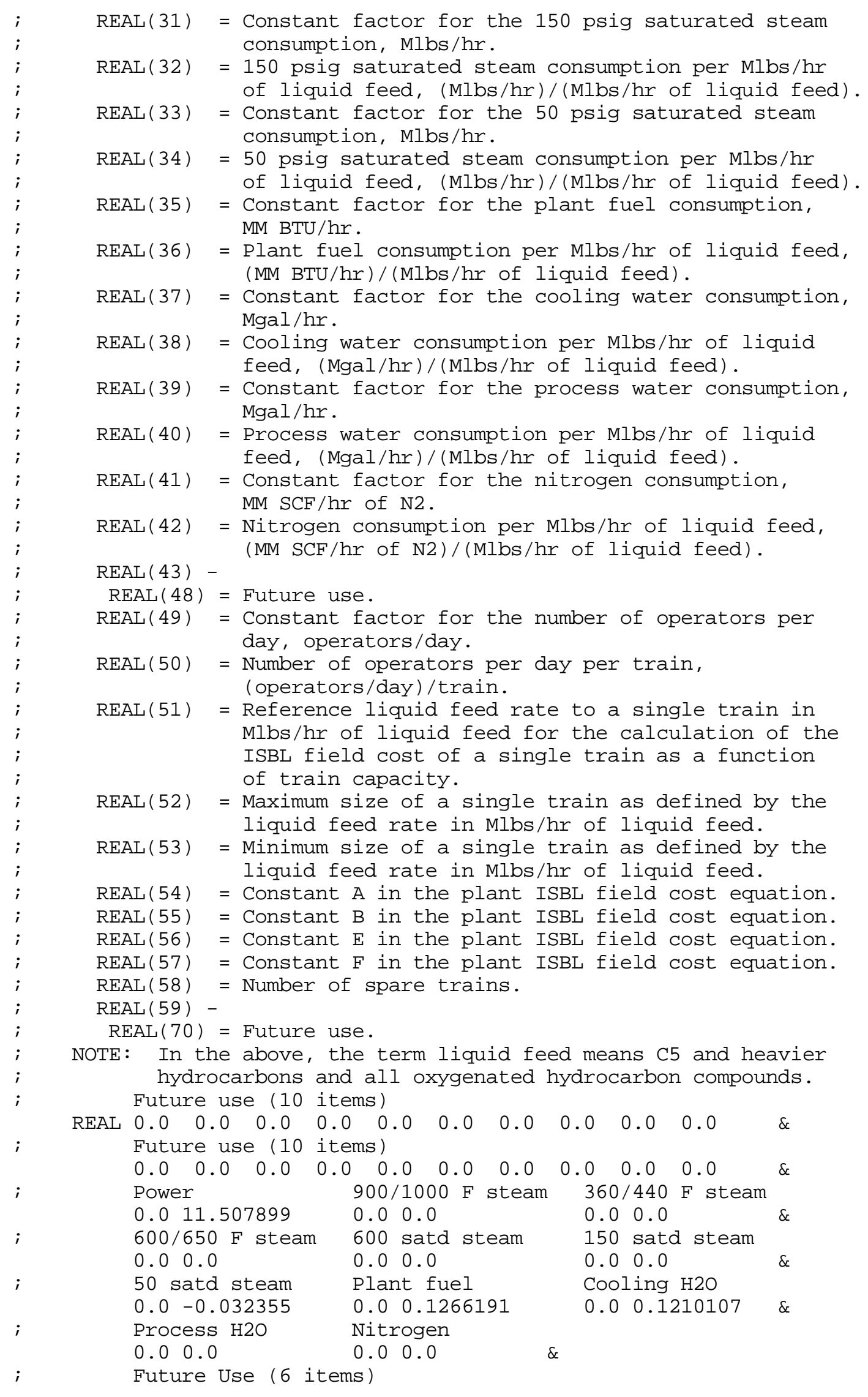




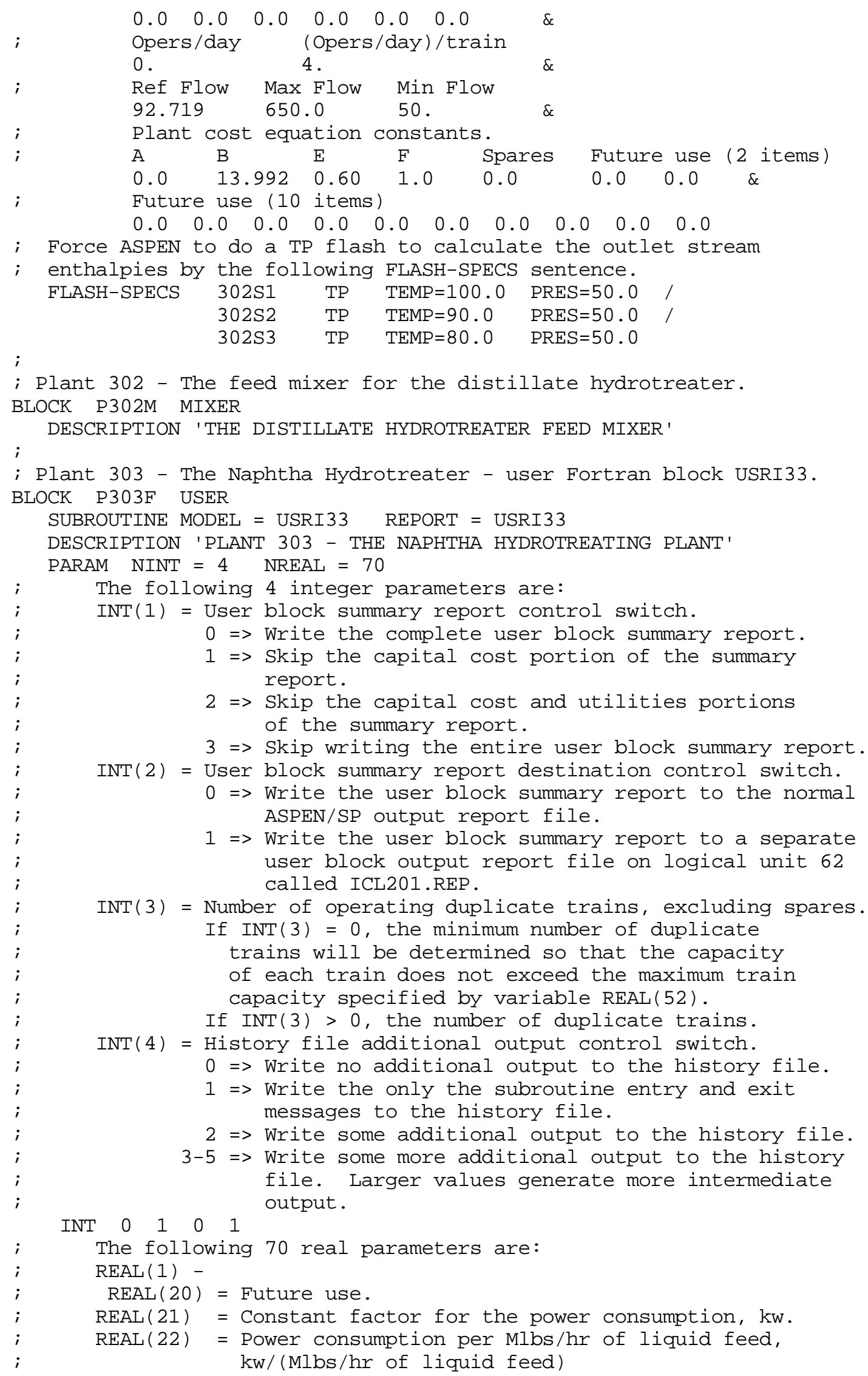




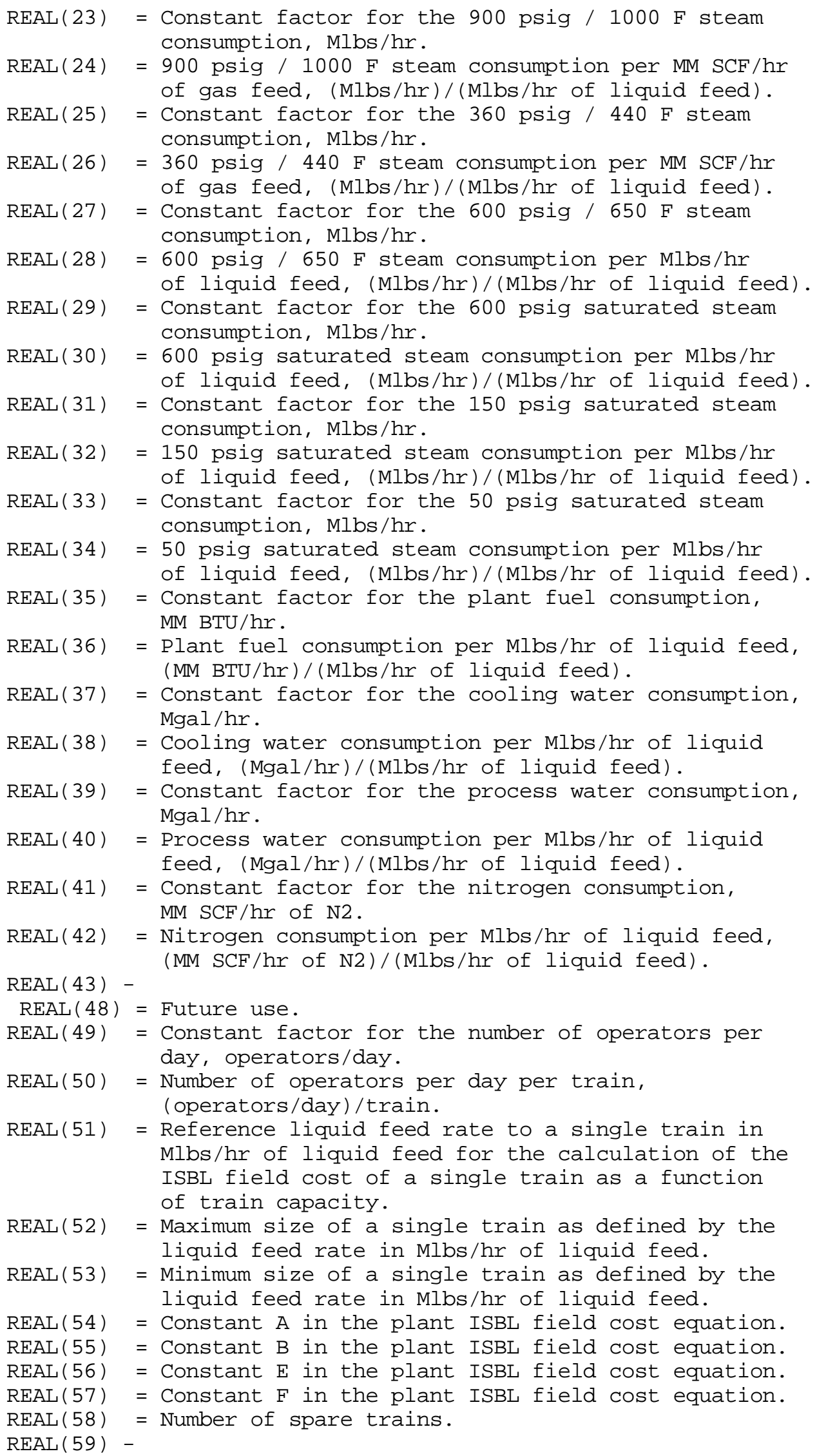




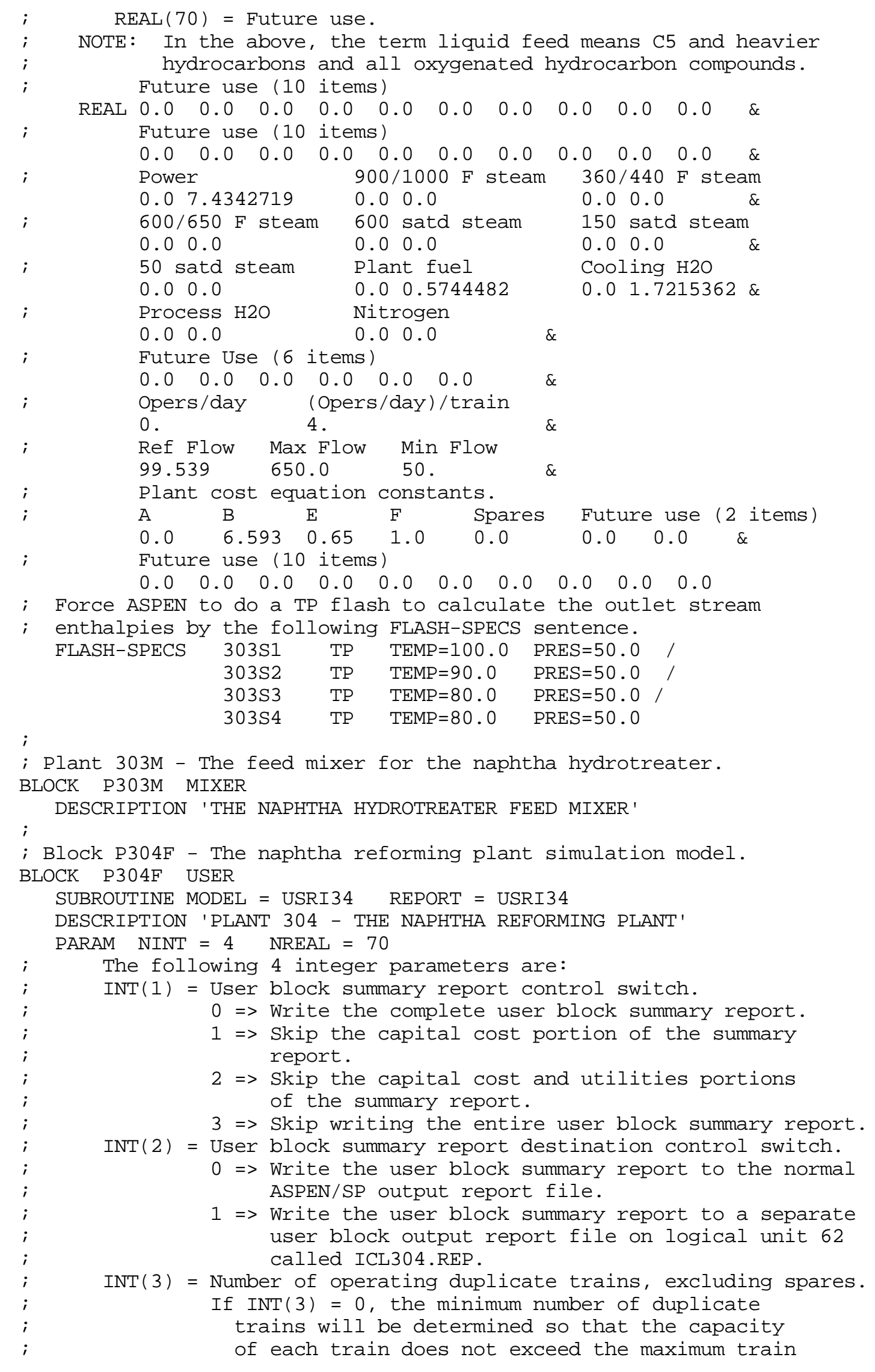




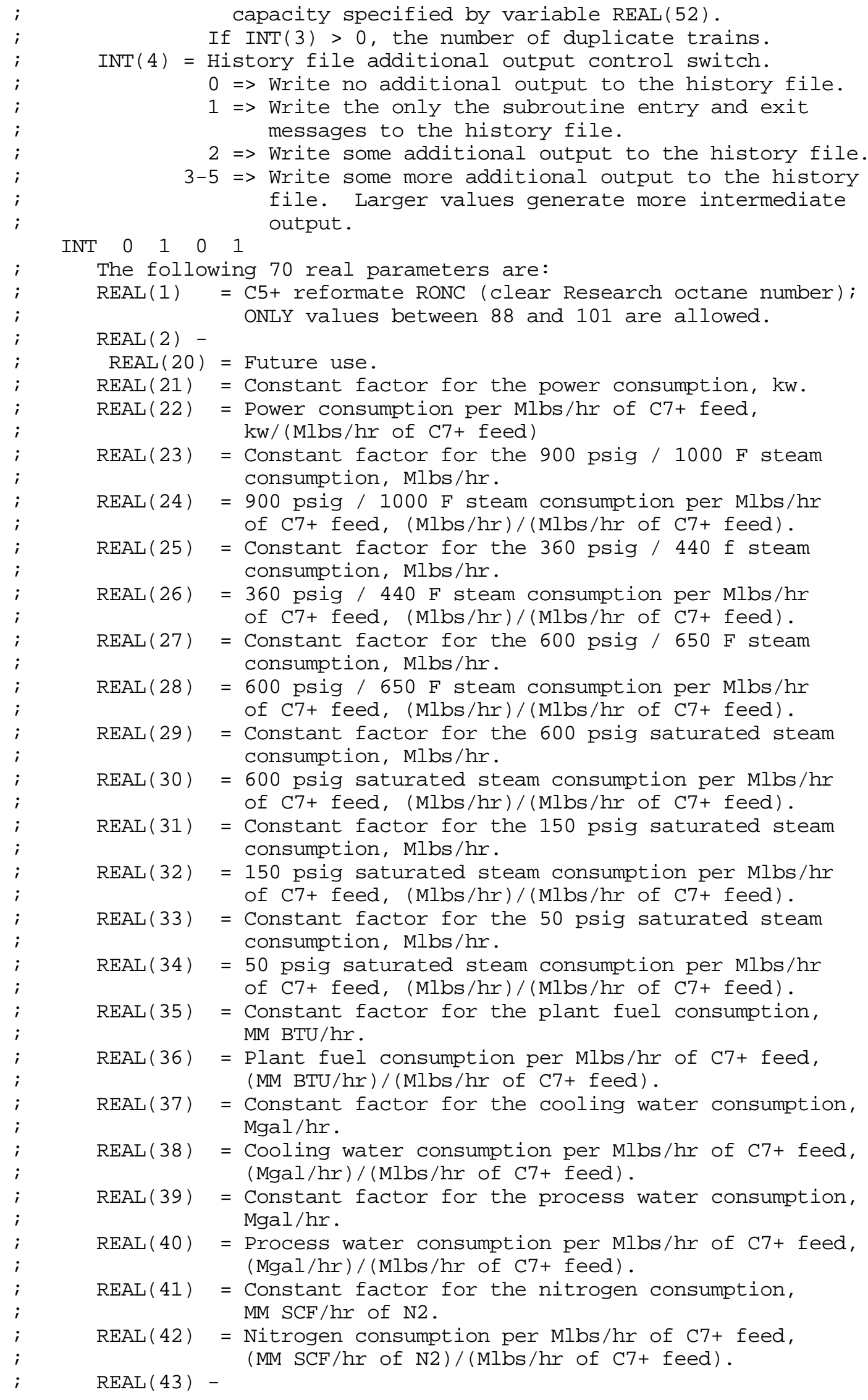




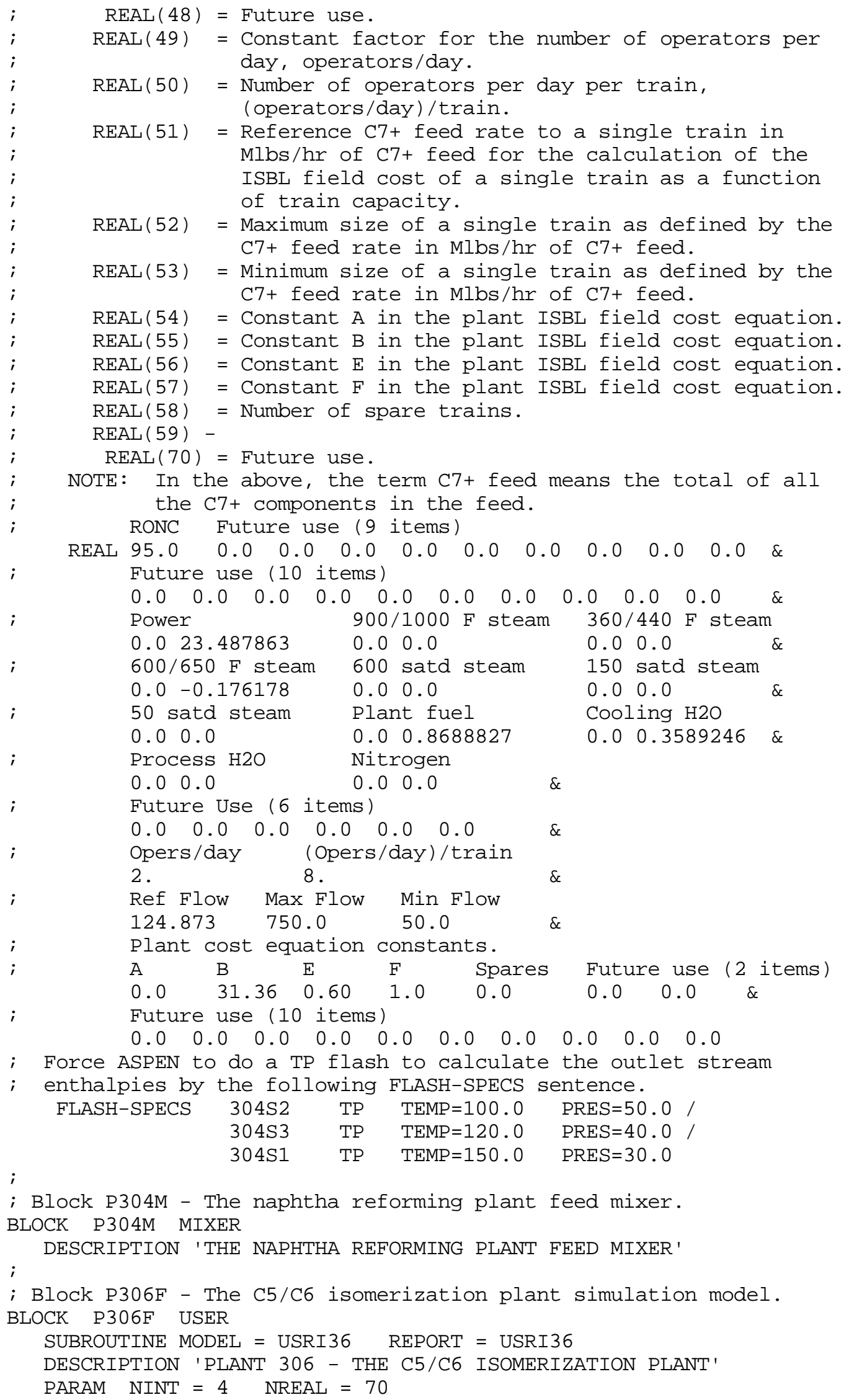


The following 4 integer parameters are:

INT(1) = User block summary report control switch.

$0=>$ Write the complete user block summary report.

$1=>$ skip the capital cost portion of the summary report.

2 => Skip the capital cost and utilities portions of the summary report.

3 => Skip writing the entire user block summary report.

INT(2) = User block summary report destination control switch.

$0 \Rightarrow$ Write the user block summary report to the normal ASPEN/SP output report file.

1 => Write the user block summary report to a separate user block output report file on logical unit 62 called ICL306.REP.

INT(3) = Number of operating duplicate trains, excluding spares.

If INT(3) $=0$, the minimum number of duplicate

trains will be determined so that the capacity

of each train does not exceed the maximum train capacity specified by variable REAL(52).

If INT(3) > 0, the number of duplicate trains.

INT(4) = History file additional output control switch.

$0=>$ Write no additional output to the history file.

$1=>$ Write the only the subroutine entry and exit messages to the history file.

2 => Write some additional output to the history file.

3-5 => Write some more additional output to the history file. Larger values generate more intermediate

INT $\quad 0 \quad 1 \quad 001$ output.

The following 70 real parameters are:

REAL (1) -

REAL (20) = Future use.

REAL (21) = Constant factor for the power consumption, $\mathrm{kw}$.

REAL (22) = Power consumption per Mlbs/hr of C5/C6 feed, $\mathrm{kw} /$ (Mlbs/hr of C5/C6 feed)

REAL (23) = Constant factor for the 900 psig / 1000 F steam consumption, Mlbs/hr.

REAL (24) = $900 \mathrm{psig} / 1000 \mathrm{~F}$ steam consumption per Mlbs/hr of C5/C6 feed, (Mlbs/hr)/(Mlbs/hr of C5/C6 feed).

REAL (25) = Constant factor for the $360 \mathrm{psig} / 440 \mathrm{~F}$ steam consumption, Mlbs/hr.

REAL (26) = $360 \mathrm{psig} / 400 \mathrm{~F}$ steam consumption per Mlbs/hr of C5/C6 feed, (Mlbs/hr)/(Mlbs/hr of C5/C6 feed).

REAL (27) = Constant factor for the 600 psig / 650 F steam consumption, Mlbs/hr.

REAL (28) $=600 \mathrm{psig} / 650 \mathrm{~F}$ steam consumption per Mlbs/hr of C5/C6 feed, (Mlbs/hr)/(Mlbs/hr of C5/C6 feed).

REAL(29) = Constant factor for the 600 psig saturated steam consumption, Mlbs/hr.

REAL (30) $=600$ psig saturated steam consumption per Mlbs/hr of C5/C6 feed, (Mlbs/hr)/(Mlbs/hr of C5/C6 feed).

REAL(31) = Constant factor for the 150 psig saturated steam consumption, Mlbs/hr.

REAL (32) = 150 psig saturated steam consumption per Mlbs/hr of C5/C6 feed, (Mlbs/hr)/(Mlbs/hr of C5/C6 feed).

REAL (33) = Constant factor for the 50 psig saturated steam consumption, Mlbs/hr.

REAL (34) = 50 psig saturated steam consumption per Mlbs/hr of C5/C6 feed, (Mlbs/hr)/(Mlbs/hr of C5/C6 feed).

REAL(35) = Constant factor for the plant fuel consumption, 


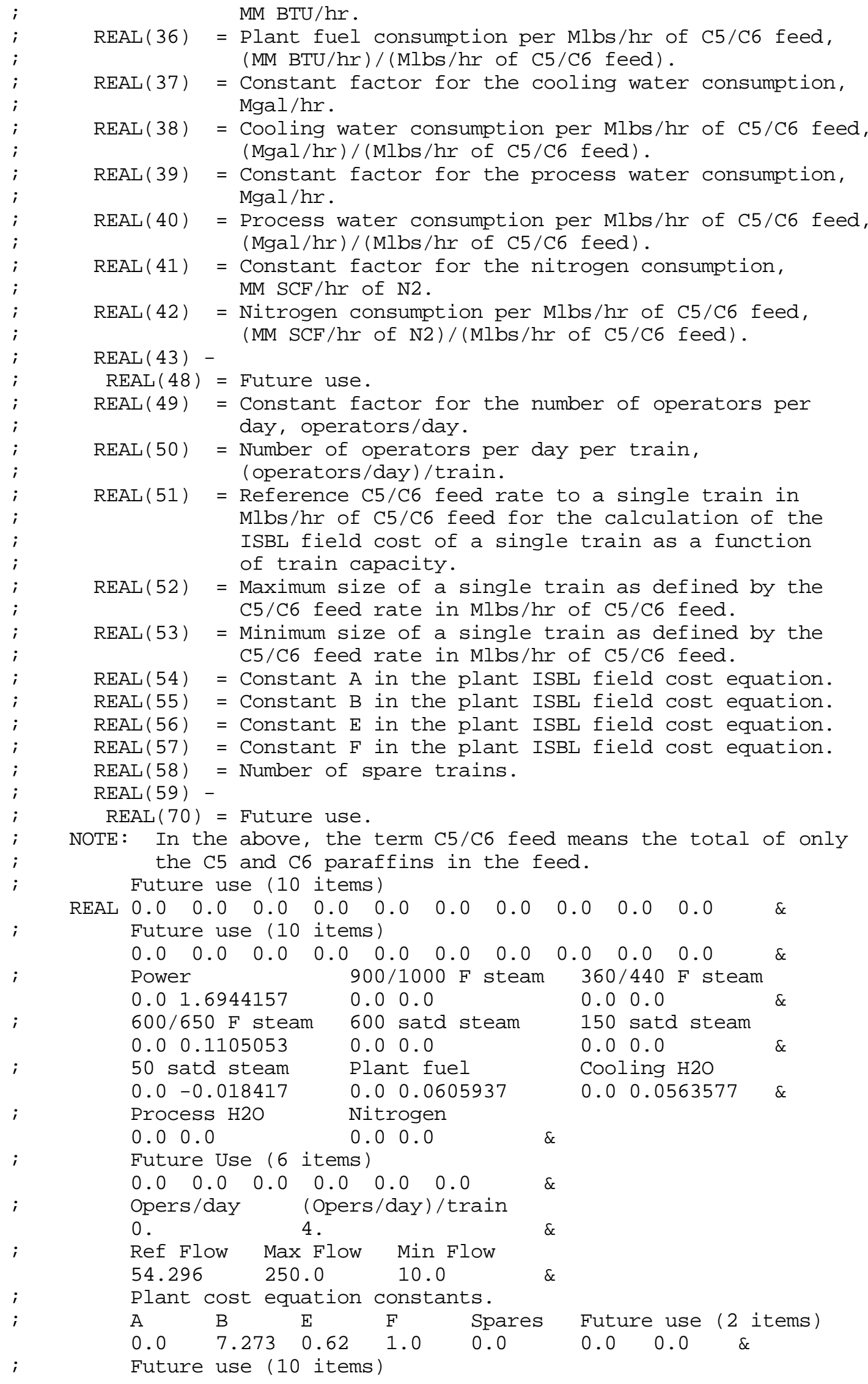




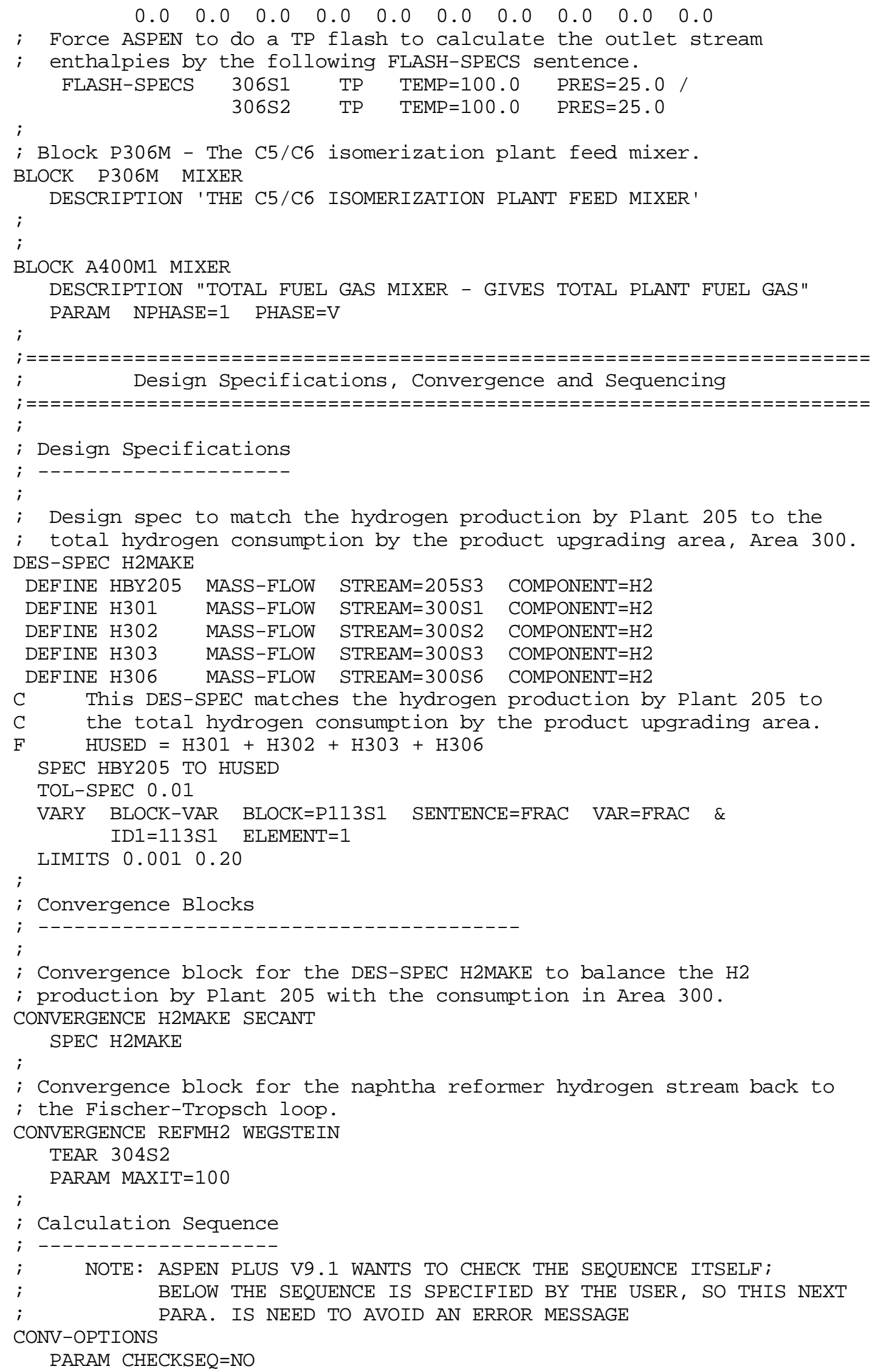




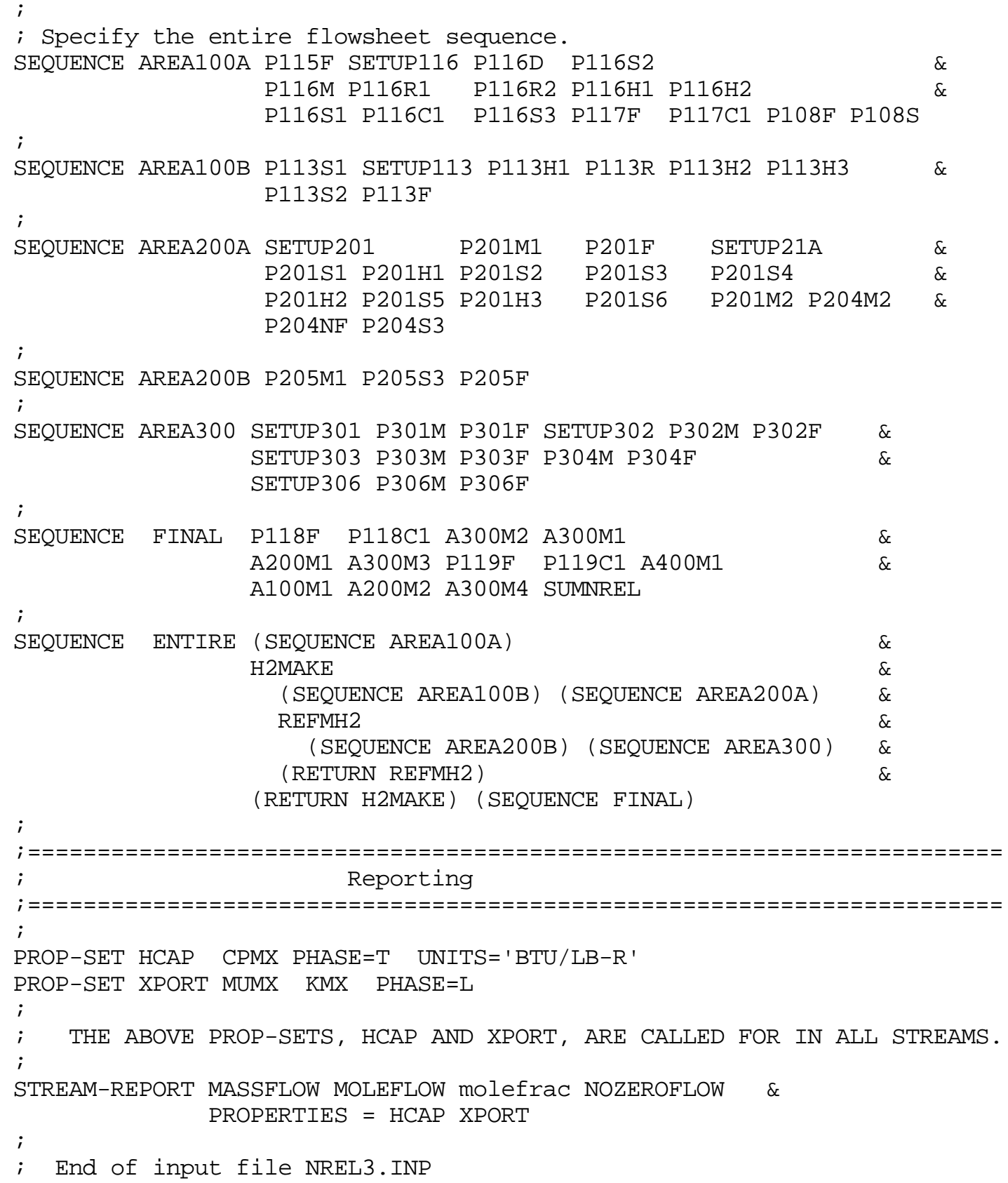




\title{
Appendix B
}

\author{
Listing of the \\ Management Summary Report \\ for the
}

Maximum Fischer-Tropsch Liquids Production Case

B - 1 
U. S. DEPARTMENT OF ENERGY

PITTSBURGH ENERGY TECHNOLOGY CENTER

DESIGN/ECONOMICS FOR

ADVANCED FISCHER-TROPSCH TECHNOLOGY

CONTRACT NOS. DE-AC22-91PC90027

AND DE-AC22-93PC91029

PLANT SUMMARY REPORTS

B - 2 
MAJOR INPUT AND OUTPUT STREAMS

\begin{tabular}{lrrr} 
INPUT & MLBS/HR & TONS/DAY & \\
DRY WOOD* & 183.750 & 2205.0 & \\
NATURAL GAS, MM SCF/HR & & 0.000 \\
RAW WATER MAKE-UP, MM GAL/SD & & 1.923 \\
& & & \\
OUTPUT & MLBS/HR & TONS/DAY & BBL/DAY \\
BUTANES & 0.000 & 0.0 & 0. \\
GASOLINE & 4.084 & 49.0 & 382. \\
DIESEL & 8.742 & 104.9 & 775. \\
REFUSE* & 0.000 & 0.0 & \\
SLAG* & 19.192 & 230.3 & 1156. \\
SULFUR & 0.000 & 0.0 & \\
TOTAL & 32.018 & 384.2 & \\
\multicolumn{4}{c}{ ELECTRIC POWER, MEGA-WH/SD } \\
* THESE STREAM FLOW RATES ARE ON A DRY BASIS.
\end{tabular}

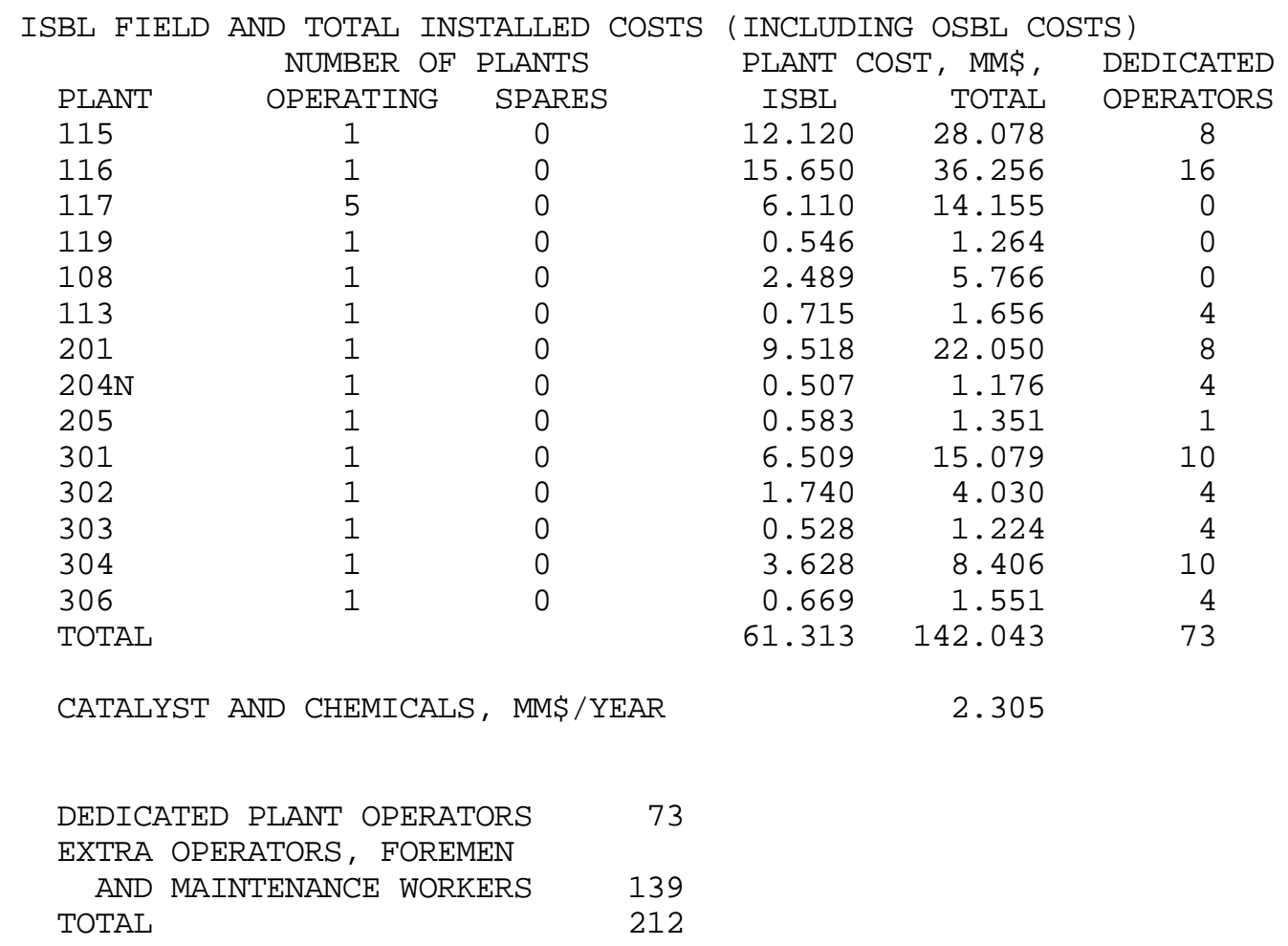


PLANT 115 - SUMMARY REPORT

WOOD DRYING PLANT

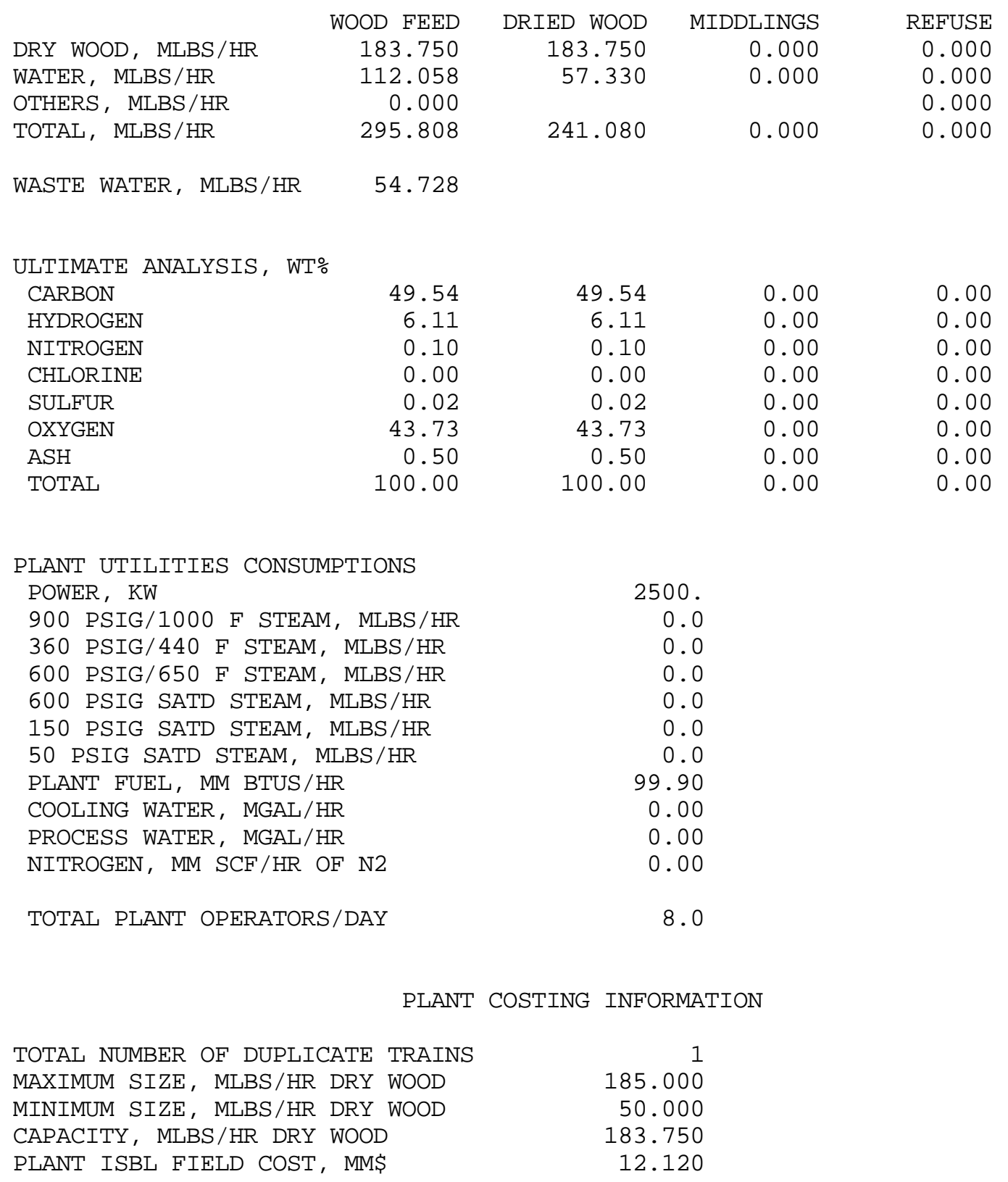


PLANT 116 - SUMMARY REPORT

WOOD GASIFICATION PLANT

WOOD DECOMPOSITION BLOCK FOR BATTELLE GASIFIER MODEL

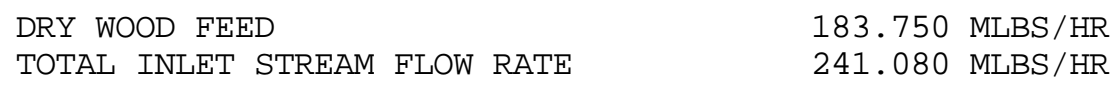

IN THE FOLLOWING TABLE, THE 900 PSIG STEAM ACTUALLY IS 975 PSIG, 750 F STEAM, AND THE 360 PSIG STEAM IS SUPERHEATED TO 530 F, NOT 440 F, AS SHOWN. THEY BOTH GO DIRECTLY TO THE COMBINED CYCLE PLANT FOR POWER GENERATION.

PLANT UTILITIES CONSUMPTIONS

POWER, KW

900 PSIG/1000 F STEAM, MLBS/HR

7700.

$360 \mathrm{PSIG} / 440$ F STEAM, MLBS/HR

600 PSIG/650 F STEAM, MLBS/HR

$-81.4$

600 PSIG SATD STEAM, MLBS/HR

$-22.0$

150 PSIG SATD STEAM, MLBS/HR

10.8

50 PSIG SATD STEAM, MLBS/HR

0.0

PLANT FUEL, MM BTUS/HR

0.0

COOLING WATER, MGAL/HR

PROCESS WATER, MGAL/HR

0.0

NITROGEN, MM SCF/HR OF N2

0.00

0.00

0.00

TOTAL PLANT OPERATORS/DAY

16.0

PLANT COSTING INFORMATION

TOTAL NUMBER OF DUPLICATE TRAINS

1

MAXIMUM SIZE, MLBS/HR DRY WOOD

185.000

MINIMUM SIZE, MLBS/HR DRY WOOD

20.000

CAPACITY, MLBS/HR DRY WOOD

183.750

PLANT ISBL FIELD COST, MM\$

15.650 
PLANT 117 - SUMMARY REPORT

F-T SYNGAS COMPRESSION PLANT

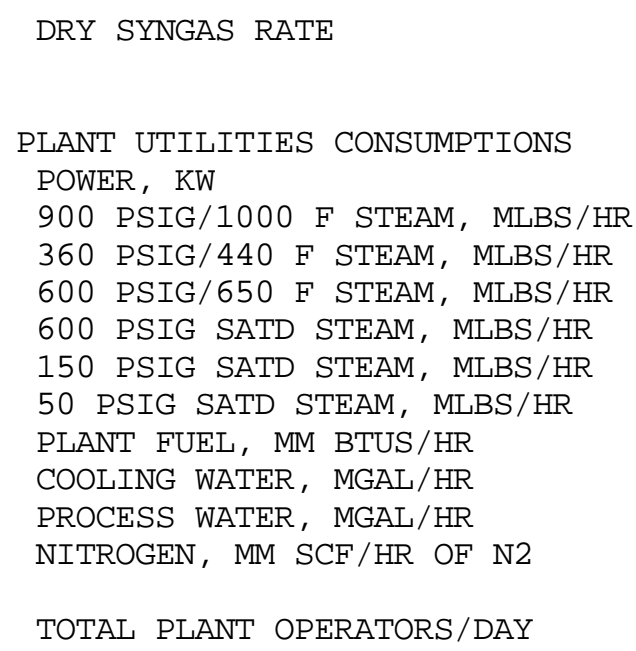

$\begin{array}{rr}5 & \\ 0.500 & \\ 0.050 & \\ \text { TOTAL } & \text { FIRST } \\ 2.421 & 0.484 \\ 6.110 & 1.222\end{array}$


PLANT 119 - SUMMARY REPORT

FUEL GAS COMPRESSION PLANT

DRY FUEL GAS RATE

PLANT UTILITIES CONSUMPTIONS

POWER, KW

900 PSIG/1000 F STEAM, MLBS/HR

360 PSIG/440 F STEAM, MLBS/HR

600 PSIG/650 F STEAM, MLBS/HR

600 PSIG SATD STEAM, MLBS/HR

150 PSIG SATD STEAM, MLBS/HR

50 PSIG SATD STEAM, MLBS/HR

PLANT FUEL, MM BTUS/HR

COOLING WATER, MGAL/HR

PROCESS WATER, MGAL/HR

NITROGEN, MM SCF/HR OF N2

TOTAL PLANT OPERATORS/DAY
$0.042 \mathrm{MM} \mathrm{SCF} / \mathrm{hr}$

97.

0.0

0.0

0.0

0.0

0.0

0.0

0.00

0.53

0.00

0.00

0.0

PLANT COSTING INFORMATION

TOTAL NUMBER OF DUPLICATE TRAINS

1

MAXIMUM SIZE, MM SCF/HR

MINIMUM SIZE, MM SCF/HR

0.200

CAPACITY, MM SCF/HR

0.010

PLANT ISBL FIELD COST, MM\$

0.042

0.546 
PLANT 108 - SUMMARY REPORT

SULFUR POLISHING PLANT

\begin{tabular}{lc} 
TOTAL SYNGAS FEED & 2.439 MM SCF/hr \\
PLANT UTILITIES CONSUMPTIONS & \\
POWER, KW & 0. \\
900 PSIG/1000 F STEAM, MLBS/HR & 0.0 \\
360 PSIG/440 F STEAM, MLBS/HR & 0.0 \\
600 PSIG/650 F STEAM, MLBS/HR & 0.0 \\
600 PSIG SATD STEAM, MLBS/HR & 0.0 \\
150 PSIG SATD STEAM, MLBS/HR & 0.0 \\
50 PSIG SATD STEAM, MLBS/HR & 0.0 \\
PLANT FUEL, MM BTUS/HR & 3.38 \\
COOLING WATER, MGAL/HR & 0.00 \\
PROCESS WATER, MGAL/HR & 0.00 \\
NITROGEN, MM SCF/HR OF N2 & 0.00 \\
TOTAL PLANT OPERATORS/DAY & 0.0 \\
\multicolumn{2}{|l}{ PLANT COSTING INFORMATION } \\
TOTAL NUMBER OF DUPLICATE TRAINS & 1 \\
MAXIMUM SIZE, MM SCF/HR & 3.500 \\
MINIMUM SIZE, MM SCF/HR & 0.300 \\
CAPACITY, MM SCF/HR & 2.439 \\
PLANT ISBL FIELD COST, MMS & 2.489
\end{tabular}

B - 8 
PLANT 113 - SUMMARY REPORT

CO SHIFT REACTOR PLANT

CO SHIFT REACTOR PLANT

DRIED SYNTHESIS GAS PRODUCTION RATE

DRIED SYNTHESIS GAS HYDROGEN PURITY

$0.040 \mathrm{MM} \mathrm{SCF} / \mathrm{hr}$

DRIED SYNTHESIS GAS HYDROGEN TO CO

48.035 MOLE 응

28.659 MOLAR RATIO

PLANT UTILITIES CONSUMPTIONS

POWER, KW

99.

900 PSIG/1000 F STEAM, MLBS/HR

0.0

360 PSIG/440 F STEAM, MLBS/HR

600 PSIG/650 F STEAM, MLBS/HR

3.0

600 PSIG SATD STEAM, MLBS/HR

0.0

150 PSIG SATD STEAM, MLBS/HR

0.0

50 PSIG SATD STEAM, MLBS/HR

0.0

0.0

PLANT FUEL, MM BTUS/HR

COOLING WATER, MGAL/HR

0.84

PROCESS WATER, MGAL/HR

NITROGEN, MM SCF/HR OF N2

1.14

0.00

TOTAL PLANT OPERATORS/DAY

4.0

PLANT COSTING INFORMATION

$\begin{array}{lr}\text { TOTAL NUMBER OF DUPLICATE TRAINS } & 1 \\ \text { MAXIMUM SIZE, MM SCF/HR } & 0.080 \\ \text { MINIMUM SIZE, MM SCF/HR } & 0.010 \\ \text { CAPACITY, MM SCF/HR } & 0.040 \\ \text { PLANT ISBL FIELD COST, MM\$ } & 0.715\end{array}$


PLANT 201 - SUMMARY REPORT

FISCHER-TROPSCH SYNTHESIS REACTORS

\begin{tabular}{|c|c|c|c|c|c|}
\hline REACTOR COMPONENT & FLOW RATES, & MLBS / HR & & AVERAGE & API \\
\hline COMPONENT & INLET & OUTLET & MOLE WT & $\mathrm{BP}, \mathrm{F}$ & GRAVITY \\
\hline н2 & 3.135 & 0.925 & & & \\
\hline N2 & 0.182 & 0.182 & & & \\
\hline $\mathrm{CO}$ & 84.520 & 8.485 & & & \\
\hline $\mathrm{CO} 2$ & 17.318 & 81.609 & & & \\
\hline H2O & 6.020 & 2.006 & & & \\
\hline $\mathrm{CH} 4$ & 15.227 & 15.713 & & & \\
\hline $\mathrm{C} 2 \mathrm{H} 4$ & 10.817 & 11.165 & & & \\
\hline $\mathrm{C} 2 \mathrm{H} 6$ & 0.000 & 0.093 & & & \\
\hline $\mathrm{C} 3 \mathrm{H} 6$ & 0.000 & 0.463 & & & \\
\hline C3H8 & 0.000 & 0.086 & & & \\
\hline IC4H8 & 0.000 & 0.024 & & & \\
\hline $\mathrm{NC} 4 \mathrm{H} 8$ & 0.000 & 0.458 & & & \\
\hline IC4H10 & 0.000 & 0.006 & & & \\
\hline $\mathrm{NC} 4 \mathrm{H} 10$ & 0.000 & 0.118 & & & \\
\hline C5H10 & 0.000 & 0.468 & & & \\
\hline $\mathrm{NC} 5 \mathrm{H} 12$ & 0.000 & 0.144 & & & \\
\hline IC $5 \mathrm{H} 12$ & 0.000 & 0.016 & & & \\
\hline C6H12 & 0.000 & 0.466 & & & \\
\hline $\mathrm{NC} 6 \mathrm{H} 14$ & 0.000 & 0.143 & & & \\
\hline IC $6 \mathrm{H} 14$ & 0.000 & 0.016 & & & \\
\hline $\mathrm{C} 7 \mathrm{H} 14$ & 0.000 & 0.421 & & & \\
\hline $\mathrm{C} 7 \mathrm{H} 16$ & 0.000 & 0.184 & & & \\
\hline $\mathrm{C} 8 \mathrm{H} 16$ & 0.000 & 0.399 & & & \\
\hline $\mathrm{C} 8 \mathrm{H} 18$ & 0.000 & 0.174 & & & \\
\hline $\mathrm{C} 9 \mathrm{H} 18$ & 0.000 & 0.372 & & & \\
\hline $\mathrm{C} 9 \mathrm{H} 2 \mathrm{O}$ & 0.000 & 0.162 & & & \\
\hline $\mathrm{C} 10 \mathrm{H} 20$ & 0.021 & 0.364 & & & \\
\hline $\mathrm{C} 10 \mathrm{H} 22$ & 0.000 & 0.149 & & & \\
\hline $\mathrm{C} 11 \mathrm{H} 22$ & 0.000 & 0.313 & & & \\
\hline $\mathrm{C} 11 \mathrm{H} 24$ & 0.000 & 0.136 & & & \\
\hline $\mathrm{C} 12 \mathrm{H} 24$ & 0.000 & 0.283 & & & \\
\hline $\mathrm{C} 12 \mathrm{H} 26$ & 0.000 & 0.123 & & & \\
\hline $\mathrm{C} 13 \mathrm{H} 26$ & 0.000 & 0.255 & & & \\
\hline $\mathrm{C} 13 \mathrm{H} 28$ & 0.000 & 0.110 & & & \\
\hline $\mathrm{C} 14 \mathrm{H} 28$ & 0.000 & 0.227 & & & \\
\hline $\mathrm{C} 14 \mathrm{H} 30$ & 0.000 & 0.098 & & & \\
\hline C15H30 & 0.000 & 0.202 & & & \\
\hline C15H32 & 0.000 & 0.087 & & & \\
\hline C16H32 & 0.000 & 0.179 & & & \\
\hline C16H34 & 0.000 & 0.077 & & & \\
\hline C17H34 & 0.000 & 0.158 & & & \\
\hline C17H36 & 0.000 & 0.068 & & & \\
\hline $\mathrm{C} 18 \mathrm{H} 36$ & 0.000 & 0.138 & & & \\
\hline C18H38 & 0.000 & 0.060 & & & \\
\hline С19H38 & 0.000 & 0.121 & & & \\
\hline $\mathrm{C} 19 \mathrm{H} 40$ & 0.000 & 0.052 & & & \\
\hline $\mathrm{C} 2 \mathrm{OH} 4 \mathrm{O}$ & 0.000 & 0.106 & & & \\
\hline $\mathrm{C} 2 \mathrm{OH} 42$ & 0.000 & 0.046 & & & \\
\hline C210P & 0.000 & 0.152 & & & \\
\hline $\mathrm{C} 22 \mathrm{OP}$ & 0.000 & 0.153 & & & \\
\hline C23OP & 0.000 & 0.154 & & & \\
\hline $\mathrm{C} 24 \mathrm{OP}$ & 0.000 & 0.154 & & & \\
\hline C25OP & 0.000 & 0.154 & & & \\
\hline $\mathrm{C} 260 \mathrm{P}$ & 0.000 & 0.154 & & & \\
\hline C27OP & 0.000 & 0.153 & & & \\
\hline C280P & 0.000 & 0.152 & & & \\
\hline C290P & 0.000 & 0.151 & & & \\
\hline C30WAX & 0.000 & 7.455 & 742.699 & 1128.3 & 36.42 \\
\hline OXVAP & 0.000 & 0.070 & 50.921 & & \\
\hline OXHC & 0.000 & 0.453 & 86.240 & & \\
\hline OXH2O & 0.000 & 0.230 & 45.556 & & \\
\hline TOTAL & 137.239 & 137.239 & & & \\
\hline TEMPERATURE， F & 331.3 & 487.6 & & & \\
\hline PRESSURE, PSIA & 325.0 & 304.0 & & & \\
\hline
\end{tabular}


PLANT 201 - SUMMARY REPORT

FISCHER-TROPSCH SYNTHESIS REACTORS

(CONTINUED)

$\begin{array}{ll}\text { F-T REACTOR CONVERSIONS: } & \\ \text { HYDROGEN CONVERSION } & 70.48 \\ \text { CARBON MONOXIDE CONVERSION } & 89.96 \\ \text { SYNGAS CONVERSION } & 83.34 \\ & \\ \text { INLET HYDROGEN TO CO RATIO } & 0.5154 \\ \text { OUTLET HYDROGEN TO CO RATIO } & 1.5155\end{array}$

FISCHER-TROPSCH SLURRY BED REACTOR DESIGN

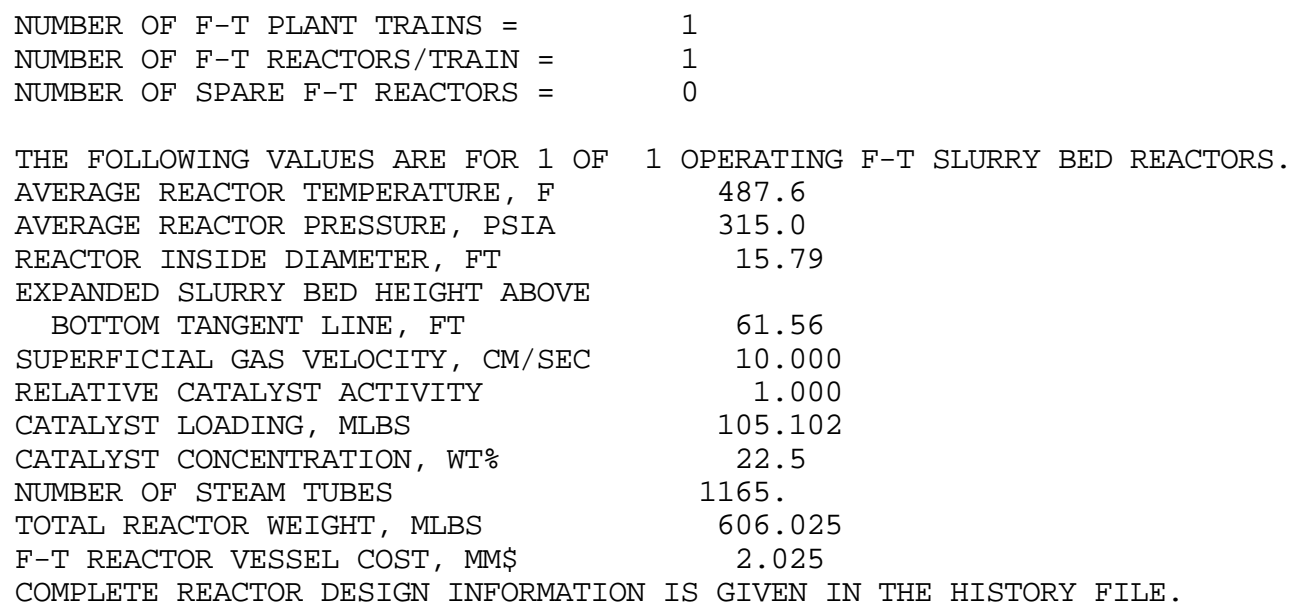

PLANT COSTING INFORMATION

TOTAL NUMBER OF DUPLICATE TRAINS 1

MAXIMUM SIZE, MM SCF/HR 8.053

MINIMUM SIZE, MM SCF/HR 2.690

NUMBER OF F-T REACTORS 1

CAPACITY, MM SCE/HR 2.520

PLANT ISBL FIELD COST, MM\$ 9.518

WARNING - THE ABOVE PLANT COSTS MAY BE IN ERROR SINCE THE CALCULATED TRAIN SIZE IS BELOW THE SPECIFIED MINIMUM TRAIN SIZE. 
EQUIPMENT SUMMARY

Plant 201 - Fischer-Tropsch Synthesis Plant

This plant has 1 parallel trains with 1 F-T slurry reactors/train and 0 spare $\mathrm{F}-\mathrm{T}$ reactor $(\mathrm{s})$.

\section{Reactors and Vessels}

\begin{tabular}{|c|c|c|c|c|}
\hline $\begin{array}{l}\text { Item } \\
\text { No. }\end{array}$ & Equipment Description & No. & $\begin{array}{l}\text { Length } \\
(\mathrm{T}-\mathrm{T}, \mathrm{ft})\end{array}$ & $\begin{array}{l}\text { Diameter } \\
\text { (ID, ft) }\end{array}$ \\
\hline $201 C-1$ & Syngas Humidifier & 1 & 4.4 & 4.0 \\
\hline $201 C-2$ & Steam Drum & 1 & 27.8 & 9.1 \\
\hline $201 C-3$ & Fischer-Torpsch Slurry Reactor & 1 & * & $\star$ \\
\hline $201 C-4$ & Hydroclone Underflow Drum & 1 & 7.3 & 2.7 \\
\hline $201 C-5$ & Shutdown Wax/Catalyst Storage & 1 & 36.8 & 18.3 \\
\hline $201 C-6$ & F-T Vapor 3-Phase Separator & 1 & 21.5 & 7.2 \\
\hline $201 C-7$ & Vapor Oxygenates Wash Column & 1 & 32.0 & 4.7 \\
\hline $201 C-8$ & High Temp F-T Liquid Separator & 1 & 7.3 & 2.2 \\
\hline $201 C-9$ & Low Temp F-T Liquid Separator & 1 & 4.7 & 1.6 \\
\hline $201 C-11$ & Catalyst Pretreater & 1 & 9.0 & 4.3 \\
\hline $201 C-12$ & Pretreated Catalyst Feed Tank & 1 & 9.0 & 4.3 \\
\hline $201 \mathrm{C}-13$ & Catalyst Pretreater OH KO Drum & 1 & 2.9 & 1.4 \\
\hline $201 C-15$ & Spent Catalyst Wash Tank & 1 & 2.9 & 1.4 \\
\hline
\end{tabular}

Heat Exchangers

---------------

$\begin{array}{clccc}\begin{array}{c}\text { Item } \\ \text { No. }\end{array} & \text { Equipment Description } & \text { No. } & \begin{array}{c}\text { Duty } \\ \text { (MM BTU/hr) }\end{array} & \begin{array}{c}\text { Type of } \\ \text { Exchanger }\end{array} \\ ----- & ------------------------- & --- & --------- & ---------- \\ 201 \mathrm{E}-1 & \text { Used Catalyst/Wax Slurry Heater } & 1 & 15.9 & \text { Shell \& Tube } \\ 201 \mathrm{E}-2 & \text { F-T Vapor Trim Cooler } & 1 & 1.0 & \text { Shell \& Tube } \\ 201 \mathrm{E}-3 & \text { F-T Vapor Air Cooler } & 1 & 13.1 & \text { Air-Fin } \\ 201 \mathrm{E}-4 & \text { Low Temp Separator Feed Cooler } & 1 & 0.1 & \text { Shell \& Tube } \\ 201 \mathrm{E}-5 & \text { Wax Heater } & 1 & 0.6 & \text { Shell \& Tube } \\ 201 \mathrm{E}-6 & \text { Catalyst Pretreater OH Cooler } & 1 & 0.3 & \text { Shell \& Tube } \\ 201 \mathrm{E}-7 & \text { Pretreater Feed/Effluent Exchngr } & 1 & 0.3 & \text { Shell \& Tube }\end{array}$

Fired Heaters

Item

No.

$201 \mathrm{~F}-1$

\section{Equipment Description}

Pretreater Circulation Gas Heater
Duty

No. (MM BTU/hr)

0.2 
EQUIPMENT SUMMARY (Continued)

Plant 201 - Fischer-Tropsch Synthesis Plant

This plant has 1 parallel trains with $1 \mathrm{~F}-\mathrm{T}$ slurry reactors/train and 0 spare $\mathrm{F}-\mathrm{T}$ reactor $(\mathrm{S})$.

\section{Compressors}

$\begin{array}{clccc}\begin{array}{c}\text { Item } \\ \text { No. }\end{array} & \text { Equipment Description } & \text { No. } & \begin{array}{c}\text { Flow Rate } \\ \text { (ACFM) }\end{array} & \begin{array}{c}\text { Brake } \\ \text { Horsepower }\end{array} \\ ----- & --------------------------- & --- & -------- & --------- \\ 201 \mathrm{~K}-1 & \text { Pretreater Circulation Gas Compr } & 1 & 64 . & 21 .\end{array}$

\section{Pumps}

Item

Equipment Description
--------- Water
Humidifier Wer Feed Water
F-T Reactor Boiler
Hydroclone Underflow
Catalyst/Wax Slurry Transfer
Wax Transfer
F-T Liquid Separator Bottoms
Wax Pretreater Feed
Pretreater Liquid
Makeup Catalyst Feed
Oxygenates Water Wash Column
Spent Catalyst Slurry

No.
---
2
2
2
2
2
2
2
2
2
2
2

$\begin{array}{cc}\begin{array}{c}\text { Flow Rate } \\ (\text { GPM })\end{array} & \begin{array}{c}\text { Brake } \\ \text { Horsepower }\end{array} \\ ----- & -------- \\ 11.0 & 0.3 \\ 2473.6 & 103.0 \\ 5.3 & 1.5 \\ 1998.4 & 164.3 \\ 249.8 & 9.2 \\ 0.3 & 0.1 \\ 9.2 & 1.8 \\ 0.5 & 0.5 \\ 3.7 & 1.0 \\ 11.0 & 1.3 \\ 2.0 & 0.1\end{array}$

Special Equipment

Item
No.
------
$201 \mathrm{~T}-1$
$201 \mathrm{~T}-2$
$201 \mathrm{~T}-4$
$201 \mathrm{~T}-5$
$201 \mathrm{~T}-6$
$201 \mathrm{~T}-7$
$201 \mathrm{~T}-8$
$201 \mathrm{~T}-9$

Equipment Description

Cyclone Separator

Hydroclone

Kerr-McGee ROSE Unit

Makeup Cat Feed Hopper Baghouse

Makeup Catalyst Feed Hopper

Catalyst Pretreater Baghouse

Spent Catalyst Filter

Holo-Flite Drier System
No. Comments

$2.1 \mathrm{ft}$ ID $\mathrm{x} 3.6 \mathrm{ft} \mathrm{T}-\mathrm{T}$

42.4 GPM

$1.1 \mathrm{MBPSD}$

$0.9 \mathrm{sq}$ ft Cloth Area

$7.9 \mathrm{ft}$ ID $\mathrm{x} 15.8 \mathrm{ft}$

$1.4 \mathrm{sq}$ ft Cloth Area

$1.8 \mathrm{GPM}$

$169.9 \mathrm{Lbs} / \mathrm{hr}$

The above is based on a proration of the baseline plant design. For either very small or very large capacity plants, the user may wish to adjust the number of spare items or the amount of parallel capacity in some plant sections. 
PLANT 204N - SUMMARY REPORT

NREL HYDROCARBON RECOVERY PLANT

PLANT FEED RATE

PLANT UTILITIES CONSUMPTIONS

POWER, KW

900 PSIG/1000 F STEAM, MLBS/HR

360 PSIG/440 F STEAM, MLBS/HR

600 PSIG/650 F STEAM, MLBS/HR

600 PSIG SATD STEAM, MLBS/HR

150 PSIG SATD STEAM, MLBS/HR

50 PSIG SATD STEAM, MLBS/HR

PLANT FUEL, MM BTUS/HR

COOLING WATER, MGAL/HR

PROCESS WATER, MGAL/HR

NITROGEN, MM SCF/HR OF N2

TOTAL PLANT OPERATORS/DAY
14.440 Mlbs/hr

13.

0.0

0.0

0.0

0.0

0.0

0.8

1.05

0.87

0.00

0.00

4.0

PLANT COSTING INFORMATION

TOTAL NUMBER OF DUPLICATE TRAINS

1

MAXIMUM SIZE, MLBS/HR

MINIMUM SIZE, MLBS/HR

200.000

CAPACITY, MLBS/HR

13.000

PLANT ISBL FIELD COST, MM\$

14.440

0.507 
PLANT 205 - SUMMARY REPORT

H2 RECOVERY PLANT

\begin{tabular}{lc} 
H2 PRODUCT RATE & 0.033 MM SCF/hr \\
PLANT UTILITIES CONSUMPTIONS & \\
POWER, KW & 0. \\
900 PSIG/1000 F STEAM, MLBS/HR & 0.0 \\
360 PSIG/440 F STEAM, MLBS/HR & 5.9 \\
600 PSIG/650 F STEAM, MLBS/HR & 0.0 \\
600 PSIG SATD STEAM, MLBS/HR & 0.0 \\
150 PSIG SATD STEAM, MLBS/HR & 0.0 \\
50 PSIG SATD STEAM, MLBS/HR & -5.9 \\
PLANT FUEL, MM BTUS/HR & 0.00 \\
COOLING WATER, MGAL/HR & 2.75 \\
PROCESS WATER, MGAL/HR & 0.00 \\
NITROGEN, MM SCF/HR OF N2 & 0.00 \\
TOTAL PLANT OPERATORS/DAY & 1.0 \\
\multicolumn{2}{|c}{ PLANT COSTING INFORMATION } \\
TOTAL NUMBER OF DUPLICATE TRAINS & 1 \\
MAXIMUM SIZE, MM SCE/HR OF H2 & 0.100 \\
MINIMUM SIZE, MM SCF/HR OF H2 & 0.010 \\
CAPACITY, MM SCF/HR OF H2 & 0.033 \\
PLANT ISBL FIELD COST, MMS & 0.583
\end{tabular}

B - 15 


\begin{tabular}{|c|c|c|c|c|}
\hline & \multicolumn{3}{|c|}{$\begin{array}{l}\text { PLANT } 301 \text { - SUMMARY REPORT } \\
\text { WAX HYDROCRACKING PLANT }\end{array}$} & \\
\hline & COMPONENT & FLOW RATES, & MLBS / HR & \\
\hline COMPONENT & FEED & & & \\
\hline $\mathrm{H} 2$ & 0.121 & & & \\
\hline $\mathrm{C} 20 \mathrm{H} 40$ & 0.106 & & & \\
\hline $\mathrm{C} 2 \mathrm{OH} 42$ & 0.046 & & & \\
\hline $\mathrm{C} 210 \mathrm{P}$ & 0.152 & & & \\
\hline $\mathrm{C} 22 \mathrm{OP}$ & 0.153 & & & \\
\hline $\mathrm{C} 23 \mathrm{OP}$ & 0.154 & & & \\
\hline $\mathrm{C} 24 \mathrm{OP}$ & 0.154 & & & \\
\hline $\mathrm{C} 25 \mathrm{OP}$ & 0.154 & & & \\
\hline $\mathrm{C} 260 \mathrm{P}$ & 0.154 & & & \\
\hline $\mathrm{C} 27 \mathrm{OP}$ & 0.153 & & & \\
\hline $\mathrm{C} 280 \mathrm{P}$ & 0.152 & & & \\
\hline C290P & 0.151 & & & \\
\hline C30WAX & 7.455 & & & \\
\hline TOTAL & 9.105 & & & \\
\hline TEMPERATURE, $F$ & 100.0 & & & \\
\hline PRESSURE, PSIA & 50.0 & & & \\
\hline PRODUCT FLOW RATES, & $\mathrm{MLBS} / \mathrm{HR}$ & & & \\
\hline COMPONENT & GASES & $\mathrm{C} 5 / \mathrm{C} 6 \mathrm{~S}$ & GASOLINE & DISTILLATE \\
\hline $\mathrm{H} 2 \mathrm{O}$ & 0.000 & 0.000 & 0.000 & 0.000 \\
\hline $\mathrm{CH} 4$ & 0.004 & 0.000 & 0.000 & 0.000 \\
\hline $\mathrm{C} 2 \mathrm{H} 6$ & 0.004 & 0.000 & 0.000 & 0.000 \\
\hline $\mathrm{C} 3 \mathrm{H} 8$ & 0.132 & 0.000 & 0.000 & 0.000 \\
\hline $\mathrm{IC} 4 \mathrm{H} 10$ & 0.175 & 0.000 & 0.000 & 0.000 \\
\hline $\mathrm{NC} 4 \mathrm{H} 10$ & 0.142 & 0.000 & 0.000 & 0.000 \\
\hline $\mathrm{NC} 5 \mathrm{H} 12$ & 0.000 & 0.184 & 0.000 & 0.000 \\
\hline $\mathrm{IC} 5 \mathrm{H} 12$ & 0.000 & 0.218 & 0.000 & 0.000 \\
\hline $\mathrm{NC} 6 \mathrm{H} 14$ & 0.000 & 0.212 & 0.000 & 0.000 \\
\hline IC6H14 & 0.000 & 0.346 & 0.000 & 0.000 \\
\hline $\mathrm{C} 7-300 \mathrm{HC}$ & 0.000 & 0.000 & 1.292 & 0.000 \\
\hline $3-350 \mathrm{HC}$ & 0.000 & 0.000 & 0.415 & 0.000 \\
\hline $350-5 \mathrm{HC}$ & 0.000 & 0.000 & 0.000 & 1.892 \\
\hline $500+\mathrm{HC}$ & 0.000 & 0.000 & 0.000 & 4.027 \\
\hline TOTAL & 0.458 & 0.960 & 1.707 & 5.919 \\
\hline TEMPERATURE, $\mathrm{F}$ & 100.0 & 150.0 & 200.0 & 300.0 \\
\hline PRESSURE, PSIA & 80.0 & 60.0 & 40.0 & 20.0 \\
\hline SOUR WATER & 0.061 & & & \\
\hline TEMPERATURE, $\mathrm{F}$ & 100.0 & & & \\
\hline PRESSURE, PSIA & 20.0 & & & \\
\hline
\end{tabular}


WAX HYDROCRACKING PLANT - SUMMARY REPORT

(CONTINUED)

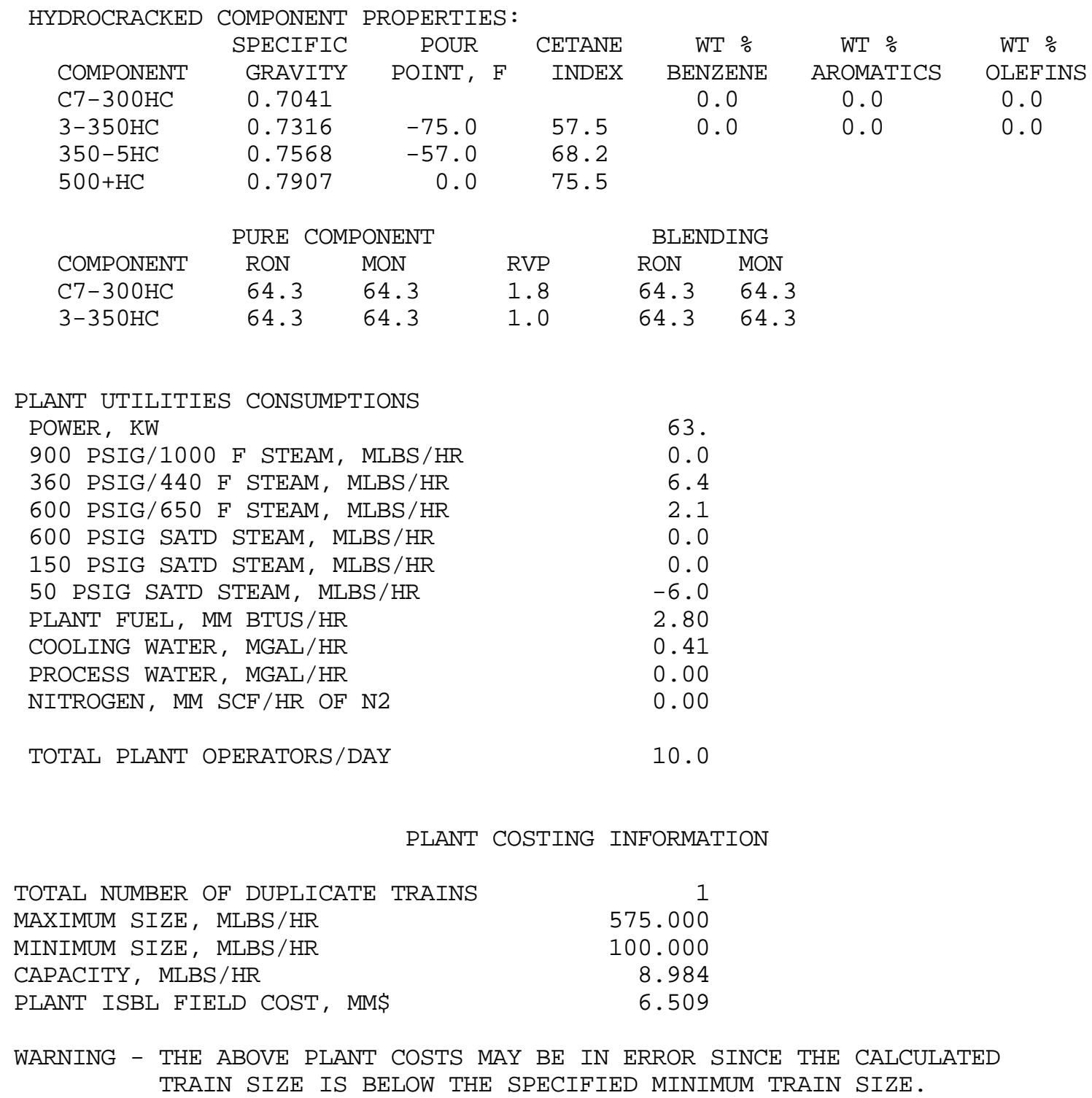


PLANT 302 - SUMMARY REPORT

DISTILLATE HYDROTREATER

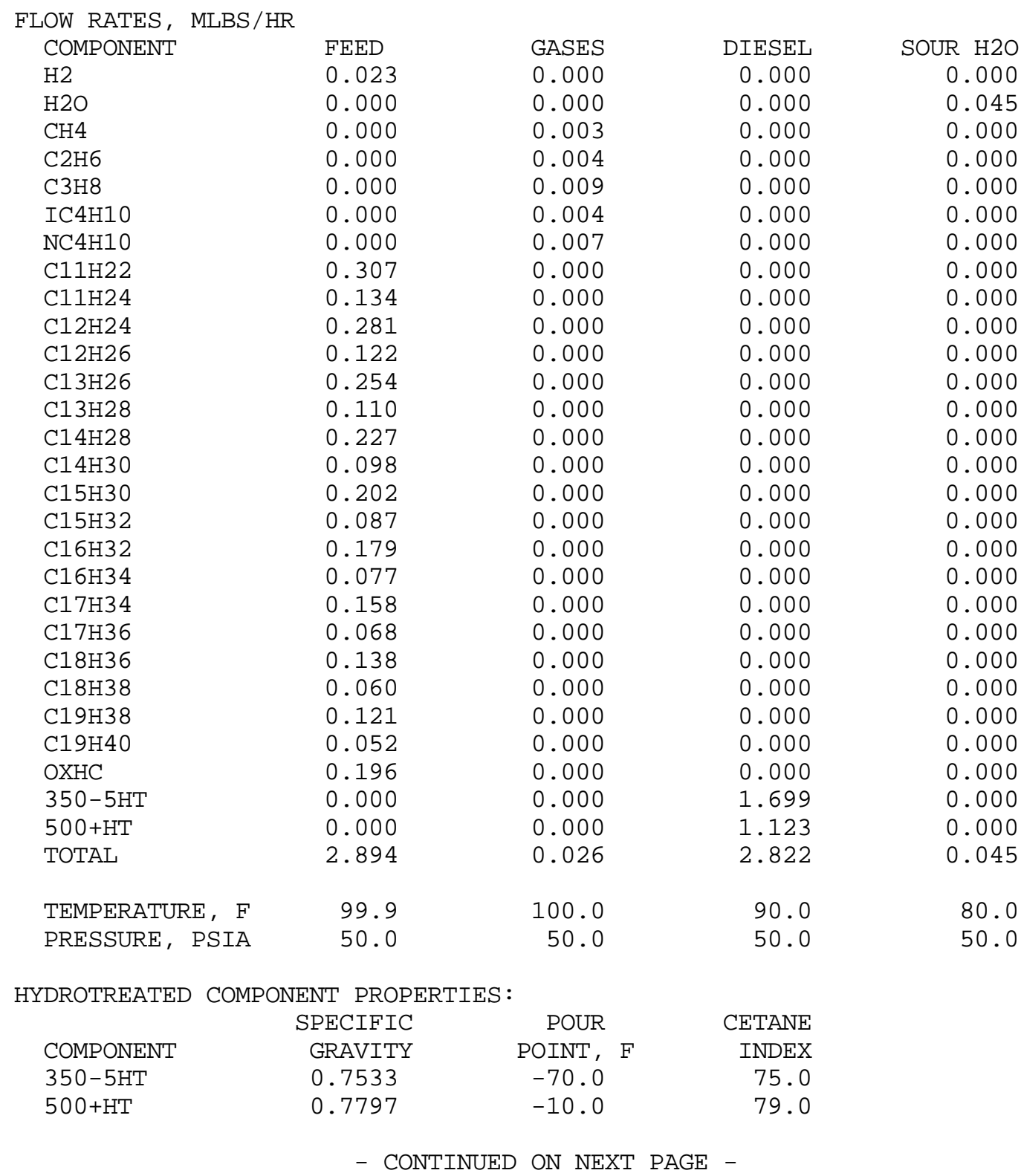


DISTILLATE HYDROTREATER - SUMMARY REPORT

(CONTINUED)

$\begin{array}{lr}\text { PLANT UTILITIES CONSUMPTIONS } & 33 . \\ \text { POWER, KW } & 0.0 \\ 900 \text { PSIG/1000 F STEAM, MLBS/HR } & 0.0 \\ 360 \text { PSIG/440 F STEAM, MLBS/HR } & 0.0 \\ 600 \text { PSIG/650 F STEAM, MLBS/HR } & 0.0 \\ 600 \text { PSIG SATD STEAM, MLBS/HR } & 0.0 \\ \text { 150 PSIG SATD STEAM, MLBS/HR } & -0.1 \\ 50 \text { PSIG SATD STEAM, MLBS/HR } & 0.36 \\ \text { PLANT FUEL, MM BTUS/HR } & 0.35 \\ \text { COOLING WATER, MGAL/HR } & 0.00 \\ \text { PROCESS WATER, MGAL/HR } & 0.00 \\ \text { NITROGEN, MM SCF/HR OF N2 } & 4.0 \\ \text { TOTAL PLANT OPERATORS/DAY } & \end{array}$

PLANT COSTING INFORMATION

TOTAL NUMBER OF DUPLICATE TRAINS 1

MAXIMUM SIZE, MLBS/HR $\quad 650.000$

MINIMUM SIZE, MLBS/HR $\quad 50.000$

CAPACITY, MLBS/HR $\quad 2.871$

PLANT ISBL FIELD COST, MMS 1.740

WARNING - THE ABOVE PLANT COSTS MAY BE IN ERROR SINCE THE CALCULATED TRAIN SIZE IS BELOW THE SPECIFIED MINIMUM TRAIN SIZE. 
PLANT 303 - SUMMARY REPORT

NAPHTHA HYDROTREATER

\begin{tabular}{|c|c|c|c|c|}
\hline $\begin{array}{l}\text { FLOW RATES, MLBS, } \\
\text { COMPONENT }\end{array}$ & FEED & GASES & $\mathrm{C} 5 / \mathrm{C} 6 \mathrm{~S}$ & GASOLINE \\
\hline $\mathrm{H} 2$ & 0.030 & 0.000 & 0.000 & 0.000 \\
\hline $\mathrm{H} 2 \mathrm{O}$ & 0.000 & 0.000 & 0.000 & 0.000 \\
\hline $\mathrm{CH} 4$ & 0.000 & 0.009 & 0.000 & 0.000 \\
\hline $\mathrm{C} 2 \mathrm{H} 6$ & 0.000 & 0.033 & 0.000 & 0.000 \\
\hline $\mathrm{C} 3 \mathrm{H} 8$ & 0.000 & 0.042 & 0.000 & 0.000 \\
\hline IC4H1O & 0.000 & 0.006 & 0.000 & 0.000 \\
\hline $\mathrm{NC} 4 \mathrm{H} 10$ & 0.000 & 0.028 & 0.000 & 0.000 \\
\hline $\mathrm{C} 5 \mathrm{H} 10$ & 0.000 & 0.000 & 0.000 & 0.000 \\
\hline $\mathrm{NC} 5 \mathrm{H} 12$ & 0.012 & 0.000 & 0.029 & 0.000 \\
\hline IC5H12 & 0.000 & 0.000 & 0.001 & 0.000 \\
\hline C6H12 & 0.121 & 0.000 & 0.000 & 0.000 \\
\hline $\mathrm{NC} 6 \mathrm{H} 14$ & 0.040 & 0.000 & 0.152 & 0.000 \\
\hline $\mathrm{IC} 6 \mathrm{H} 14$ & 0.004 & 0.000 & 0.017 & 0.000 \\
\hline C7H14 & 0.217 & 0.000 & 0.000 & 0.000 \\
\hline $\mathrm{C} 7 \mathrm{H} 16$ & 0.097 & 0.000 & 0.000 & 0.000 \\
\hline $\mathrm{C} 8 \mathrm{H} 16$ & 0.288 & 0.000 & 0.000 & 0.000 \\
\hline $\mathrm{C} 8 \mathrm{H} 18$ & 0.132 & 0.000 & 0.000 & 0.000 \\
\hline $\mathrm{C} 9 \mathrm{H} 18$ & 0.325 & 0.000 & 0.000 & 0.000 \\
\hline С9H2O & 0.144 & 0.000 & 0.000 & 0.000 \\
\hline $\mathrm{C} 10 \mathrm{H} 20$ & 0.346 & 0.000 & 0.000 & 0.000 \\
\hline $\mathrm{C} 10 \mathrm{H} 22$ & 0.142 & 0.000 & 0.000 & 0.000 \\
\hline $\mathrm{OXHC}$ & 0.181 & 0.000 & 0.000 & 0.000 \\
\hline $\mathrm{C} 7-300 \mathrm{HT}$ & 0.000 & 0.000 & 0.000 & 1.342 \\
\hline $3-350 \mathrm{HT}$ & 0.000 & 0.000 & 0.000 & 0.381 \\
\hline TOTAL & 2.080 & 0.117 & 0.198 & 1.723 \\
\hline TEMPERATURE, $\mathrm{F}$ & 95.8 & 100.0 & 90.0 & 80.0 \\
\hline PRESSURE, PSIA & 50.0 & 50.0 & 50.0 & 50.0 \\
\hline SOUR WATER & & 0.042 & & \\
\hline
\end{tabular}

- CONTINUED ON NEXT PAGE - 


\section{PLANT 303 - SUMMARY REPORT \\ NAPHTHA HYDROTREATER \\ (CONTINUED)}

$\begin{array}{ll}\text { PLANT UTILITIES CONSUMPTIONS } & 15 . \\ \text { POWER, KW } & 0.0 \\ 900 \text { PSIG/1000 F STEAM, MLBS/HR } & 0.0 \\ 360 \text { PSIG/440 F STEAM, MLBS/HR } & 0.0 \\ 600 \text { PSIG/650 F STEAM, MLBS/HR } & 0.0 \\ 600 \text { PSIG SATD STEAM, MLBS/HR } & 0.0 \\ \text { 150 PSIG SATD STEAM, MLBS/HR } & 0.0 \\ 50 \text { PSIG SATD STEAM, MLBS/HR } & 1.18 \\ \text { PLANT FUEL, MM BTUS/HR } & 3.53 \\ \text { COOLING WATER, MGAL/HR } & 0.00 \\ \text { PROCESS WATER, MGAL/HR } & 0.00 \\ \text { NITROGEN, MM SCF/HR OF N2 } & 4.0 \\ \text { TOTAL PLANT OPERATORS/DAY } & \end{array}$

PLANT COSTING INFORMATION

TOTAL NUMBER OF DUPLICATE TRAINS 1

MAXIMUM SIZE, MLBS/HR $\quad 650.000$

MINIMUM SIZE, MLBS/HR 50.000

CAPACITY, MLBS/HR 2.050

PLANT ISBL FIELD COST, MMS 0.528

WARNING - THE ABOVE PLANT COSTS MAY BE IN ERROR SINCE THE CALCULATED TRAIN SIZE IS BELOW THE SPECIFIED MINIMUM TRAIN SIZE. 
PLANT 304 - SUMMARY REPORT

NAPHTHA REFORMING PLANT

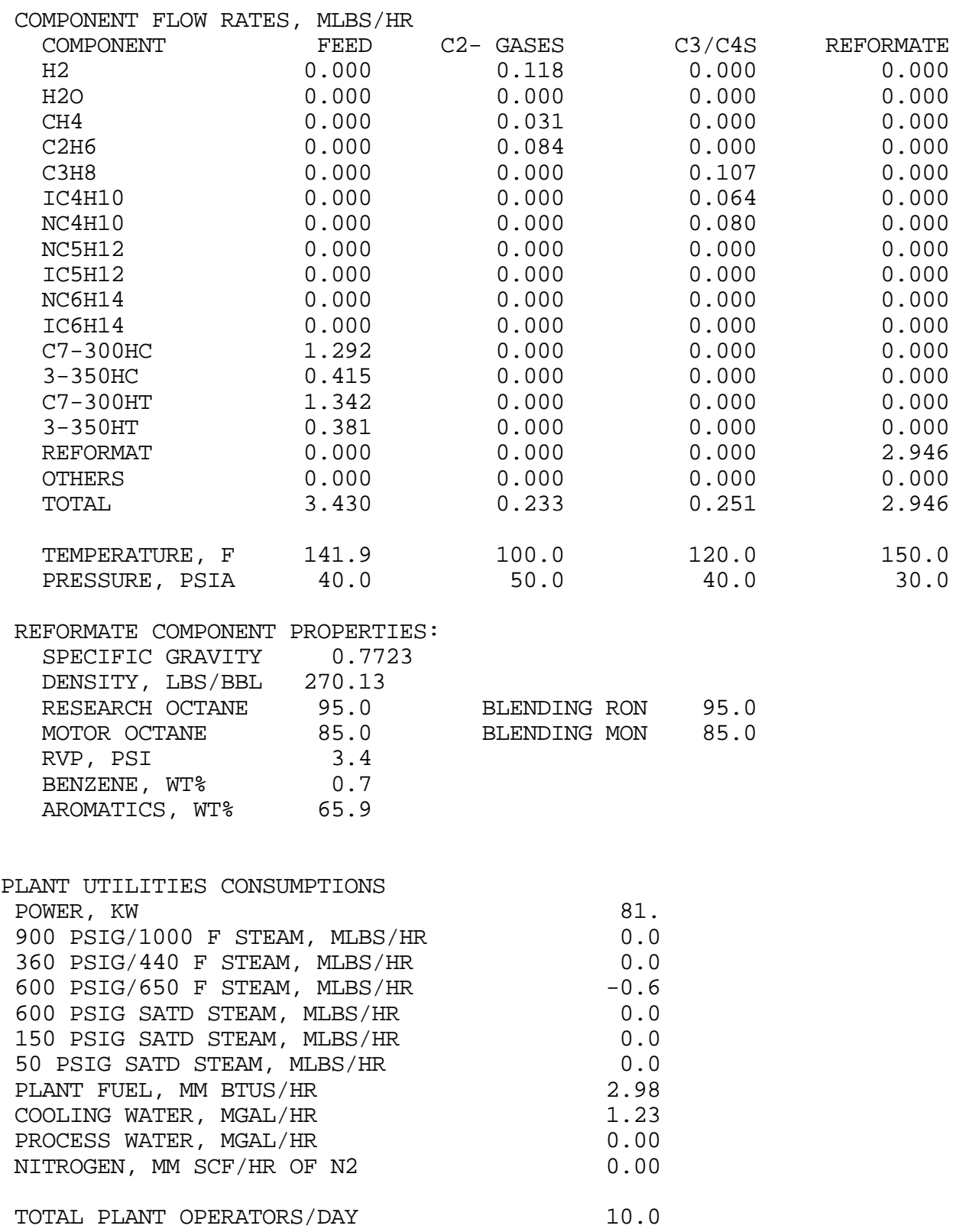

PLANT COSTING INFORMATION

$\begin{array}{lr}\text { TOTAL NUMBER OF DUPLICATE TRAINS } & 1 \\ \text { MAXIMUM SIZE, MLBS/HR } & 750.000 \\ \text { MINIMUM SIZE, MLBS/HR } & 50.000 \\ \text { CAPACITY, MLBS/HR } & 3.430 \\ \text { PLANT ISBL FIELD COST, MMS } & 3.628\end{array}$

WARNING - THE ABOVE PLANT COSTS MAY BE IN ERROR SINCE THE CALCULATED TRAIN SIZE IS BELOW THE SPECIFIED MINIMUM TRAIN SIZE. 


\begin{tabular}{|c|c|c|c|c|}
\hline \multirow[b]{2}{*}{ COMPONENT FLOW RATES, } & \multicolumn{4}{|c|}{ PLANT 306 - SUMMARY REPORT } \\
\hline & MLBS/HR & & & \\
\hline COMPONENT & FEED & GASES & & MERATE \\
\hline H2 & 0.002 & 0.000 & & 0.000 \\
\hline N2 & 0.000 & 0.000 & & 0.000 \\
\hline $\mathrm{O} 2$ & 0.000 & 0.000 & & 0.000 \\
\hline $\mathrm{H} 2 \mathrm{~S}$ & 0.000 & 0.000 & & 0.000 \\
\hline $\mathrm{CO}$ & 0.000 & 0.000 & & 0.000 \\
\hline $\mathrm{CO} 2$ & 0.000 & 0.000 & & 0.000 \\
\hline $\mathrm{H} 2 \mathrm{O}$ & 0.000 & 0.000 & & 0.000 \\
\hline $\cos$ & 0.000 & 0.000 & & 0.000 \\
\hline $\mathrm{CH} 4$ & 0.000 & 0.001 & & 0.000 \\
\hline $\mathrm{C} 2 \mathrm{H} 4$ & 0.000 & 0.000 & & 0.000 \\
\hline $\mathrm{C} 2 \mathrm{H} 6$ & 0.000 & 0.000 & & 0.000 \\
\hline $\mathrm{C} 3 \mathrm{H} 6$ & 0.000 & 0.000 & & 0.000 \\
\hline $\mathrm{C} 3 \mathrm{H} 8$ & 0.000 & 0.014 & & 0.000 \\
\hline $\mathrm{IC} 4 \mathrm{H} 8$ & 0.000 & 0.000 & & 0.000 \\
\hline $\mathrm{NC} 4 \mathrm{H} 8$ & 0.000 & 0.000 & & 0.000 \\
\hline IC4H10 & 0.000 & 0.006 & & 0.000 \\
\hline $\mathrm{NC} 4 \mathrm{H} 10$ & 0.000 & 0.000 & & 0.000 \\
\hline C5H10 & 0.000 & 0.000 & & 0.000 \\
\hline NC5H12 & 0.213 & 0.000 & & 0.000 \\
\hline IC5H12 & 0.218 & 0.000 & & 0.000 \\
\hline $\mathrm{C} 6 \mathrm{H} 12$ & 0.000 & 0.000 & & 0.000 \\
\hline $\mathrm{NC} 6 \mathrm{H} 14$ & 0.364 & 0.000 & & 0.000 \\
\hline IC6H14 & 0.363 & 0.000 & & 0.000 \\
\hline ISOMERAT & 0.000 & 0.000 & & 1.139 \\
\hline OTHERS & 0.000 & 0.000 & & 0.000 \\
\hline TOTAL & 1.160 & 0.021 & & 1.139 \\
\hline TEMPERATURE, $\mathrm{F}$ & 130.9 & 100.0 & & 100.0 \\
\hline PRESSURE, PSIA & 50.0 & 25.0 & & 25.0 \\
\hline ISOMERATE COMPONENT & PROPERTIES & & & \\
\hline SPECIFIC GRAVITY & 0.6501 & & & \\
\hline DENSITY, LBS/BBL & 227.40 & & & \\
\hline RESEARCH OCTANE & 81.7 & BLENDING & $\mathrm{RON}$ & 81.7 \\
\hline MOTOR OCTANE & 81.1 & BLENDING & MON & 81.1 \\
\hline$(\mathrm{R}+\mathrm{M}) / 2$ & 81.4 & & & \\
\hline RVP, PSI & 10.8 & & & \\
\hline
\end{tabular}




\section{C5/C6 ISOMERIZATION PLANT - SUMMARY REPORT \\ (CONTINUED)}

$\begin{array}{lr}\text { PLANT UTILITIES CONSUMPTIONS } & 2 . \\ \text { POWER, KW } & 0.0 \\ 900 \text { PSIG/1000 F STEAM, MLBS/HR } & 0.0 \\ 360 \text { PSIG/440 F STEAM, MLBS/HR } & 0.1 \\ 600 \text { PSIG/650 F STEAM, MLBS/HR } & 0.0 \\ 600 \text { PSIG SATD STEAM, MLBS/HR } & 0.0 \\ \text { 150 PSIG SATD STEAM, MLBS/HR } & 0.0 \\ 50 \text { PSIG SATD STEAM, MLBS/HR } & 0.07 \\ \text { PLANT FUEL, MM BTUS/HR } & 0.07 \\ \text { COOLING WATER, MGAL/HR } & 0.00 \\ \text { PROCESS WATER, MGAL/HR } & 0.00 \\ \text { NITROGEN, MM SCF/HR OF N2 } & 4.0 \\ \text { TOTAL PLANT OPERATORS/DAY } & \end{array}$

PLANT COSTING INFORMATION

TOTAL NUMBER OF DUPLICATE TRAINS 1

MAXIMUM SIZE, MLBS/HR 250.000

MINIMUM SIZE, MLBS/HR 10.000

CAPACITY, MLBS/HR 1.158

PLANT ISBL FIELD COST, MM\$ 0.669

WARNING - THE ABOVE PLANT COSTS MAY BE IN ERROR SINCE THE CALCULATED TRAIN SIZE IS BELOW THE SPECIFIED MINIMUM TRAIN SIZE. 


\begin{tabular}{|c|c|c|c|c|c|}
\hline & & UTILITIES & SUMMARY & & \\
\hline & & & COOLING & PROCESS & \\
\hline PLANT & POWER & FUEL & WATER & WATER & NITROGEN \\
\hline NO. & $\mathrm{KW}$ & MMBTUS/HR & MGAL/HR & MGAL/HR & $\mathrm{MMSCF} / \mathrm{HR}$ \\
\hline 115 & 2500 . & 99.900 & 0.00 & 0.00 & 0.000 \\
\hline 116 & 7700 & 0.000 & 0.00 & 0.00 & 0.000 \\
\hline 117 & 13191. & 0.000 & 345.68 & 0.00 & 0.000 \\
\hline 119 & 97. & 0.000 & 0.53 & 0.00 & 0.000 \\
\hline 108 & 0 & 3.381 & 0.00 & 0.00 & 0.000 \\
\hline 113 & 99. & 0.838 & 1.14 & 0.00 & 0.000 \\
\hline 201 & 274 . & 5.904 & 4.94 & 0.56 & 0.000 \\
\hline $204 \mathrm{~N}$ & 13. & 1.051 & 0.87 & 0.00 & 0.000 \\
\hline 205 & 0 & 0.000 & 2.75 & 0.00 & 0.000 \\
\hline 301 & 63. & 2.802 & 0.41 & 0.00 & 0.000 \\
\hline 302 & 33. & 0.364 & 0.35 & 0.00 & 0.000 \\
\hline 303 & 15. & 1.178 & 3.53 & 0.00 & 0.000 \\
\hline 304 & 81. & 2.981 & 1.23 & 0.00 & 0.000 \\
\hline 306 & 2. & 0.070 & 0.07 & 0.00 & 0.000 \\
\hline OTHERS & 0 & 0.000 & 0.00 & 0.00 & 0.000 \\
\hline 31 & -109923. & 614.681 & 1543.80 & -0.56 & 0.000 \\
\hline TOTAL & -85856 & 733.148 & $1905.30 *$ & 0.00 & 0.000 \\
\hline
\end{tabular}

* = TOTAL COOLING WATER RECIRCULATION.

\begin{tabular}{|c|c|c|c|c|c|c|}
\hline PLANT & 900 PSIG & 360 PSIG & 600 PSIG & 600 PSIG & 150 PSIG & 50 PSIG \\
\hline NO. & $1000 \mathrm{~F}$ & $440 \mathrm{~F}$ & $650 \mathrm{~F}$ & SATD & SATD & SATD \\
\hline 115 & 0.0 & 0.0 & 0.0 & 0.0 & 0.0 & 0.0 \\
\hline 116 & -81.4 & -22.0 & 10.8 & 0.0 & 0.0 & 0.0 \\
\hline 117 & 0.0 & 0.0 & 0.0 & 0.0 & 0.0 & 0.0 \\
\hline 119 & 0.0 & 0.0 & 0.0 & 0.0 & 0.0 & 0.0 \\
\hline 108 & 0.0 & 0.0 & 0.0 & 0.0 & 0.0 & 0.0 \\
\hline 113 & 0.0 & 3.0 & 0.0 & 0.0 & 0.0 & 0.0 \\
\hline 201 & 0.0 & -128.8 & 1.3 & 0.0 & 0.0 & -0.3 \\
\hline $204 \mathrm{~N}$ & 0.0 & 0.0 & 0.0 & 0.0 & 0.0 & 0.8 \\
\hline 205 & 0.0 & 5.9 & 0.0 & 0.0 & 0.0 & -5.9 \\
\hline 301 & 0.0 & 6.4 & 2.1 & 0.0 & 0.0 & -6.0 \\
\hline 302 & 0.0 & 0.0 & 0.0 & 0.0 & 0.0 & -0.1 \\
\hline 303 & 0.0 & 0.0 & 0.0 & 0.0 & 0.0 & 0.0 \\
\hline 304 & 0.0 & 0.0 & -0.6 & 0.0 & 0.0 & 0.0 \\
\hline 306 & 0.0 & 0.0 & 0.1 & 0.0 & 0.0 & 0.0 \\
\hline OTHERS & 0.0 & 0.0 & 0.0 & 0.0 & 0.0 & 0.0 \\
\hline 31 & 81.4 & 135.5 & -13.7 & 0.0 & 0.0 & 11.5 \\
\hline TOTAL & 0.0 & 0.0 & 0.0 & 0.0 & 0.0 & 0.0 \\
\hline
\end{tabular}

IN THE ABOVE TABLES, POSITIVE VALUES DESIGNATE NET CONSUMPTION, AND NEGATIVE VALUES DESIGNATE NET PRODUCTION.

$\begin{array}{lr}\text { FUEL GAS PRODUCTION, MMBTUS/HR } & 733.148 \\ \text { PURCHASED NATURAL GAS, MMBTUS/HR } & 0.000 \\ \text { ELECTRIC POWER FOR SALE, MW } & 85.856 \\ \text { COOLING WATER, MGAL/HR } & 1543.80 \\ & \\ \text { PLANT FIELD COST, MM\$ } & 17.300\end{array}$

